\title{
Food and nutritional security in Africa: A comparative analysis
}

\author{
Yesake Demeke Andeyhun
}

Thesis presented in partial fulfilment of the requirements for the degree of Master of Science in Agricultural Economics in the Faculty of AgriSciences at Stellenbosch University

Supervisor: Prof. N. Vink

April 2014 


\section{Declaration}

By submitting this thesis electronically, I declare that the entirety of the work contained therein is my own, original work, that I am the sole author thereof (save to the extent explicitly otherwise stated), that reproduction and publication thereof by Stellenbosch University will not infringe any third party rights and that I have not previously in its entirety or in part submitted it for obtaining any qualification.

April 2014

Copyright $\subset 2014$ Stellenbosch University

All rights reserved 


\begin{abstract}
In this study the food and nutritional security of the African continent was analysed based on the three main pillars of food security, namely availability, accessibility and utilisation.
\end{abstract}

FAO's Food Balance Sheet method of per capita caloric food supply along with food production, trade and food aid was used for the food availability analysis. Accordingly, the majority of Eastern and Central Africa countries still remain below FAO's recommended caloric food supply level. While Ghana and Egypt showed impressive progress, Madagascar and Zambia recorded a deteriorating performance of caloric food supply. Per capita cereal production showed deteriorating performance in Sudan, DRC, Madagascar, South Africa and Nigeria. However, the rate of area harvest (except in South Africa) and yield (except in DRC) increased over the case study countries. On the other hand the majority of African countries struggle to maintain their agricultural trade surplus. Also food aid was found to be more important in the East African region. Among the case study countries, the DRC, Sudan and Ethiopia showed increasing trend of cereal aid receipt over time.

The food accessibility analysis of the continent revealed that Africa showed impressive economic growth over the last decade. While it was widespread, those countries with less dependence on mineral resources showed better performance in poverty reduction and income distribution. Besides the economic factors, physical, political and sociocultural factors are also important factors of food accessibility.

The food utilisation analysis found that child malnutrition was generally decreasing over the case study countries. However, the level of micronutrient deficiency, especially in children under the age of five, was found to be high in almost all of the case study countries. Except in Egypt, South Africa and Zambia, the percentage of the population with access to better sanitation services was under $30 \%$ in all the case study countries. In the DRC, Ethiopia, Madagascar and Mozambique, the percentage of the population with access to improved water services was less than $50 \%$.

Although challenged by complex factors, the analysis found out a positive relationship of agricultural growth and food and nutritional security in Africa. Besides its importance as an engine for economic growth and poverty reduction, agriculture enhances nutritional security through the provision of cheap and nutritious food even to remote rural areas. On the other hand the expansion of supermarkets and food price variability found to be both opportunities for and threats to food security. Also unfair international trade environment is negatively affecting food security. 
To this end, agricultural promotion accompanied with political stability, investment on infrastructure, national and regional market integration together with maintaining productive and sustainable safety nets and social protection schemes are found to be very important.

The study used electronic databases of the EIU'es Global Food Security Index, FAO's FAOSTAT database, the African Development Bank (AfDB) and the World Bank among others. Analysis of the long-term statistical trends in the quantitative data and a systematic qualitative literature review were the methods employed for undertaking this research at the regional and national level. 


\section{Opsomming}

In hierdie studie is voedsel- en voedingsekerheid op die Afrika-vasteland op grond van die drie hoofkomponente van voedselsekerheid ontleed, naamlik die beskikbaarheid, toeganklikheid en aanwending van voedsel.

Voedselbeskikbaarheid is aan die hand van die parameters van voedselproduksie, -handel en hulp ondersoek. Uit die lande waarvan gevallestudies onderneem is, toon Zambië "en daling in kaloriese voedselvoorraad. Ook Nigerië, Soedan en Madagaskar toon "n afname in die vlak van kaloriese voedselvoorraad oor die afgelope paar jaar. Dít kan verband hou met die waargenome afname in landbouproduksie per kop in daardie lande. Die landbouhandelsontleding dui aan dat Afrika sedert die $1980^{\circ} \mathrm{s}$ " $\mathrm{n}$ suiwer invoerder ten opsigte van landbou geword het. Vier studielande, naamlik Ghana, Ethiopië, Suid-Afrika en Zambië, het egter in $2011^{\text {ee }} \mathrm{n}$ landbouhandelsurplus getoon. Daarenteen word voedselhulp oënskynlik al hoe belangriker in die Oos-Afrika-streek. Onder die studielande het die Demokratiese Republiek die Kongo (DRK), Soedan en Ethiopië mettertyd "n toename in graanhulpontvangste getoon.

Die ontleding van voedseltoeganklikheid op die vasteland het aan die lig gebring dat Afrika oor die afgelope dekade indrukwekkende ekonomiese groei beleef het. Hoewel dié groei wydverspreid was, het lande wat minder afhanklik is van minerale hulpbronne beter presteer wat armoedevermindering en inkomsteverdeling betref. Benewens die ekonomiese faktore, is fisiese, politieke en sosiokulturele faktore ook belangrike bepalers van voedseltoeganklikheid.

Die ontleding van voedselaanwending het bevind dat wanvoeding onder kinders in die studielande aan die afneem is. Tog is daar " $n$ hoë vlak van mikrovoedingstoftekorte in bykans al die lande wat bestudeer is, veral by kinders onder die ouderdom van vyf. Buiten Egipte, Suid-Afrika en Zambië, het minder as 30\% van die bevolking in die studielande met verloop van tyd toegang tot beter sanitasiedienste bekom. Daarbenewens het minder as $50 \%$ van die bevolking in die DRK, Ethiopië, Madagaskar en Mosambiek mettertyd toegang tot beter waterdienste verkry.

Hierdie navorsing beklemtoon ook dat landbougroei in Afrika die hoeksteen van voedsel- en voedingsekerheid bly. Benewens die belang daarvan as " $n$ werktuig vir ekonomiese groei, versterk landbou voedingsekerheid deur goedkoop, voedsame kos te voorsien; deur metodes te bied vir die verhoging van voedingswaarde, soos industriële verryking en bioverryking, en deur met behulp van landbouvoorligtingsdienste in die voedingsbehoeftes van afgeleë landelike gebiede te voorsien. 
In hierdie opsig word die uitbreiding van supermarkte en die wisselvalligheid van kospryse as "n geleentheid sowel as "n bedreiging vir voedselsekerheid beskou. Hoewel supermarkte goedkoop kos van gehalte aan stedelike en buitestedelike inwoners verskaf, kan die gevolglike marginalisasie van kleinskaalboere uit die verskaffingsketting, sowel as die toenemende gesondheidsgevare verbonde aan verwerkte voedsel, "n bedreiging inhou. Die styging in kospryse kan ook op lang termyn " $n$ geleentheid bied om boerderyinkomste te verhoog, terwyl dit op kort termyn voedseltoeganklikheid vir arm mense beduidend ondermyn. In dié verband verseker die instandhouding van produktiewe en volhoubare veiligheidsnette en maatskaplike beskermingskemas nie net voedseltoeganklikheid vir die armes nie, maar versterk dit ook algehele voedingsekerheid.

Hierdie navorsing op streeks- en nasionale vlak is met behulp van " $n$ langtermynontleding van statistiese tendense in kwantitatiewe data sowel as "n stelselmatige kwalitatiewe literatuuroorsig onderneem. 


\section{Acknowledgements}

First and for most I would like to give thanks and praise to almighty God, whose blessings are up on me in every steps of my life. I would like to thank my beloved mother Adanech Yirga and my lovely father Demeke Andeyhun and all my family for being by my side all the time. I thank you my supervisor Professor Nick Vink for your encouraging and always positive approach throughout my study. I would like to thank you Professor Luc D'haese, Ghent University, Department of Agricultural Economics, for your encouragement and valuable comment on my thesis. I also thank Professor J Van Rooyen, Dr. Jan P Lombard, Dr. Cecilia Punt and all the Agricultural Economics Department members of Stellenbosch University for their kind and helpful comment and support throughout my study. Last but not the least; I would like to thank the African Capacity Building Foundation (ACBF), Ethiopian Development Research Institute (EDRI) and Ethiopian Investment Agency (EIA), for your financial support and positive attitude over the course of my study.

Thanks a lot for all of my friends at home and here in South Africa for your encouragement. 


\section{Contents}

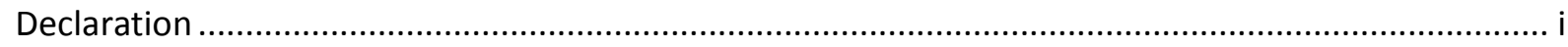

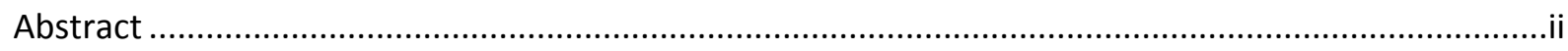

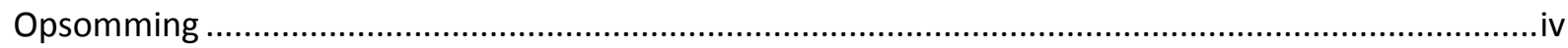

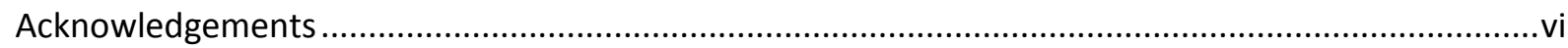

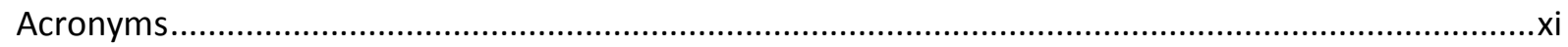

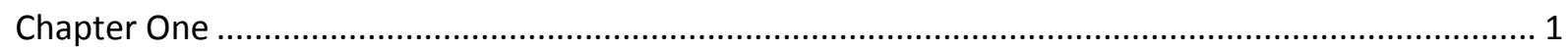

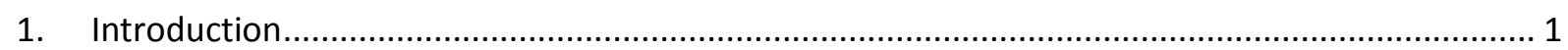

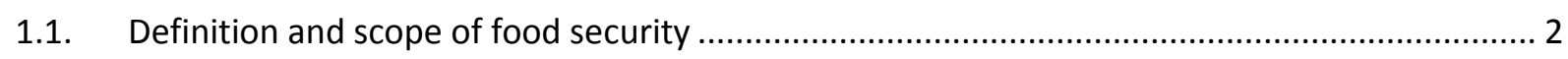

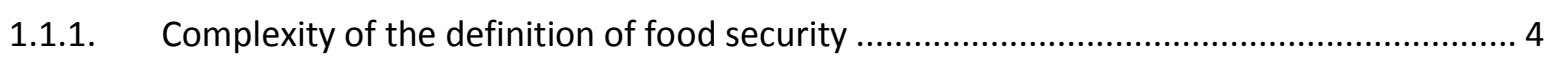

1.2. Overview of African food security status ........................................................................... 5

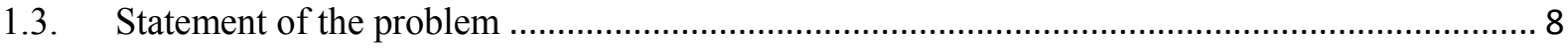

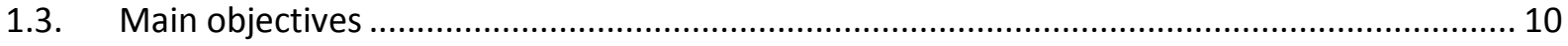

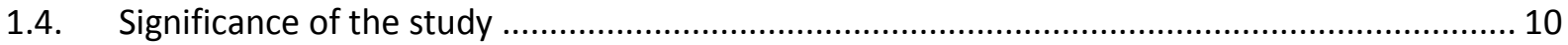

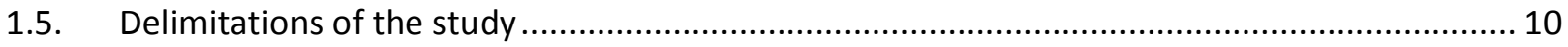

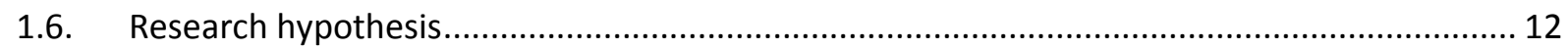

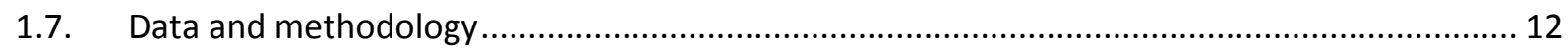

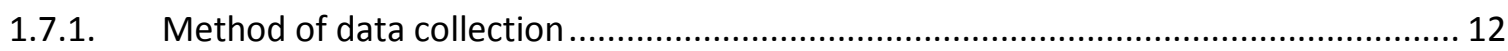

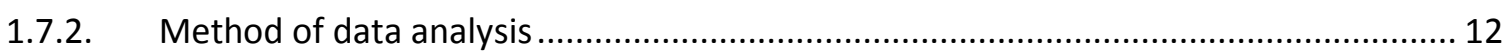

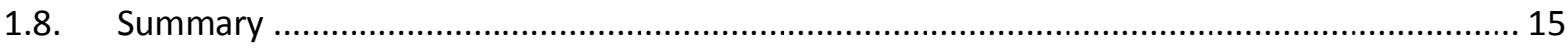

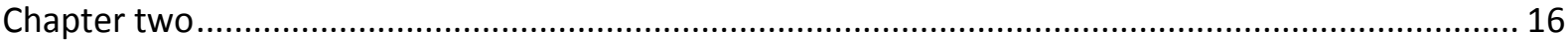

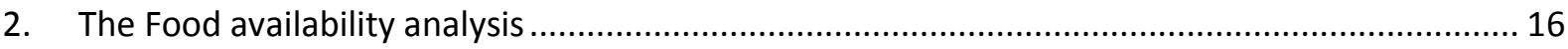

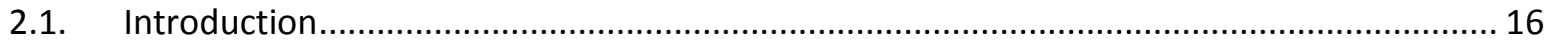

2.2. National food availability measurement techniques ....................................................... 17

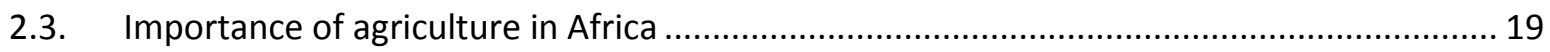

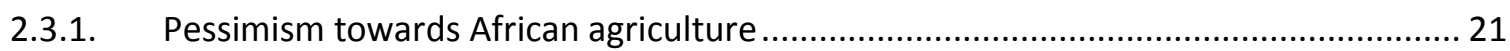

2.3.2. Challenges facing African agriculture and food security ............................................ 22

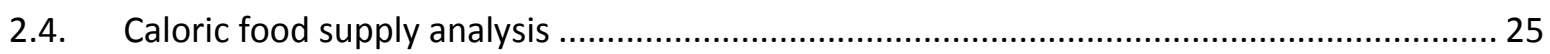

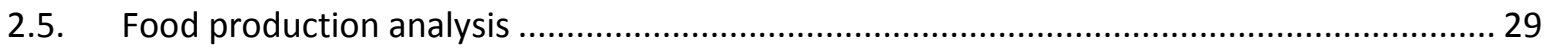

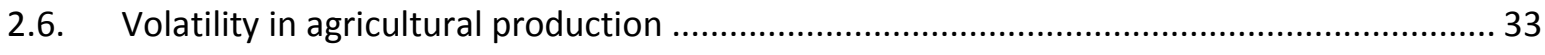

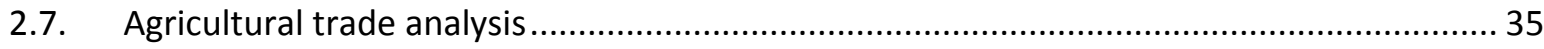

2.7.1. Self-sufficiency ratio (SSR) and import dependency ratio (IDR) ................................ 38

2.7.2. Factors relating to Africa's agricultural import dependency ...................................... 40 


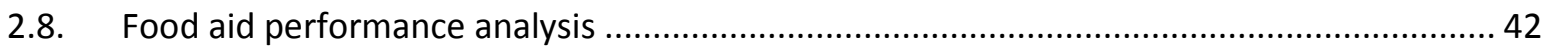

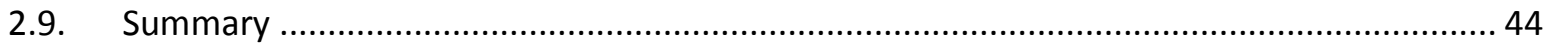

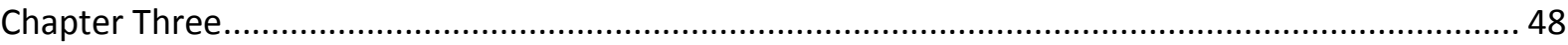

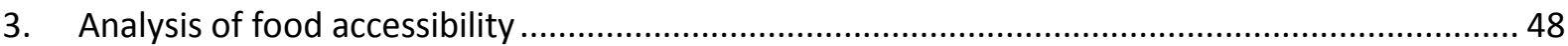

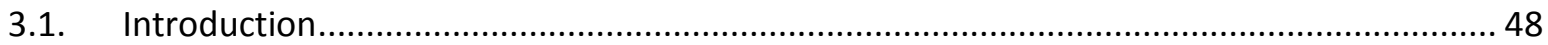

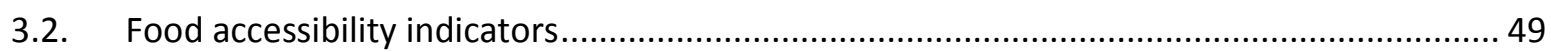

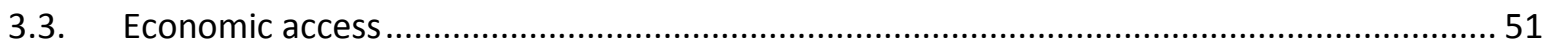

3.3.1. Agriculture as engine of economic growth ................................................... 55

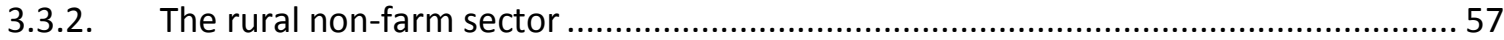

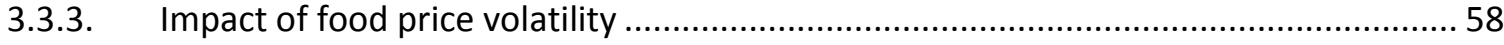

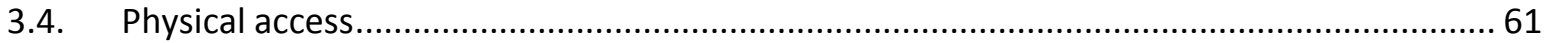

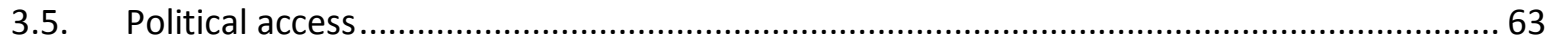

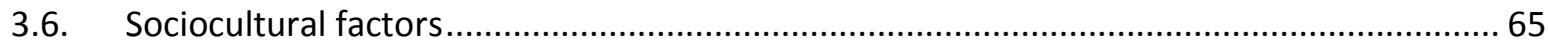

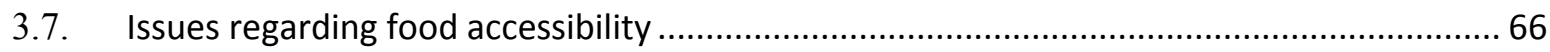

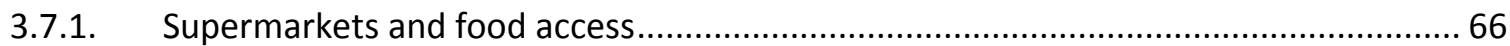

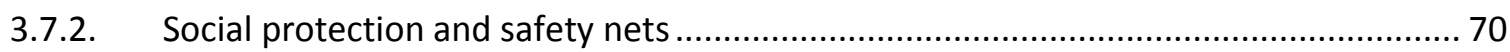

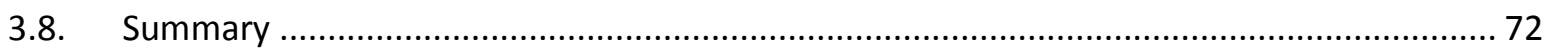

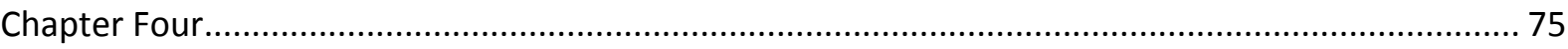

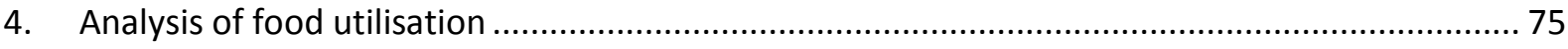

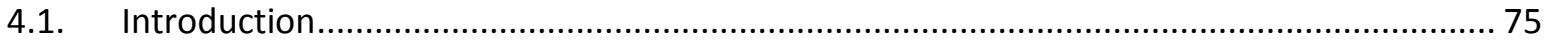

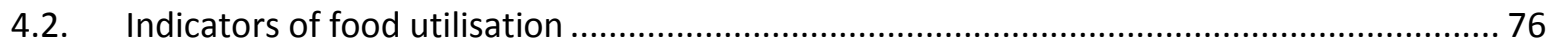

4.3. Assessment of African nutritional security .......................................................... 77

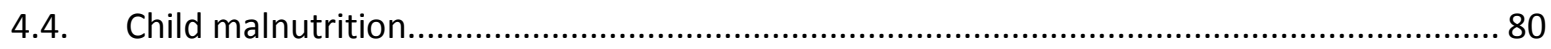

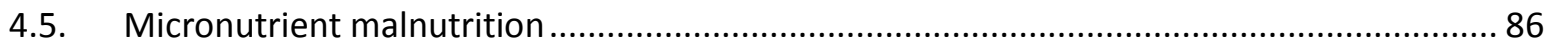

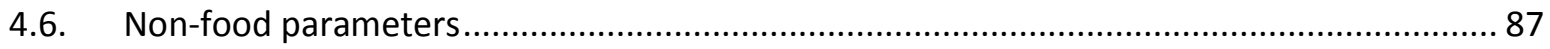

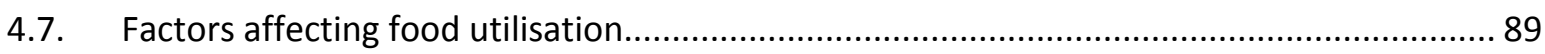

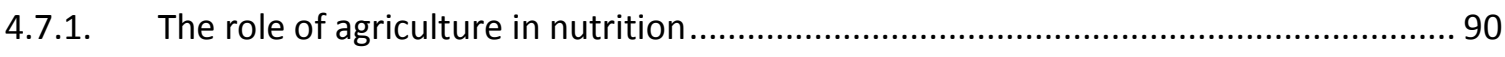

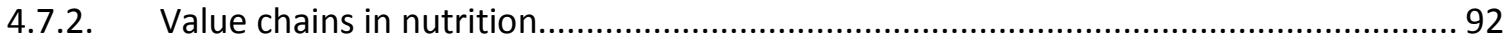

4.7.3. Nutritional intervention strategies......................................................... 93

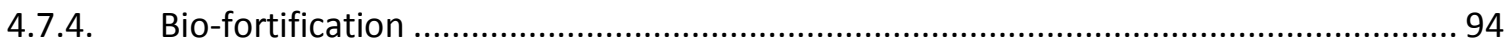

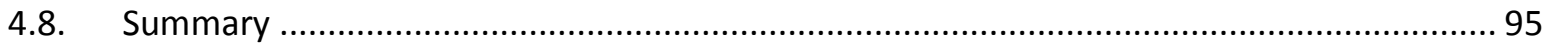

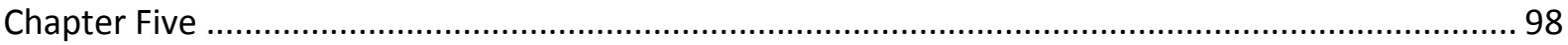

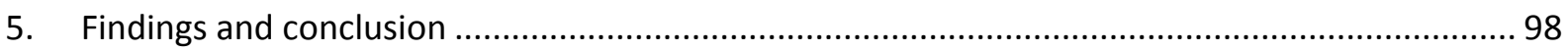

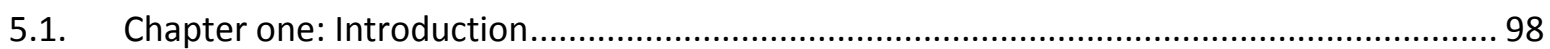

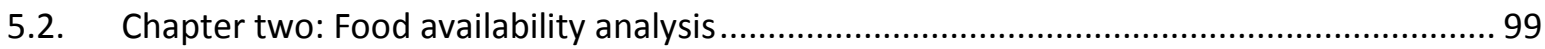


5.3. Chapter three: Food accessibility analysis ....................................................... 103

5.4. Chapter Four: Analysis of food utilisation .................................................... 107

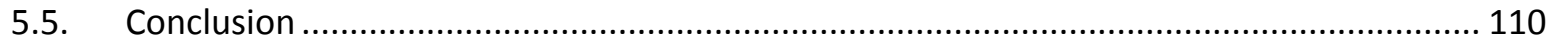

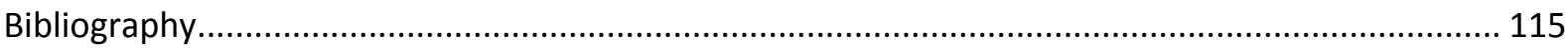

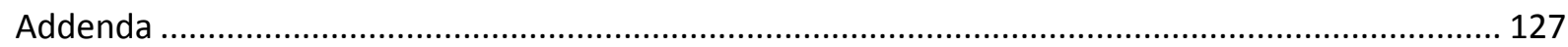

Addendum A: Africa regional classification based on United Nations (2013) ............................ 127

Addendum B: African countries below and above FAO's recommended value of daily food calorie intake (2 $300 \mathrm{kcal} / \mathrm{capita} /$ day) in 2009 ...................................................................... 128

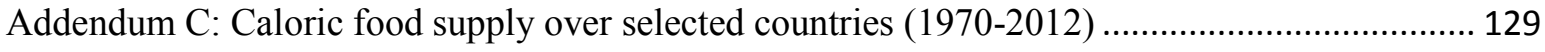

Addendum D: Sub-Saharan Africa countries ${ }^{\text {ee }}$ food affordability indicators based on the Economist Intelligence Unit (Global food security index ranking)

Addendum E: Estimated prevalence (\%) of stunted pre-school children 1990-2020, Based on UN region and sub-region classification.

Addendum F: Gender disparity in prevalence of underweight children under the age of five in selected countries

Addendum G:Rural-urban prevalence of underweight in children under the age five in selected countries

\section{List of Figures}

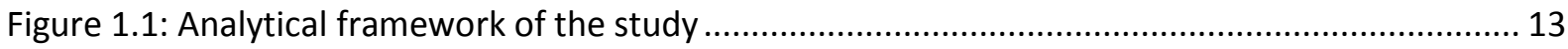

Figure 2.1: Food availability ranking of 28 SSA (EIU, 2013) ........................................................ 19

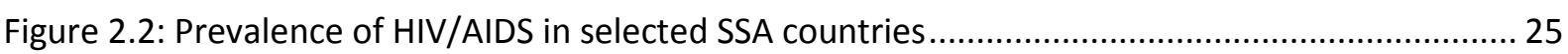

Figure 2.3: Dietary energy supply trend in Kcal/capita/day....................................................... 26

Figure 2.4: Trend of caloric food supply in Kcal/capita/day in selected countries ............................ 27

Figure 2.5: Annual growth rate in caloric food supply for the last five decades ................................ 28

Figure 2.6: The share of cereals, roots and tubers in dietary energy supply of the selected countries 30

Figure 2.7: Performance of per capita cereal production (in tons) (1984/86 to 2010/12) ................. 31

Figure 2.8: Maize and wheat production (tons) in selected countries in the year 2011 .................... 32

Figure 2.9: Per capita roots and tubers production (tones) $(1984 / 86$ to 2010/12) ............................ 33

Figure 2.10: Volatility in agricultural production in selected countries in Africa............................... 34

Figure 2.11: Africa's total agricultural import and export trends (current value) ............................. 35

Figure 2.12: Net agricultural export trend over case study countries (current values) ...................... 36

Figure 2.13: Wheat and Poultry import trend in to Africa between 1961 and 2011 (current values) . 37

Figure 2.14: Value of coffee, tea and cocoa exports in different decades (current values) ................ 38

Figure 2.15: Percentage increase in cereal SSR and IDR in 2010 from that of 1970 in selected

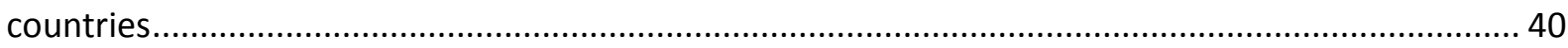

Figure 2.16: Average total cereal aid to Africa (1988 to 2012) ...................................................42

Figure 2.17: Five-year average cereal aid in selected countries (1988 to 2012)..............................43

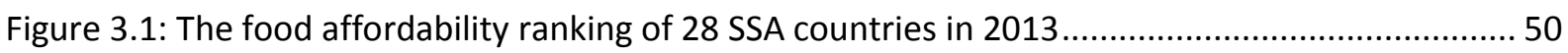

Figure 3.2: The decadal average GDP per capita growth rate over selected countries ..................... 53 
Figure 3.3:Domestic food price variability measured as deviation over the trend of the previous five years (2012).....

Figure 3.4: The rate of transparency, accountability and corruption in the public sector $(1=$ low to $6=$

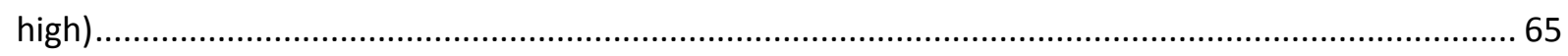

Figure 4.1: Food quality and safety ranking of SSA countries .................................................... 78

Figure 4.2: World ranking of food utilisation and its indicators in selected countries ...................... 79

Figure 4.3: Urban and rural prevalence of stunting in selected SSA countries based on recent DHS

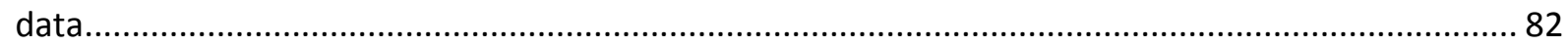

Figure 4.4: Performance in reducing the prevalence of underweight in the selected countries .........83 83

Figure 4.5: Proportion of wasting in children under the age of five in selected SSA countries........... 84

Figure 4.6: Progress in relation to the under-five mortality rate per 1000 live births (MDG4) in

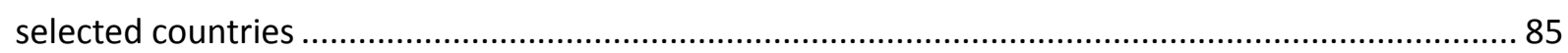

Figure 4.7: Prevalence of micronutrient malnutrition in selected countries in 2011 ........................86

Figure 4.8: Percentage of population with improved access to water and sanitation in 2010 ...........88

Figure 4.9: The growth rate in access to improved water sources and sanitation services between 1990 and 2010 .

\section{List of Tables}

Table 1.1:Profile of the case study countries 141

Table 1.2 Food security dimensions, indicators and measurement techniques................................ 14

Table 2.1: Food availability indicators in selected countries ........................................................ 29

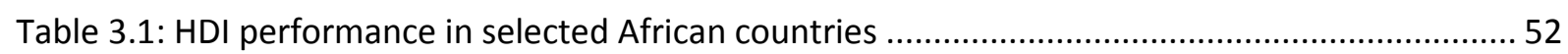

Table 3.2: Economic growth on poverty reduction and income inequality over selected African

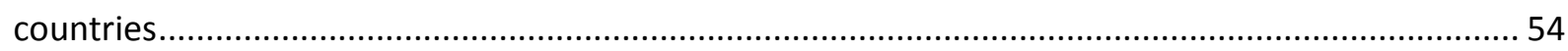

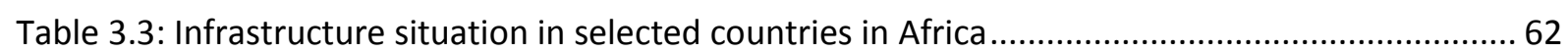

Table 4.1: Prevalence of child malnutrition under the age of five in selected countries and different

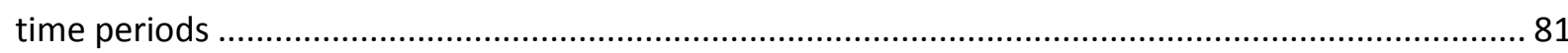

Table 5.1: Food availability indicating parameters growth rate over selected countries................. 101

Table 5.2: The world ranking of food affordability and its indicators by the EIU (2013) .................. 104 


\section{Acronyms}

ACBF African Capacity Building Foundation

AEZ Agro Ecological Zone

AfDB African Development Bank

AfDR African Development Report

AIDS Acquired Immune Deficiency Syndrome

AU African Union

CAADP Comprehensive African Agriculture Development Programme

CAGR Compound Annual Growth Rate

CGE Computable General Equilibrium

CIF Cost, Insurance and Freight

DRC the Democratic Republic of Congo

ECA Economic Commission for Africa

EDRI Ethiopian Development Research Institute

EIA Ethiopian Investment Agency

EIU Economist Intelligence Unit

EMM Economy-Wide Multimarket Model

ESA Eastern and Southern Africa

EU European Union

FAO Food and Agricultural Organization of the United Nations

FBS Food Balance Sheets

FOB Free on Board

GDP Gross Domestic Product

GFSI Global Food Security Index

GHI Global Hunger Index

HDI Human Development Index

IDR Import Dependency Ratio 
IFPRI International Food Policy Research Institute

IPCC Intergovernmental Panel on Climate Change

MDGs Millennium Development Goals

NEPAD The New Economic Partnership for Africa ${ }^{e e}$ s Development

OECD Organization for Economic Co-operation and Development

PSNP Productive Safety Net Programme

R\&D Research and Development

SD Standard Deviation

SSA sub Saharan Africa

SSR Self Sufficiency Ratio

U.S.A United States of America

UN United Nations

UNDP United Nations Development Programme

UNICEF United Nations Children "s Fund

WFP World Food Programme

WHO World Health Organization 


\section{Chapter One}

\section{Introduction}

The last decade is the period in which Africa has started to see spectacular and sustained economic growth and development after long term stagnation and setback. According to the World Bank (2013b), Sub Saharan Africa (SSA) region excluding South Africa, recorded a high GDP growth rate of 5.8\%. Although such aggregate figure hide the diversity in performance, the growth extended over a vast majority of the countries on the continent, encompassing both resource rich and resource poor ones (Vink, 2012).

On contrary, although a single developing nation in Africa is assisted by an average of thirty aid organisations to maintain the food and nutritional security objectives, the region still remains highly food insecure (Heidhues, 2004). According to the FAO's projection for 2010 to 2012, around 234 million undernourished people live in SSA, which is about $26.8 \%$ of the population (FAO, 2012a). There is also an estimation of a sizable increase in the size of the food insecure population in the region over the coming decade, with the proportion of the population that is food insecure being expected to rise from $29.4 \%$ in 2013 to $33.8 \%$ in 2023 (Meade \& Rosen, 2013). It should be also noted that about $80 \%$ of the food insecure population lives in rural Africa, with small scale farmers constituting $50 \%$ of the figure and the remaining 30\% represented by the landless rural poor (Mwaniki, 2006).

In this respect, this research aimed to investigate the pattern of poverty reduction and food security along with the economic growth pattern in the region. Accordingly, the food and nutritional security performance of Africa, focusing on specific, representative countries, was scrutinised by using the framework of the food security dimensions that are applied in the Economist Intelligence Unit (EIU) Global Food Security Index (GFSI) (EIU, 2012). The index basically uses the three food security dimensions of availability, affordability and utilisation, along with their respective indicators.

The role of agriculture in all of these dimensions, coupled with parameters that indicate food security, was also analysed. Different background factors of agriculture and food security were investigated quantitatively and qualitatively in the context of Africa. The discussion of the research starts by exploring the definition and scope of food security and its measurement techniques. Following that, the food availability dimension and its determining factors are discussed. Food accessibility and food utilisation are the subsequent chapters, which collectively lead to the final findings and conclusions of the research. 


\subsection{Definition and scope of food security}

Food security arose as a global concern after the first conference of food and agriculture in 1943, which stated food security as being a "secure, adequate and suitable supply of food for everyone" (Gross, Schoeneberger, Pfeifer \& Preuss, 2000; Weingärtner, 2005). Subsequently, agricultural surplus from donor countries such as the U.S.A and Canada started to be shipped to overseas countries in the 1940s and 1950s (Gross et al., 2000, Weingärtner, 2005). Following this, the understanding of food aid as a barrier to the development of food selfsufficiency (Madziakapita, 2009) turned the concept into food for development in the 1960s. From the 1970s, the concept of food assurance to keep a sustainable food supply during food crises persisted until the 1980s. The concept was broadened in the 1980 s to incorporate demand side factors, due to the realisation that food availability alone did not necessarily guarantee food security (Gross et al., 2000). In the 1990s, an international and national commitment was proposed to abolish or decrease hunger, and recently the debate shifted to food preferences and nutritional security (Panagariya, 2002; Pinstrup-Andersen, 2009).

Devereux \& Maxwell, (2001) argue that, until the turn of the millennium, the concept of food security showed three paradigm shifts. The first was the shift from the global and national level to household and individual level. The second was the shift from a food first perspective to a livelihood perspective. And the last was the shift from objective indicator to subjective perception, which includes issues associated with food quality and safety (Devereux \& Maxwell, 2001; Maxwell, 1996).

Through its evolution and the changing views on it, the definition of food security has also showed progressive changes. The first definition of food security in 1974 basically focused on food availability and food price stability issues (UN, 1975 cited in Panagariya, 2002:27):

Availability at all times of adequate world food supplies of basic foodstuffs to sustain a steady expansion of food consumption and to offset fluctuation in production and prices.

Subsequently, a breakthrough in famine and food security analysis came into picture in the seminal work of Sen's entitlement approach (Sen, 1981). His argument was different, as it considered both the supply-and demand-side factors of the food security equation. Accordingly, he empirically illustrated demand factors, which are lack of effective demand or individuals ${ }^{\text {ee }}$ inability to command the market can result in extreme food insecurity and famine (Sen, 1981). Moreover, the observed success of the green revolution, which resulted in an 
adequate food supply, did not result in a dramatic decline in malnutrition and poverty, which required the modification of the definition of food security (Clay, 2002).

Consequently, by 1983, the FAO had elaborated the definition of food security to incorporate the accessibility of available food for vulnerable groups through a consideration of both the supply and demand sides of the food security equation, as follows:

Ensuring that all people at all times have both physical and economic access to the basic food they need (FAO, 1983 cited in Clay, 2002:2).

The definition of food security was further amended after the World Bank ${ }^{\text {ee }}$ (1986) influential report on poverty and hunger, which stated that food security amounted to "access of all people at all times to enough food for an active, healthy life"

Moreover, this definition addressed the concept of the temporal dynamics of food insecurity, which encompass chronic and transitory food insecurity situations. The former is linked to continuing or structural poverty, and the latter to periods of intensified pressure resulting from natural disasters, economic collapse or conflict (Clay, 2002; Pinstrup-Andersen, 2009).

In the mid-1990s, the definition of food security expanded to include food safety and nutritional balance. Consequently, the 1996 World Food Summit redefined food security to include nutrition, food safety and preference, as follows:

Food security exists when all people, at all times, have physical and economic access to sufficient safe and nutritious food that meets their dietary needs and food preferences for an active and healthy life (FAO, 1996).

Moreover, in 2001, the definition was again redefined to incorporate the social access dimension:

Food security is a situation that exists when all people, at all times, have physical, social and economic access to sufficient, safe and nutritious food that meets their dietary needs and food preferences for an active and healthy life (Panagariya, 2002).

Sanchez et al. (2005, cited in Madziakapita 2009:29) elaborated the definition further by incorporating the cultural aspect, as "food insecurity is a condition that exists when people do not have physical and economical access to sufficient, safe, nutritious and culturally acceptable food to meet their dietary needs to lead an active and healthy life". 
Accordingly, food security is said to be achieved "if adequate food (quality, quantity, safety, sociocultural acceptability) is available and accessible for and satisfactorily utilized by all individuals at all times to live a healthy and happy life" (Gross et al., 2000:4). This definition of food security includes physical and temporal determinants. The physical determinants are the availability, accessibility and utilisation of food, and the temporal determinant is called stability, which includes risks such as climatic fluctuations, conflict, job loss and epidemic diseases that may affect any one of the three physical elements (Webb et al., 2006).

The three physical determinants of food security have a hierarchical nature, as availability is a necessary but not sufficient condition to ensure access, while accessibility, in turn, is a necessary but not sufficient condition for effective utilisation (Barrett 2010; Webb et al., 2006). Moreover, stability, which is the temporal determinant of food security, recognises that all the three physical determinants should be realised simultaneously (Vink, 2012).

\subsubsection{Complexity of the definition of food security}

Although the current definition of food security encompasses its three internationally accepted dimensions, the definition remains subjective and vague in terms of practical application and the measurement of food security (Vink, 2012). According to PinstrupAndersen (2009), the introduction of "food preferences" in the current definition of food security changes the concept from ordinary access to enough food, to access to preference. Therefore, in practice, it could be problematic to measure individuals ${ }^{\text {ee }}$ food preferences, in accordance with local food habits, cultural acceptability and human dignity (Maxwell, 1996). In the light of this, Vink (2012) argues that the definition of food security remains open ended and that it needs specific attention, as the measurement of individualse dietary preferences is a challenge that ultimately affects policy interventions.

Barrett (2010) adds that, being a multidimensional concept, access becomes more difficult to measure than availability. Webb et al. (2006) also emphasised that measuring food accessibility is vital and needs special focus on fundamental measurement techniques and a shift from objective to subjective measurements at the household level. In this regard, for Maxwell (1988, cited in Maxwell, 1996), the subjective dimension of food security carries more weight and is defined as:

A country and people are food secure when their food system operates in such a way as to remove the fear that there will not be enough to eat. In particular, food security will be achieved when the poor and vulnerable, particularly women and children and those living in marginal areas, have secure access to the food they want. 
However, according to Pinstrup-Andersen (2009), as availability does not assure access in the national and global context, enough calories also do not necessarily imply a healthy and nutritional diet. Non-food parameters such as access to health, clean water, education and so on can affect individuals ${ }^{e e}$ access to a nutritious diet in developing countries. However, the case might be different for individuals who live in developed countries, where their preferences could play a relatively significant role. Accordingly, the term "preferences" would not be a problem if it was perceived to mean socially and culturally acceptable within religious and ethical values, rather than a broader interpretation of meaning a household or individual preference (Pinstrup-Andersen, 2009). In this regard, when considering household food security and the implementation of policies and programmes, household behaviour should also be taken into consideration (Pinstrup-Andersen, 2009).

The understanding and application of the concept of food security therefore remain broad. To this end, Clay (2002) argues that the international community has accepted the broad, common goals of "human security", of which food security is one component, but in practice has narrowed it to simpler objectives of the reduction and elimination of poverty, as declared in the Millennium Development Goals (MDGs) (Clay, 2002). Panagariya (2002) argues that, through its evolution, the term food security has become more complicated and its perception as a goal per se is a tall order; it therefore rather should be understood as a set of interrelated activities that contribute to the active and healthy life of an individual (Panagariya, 2002).

\subsection{Overview of African food security status}

The overall picture of Africa with regard to food and nutritional security remains negative. The countries with a high level of undernourishment and with the lowest level of food security are highly concentrated in the sub-Saharan Africa region (EIU, 2012). The region is also characterised by chronic and transitional food insecurity. According to the FAO (2008a), chronic food insecurity refers to a condition where people are suffering from a lack of the minimum food they should get for a healthy life over a prolonged period of time. The main background factors include prolonged poverty, lack of assets or shortage of capital, such as diminished access to productive or financial resources. Transitory food insecurity is a sudden drop in the ability to produce or access enough food to maintain a good nutritional status (FAO, 2008a). It may result from short-term shocks and fluctuations in food availability and access, including year-to-year variations in domestic food production, food prices and household incomes (FAO, 2008a). 
Globally, according to the FAO ${ }^{\text {ee }}$ s estimates, about $12.5 \%$ of the world population is estimated to be chronically food insecure in terms of dietary energy supply (FAO, 2012a). Of this, $97.7 \%$ or 852 million undernourished people live in developing countries and 234 million of these live in the sub-Saharan Africa region (FAO, 2012a). The prevalence of malnutrition also varies geographically across Africa, with the lowest level, of around 4\%, in Northern Africa, and $14 \%$ in Western Africa; the highest level, of $40 \%$, is found in Central Africa (Mwaniki, 2006; Wiggins \& Keats 2009). According to Wiggins \& Keats (2009) prevalence of undernourishment has been rising in Central Africa and fractionally in North Africa, while it is declining in other parts, specifically West Africa is on the right track of achieving the MDG hunger reduction objective (Wiggins \& Keats, 2009).

The recent FAO report, on the other hand, revealed that there has been more marked progress in the reduction of hunger than it was previously believed (FAO, 2012a). It states that developing countries could achieve the MDG target of reducing the proportion of people suffering from chronic hunger by half between 1990 and 2015 (FAO, 2012a). Accordingly, if the rate of decline continues at the same pace in the developing region as over the past 20 years, estimates put undernourishment at $12.5 \%$ by 2015 , which is closer to the MDG goal of $11.6 \%$ from $23.2 \%$ in 1990/92. In contrast, Africa showed a sluggish rate of reduction, from $27.3 \%$ to $22.9 \%$, during the period from $1990 / 92$ to $2010 / 12$, with the absolute number of undernourished people increased from 175 million to 239 million in the same period (FAO, 2012a).

This study focuses on the three main dimensions of food security: availability, accessibility and utilisation as used in EIU (2012). Although food availability analysis theoretically is limited to the food supply side of the food security equation, it has important implications for the understanding of the overall food security situation of a region. However, to get a more complete picture of regional food security, a comprehensive analysis of food supply, access and utilisation is important. The Economist Intelligence Unit (EIU) used such a technique for its global food security index analysis, in which food availability was weighted to be $44 \%$, and affordability and utilisation represented $40 \%$ and $16 \%$ of the weighted national food security analysis respectively.

Food availability can be defined as "the availability of sufficient quantities of food of appropriate quality, supplied through domestic production or imports (including food aid)" (FAO, 2006a). It can be explained through the two concepts of food self-sufficiency and food self-reliance. These are distinguished from each other in their consideration of trade as a 
means of food supply, as food self-sufficiency relies more heavily on domestic production than on import (Deb et al., 2009; Panagariya, 2002). According to the FAO, 48 out of 63 lower income countries (per capita incomes of US\$785 or less) are net food importers (Panagariya, 2002), which implies that trade plays a greater role in food availability in regions such as SSA.

In the light of this, although Africaes per capita agricultural production has been growing for the past thirty years (Vink, 2012; Wiggins \& Keats, 2009), the rise in caloric food intake has showed slow progress; it was only $2150 \mathrm{kcal} /$ day in 2003 compared to $2050 \mathrm{kcal} /$ day thirty years ago (Panagariya, 2002). However, since the mid-1990s, the per capita availability of food has increased and this intake reached $2500 \mathrm{kcal} /$ person in 2009, which is a significant improvement (Wiggins \& Keats, 2009).

In light of this, the performance of agricultural growth is an important dimension of overall food security in Africa. Studies have shown that agriculture in SSA plays a very important role in employment and gross domestic product (GDP) share (Devereux, 1999; FAO 2012a). In this regard, small-scale farmers account for more than $90 \%$ of agricultural production in Africa (IFPRI, 2004). Moreover, they represent four fifth of the developing world ${ }^{\text {ee }}$ food production (FAO, 2011 cited in Fan et al.2013). However, the proportion of food insecurity is also higher among poor subsistence farmers and landless tenants in rural areas, who collectively account for about $80 \%$ of the undernourished (Panagariya, 2002).

In this regard, a detailed analysis of African food security with respect to the agricultural sector and its dimensions was undertaken by Vink (2012). The author analysed the performance of African agriculture in terms of the four pillars of food security and highlighted the pressure on the success of small-scale farming to achieve food security objectives. He argued that with regard to agricultural productivity, there is a higher prospect to large-scale farming relying on farming land expansion in Africa, because it allows overcoming institutional and infrastructural constraints which could not be easily handled by small-scale farmers (Vink, 2012).

In terms of food accessibility (affordability), the region shows significant variation from country to country. The recent global food security index of the EIU ranks South Africa, Botswana and Uganda the highest, whereas Nigeria, DRC and Chad were ranked the least food-affordable countries in SSA (EIU, 2012). The term "food affordability" signifies the demand for food and is affected by economic factors, physical infrastructure and consumer preferences (Burchi \& De Muro, 2012). The concept of accessibility originated from Sen se $^{\text {ec }}$ 
entitlement approach and has matured further to assess the root causes of food insecurity using the capability approach (Sala-i-Martin \& Pinkovskiy, 2010).

Africae $^{\text {ee }}$ economic growth over the past decade has been impressive and has turned the attention of the international media from their usual negative reports to positive pictures of the continent (Vink, 2012). According to a study by Sala-i-Martin and Pinkovskiy (2010), Africa showed a rapid reduction in poverty from 1970 to 2006, a situation that is enjoyed by a significantly larger number of countries, including mineral rich and resource poor, landlocked and coastal, and even those that have been geographically or historically disadvantaged (Vink, 2012). Accordingly, if this pace of economic growth continues, there is the probability of achieving the MDG of halving the proportion of the population living on less than one dollar per day by 2015 (Sala-i-Martin \& Pinkovskiy, 2010).

The third dimension of food security is food utilisation, which is usually a biological perspective that involves the ability of the human body to ingest and metabolise food (Gross et al., 2000). Good care and feeding practices and food preparation, a diverse diet and good intra-household distribution of food affects the individual's nutritional intake (FAO, 2008a). The food utilisation dimension of food security is also a factor of other non-food parameters, such as sanitation, access to a clean water supply and good health (Pinstrup-Andersen, 2009). Africaes progress with respect to these non-food nutritional indicators has also shown improvement over the past two decades. Accordingly, drinking water coverage increased to $61 \%$, showing a $12 \%$ increase from 1990 to 2010 , and sanitation coverage increased to $30 \%$, showing a 4\% increase in the same period (WHO, 2010).

The fourth dimension of food security is called "stability". Stability refers to the concept of access to adequate food at all times, or not being at risk of losing access to food due to seasonal food insecurity or sudden shocks such as economic or climatic crises (FAO, 2006a). Therefore, according to the FAO (2006a), stability includes both the availability and accessibility dimensions of food security. In this regard, the components of stability, namely food production volatility and food price volatility, are included in the food availability and food accessibility analysis sections of this research.

\subsection{Statement of the problem}

Different studies have identified the rate and prevalence of food insecurity in Africa. For instance, the recent Economist Intelligence Unit assessment of the global food security index identified most of the SSA countries as being the most food insecure in the world (EIU, 
2013). The index is a multidimensional indicator of food in/security, combining food availability, accessibility and utilisation. The Global Hunger Index (GHI) of the International Food Policy Research Institute (IFPRI) is another hunger-monitoring index, which has published the status of food insecurity globally for the past eight years (IFPRI, 2012). Their report also shows that sub-Saharan Africa and South Asia are the most food insecure regions. However, the 2012 report highlighted that four SSA countries, namely Angola, Ethiopia, Malawi and Niger, had reduced their score by more than $50 \%$ from the 1990 GHI score. The FAO ${ }^{e s}$ report on the state of food insecurity in the world is another yearly assessment of the prevalence of undernourishment around the world (FAO, 2012a).

Besides these global and national indexes of food security, different studies focusing on Africa have also shown the inter-regional diversity of the continent in terms of food security. For instance, Kidane et al., (2006) studied "food security and agricultural development in subSaharan Africa". Their study investigated the prevalence of food insecurity in SSA by taking ten representative countries and using the food supply and accessibility dimensions of food security. A study by Boussard et al., (2005) also analysed the food security situation of Africa by taking some representative countries and analysing the caloric food supply, food availability and access parameters. The analysis also identified the bottlenecks to achieving food security in Africa and provided possible policy interventions. Vink (2012) used the four dimensions of food security: availability, accessibility, utilisation and stability, to investigate food security and agricultural growth pattern in Africa.

From these perspectives, this research aimed to investigate the food security situation in Africa by taking ten representative countries (although not perfectly representative) from Northern, Central, Eastern, Western and Southern Africa. The analysis follows a comparative investigation of these representative countries on the three main dimensions of food security. In this regard, the research investigated the following two main research problems:

$>$ Africa is a continent with great diversity specifically in terms of food and nutritional security, which calls for detail investigation for appropriate policy and strategy.

$>$ The role of agriculture with respect to enhancing food and nutritional security in Africa, specifically how it interacts with each of these dimensions of food security. 


\subsection{Main objectives}

a. The main objective of this thesis is to comparatively investigate the regional and national food and nutritional security situation of Africa using the three pillars of food security to illustrate regional diversity for appropriate policy recommendation. It used food availability, accessibility and utilization as analytical framework. It did not include the fourth pillar - food stability, however it is indirectly analysed in availability and accessibility sections taking production and food price volatility amongst its indicators.

b. The study also aimed to highlight the importance of agriculture in achieving food and nutritional security through analysing its interaction with food availability, accessibility and utilisation. In conjunction to this, it empirically investigated agricultural policy strategies in enhancing food and nutritional security in Africa.

\subsection{Significance of the study}

The research provides a detailed picture of Africa ${ }^{e e}$ s food and nutritional security status. The study is relevant in terms of explaining factors playing a crucial role in African food and nutritional security. Specifically, the research addresses the main progress in and lagging behind of the regional and national food security situation in terms of the food availability, accessibility and utilisation indicators of food security. Also, the role that agriculture currently is playing and the role it should play will be important inputs for policy making, prioritising projects and designing food security intervention strategies. Moreover, inter-regional and inter-country comparisons and interpretation of food security factors enhance the visualisation of the heterogeneity of the food security status of the region for appropriate policy making.

\subsection{Delimitations of the study}

The study is limited to an analysis of food security at the regional and national level. The study area is limited to Africa; however more emphasis is put on the sub-Saharan Africa (SSA) region because of the relatively widespread prevalence of food insecurity in the region. More specifically for the quantitative data analysis, ten countries were selected on the basis of their diverse rankings - from top to medium to low - in the EIU ${ }^{e e}$ global food security index (see Table 1.1). The selection also considered their geographical representation of Egypt and Sudan $^{1}$ from Northern Africa; Ghana and Nigeria from Western Africa; Ethiopia ${ }^{2}$, Mozambique, Madagascar and Zambia from Eastern Africa; DRC from Middle Africa; and

\footnotetext{
${ }^{1}$ Refers to the former Sudan.

${ }^{2}$ The data used from 1993 onwards excludes Eritrea.
} 
South Africa from Southern Africa region. According to the CIA (2013) these countries represent almost $60 \%$ of Africa ${ }^{a e}$ s total population size. Furthermore, in most of these countries agriculture plays important role in their economy as indicated on table 1.1. Also according to FAOSTAT (2013) data, these countries represent nearly 60\% of total cereal production of Africa. However, depending on the availability of data and the context of each section, some countries have been added and removed throughout the research. Also, unless specified, the sub-regional classification of Africa followed the UN classification of Northern, Eastern, Middle, Southern, and Western Africa ${ }^{3}$.

Table 1. 1: Profile of the case study countries

\begin{tabular}{|l|l|l|l|l|}
\hline Country & World rank $\ddagger$ & $\begin{array}{l}\text { African } \\
\text { rank } \ddagger\end{array}$ & Population & $\begin{array}{l}\text { Share of } \\
\text { agriculture } \\
\text { to GDP }\end{array}$ \\
\hline South Africa & $39^{\text {th }}$ & $1^{\text {st }}$ & $48,601,098$ & $2.6 \%$ \\
\hline Egypt & $56^{\text {th }}$ & $5^{\text {th }} *$ & $85,294,388$ & $14.7 \%$ \\
\hline Ghana & $67^{\text {th }}$ & $3^{\text {rd }}$ & $25,199,609$ & $22.7 \%$ \\
\hline Nigeria & $86^{\text {th }}$ & $10^{\text {th }}$ & $174,507,539$ & $30.9 \%$ \\
\hline Ethiopia & $90^{\text {th }}$ & $13^{\text {th }}$ & $93,877,025$ & $46.4 \%$ \\
\hline Mozambique & $93^{\text {rd }}$ & $16^{\text {th }}$ & $24,096,669$ & $29.5 \%$ \\
\hline Madagascar & $96^{\text {th }}$ & $18^{\text {th }}$ & $22,599,098$ & 27.9 \\
\hline Zambia & $100^{\text {th }}$ & $22^{\text {nd }}$ & $14,222,233$ & $20.4 \%$ \\
\hline Sudan & $104^{\text {th }}$ & $25^{\text {th }}$ & $34,847,910$ & $27.6 \%$ \\
\hline DRC & $107^{\text {th }}$ & $28^{\text {th }}$ & $75,507,308$ & $44.2 \%$ \\
\hline
\end{tabular}

Source: Adapted from EIU (2013) and CIA (2013) database

¥Refers to the food security ranking by EIU (2013)

*Egypt ranked in Middle East and North Africa region

In terms of time period, the quantitative data analysis covered the long-term available data, depending on the context of each section. Based on data availability, generally the study period covered fifty years of data from 1961 to 2011. The food availability analysis covers the production, yield and farm size growth performance of specific agricultural commodities for the period of $1984 / 86$ to $2010 / 12$. The commodities mainly focus on cereals and, roots and tubers due to the fact that about $62 \%$ of the dietary energy in Africa is derived from these commodities (FAO, 2013).

For the food accessibility analysis, the indicators on the selected countries used existing data from 1961 onwards. Existing recent data on the indicators of food utilisation were also used for the food utilization analysis. The stability dimension of food security did not form part of the quantitative analysis, as its measurement was found to be complex. However, food

\footnotetext{
${ }^{3}$ The UN classification of Africa's sub-regions is attached in addendum A
} 
production variability was investigated in the food availability analysis. Also, the concept of food price volatility was analysed in the food accessibility analysis.

The analytical framework for the research was limited to the three dimensions of food security used by the Economist Intelligence Unit (EIU, 2012) (see Figure 1.1). These dimensions are derived from the original definition of food security as "food availability", "food accessibility" and "food utilization". The fourth dimension, "stability", is not analysed directly, but its important indicators of production volatility and food price variability are analysed in availability and accessibility sections respectively.

\subsection{Research hypothesis}

There is regional and national diversity on the performance of food and nutritional security in Africa. Some countries are more effective in achieving it where agriculture plays important role for that.

\subsection{Data and Methodology}

\subsubsection{Method of data collection}

The analysis of secondary qualitative and quantitative data was the main method for doing this research. Secondary analysis is "a research strategy which makes use of pre-existing quantitative data or pre-existing qualitative research data for the purpose of investigating new questions or verifying previous studies" (Heaton, 2004:16). Therefore, different sources of secondary data available on the web pages of national and international organisations, government organisations and non-governmental organisations dealing with food and nutritional security were used as a source of raw and processed data. Electronic and nonelectronic, published and unpublished journals, books, reports, conference proceedings and so on were also used.

Among the sources of the data used for quantitative analysis were: the EIU's Global Food Security Index, FAO"s FAOSTAT database, the African Development Bank (AfDB), the UNDP, UNICEF, WHO, the Global Hunger Index (GHI) of International Food Policy Research Institute (IFPRI), the World Development Indicators and African Development Indicators of the World Bank, and other relevant indexes and data sources.

\subsubsection{Method of data analysis}

The analytical framework was constructed on the basis of the methods used by different studies of food security. In addition, the framework followed the definition of food security, 
founded on the three main dimensions, namely food availability, food accessibility and food utilisation. These dimensions are also used in global food security index analyses by the Economist Intelligence Unit (EIU, 2012).

In terms of measuring food in/security, a single indicator cannot manifest the extent of prevalence, as it is composed of different, complex factors (Cunningham, 2005). According to Clay (2002), the measurement of food security, which comprises undernourishment and undernutrition, is not straightforward and uses the "food balance sheet", "national income distribution" and "expenditure data" (Clay, 2002).

According to Cunningham (2005), there are five ways of assessing hunger and malnutrition. The first one is by using qualitative methods that assess hunger and the behavioural response, while measuring the stability of supply. The second is the FAO method of dietary intake and its relation to energy needs. The third and fourth methods are the individual dietary survey and the household income and expenditure survey methods that help measure access to food supplies. The final one is anthropometry measures, which focus on the biological utilisation of food by indicating the effect of malnutrition on growth and thinness (Cunningham, 2005).

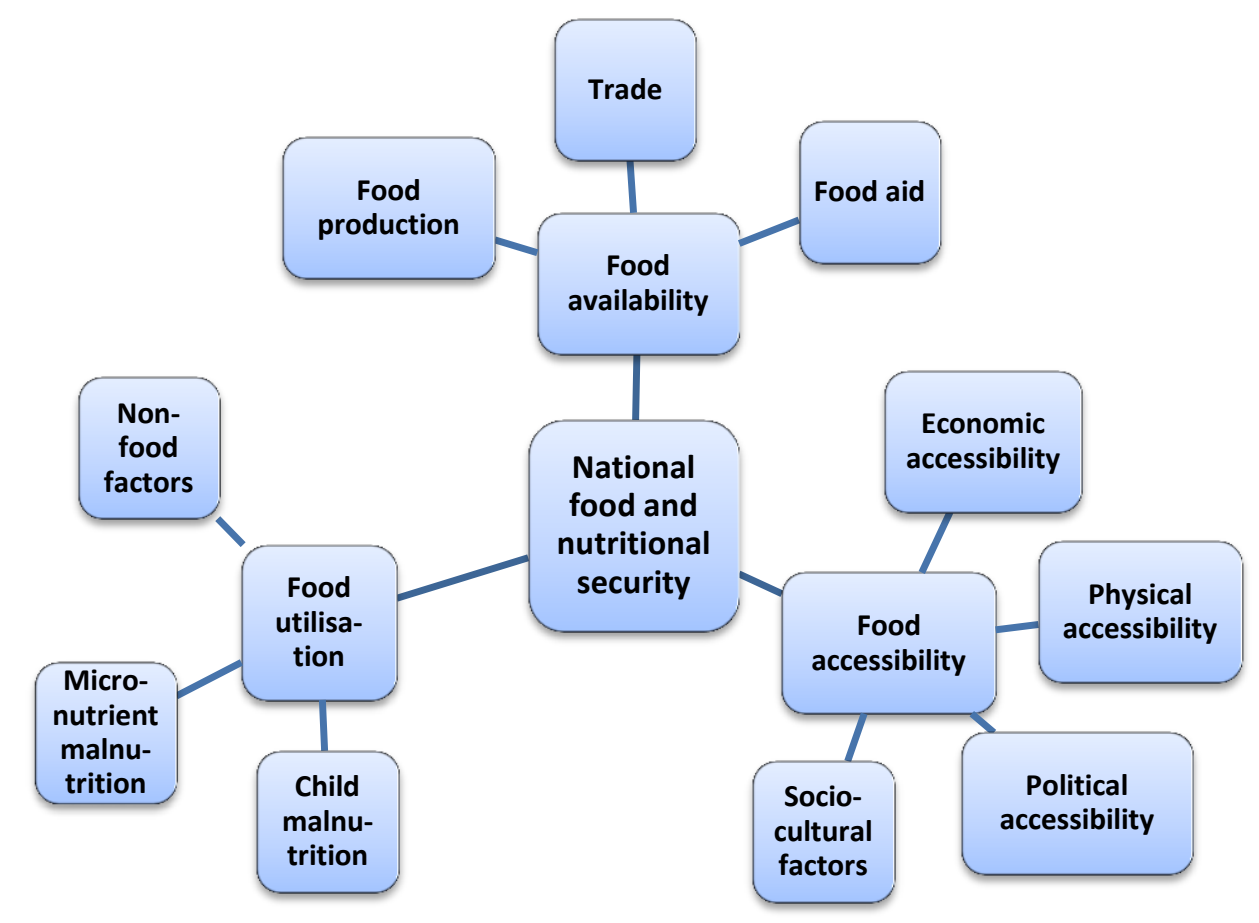

Figure 1.1: Analytical framework of the study

Accordingly, for the purpose of this research, the comparative analysis of national food and nutritional security over the selected countries in Africa was undertaken on the basis of the three main pillars of food security (see Figure 1.1). The determining factors and measurement parameters of these dimensions of food security at the national level used in this research are 
summarised in Table 1.2. In addition, the details of the measurement techniques of each food security dimensions are discussed in the respective chapters.

Table 1.2 Food security dimensions, indicators and measurement techniques

\begin{tabular}{|c|c|c|c|c|}
\hline $\begin{array}{l}\text { Food security } \\
\text { dimension }\end{array}$ & Parameters & Indicators & $\begin{array}{l}\text { Quantitative data } \\
\text { source }\end{array}$ & $\begin{array}{l}\text { Method of } \\
\text { analysis }\end{array}$ \\
\hline \multirow[t]{4}{*}{$\begin{array}{l}\text { Food } \\
\text { availability }\end{array}$} & $\begin{array}{l}\text { Dietary energy } \\
\text { supply }\end{array}$ & Per capita calorie intake & \multirow{4}{*}{ FAOSTAT, EIU } & \multirow{4}{*}{$\begin{array}{l}\text { Statistical } \\
\text { analysis and } \\
\text { literature } \\
\text { review }\end{array}$} \\
\hline & Production & $\begin{array}{l}\text { Amount, yield, area } \\
\text { harvested }\end{array}$ & & \\
\hline & Trade & Net import, IDR, SSR & & \\
\hline & Food aid & Total cereal aid & & \\
\hline \multirow[t]{4}{*}{$\begin{array}{l}\text { Food } \\
\text { accessibility }\end{array}$} & Economic & $\begin{array}{l}\text { GDP per capita, HDI, } \\
\text { GINI index, Food price } \\
\text { volatility }\end{array}$ & \multirow{3}{*}{$\begin{array}{l}\text { African } \\
\text { development } \\
\text { indicators, world } \\
\text { development } \\
\text { indicators and } \\
\text { EIU }\end{array}$} & \multirow{3}{*}{$\begin{array}{l}\text { Statistical } \\
\text { analysis and } \\
\text { literature } \\
\text { review }\end{array}$} \\
\hline & Physical & Infrastructure level & & \\
\hline & Political & $\begin{array}{l}\text { Accountability and } \\
\text { corruption index }\end{array}$ & & \\
\hline & Sociocultural & $\begin{array}{l}\text { Qualitative (literature } \\
\text { review) }\end{array}$ & -- & $\begin{array}{l}\text { Literature } \\
\text { review }\end{array}$ \\
\hline \multirow{3}{*}{$\begin{array}{l}\text { Food } \\
\text { utilisation }\end{array}$} & Child malnutrition & Anthropometric measures & \multirow{3}{*}{$\begin{array}{l}\text { WHO, World } \\
\text { Bank, UNICEF, } \\
\text { EIU, MEASURE- } \\
\text { DHS }\end{array}$} & \multirow{3}{*}{$\begin{array}{l}\text { Statistical } \\
\text { analysis and } \\
\text { literature } \\
\text { review }\end{array}$} \\
\hline & $\begin{array}{l}\text { Micronutrient } \\
\text { malnutrition }\end{array}$ & $\begin{array}{l}\text { Iron, iodine and vitamin } \\
\text { A deficiency }\end{array}$ & & \\
\hline & $\begin{array}{l}\text { Non-food } \\
\text { parameters }\end{array}$ & $\begin{array}{l}\text { Access to clean water, } \\
\text { health and sanitation }\end{array}$ & & \\
\hline
\end{tabular}




\subsection{Summary}

Starting from considering only the food supply side, the definition and concept of food security has shown progressive change roughly for the past half a century (Weingärtner, 2005). One of the important breakthrough in thinking about food security was the introduction of demand factors into the food security equation, following Amartya Sen's entitlement approach. As a result, the current definition of food security incorporates important demand factors such as physical and economic accessibility of safe, nutritious and culturally acceptable food.

The introduction of "food preferences" into the current definition of food security changes the concept from access to enough food to access to preference (Pinstrup-Andersen, 2009). However, understanding and measuring individuals ${ }^{\text {ee }}$ food preferences appears to be difficult, which in turn can affect the policies and strategies of addressing food insecurity. Therefore, through its evolution and progress, the definition of food security has lost its simplicity. As a result, it should be considered not as a goal in itself, but rather as a set of interactive activities that contribute to an active and healthy life.

The current definition of food security realises the four internationally accepted dimensions of food security: availability, accessibility, utilisation and stability. However, using EIU's global food security index (EIU, 2012) the research systematically analysed the food and nutritional security situation of the region, based on the three dimensions of food security: availability, accessibility and utilisation. To this end, this research identified ten countries in which collectively represent larger share of Africa ${ }^{e e}$ s agricultural production (around 60\% total cereal production) and population size (nearly 60\%). Also these countries evenly represent Africa geographically; moreover the selection considered their food security ranking on EIU (2013) index. These countries are the DRC, Egypt, Ethiopia, Ghana, Madagascar, Mozambique, Nigeria, South Africa, Sudan and Zambia. Depending on data availability for those quantitatively measureable parameters of food security, fifty years of data from 1961 to 2011 is generally used. 


\section{Chapter two}

\section{The Food Availability Analysis}

\subsection{Introduction}

The concept of food availability was considered as the only determining factor of food security for a long time. As a theory, it originated in the famous demographical and famine analysis by Thomas Robert Malthus, who analysed population growth and food supply in the late eighteenth century. According to the Malthusian hypothesis, food insecurity and famine can result from unbalanced growth rates in food supply, which increase in an arithmetic ratio, and food demand, which is a factor of unchecked population growth that increases in a geometric ratio (Malthus, 1798).

However, Malthuses hypothesis accustomed to be unlikely, as without war or famine the world population growth could actually be controlled as a result of improved education, health, income growth and urbanisation that enhanced better use of birth control (Paarlberg, 2010). On top of that, the agricultural productivity success of the last half a century, in which the world fed a population that had doubled with only a $12 \%$ increase in cultivated land area, has disproved the Malthusian threat that food production would be exceeded by population growth (Fuglie \& Nin-Pratt, 2012). In spite of this success in agricultural productivity, population pressure is still one of the main drivers of food demand, as recent studies have forecast that, by 2050 , the world will have to increase its food production by about $60 \%$ from its current level to meet the food demand of nine billion people (Alexandratos \& Bruinsma, 2012).

Besides population growth, a rise in per capita consumption has also resulted in increased demand for the available food (Kearney, 2010). Food consumption patterns follow a change in trend from initially undernourished to staple crops such as grains, roots, tubers and pulses, and then to more energy-rich foods such as meat, vegetable oil and sugar (Godfray et al., 2010). And this shift in dietary preference necessitates more grains to be used for animal feed than for direct consumption, which overall is a more inefficient process than direct consumption (Godfray et al., 2010).

Another driving factor for the increasing need for agricultural and food commodities is the recent demand surge from biofuels. According to a comparison done by the World Watch Institute, the amount of grain needed to fill the 90-litre petrol tank of a $4 \times 4$ vehicle using bioethanol fuel could feed a person for a year (Carol, 2008, cited in Molony \& Smith, 2010). 
The impact of biofuels on food security therefore can be categorised as threefold. First, biofuels are diverting available food away from human consumption; second, biofuel production is competing for the limited resources (land and water) used for food production; and third, the combination of the two leads to food price escalation, which results in food access by the poor being undermined (see Section 3.3.3) (Molony \& Smith, 2010).

According to Elmulthum et al., (2011), the supply of food is also affected by natural factors such as floods, droughts, crop diseases and so on. In this regard, recent findings claim that some natural disasters are associated with human activities that brought about climate change, which affects agricultural production and food security (Müller et al., 2011). Besides these, human-induced factors such as political instability and armed conflict, and institutional factors like market failure, can also hinder food availability.

When considering food supply, there are three main mechanisms of achieving regional, national as well as household food supply. The first is food production through agriculture and the agro-processing industries, the second is using trade as a means of food availability, and the third is food aid (Kidane et al., 2006). This section largely relies on these factors of availability as analytical framework.

The first section discusses food availability measurement techniques used in different indices by different institutions. This is followed by evidence regarding the caloric food intake performance of the region, as well as of the case study countries. The next section is devoted to a detailed analysis of Africa ${ }^{e e}$ s food production over specific period of time, taking specific commodities in the case study countries. Then agricultural trade performance and the current trade dynamics, with trade liberalisation and globalisation, are discussed. The food selfsufficiency ratio (SSR) and import dependency ratio (IDR), which analyse production and consumption trends in Africaes sereal production, are also investigated. Following that, Africaes current agricultural trade and background factors are discussed. Finally, food aid performance in the region and in the specific countries was investigated.

\subsection{National food availability measurement techniques}

The estimates of national food supplies for most countries are organised and updated by the Food Balance Sheets (FBS) of the Food and Agricultural Organization (FAO) of the United Nations (Babu \& Sanyal, 2009; De Rose et al., 1998). Generally, these provide information on the food supply situation of about 200 countries (and territories) for around 300 different kinds of food commodities and 380 processed products (Kelly et al., 1991). They provide information about the supply of a specific commodity of production - stock changes of 
imports and exports, and uses for food, feed, seed, waste, food manufacture and others at the national level (Jacobs \& Sumner, 2002; Kelly et al., 1991). Finally the balance sheets also provide estimates of the nutrient content (calories, protein and fat) per unit of each food, expressed as per day and per capita nutrient availability (De Rose et al., 1998).

Although the FBS shows the available food for consumption, capturing post-harvest losses such as losses on farm and during distribution and processing, the actual consumption might be lower than the estimated level due to the degree of losses of edible food and nutrients at household level (FAO, 2012b). The FBS also is subject to errors associated with coverage and the accuracy of statistics on populations, food production, supply and utilisation of nutrients in specific countries, especially in countries with subsistence farming (De Rose et al., 1998). However, the use of internal and external consistency checks, such as surveys, and the relevant technical, nutritional and economic expertise are helping reduce the accuracy gap (FAO, 2012b). To this end, the FBS provides the best available information of national food supplies, in spite of its shortcomings (De Rose et al., 1998).

Besides measuring household access to food, the household income and expenditure survey is another method used for the measurement of food availability at the national level. Food consumption surveys and income/budget expenditure surveys are the two methods that, in practice, are affected the most by the duration or timing of data collection (De Rose et al., 1998). This means that, at the time of completion of the surveys, the results may be significantly different from what is actually being experienced in real time, as food availability varies over time. Also, the household survey method sometimes may show significantly different results from that of FBS (De Rose et al., 1998).

On the other hand, in their analysis of the Global Food Security Index (GFSI), the Economist Intelligence Unit (EIU) used weighted food availability indicators to determine the ranking of countries (EIU, 2012). Accordingly, the primary indicators used to determine national food availability were sufficiency of supply, public expenditure on agricultural $R \& D$, agricultural infrastructure, volatility of agricultural production, and political stability risk. Of these indicators, sufficiency of supply was given a higher weighting of $34.7 \%$, determined by the two factors of average food supply measured by kcal/capita and dependence on chronic food aid. The 2013 update of the EIU ${ }^{\text {ee }}$ food availability analysis consequently ranked Botswana, South Africa and Ghana as the top three countries in sub-Saharan Africa, while Sudan, Chad and Togo were the last three countries, ranked at the bottom of sub-Saharan Africa countries 
(see Figure 2.1). Countries such as Senegal, Tanzania and Ethiopia showed a significant improvement in food availability compared to their rankings in 2012.

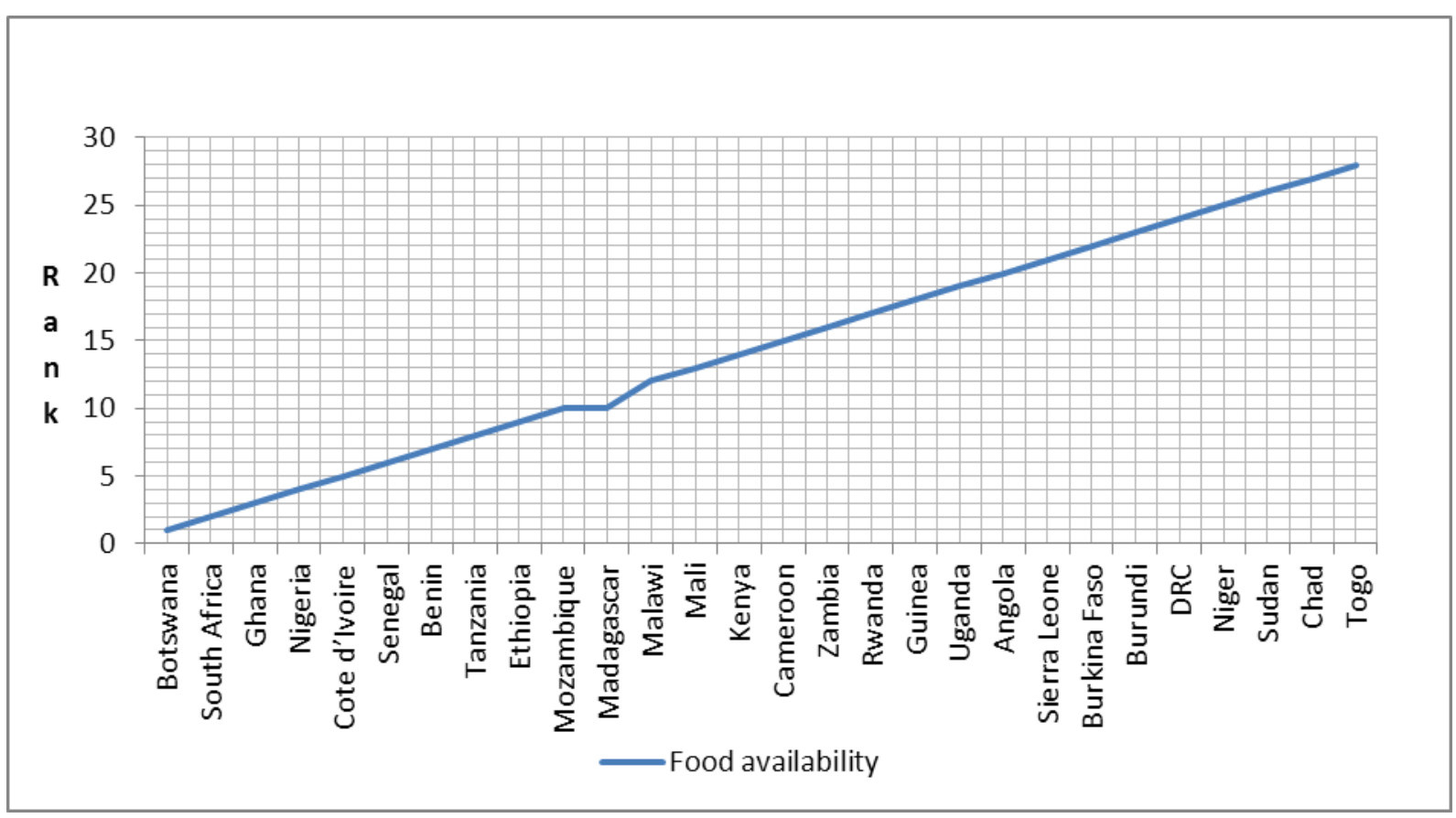

Figure 2.1: Food availability ranking of 28 SSA (EIU, 2013)

Source: Constructed based on EIU (2013)

In the next sections, agricultural importance and the challenges it face in the context of Africa is discussed. On the next section, regional and national food availability in the selected countries are analysed on the basis of the FBS approach. The sections use different indicators of food availability, starting with caloric food supply and prevalence of undernourishment, and followed in the next sections by a detailed evaluation of the three determinant factors of food availability, namely food production, trade and food aid.

\subsection{Importance of agriculture in Africa}

According to Diao (2007), more than $90 \%$ of Africa ${ }^{\text {ee }}$ population live in low-income countries with an average per capita income of a dollar per day. While the majority of the population live in rural areas, agriculture constitutes a significant share of the GDP. According to Kidane et al. (2006:98), agriculture constituted more than 40\% of the GDP of 13 SSA countries and $20 \%$ to $39.9 \%$ of the GDP of 17 SSA countries in the period of 2000 to 2003. Moreover, agriculture contributed $12 \%$ of the GDP growth in Africa between the years 2002 to 2007 (McKinsey, 2010). Therefore agriculture should actually be the centrepiece of African economic growth and development. Generally, if a sector employs two-thirds of the labour force and accounts for one-fifth of the economy, it plays a critical role in economic and social policy making (Devereux \& Maxwell, 2001). 
According to De Janvry \& Sadoulet (2010), agriculture can be the leading sector for overall economic growth and a means of food security in poor agriculture-based countries of SSA. Four reasons are given for this: one is because food remains imperfectly tradable in this region as a result of high transaction costs and the prevalence of staple foods that are only slightly traded (roots, tubers and local cereals). In this case, agriculture used to feed the poor and its productivity determines food prices and wage costs, which in turn determine the competitiveness of tradable sectors (World Bank, 2008). Second, agriculture has a larger growth multiplier effect on the other sectors of the economy. In Africa, agriculture has a multiplier effect of 1.3 to 1.5 , which means that an additional $\$ 1$ in the agricultural sector generates 30 to 50 cents in the non-agricultural sector (De Janvry \& Sadoulet, 2010).

The third reason is that agriculture is the largest sector in SSA and its growth results in pronounced aggregate growth. And finally, agriculture and its linkage with the agroindustry is a viable and competitive advantage of the African economy. This is due to the fact that Africa ${ }^{e e}$ factor endowment of natural resources and unskilled or semi-skilled labour gives rise to a comparative advantage in agriculture and agroindustry. There also is a higher cost of doing business in other complex manufacturing sectors in Africa than in the agricultural sector, due to the lower level of infrastructure. Moreover, compared to other countries, the scarcity of legal, financial and other institutions hinders manufacturing sector competence. In addition, the necessity of economies of scale make manufacturing harder to newcomers in comparison to some agro-processing activities, which have already been established in some African countries (horticultural export in Kenya and Senegal and cut flowers in Ethiopia) (De Janvry \& Sadoulet, 2010).

An empirical analysis by Diao et al. (2010) of the role of agriculture-led economic growth in the reduction of poverty compared to non-agriculture-led economic growth has also emphasised the importance of agriculture in Africa (Diao et al., 2010). The study investigated selected SSA countries, namely Ethiopia, Ghana, Kenya, Rwanda, Uganda, and Zambia. Two types of models were implemented, namely an economy-wide multimarket model (EMM) for Ethiopia, Ghana and Rwanda, and computable general equilibrium (CGE) models for Kenya, Uganda and Zambia. The models analysed two scenarios of the effect of agricultural and nonagricultural led economic growth on a reduction in poverty. The result of the calculation of poverty-growth elasticity for the two scenarios showed that growth accompanied by agriculture had larger effect on poverty reduction (Diao et al., 2010). 


\subsubsection{Pessimism towards African agriculture}

Although historical and analytical evidence strongly supports agriculture as the driver of African growth and food security, the agricultural sector remains underdeveloped. Compared to other regions of the world, it is characterised by rain-fed cultivation under increasing land degradation and low levels of input supplies such as improved seed, technology and fertiliser applications (Msangi et al., 2012). Moreover, almost half of the agricultural land in SSA is in arid and semi-arid (dry land) areas, often with poor soil quality (Ehui \& Pender, 2005, cited in Graaff et al., 2011). The contemporary challenges that Africa is facing compared to that of Asian countries in their green revolution are also complex and unique (Diao et al., 2010). One example is the weak growth-linkages resulted from a highly globalised environment and the determination of food prices by border prices rather than domestic supply can be mentioned (Diao et al., 2010).

Owing to its low performance and the challenges surrounding it, there is some scepticism towards agricultural success in Africa. Some researchers argue that, in order for Africa to reap the benefits of agriculture, large commercial farms may be a better option (Collier, 2008, cited in Wiggins, 2009). For instance Collier (2002) argued that dependence on a primary commodity can result in exposure to price shocks and slow growth, poor governance and more violent conflict (Collier, 2002). Ellis (2005:135) adds that:

The agricultural skeptic considers that there are certain problems about agriculture in liberalized markets that are substantially underestimated by the agriculture optimists, as there are trends of declining farm size in many densely settled small farm rural areas.

Dercon (2009), on the other hand, argues that agricultural importance as an engine of growth in Africa is unlikely and context specific. For resource-rich countries (like Nigeria, Angola and Congo), agriculture has no role in driving overall growth other than acting as a means of diversification and building up productive capacity. The issue in such countries is to manage wealth distribution, for which agriculture is not the one and only way; rather, investing in rural infrastructure could help more in redistribution (Dercon, 2009).

Secondly, in coastal and well-located countries (such as Ghana, Cote deTvoire, Kenya and South Africa), their comparative advantage is the world trade opportunity offered by their location. Their priorities therefore should focus on trade infrastructure, market institutions, investing in skills and supporting a well-working labour market to tap the opportunities 
offered by globalisation. Therefore, supporting industrial development for manufacturing is the best route for development (Dercon, 2009).

Thirdly, the resource-poor, landlocked countries (such as Burkina Faso, Ethiopia and Burundi) are dependent on their better located neighbours to pull them into trade-oriented opportunities. But this opportunity is unlikely, due to their low level of infrastructure and their neighbours ${ }^{\text {ee }}$ lower integration with the world economy. As a result, it is possible to assume that these countries effectively are closed economies, regardless of trade liberalisation. In such countries, agricultural growth is important for promoting overall growth and poverty reduction (Dercon, 2009).

\subsubsection{Challenges facing African agriculture and food security}

Among the main constraints to African agricultural growth is the difficulty of promoting and adopting improved farming technologies (Badiane \& Delgado, 1995). Increasing access to international markets and maintaining the competitiveness of African products in domestic as well as foreign markets is another challenge (Badiane \& Delgado, 1995). The international market distortion and adoption of tariff and non-tariff barriers coupled with lower quality of production in Africa, gave rise to the low competitiveness of African agriculture in the global market (Aksoy \& Beghin, 2005).

The impact of market failure on equitable agricultural growth and poverty reduction has been discussed by Dercon (2009). He analysed three types of market failures: "credit market failure and poverty traps", "insurance market failures and risk-induced poverty traps", and "spatial externalities". Unequal asset access leads to credit market failures. This is due to the fact that the threshold level of asset required to access credit can be a barrier to those with limited asset holdings from entering into profitable activities, which in turn drives them into poverty traps.

Evidence shows that risk and shocks are also causes of lower growth in the incomes of the poor and might also lead them into poverty traps (Boussard et al., 2005; Dercon, 2009). This is because there is a high rate of prevalence of natural disasters, droughts, health problems, agricultural pests, economic shocks, conflict and insecurity in developing countries. In this regard, market failure due to asymmetric information and enforcement issues leads to disproportionate access to insurance and protection by the poor (Dercon, 2009). The case of spatial externality is associated with the geographical disparity in growth and poverty reduction due to market failure to address regionally balanced growth patterns.

An empirical study by Graaff et al. (2011) investigated the constraints and challenges facing agricultural production and food security in selected SSA countries, using data from 40 years. 
Eight countries were chosen for the study based on their geographical and agricultural diversity: Ethiopia, Burkina Faso, Senegal, Kenya, Rwanda, Malawi, Cameroon and South Africa. Using FAOSTAT as the main data source, the study analysed the main constraints of agricultural growth, namely land, labour, water and institutions, on yield growth in crop as well as livestock production (Graaff et al., 2011).

The results of the study showed that labour shortage during peak seasonal farm activities may result in a reduction in yield; also, land degradation and soil nutrient depletion, drought and water scarcity were highlighted as constraints to crop production. A lack of institutional support, such as outlets for farm output, adequate farm input supply, production credit, extension services, agricultural research support and all-weather roads, are important institutional constraints. The authors concluded that much attention should be paid to the constraints and opportunities of individual countries, along with recognition of the greater diversity in SSA (Graaff et al., 2011).

\subsubsection{Rapid population growth}

Africa is the region with the highest rate population growth rate of all the regions in the world (United Nations, 2006; cited in Binswanger-Mkhize, 2009). Rapid population growth is a threat to agriculture and global food security, as it increases the global demand for agricultural products. However, there is an argument that technological advancement and production expansion of cultivated areas can sustain the increasing demand (Rosegrant \& Cline, 2003). The world population rose by about 74\% within 35 years between 1975 and 2005, from 3.7 billion to 6.5 billion, and the African population showed a 2.5 times higher level of population growth during the same period (Bakker, 2011). The result of such population pressure in countries with a lower level of growth and industrialisation is directly related to a demand for more agricultural land, which in turn leads to increased deforestation and associated land degradation (Bakker, 2011).

Global agricultural land is expected to increases by up to 14\% between 2010 and 2030 and, as a result of this, the per capita food level is also expected to rise (Schneider et al., 2011). However, in sub-Saharan Africa, around 500 million people will be added in the coming 20 years (Bremner, 2012). While the proportion of undernourished children in SSA is declining, the absolute number of undernourished children showed a 50\% increase from 1990 onwards due to high fertility and limited reproductive health in the region (Bremner, 2012).

However, in spite of this, the recent economic and agricultural growth in Africa is good news for demographic transition, where on the other hand the slower rate of demographic transition 
has already resulted in much higher dependency rates, with about $40 \%$ of the population in the SSA region under the age of 15 (Binswanger-Mkhize, 2009; Bremner, 2012). In the light of this, increasing the investment in family planning, empowering women and girls to improve health and eliminate hunger, and supporting research and programmes that link agriculture, nutrition and reproductive health, are some policy recommendations (Bremner, 2012).

\subsubsection{Climate change}

Agriculture and food production are directly affected by climate change through changing agro-ecological conditions, and indirectly by a hampered demand for agricultural products affecting income growth and distribution (Schmidhuber \& Tubiello, 2007). Due to the fact that Africa is already burdened with poverty, food insecurity and low adaptive and mitigation capacity, the impact of climate change poses a risk in African societies (Müller et al., 2011). According to the Intergovernmental Panel on Climate Change (IPCC), the yield from rain-fed agriculture in some African countries could be reduced by up to $50 \%$ by 2020 (Müller et al., 2011). While the degree of certainty of this statistic remains controversial, it is enough to say that at least some parts of Africa are under risk of climate change.

Kala, Kurukulasuriya \& Mendelsohn (2012) investigated the impact of climate change on the basis of the Agro Ecological Zone (AEZ) classification of Africa. Based on their analysis, climate change shifts the AEZs towards desert and semi-arid classifications in the future. Accordingly, Africa will incur an estimated $\$ 14$ billion to $\$ 70$ billion of annual welfare losses by 2070 to 2100 , coupled with climate change incidents (Kala et al., 2012).

The impact of climate change on food security has been discussed by Schmidhuber and Tubiello (2007), who say that it directly and indirectly affects food production and trade, which influence food availability and its stability. Climate change also affects food utilisation through increased pressure on food safety due to the associated expansion of vector-, waterand food-borne diseases. Climate change also hampers food accessibility by stimulating food price volatility and diminishing the agricultural GDP gain of poor countries, coupled with lower agricultural productivity (Schmidhuber \& Tubiello, 2007).

\subsubsection{Other factors}

Among other main factors that are challenging African agriculture and food security significantly are the high rate of prevalence of HIV/AIDS is the one. This affects all the dimensions of food security, availability, access, stability and utilisation (De Waal \& Tumushabe, 2003). According to the World Bank, 5\% of the SSA population between the 
ages of 15 and 49 lives with HIV/AIDS (World Bank, 2013a). Although some progress has been made, the percentage of prevalence of HIV/AIDS in the Southern African region remains at an unacceptably high level. As shown in Figure 2.2, the percentage prevalence of HIV/AIDS in the SSA region is declining overall, and some countries have shown a progressive reduction in the past couple of years, while others have not shown significant change.

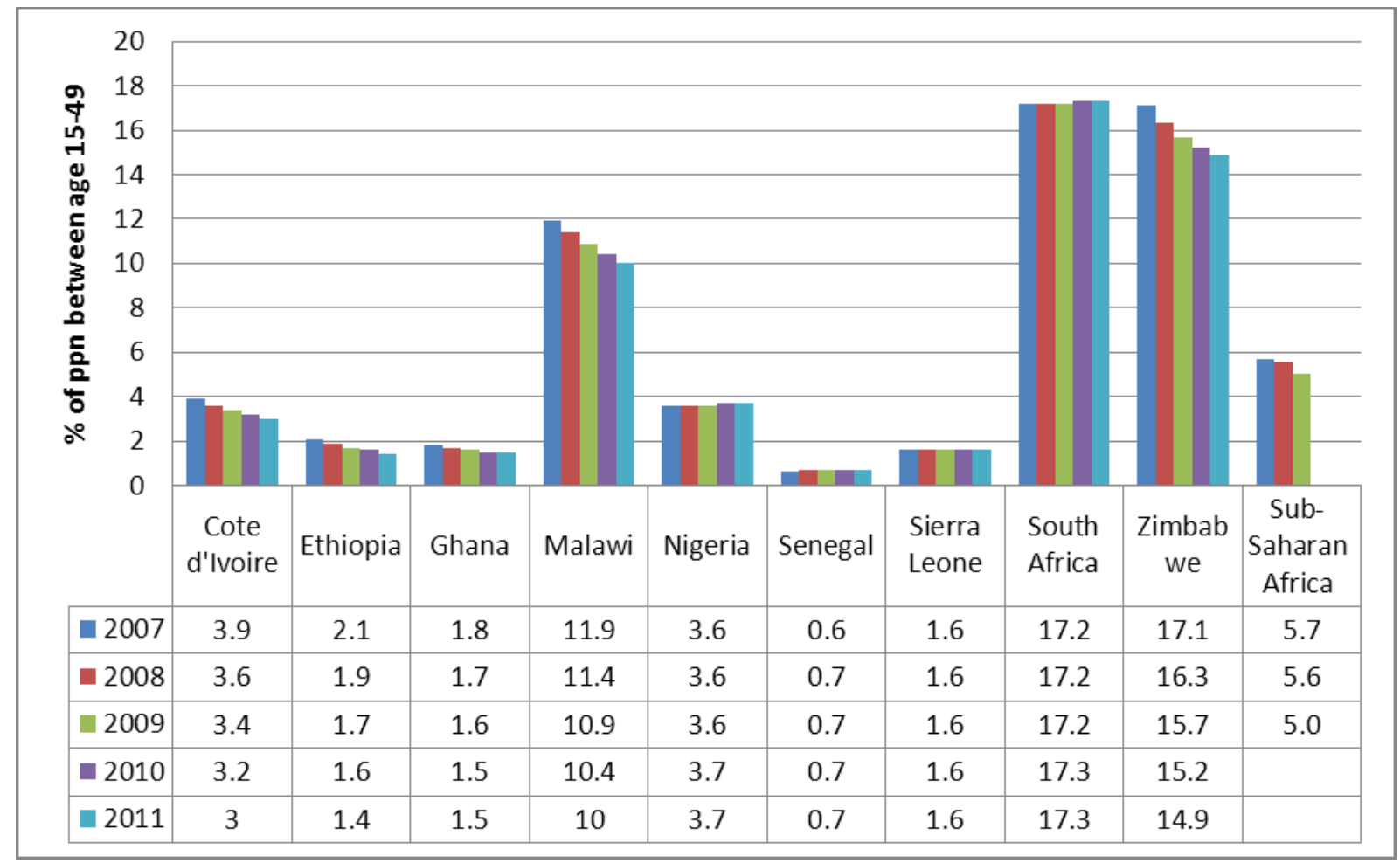

Figure 2.2: Prevalence of HIV/AIDS in selected SSA countries

Source: Based on the World Bank (2013a) data

Political instability and civil strife are further factors affecting African food security. There is a causal relationship between food insecurity and political instability, in which one can be a cause as well as an effect of the other (Maxwel, 2012). But either of them can appear without the existence of the other, and there also are some common drivers of both food security and political instability, such as climate change (Maxwel, 2012). The 2007/08 Arab Spring, which expanded to more than 30 countries, is one example of the interrelationship between food price spikes and political instability (Asongu, 2012).

\subsection{Caloric food supply analysis}

Figure 2.3 shows the sub-regional trend of caloric food supply in Africa in comparison to the South Eastern Asian region. Except for the Southern African region, the remaining subregions were all in similar lower level of average daily caloric food supply of around 2000 
$\mathrm{kcal} /$ capita/day in the early 1960s. Interestingly, the Southeast Asian region had an even lower level of caloric food supply in 1961, which showed continuous progress to the current level, which exceeded Africa ${ }^{e e}$ s average in 2009. According to the FAO's 2009 data, twentyone countries in SSA are still below the FAO's standard of daily caloric energy supply of $2300 \mathrm{kcal} / \mathrm{capita} / \mathrm{day}^{4}$ (see Addendum B). The Northern Africa sub-region is the highest, with an average caloric food supply of $3000 \mathrm{kcal} / \mathrm{day}$. It showed an enormous increase in the 1970s, after which it kept on increasing, but at a relatively slower rate.

The Western Africa region, on the other hand, started with the same lower level in 1961, and registered a declining rate of caloric food supply until around the mid-1980s. Since then, it has shown impressive growth, recognised as the highest growth rate recorded between the mid-1980s and the mid-1990s. The Eastern and Middle Africa regions showed an almost similar trend of decreasing rate from the 1970s to the mid-1990s. Since then, the two regions are realising an increasing trend of caloric food supply. The Southern Africa region showed an almost stable growth rate, although with some fluctuation especially in the 1990s.

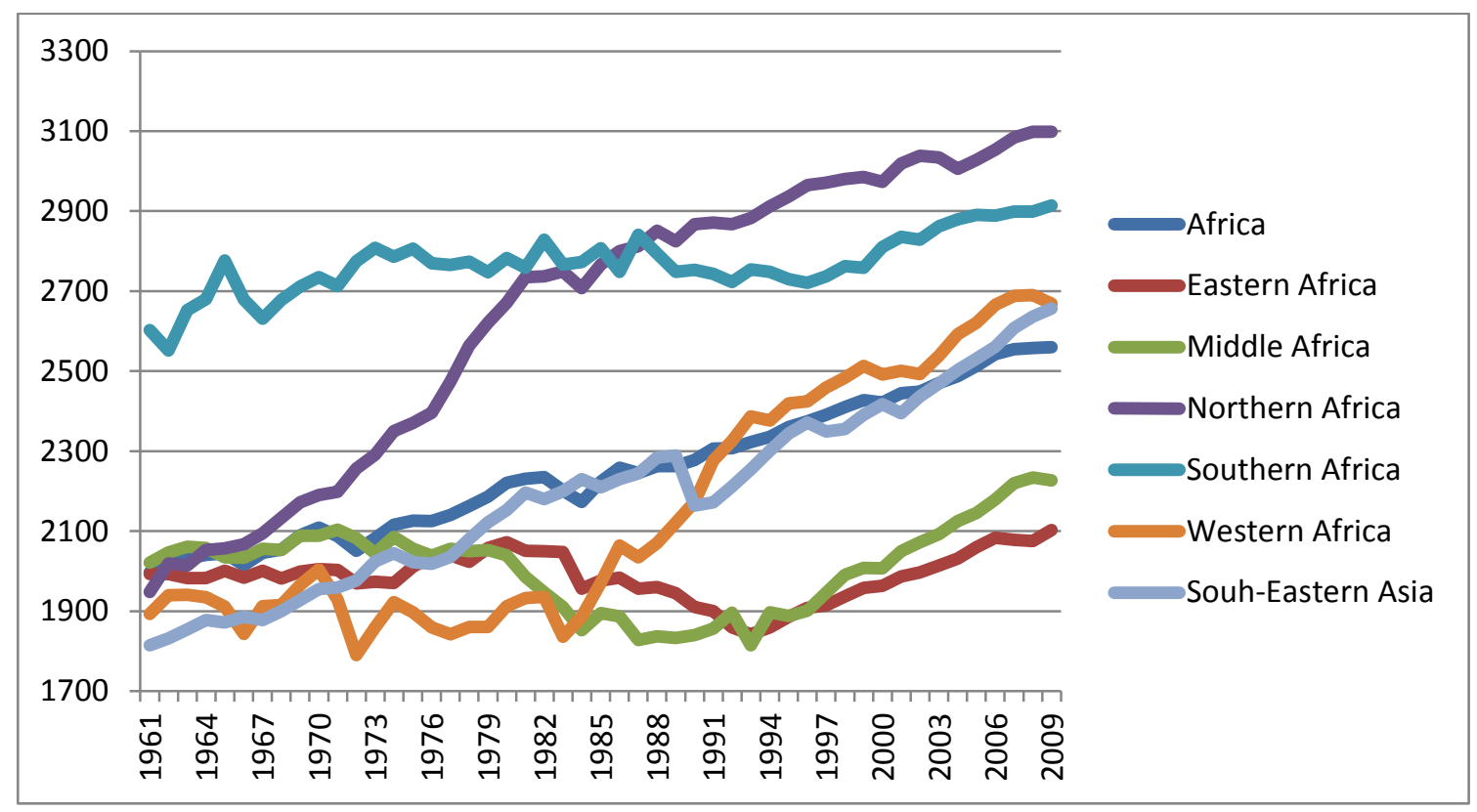

Figure 2.3: Dietary energy supply trend in Kcal/capita/day

Source: Based on FAOSTAT (2013) data

The dietary energy supply performance over the selected case study countries for the period 1961 to 2012 is depicted in Figure 2.4 below. It shows that, until the year 1990, a fluctuating performance was prevailing, which afterwards led to an improvement. Of the case study countries, impressive performance was registered in Ghana and Egypt, with both having the

\footnotetext{
${ }^{4}$ Until recently, the benchmark was $2100 \mathrm{kcal} / \mathrm{day}$, but it was updated by the FAO to $2300 \mathrm{kcal} / \mathrm{day}$ as of June 2012 (EIU, 2012)
} 
highest annual growth rates of $1.2 \%$ and 1.1\% respectively between 1961 and 2012. Nigeria and Sudan each recorded a $0.8 \%$ annual growth rate, while Ethiopia registered a $0.4 \%$ rate. Mozambique and South Africa recorded a 0.3\% annual growth rate during the same period. On the other hand, Madagascar and Zambia recorded a deteriorating performance of dietary energy supply, with an annual rate of reduction of $-0.4 \%$ each during the same period of 1961 to 2012 .

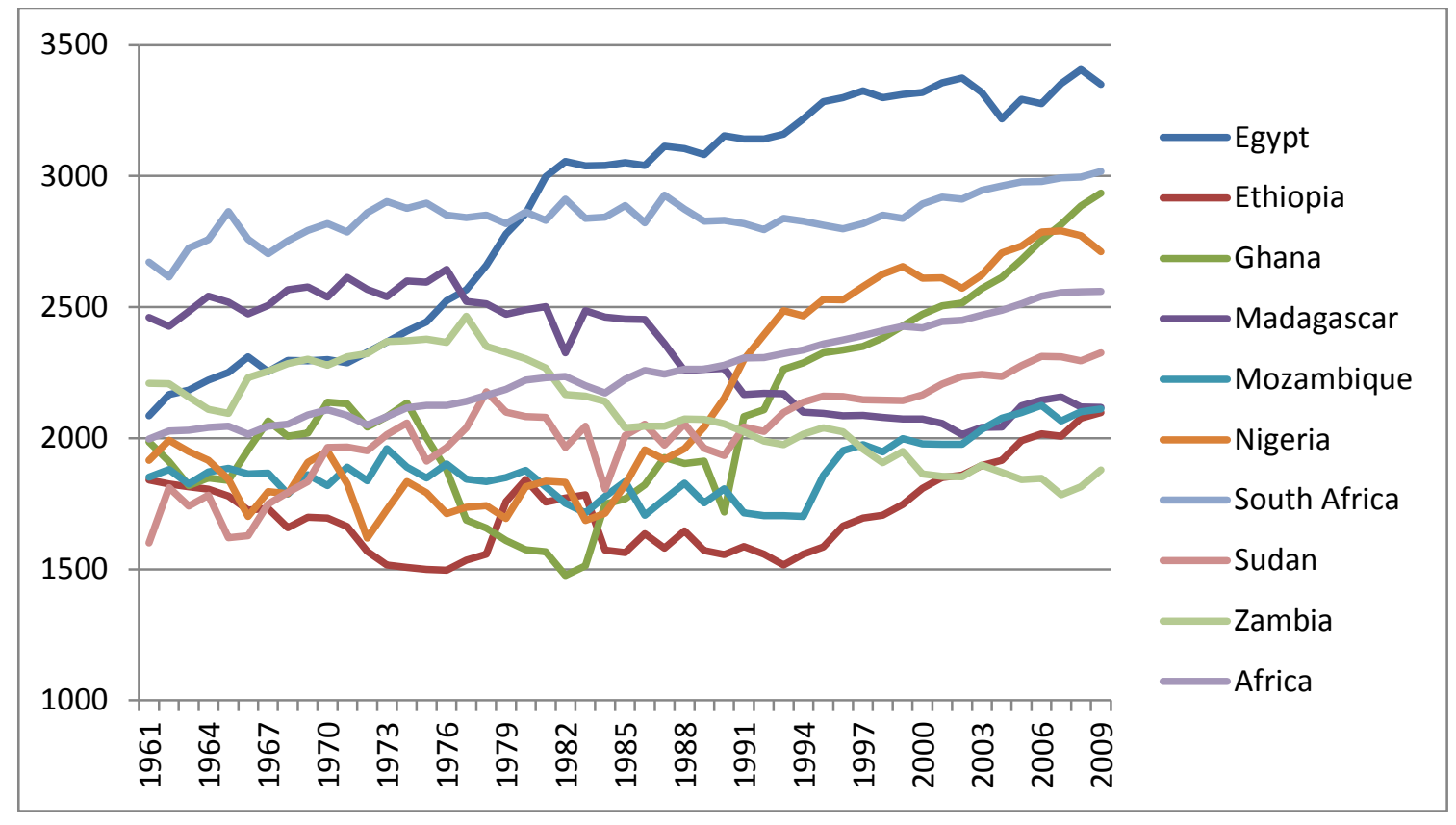

Figure 2.4: Trend of caloric food supply in Kcal/capita/day in selected countries

Source: Constructed based on FAOSTAT (2013) data

The annual growth rate in caloric food supply for the case study countries over each decade between 1961 and 2012 is shown in Figure 2.5. The performance of Ghana can be highlighted as impressive. As shown in the figure, Ghana experienced a steep decline in the 1970s, at an annual reduction rate of $-3 \%$, that led to it having the lowest level (of $1476 \mathrm{kcal} / \mathrm{capita} / \mathrm{day}$ ) of caloric food supply in 1982. Rising from this very low level, a dramatic increase was recorded in each consecutive decade, bringing it up to the current highest caloric food supply of $3150 \mathrm{kcal} / \mathrm{capita} /$ day in 2012. Egypt also recorded the highest increase in the 1970s, with an annual growth rate of $2.2 \%$, which surpassed $3000 \mathrm{kcal} / \mathrm{capita} /$ day by the early $1980 \mathrm{~s}$. Except for Madagascar and Zambia, most of the selected countries showed an increasing rate of caloric food supply over the past two decades. 


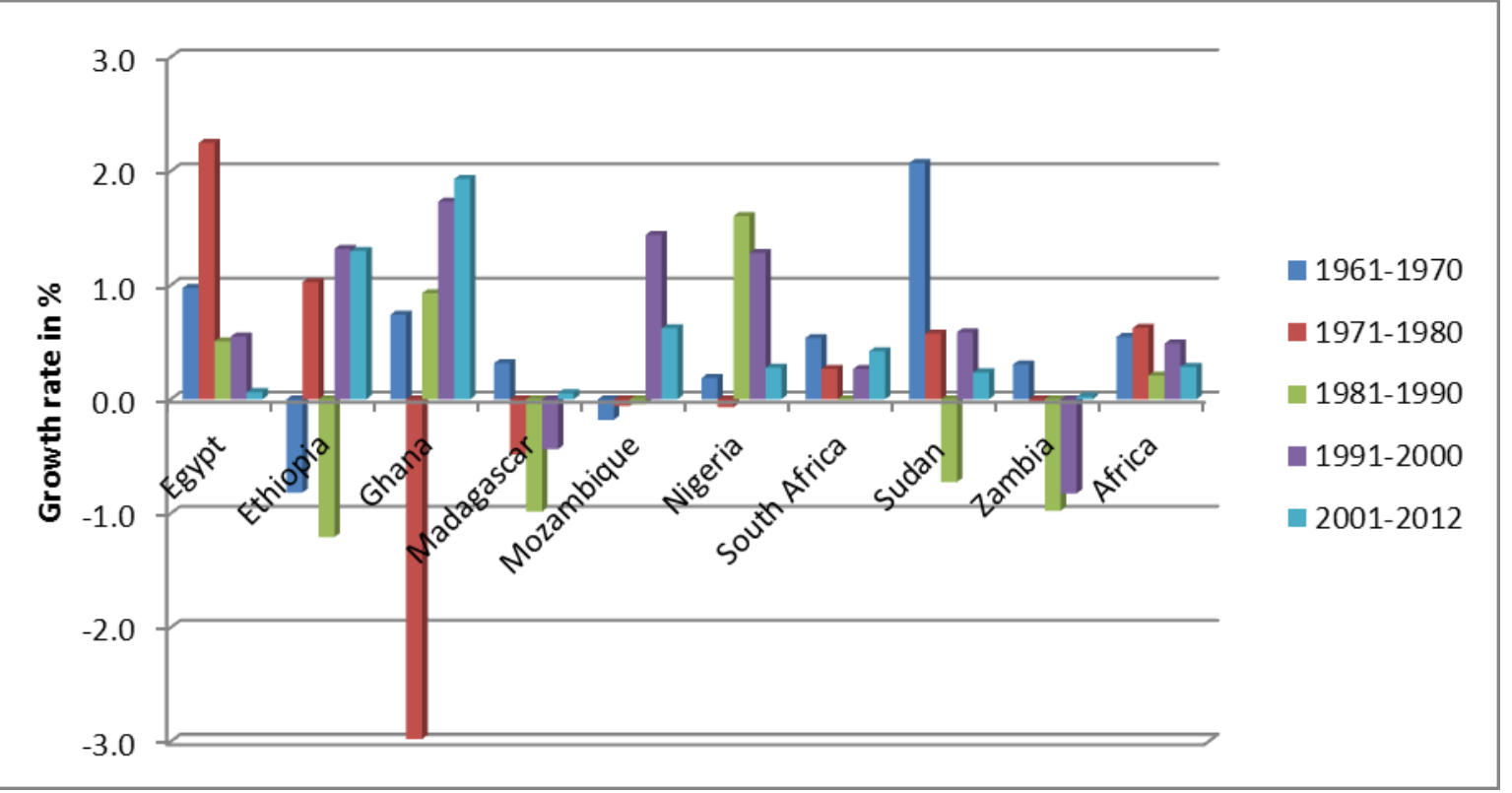

Figure 2.5: Annual growth rate in caloric food supply for the last five decades

Source: Constructed based on FAOSTAT (2013) data

In terms of the FAO's food security indicators, Africa remains behind the rest of the world, as shown in Table 2.1. Besides being home to the largest proportion of undernourished population, Africa recorded a poor status in terms of political stability, road infrastructure, and food supply adequacy and stability. However, performance in African countries is diverse, for instance, the West African countries of Ghana and Nigeria recorded an impressive reduction in undernourishment to a level below 5\% in 2012, from their higher levels of $40.5 \%$ and $19.3 \%$ respectively in 1990/92. Also, Ethiopia and Mozambique recorded a significant reduction in their levels of undernourishment during this period, although the levels are still very high. In contrast, Zambia performed poorly, with its level of undernourishment increasing to $47.5 \%$ in 2012 from $34.3 \%$ in the early 1990 s. 
Table 2.1: Food availability indicators in selected countries

\begin{tabular}{|c|c|c|c|c|c|c|}
\hline & $\begin{array}{l}\text { Prevalence of } \\
\text { under- } \\
\text { nourishment } \\
\text { in } 2012(\%)\end{array}$ & $\begin{array}{l}\text { Dietary energy } \\
\text { supply (Kcal/ } \\
\text { capita/day) } \\
2012\end{array}$ & \begin{tabular}{|l|} 
Ave. protein \\
supply (2007- \\
2009) \\
(gr/capita/day)
\end{tabular} & $\begin{array}{l}\text { Prevalence of } \\
\text { food } \\
\text { inadequacy in } \\
2012(\%)\end{array}$ & $\begin{array}{l}\text { Food supply } \\
\text { variability in } \\
2010 \text { (Kcal/ } \\
\text { capita/day) }\end{array}$ & $\begin{array}{l}\text { Road density } \\
\text { (per } 100 \mathrm{sq} \mathrm{km} \text { ) } \\
\text { of land in } 2000\end{array}$ \\
\hline World & 12.5 & 2840 & 78 & 19.1 & 9.2 & $\ldots$ \\
\hline Africa & 22.9 & 2530 & 64 & 28.9 & 15.7 & 7.6 \\
\hline SSA & 26.8 & 2380 & 58 & 33.3 & 20.4 & 7.9 \\
\hline Egypt & $<5$ & 3380 & 98 & $<5$ & 43 & $10.03 * * *$ \\
\hline Ethiopia & 40.2 & 2160 & 59 & 46.9 & 19.0 & $4.02+$ \\
\hline Ghana & $<5$ & 3150 & 59 & 6.7 & 40.5 & $45.91 * * *$ \\
\hline Madagascar & 33.4 & 2070 & 49 & 42.1 & 32.5 & 8.5 \\
\hline Mozambique & 39.2 & 2130 & 39 & 46.1 & 25.4 & 3.8 \\
\hline Nigeria & 8.5 & 2700 & 65 & 13.1 & 61.6 & $20.91 * *$ \\
\hline South Africa & $<5$ & 3070 & 83 & 6.2 & 7.7 & 29.7 \\
\hline $\begin{array}{l}\text { Sudan } \\
\text { (former) }\end{array}$ & 39.4 & 2270 & 73 & $\ldots$ & 25.7 & 0.5 \\
\hline Zambia & 47.4 & 1860 & 46 & 56.3 & 31.4 & 8.9 \\
\hline $\begin{array}{l}\text { Southeast } \\
\text { Asia }\end{array}$ & 10.9 & 2760 & 64 & 18.1 & 15.1 & $20.17^{*}$ \\
\hline
\end{tabular}

Source: Adapted from FAO food security indicators (FAO, 2013)

N.B.: Available data used for $* 1999, * * 2004, * * * 2009,+2007 ;(. .$.$) no data$

\subsection{Food production analysis}

In this section, the food availability performance of the case study countries from 1984/86 to $2010 / 12$ is analysed. According to the FAO, about $62 \%$ of the dietary energy supply in Africa is derived from cereals, roots and tubers (FAO, 2013). This can also be seen in Figure 2.6, which shows that, except in Sudan (48\%) and South Africa (54\%), cereals and, roots and tubers contribute more than $60 \%$ of the dietary energy supply in the selected countries. Therefore, the production, yield and area expansion performance of these commodities over the case study countries is investigated. 


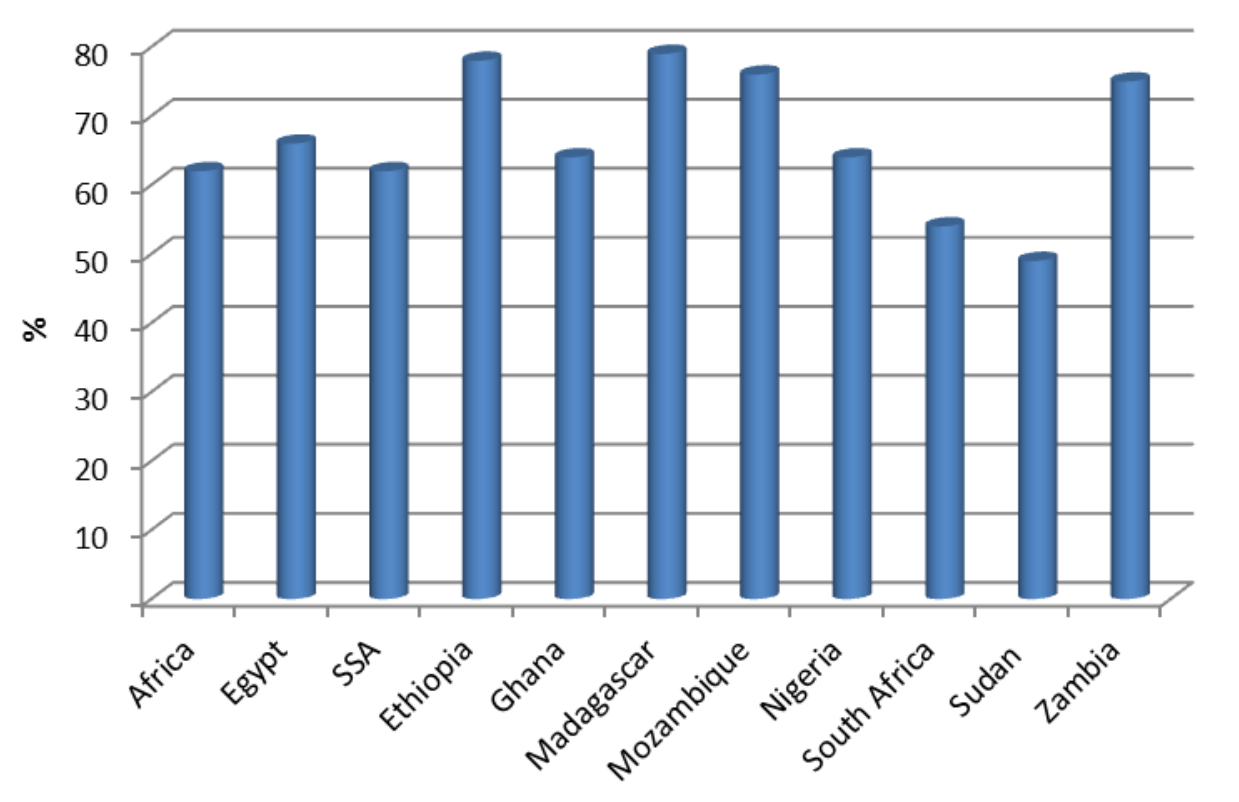

Figure 2.6: The share of cereals, roots and tubers in dietary energy supply of the selected countries Source: Based on the FAO's (2013) food security indicators

The statistical technique of compound annual growth rate (CAGR), which has been used in different studies such as that of IPAR (2009), is applied to calculate the annual growth rate of the parameters, which is given by the formula:

$$
\mathrm{Y}_{\mathrm{tn}}=\mathrm{Y}_{\mathrm{o}}(1+\mathrm{r})^{\mathrm{t}} \rightarrow \mathrm{r}=\left[\left(\mathrm{Y}_{\mathrm{t}} / \mathrm{Y}_{\mathrm{o}}\right)^{(1 /(\mathrm{tn}-\mathrm{to})}\right]-1
$$

where $\mathrm{Y}_{\mathrm{tn}}=$ value of (production/yield/area) in the final year

$$
\begin{aligned}
& Y_{\mathrm{o}}=\text { value of (production/yield/area) in the base year } \\
& \mathrm{r}=\text { compound annual growth rate }(\mathrm{CAGR}) \\
& \mathrm{t}_{\mathrm{n}}=\text { final year } \\
& \mathrm{t}_{\mathrm{o}}=\text { initial year }
\end{aligned}
$$

Figure 2.7 shows the performance of per capita cereal production during the period of $1984 / 86$ to $2010 / 12$. During this period, Africa recorded a $0.4 \%$ annual per capita cereal production growth rate ${ }^{5}$. Except the Southern Africa region; the rest of sub-regions of Africa also recorded an increasing rate. Among the case study countries, the highest declining rate observed in Sudan (-1.6\%) followed by DRC (-1.4\%) Madagascar (-0.2\%) and South Africa

\footnotetext{
${ }^{5}$ Per capita production growth rate refers to the CAGR of specific commodity compared to the population growth rate.
} 
$(-0.4 \%)$ have also showed a declining rate with a marginal reduction rate recorded in Nigeria (-0.1). Ethiopia (2.5\%), Mozambique (2.2\%), Egypt (1.7\%) and Ghana (1.7\%) performed the best in this regard, recording the highest rate even more than S-E Asia region (1.4\%).

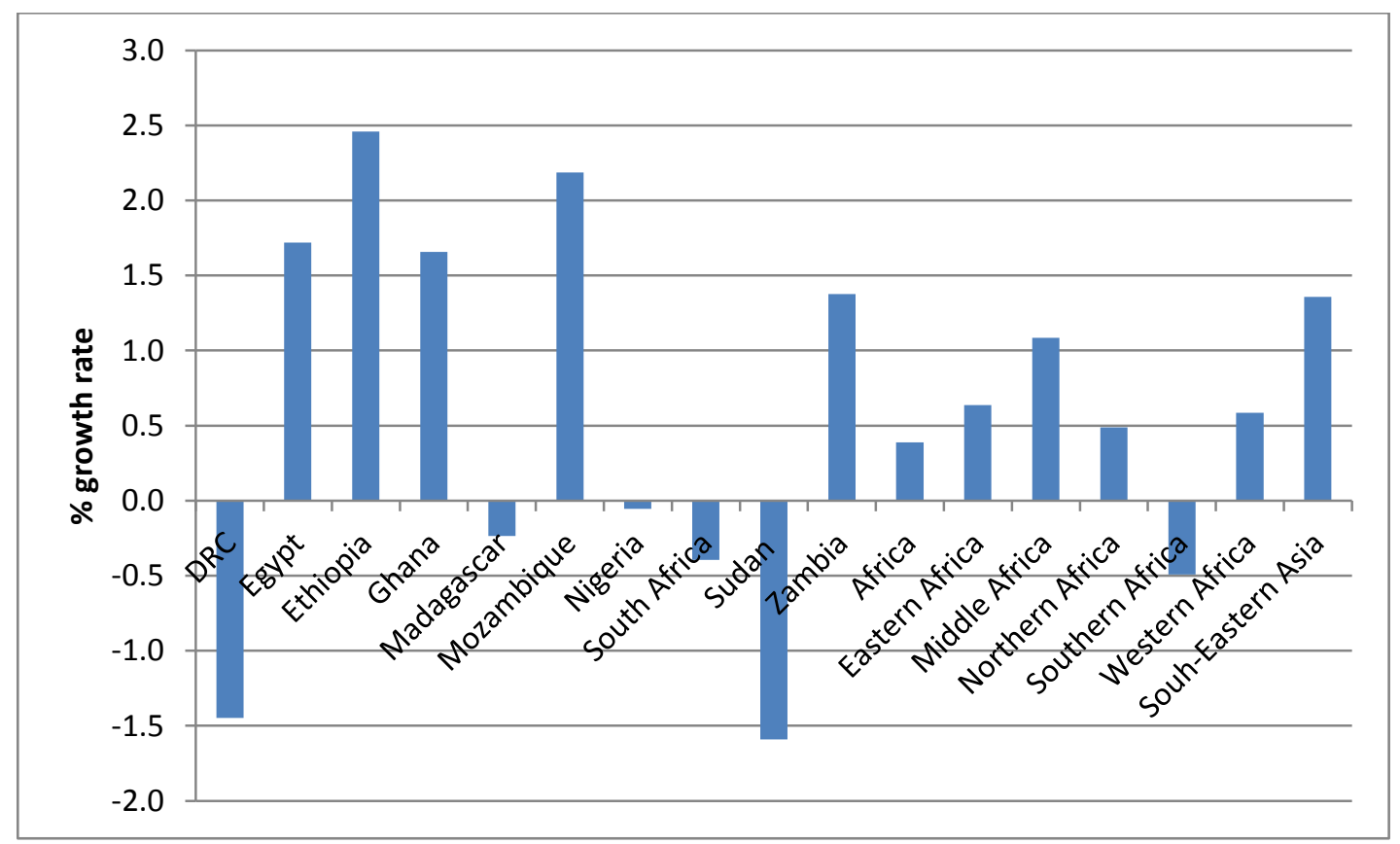

Figure 2.7: Performance of per capita cereal production (in tons) $(1984 / 86$ to 2010/12)

Source: Based on FAOSTAT (2013) data

Except Southern Africa region and South Africa in all of the sub-regions and case study countries the rate of expansion of area harvest is positive. Also except for DRC, the rest of the case study countries recorded a positive rate of yield growth. Although South Africa recorded the highest decline in area harvest of cereals, it also registered the highest rate of increase in cereal yield growth during the study period of $1984 / 86$ to $2010 / 12$. However, the overall production growth in this country remains below the population growth rate which resulted in negative per capita cereal production rate.

Maize is the most important food crop in SSA; for instance, in 2009 it accounted for around $32 \%, 23 \%$ and $20 \%$ of total dietary intake in the Eastern Africa countries of Kenya, Tanzania and Ethiopia respectively (Dillon \& Barrett, 2013). In this study it showed an increasing per capita growth rate in all the case study countries except for the DRC and Sudan for the period of $1984 / 86$ to $2010 / 12$. The highest yield increase in per capita maize production was recorded in Sudan (4.1\%) and South Africa (4\%). However, both these countries also recorded a declining rate of area harvest at a rate of $-2 \%$ each during 1984/86 to 2010/12. Mozambique (3.3\%), Ethiopia (3\%) and Nigeria (3\%) are the best performers of increased per 
capita maize production even more than S-E Asia which recorded 2.3\% during the same period.

South Africa, Egypt and Ethiopia are identified as the primary wheat producers on the continent (figure 2.8). The per capita growth in production for the study period of 1961 to 2011 showed an increase of $1.5 \%$ and $0.5 \%$ in Egypt and Ethiopia respectively, while a $-0.4 \%$ annual rate of reduction was recorded in South Africa, coupled with a reduction in area harvested of this crop. The highest yield growth rate of wheat production was recorded in South Africa (3.4\%), followed by Egypt (2\%) and Ethiopia (1.9\%). In terms of expansion in area harvested, Egypt recorded a growth rate of $1.6 \%$ and Ethiopia 1.1\%, while South Africa recorded a declining rate of $-1.7 \%$ per annum.

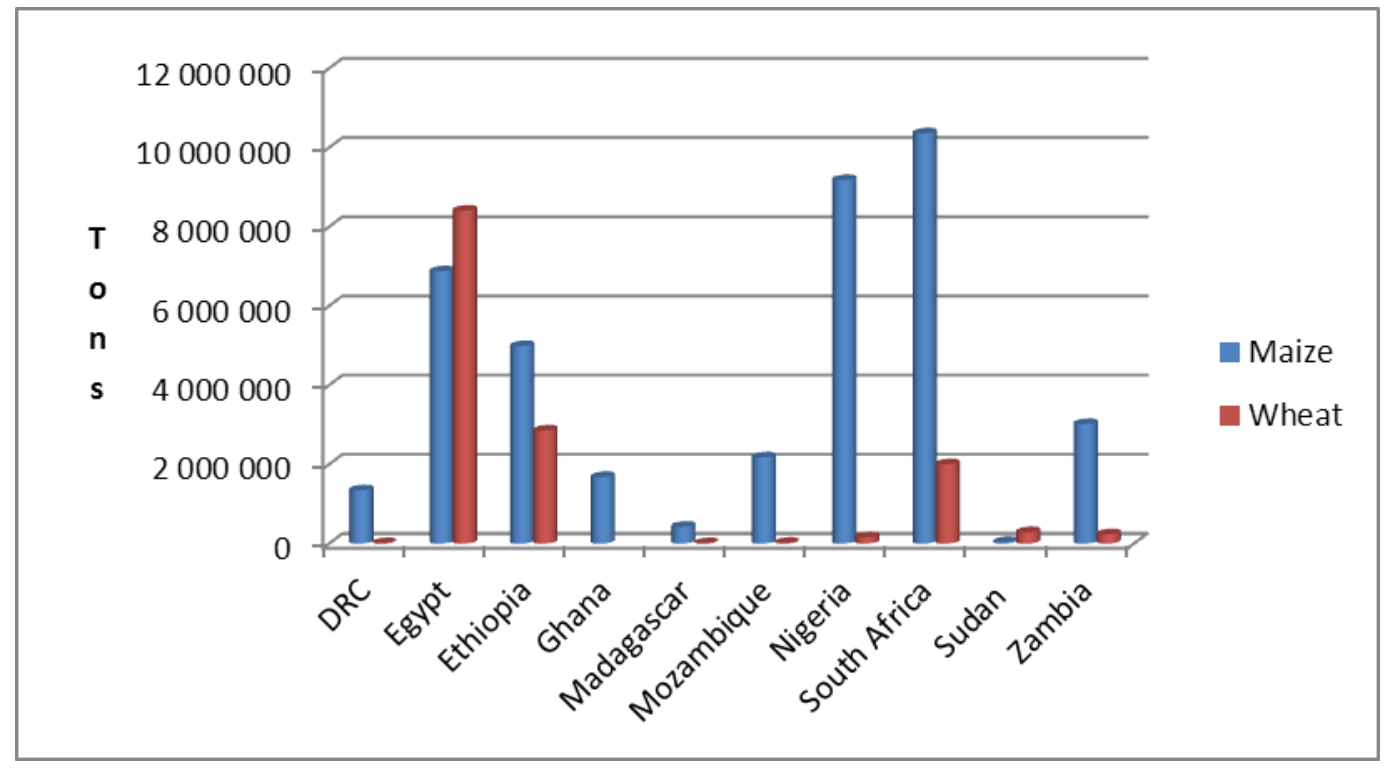

Figure 2.8: Maize and wheat production (tons) in selected countries in the year 2011

Source: based on FAOSTAT (2013) data

Per capita roots and tubers production in Africa showed higher growth rate than the S-E Asia region (Figure 2.9). Only the Middle Africa sub region recorded a declining rate of $-0.5 \%$ of all the sub-regions. Out of the case study countries, the Western Africa countries of Nigeria and Ghana recorded the highest rate of $4.2 \%$ and $3.7 \%$ respectively. DRC recorded the highest decline rate of $-2.9 \%$ followed by Madagascar with a $-1.3 \%$ decline during the study period of $1984 / 86$ to $2010 / 12$. In all of the sub-regions of Africa and the case study countries an increasing rate of yield and area harvest of roots and tubers recorded except for DRC that experienced a marginal rate of decline in yield. 


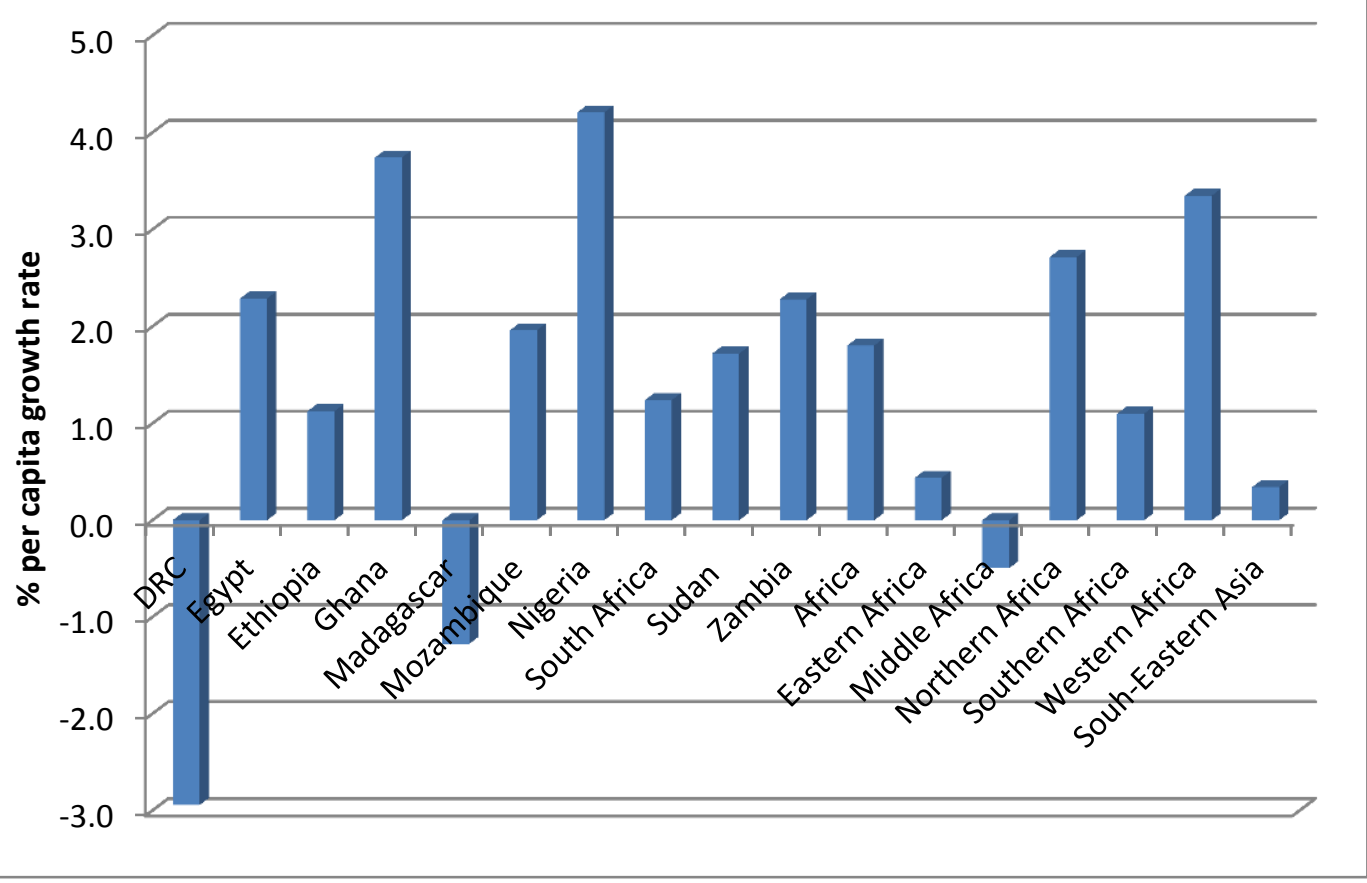

Figure 2.9: Per capita roots and tubers production (tones) (1984/86 to 2010/12)

Source: Based on FAOSTAT (2013) data

\subsection{Volatility in agricultural production}

Agricultural production volatility is among the main indicators used in EIU ${ }^{e e}$ s food availability measurement, in which the standard deviation of the annual growth in agricultural production between the 1990 and 2010 was used. On the other hand, per capita food production variability was measured as a factor of stability or sustainability of food supply in the FAO"es food security indicators (2012b). Accordingly, in 2010, Africae s per capita food production variability measured with respect to a constant 2004-2006 int ${ }^{\text {ee }} \$$ per capita value stands at a level of standard deviation of 3.1. The Northern Africa region recorded a standard deviation of 6.3, which is higher than the SSA average value. Deviation 


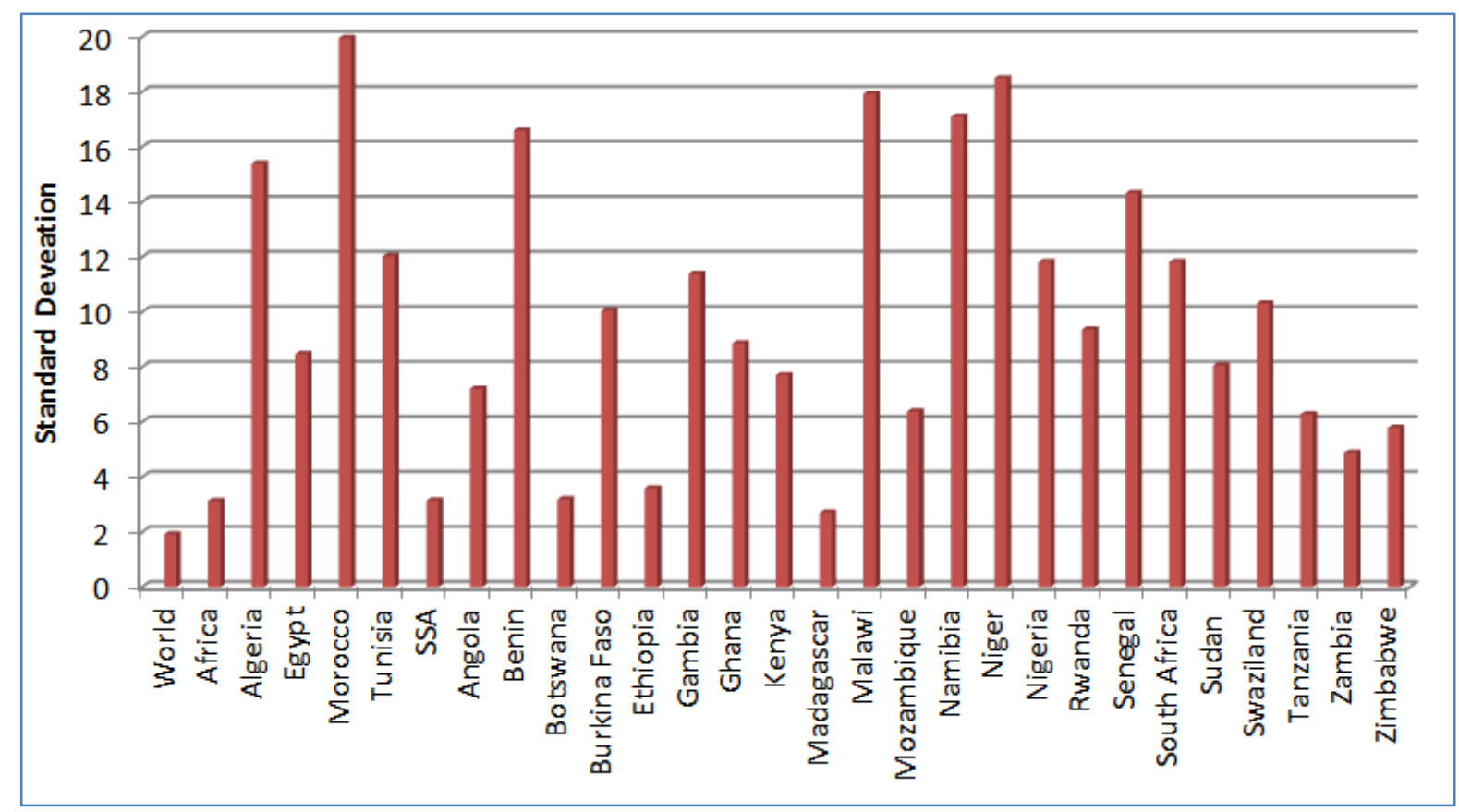

Figure 2.10: Volatility in agricultural production in selected countries in Africa

Source: Based on FAO's data on food security indicators (2012b)

As shown in Figure 2.10, most of the countries in Northern Africa recorded higher production variability, such as Morocco with 20, Algeria 15.4 and Tunisia 12. The highest food production volatility in 2010 in the SSA region was recorded in Niger at 18.5, Malawi at 18 and Namibia at 17.1. According to FAO (2012b) the lowest recorded was in Western Sahara (0.4), Equatorial Guinea (1) and Congo (1.5). Among the case study countries, Nigeria and South Africa each recorded the highest value of 11.8. They were followed by Ghana (8.9), Egypt (8.5) and Mozambique (6.4). The lowest values were recorded in the DRC (1.9), Ethiopia (3.6) and Zambia (4.9). 


\subsection{Agricultural trade analysis}

In terms of agricultural trade, Africa became net agricultural commodities importer especially from the 1980s onwards (see Figure 2.11). Total agricultural commodities import increased at a rate of $7.7 \%$ between 1961 and 2010. In the same period, total agricultural export rose at a rate of $4.7 \%$. Compared to agricultural export growth rate the highest rate of increase in import observed in Middle and Northern Africa regions at a rate of $4.1 \%$ each during the same period.

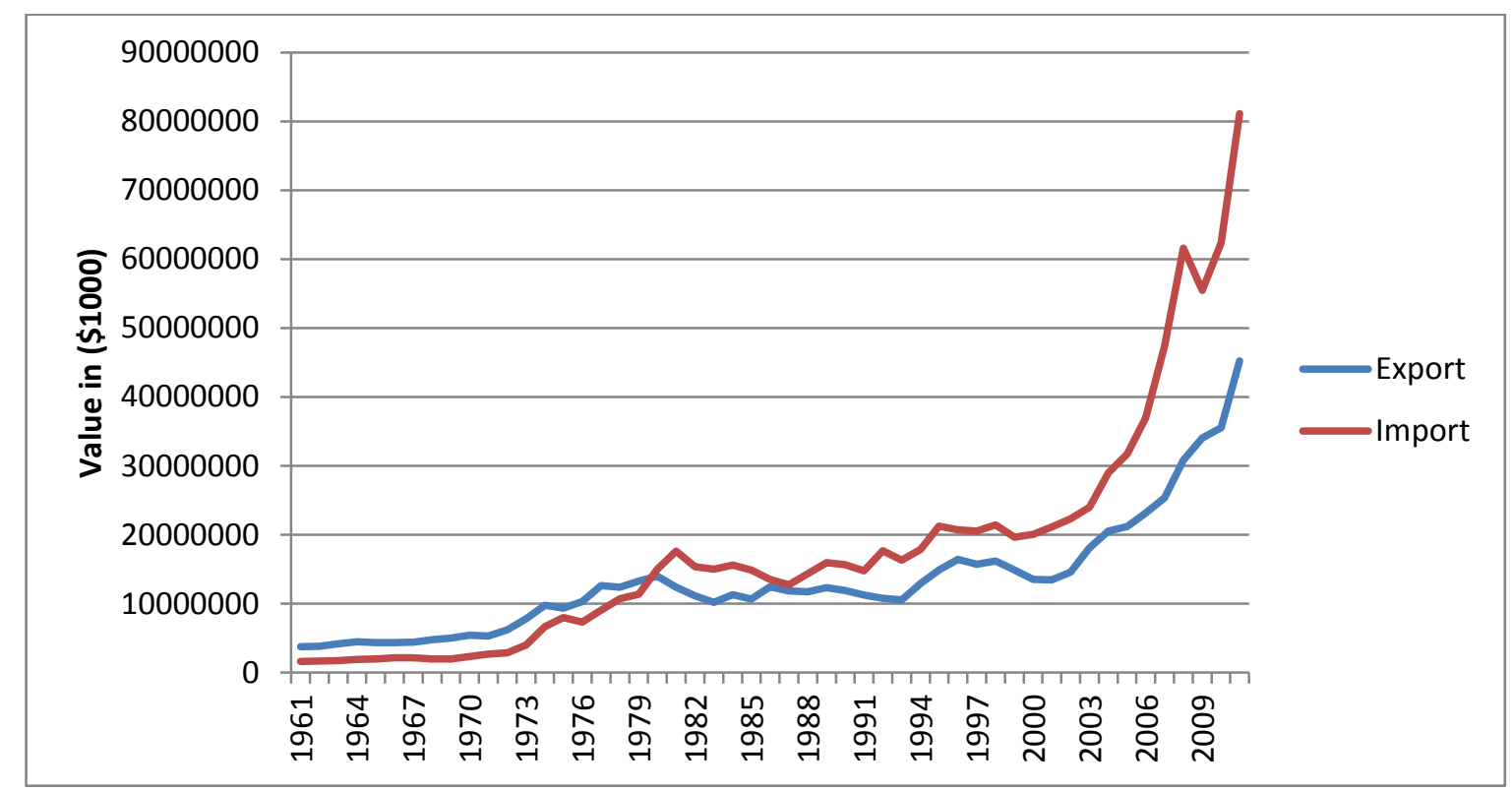

Figure 2.11: Africa's total agricultural import and export trends (current value)

Source: Based on FAOSTAT (2013) data

Around ninety percent of these primary import commodities in Africa are originated from outside of Africa, especially from North America and Europe. Africaes share of international trade is also insignificant compared to its potential. For instance, between 2005 and 2007, African agricultural exports and imports represented less than $5 \%$ of the global market. In some countries the agricultural trade deficit is much higher, to the extent that total merchandise export cannot afford to say agricultural import bills (Rakotoarisoa et al., 2011). Intra-Africa trade is also much lower, with only about one-fifth of African food exports that stayed in Africa, while about $88 \%$ of agriculture import originated from outside of Africa between 2004 and 2007 (Rakotoarisoa et al., 2011). Among the case study countries, the highest increase in net agricultural import observed in Egypt followed by Nigeria (see Figure 2.12). While most of the countries started experiencing agricultural trade deficit since the 1970s, by the year 2011 four of the ten case study countries are in agricultural trade surplus. These countries are Ghana, Ethiopia, South Africa and Zambia. 


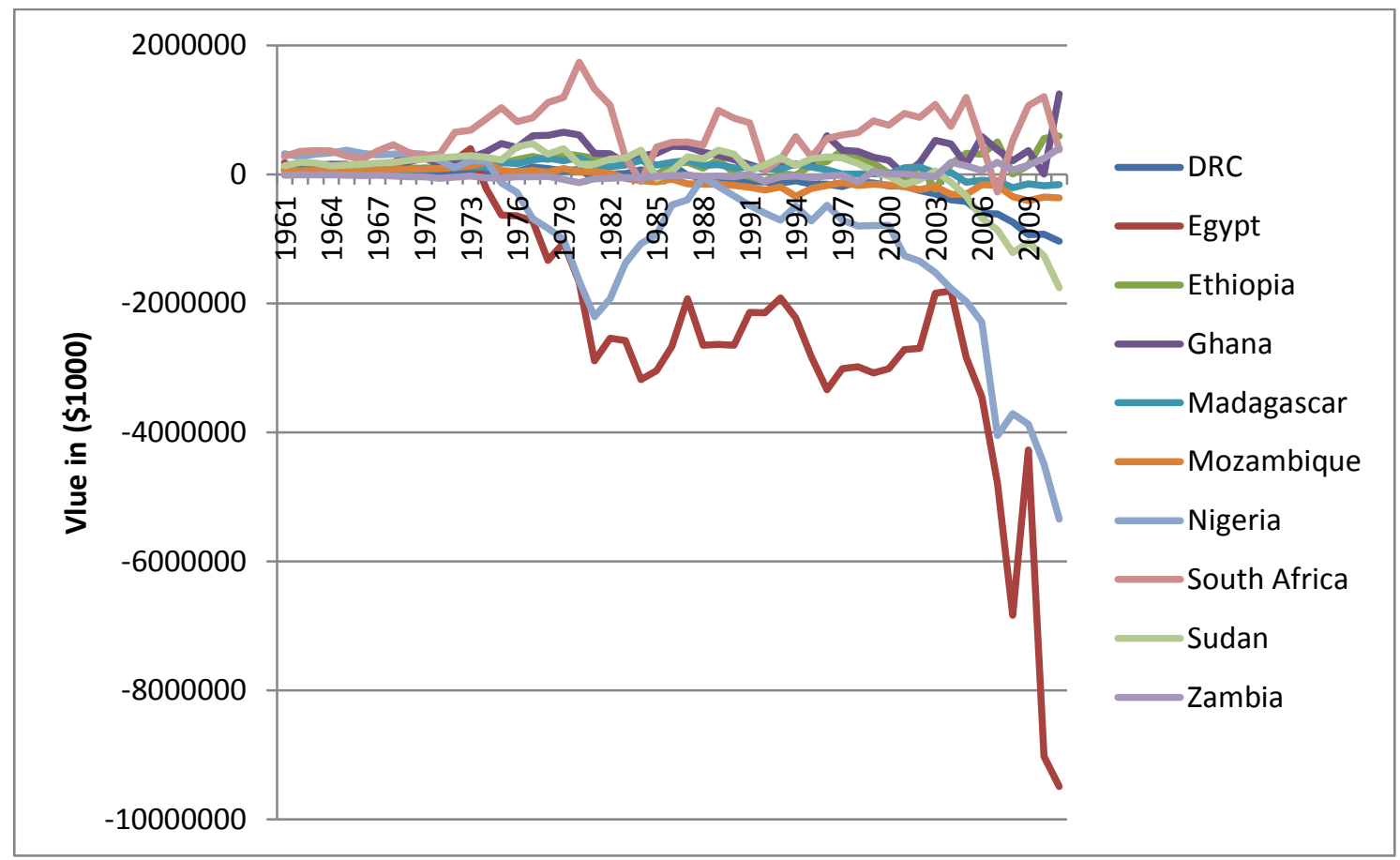

Figure 2.12: Net agricultural export trend over case study countries (current values)

Source: Based on FAOSTAT (2013) data

Among the important commodities imported in to Africa, wheat and poultry meat are the main ones especially over the recent years (Figure 2.13). Egypt is observed to be the highest importer of what followed by Nigeria. Over the last decade, increased rate of wheat import is also observed in most of the case study countries. South Africa recorded the highest rate of poultry meat import in the year 2011. It followed by Ghana, Egypt and DRC. In the rest of the case study countries its value is insignificant. 


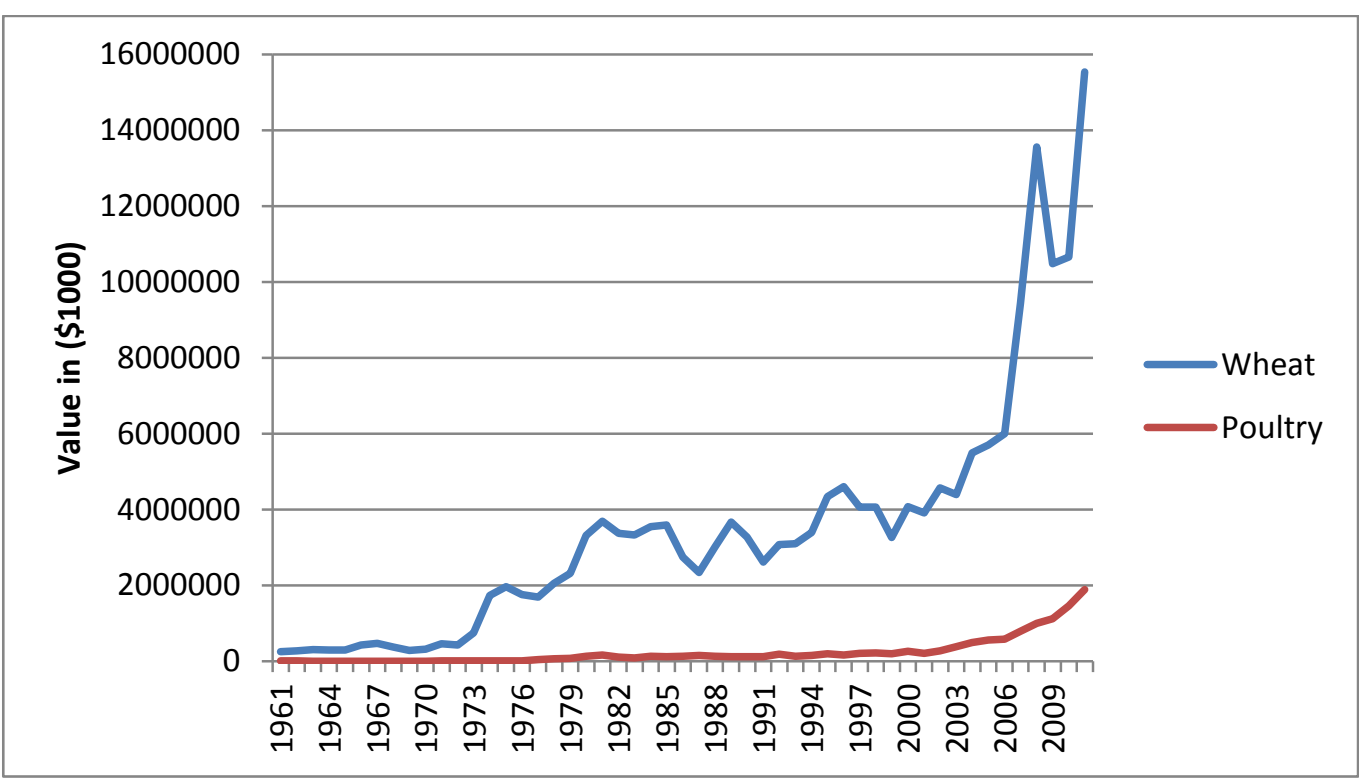

Figure 2.13: Wheat and Poultry import trend in to Africa between 1961 and 2011 (current values)

Source: Constructed from FAOSTAT (2013) data

African agricultural export did not increase much compared to the import value, and the commodities are still dominated by traditional exports (coffee, cocoa, tea and spices). However, in recent times, the share of export of new products (cut flowers, semi-processed fruits and vegetables, and textile products) is increasing. The inter-Africa agricultural trade performance is also not satisfactory; this is dominated by cereals, live animals, meat and dairy products, whereas the majority of cash crops of coffee, cocoa and tea are exported outside of Africa. However, the share of agricultural export of total merchandise exports fell from $42 \%$ to less than 6\% from 1960 to 2007 (Rakotoarisoa et al., 2011).

Figure 2.14 shows the performance of exports of coffee, tea and cocoa, which recovered recently from their deteriorating performance since the 1970 s, in the main exporting countries - Ghana, which showed a $44 \%$ increase and Nigeria, which showed a $15 \%$ increase in the 2000 s compared to value in the 1970 s. Compared to the relatively higher value of the 1980 s, Ethiopia also recorded a 27\% increase in the 2000s. On the other hand, Madagascar recorded a low level of performance, with $80 \%$ decline in the 2000 s compared to the 1980 s, even though it showed a marginal increase from the value in the 1990s. In the light of this, the case of the DRC is the exceptional one, as it recorded a progressively huge decline from the 1980s to its lowest level in the 2000s. This may be linked to the prevailing political instability within that country. In the rest of the selected countries, these commodities represented an insignificant proportion of agricultural exports. 


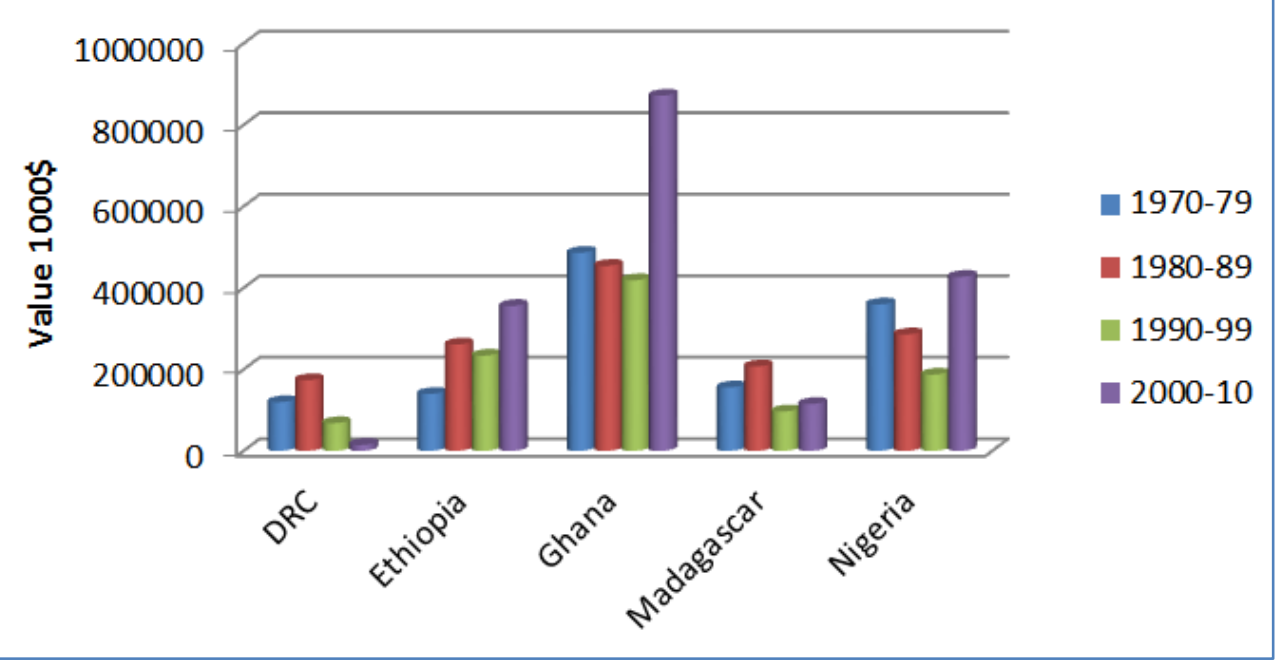

Figure 2.14: Value of coffee, tea and cocoa exports in different decades (current values)

Source: Constructed from FAOSTAT (2013) data

\subsubsection{Self-sufficiency ratio (SSR) and import dependency ratio (IDR)}

According to the FAO (2001), the self-sufficiency ratio (SSR) is an indicator of a country"s ability to fulfil its food demand from its own production and is determined by the two factors of production and consumption. The import dependency ratio (IDR) represents a country's dependence on imports of a specific commodity, assuming that the commodity is not reexported. Both parameters are expressed in percentage, which indicates the degree of production level and import level of a specific commodity in the specific country.

Luan et al., (2013) analysed the trend in the African self-sufficiency ratio from 1961 to 2007, incorporating GDP per capita over 52 countries using cereals and starchy roots as the main parameters. They found that Africaees SSR was lower at the time of their study than in the 1960s. The Northern and Southern Africa regions also showed a decrease in SSR (Luan et al., 2013).

SSR and IDR can be calculated using the formula given by Yoshii, Trung and Oyama (2009) for a study in Japan:

$\mathrm{SSR}=\frac{\text { Production }}{\text { Production+import }- \text { exports }} \times 100$

and $\mathrm{IDR}=\frac{\text { Imports }}{\text { production+import }- \text { exports }} \times 100$

Based on FAOSTAT data from 1970 to 2010 the SSR and IDR of total cereals production over Africa and the case study countries have been analysed. Accordingly, Africa recorded a deteriorating performance in terms of self-sufficiency of total cereal production. A $23 \%$ 
decline in the level of self-sufficiency of cereal production was registered in 2010 in comparison to that of 1970. Of the sub-regions, the Northern Africa region registered the highest decline of 44\%, followed by Middle Africa, Southern Africa, Eastern Africa and West Africa, which recorded $18 \%, 17 \%, 12 \%$ and $11 \%$ decline respectively over the study period. The performance of SSR in Africa is found to be poor in comparison to that in Southeast Asia, which recorded only a $0.2 \%$ decline during the same period.

In the case study countries, the highest decline was recorded in Sudan (35\%), followed by Nigeria (17\%), Mozambique (16\%), South Africa (15\%), Egypt (16\%) and Ethiopia (11\%). The DRC, Madagascar and Ghana registered a relatively lower rate of decline of $8 \%, 6 \%$ and $5 \%$ respectively. Zambia, in contrast, recorded an impressive improvement in the SSR of cereal production of $25 \%$ within the study period.

The import dependency ratio (IDR) also showed worsening performance in Africa and in all of the case study countries except for Zambia. The analysis revealed that, in 2010, Africa was four times more import dependent than 1970 for its cereal consumption. The Northern Africa region recorded the highest IDR value of an $86 \%$ increase in 2010 from the value in the 1970s. Eastern Africa, Western Africa and Southern Africa became three times more import dependent by 2010 than in 1970 in relation to cereal consumption. The Middle Africa region also registered a $19 \%$ increase in IDR during the study period. This performance is poor in comparison with S-E Asia, which recorded an increase of only $2 \%$ in IDR during the same period.

The IDR performance in the case study countries is shown in Figure 2.15, which shows that Sudan recorded the highest increase of $60 \%$, followed by Mozambique, Nigeria and Egypt, with increases of $21 \%, 20 \%$ and 19\% respectively. Ethiopia, the DRC, South Africa, and Ghana recorded a $12 \%, 11 \%, 9 \%$ and $7 \%$ increase in import dependency respectively during the study period, while Madagascar registered a slight increase of 3\%. Only Zambia recorded a decline in import dependency - of $20 \%$ - during the period. 


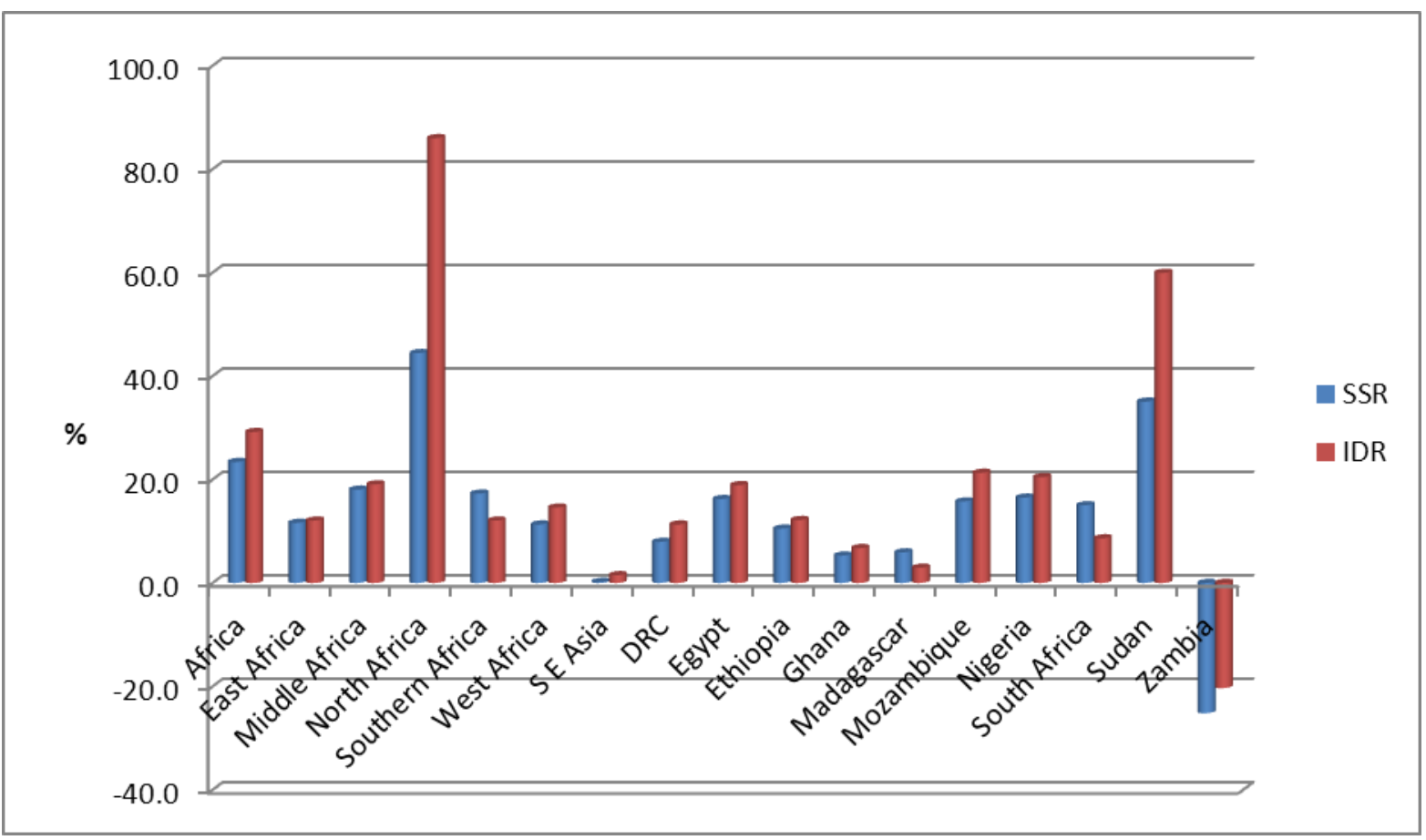

Figure 2.15: Percentage increase in cereal SSR and IDR in 2010 from that of 1970 in selected countries

Source: Calculated and constructed from FAOSTAT (2013) data

From the analysis it can be concluded that, while the case of Zambia cautions against attempting generalisations for Africa, the overall analysis indicates that Africa became increasingly import dependent for its cereal consumption, while its self-sufficiency is deteriorating over time.

\subsubsection{Factors relating to Africa's agricultural import dependency}

The increasing performance of agricultural imports in Africa can be associated with different factors. According to Rakotoarisoa et al. (2011), both supply and demand side factors have played a role in the growth in net agricultural imports in Africa. Accordingly, although there is an increased per capita agricultural growth especially since the 1985, its insufficient growth coupled with poor land ownership and management, low yield and productivity, poor infrastructure and the low level of agricultural investment, as well as institutional deficiencies, conflicts and instability, are the main supply-side constraints. On the demand side, high population growth rate and increasing demand to high value products such as meat products, could be the main factors (Rakotoarisoa et al., 2011).

However, beyond these factors, the international market distortions linked with adoption of domestic agricultural production and export subsidies by member countries of the Organisation for Economic Co-operation and Development (OECD) have also played an important role. According to Rakotoarisoa et al. (2011), between 1986 and 2007, the agricultural producer support in OECD countries is estimated to be about $31 \%$ of the total 
value of their production. While the value of direct support declined to $19 \%$ in 2011 , the estimated direct support to producers stood at USD 252 billion (EUR 182 billion) (OECD, 2012). This amount is significantly higher than the amount these countries spend on foreign aid, which is around $\$ 60$ billion per year (of which Africa gets one fifth) (Moss \& Bannon, 2004).

While the higher proportion of Africa ${ }^{e e}$ agricultural imports originate from the EU and U.S.A, at nearly $29 \%$ and $13 \%$ respectively (Rakotoarisoa et al., 2011), Africa clearly is a victim of the dumping of highly subsidised agricultural surplus. For instance, the observed subsidised poultry dumping to Africa is good example (FAO, 2006b). Such dumping of agricultural

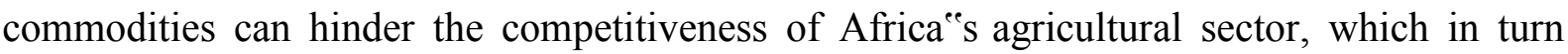
directly affects economic growth and employment and exacerbates the level of poverty and food insecurity.

Moreover, the subsidy schemes in those developed countries are put in place at the expense of the large number of taxpayers in those rich countries and borne by consumers via the charging of higher prices (Moss \& Bannon, 2004). The main beneficiaries of such subsidy schemes in the rich countries are not small farmers, as is mostly perceived, but rather the corporate and large-scale producers with highly mechanised farms that represent a significantly small segment of the population (Moss \& Bannon, 2004). This could be a result of different factors, of which political motives play an important role in supporting domestic agricultural subsidies and export promotion. Its political significance was emphasised by the US Secretary for Agriculture, John Block, in 1986:

The idea that developing countries should feed themselves is an anachronism from a bygone era. They could better ensure their food security by relying on US agricultural products, which are available, in most cases, at much lower cost (Patel \& McMichael, 2010).

In the light of this, critics highly condemn the hypocrisy of rich countries in manipulating free trade while upholding tariff and non-tariff barriers, accompanied with production and export subsidies of their farmers (The New York Times, 2003). In the words of Landis (2010), "EU protectionism is a continuing tragedy, causing unnecessary poverty, hunger and disease". According to Landis (quoting the UN), the developing world every year loses more than $\$ 700$ billion in export income, which is 14 times the foreign aid that the poor countries could get every year. However there is also an argument that the removal of subsidies and trade distortions alone cannot surpass the technical and institutional constraints of poor countries in 
exploiting the advantages of free trade (Anderson et al., 2010, cited by Rakotoarisoa et al., 2011).

\subsection{Food aid performance analysis}

Food aid can be categorised into three types - programme food aid, project food aid and emergency food aid (Boussard et al., 2005). Programme food aid is supplied by donor countries as a grant or loan and is not targeted to specific groups but sold in local markets. Project food aid is mostly supplied as a grant and focuses on enhancing poverty alleviation and disaster prevention activities. While usually freely distributed to targeted beneficiaries, it may be sold in the open market. Emergency food aid aims to support target groups that are affected by man-made and natural disasters, and is freely distributed to beneficiaries (Boussard et al., 2005).

According to Kidane et al. (2006), while around $90 \%$ of the food aid is composed of cereals, in the past more than half of food aid was granted to SSA in programme or project food aid schemes, nowadays its share is declining and more attention is focused on emergency food aid. And also food aid to SSA has increased significantly since the 1970s and reached a peak of six million tons by 1992 (Kidane et al., 2006). The regional distribution of food aid in Africa is depicted in Figure 2.16.

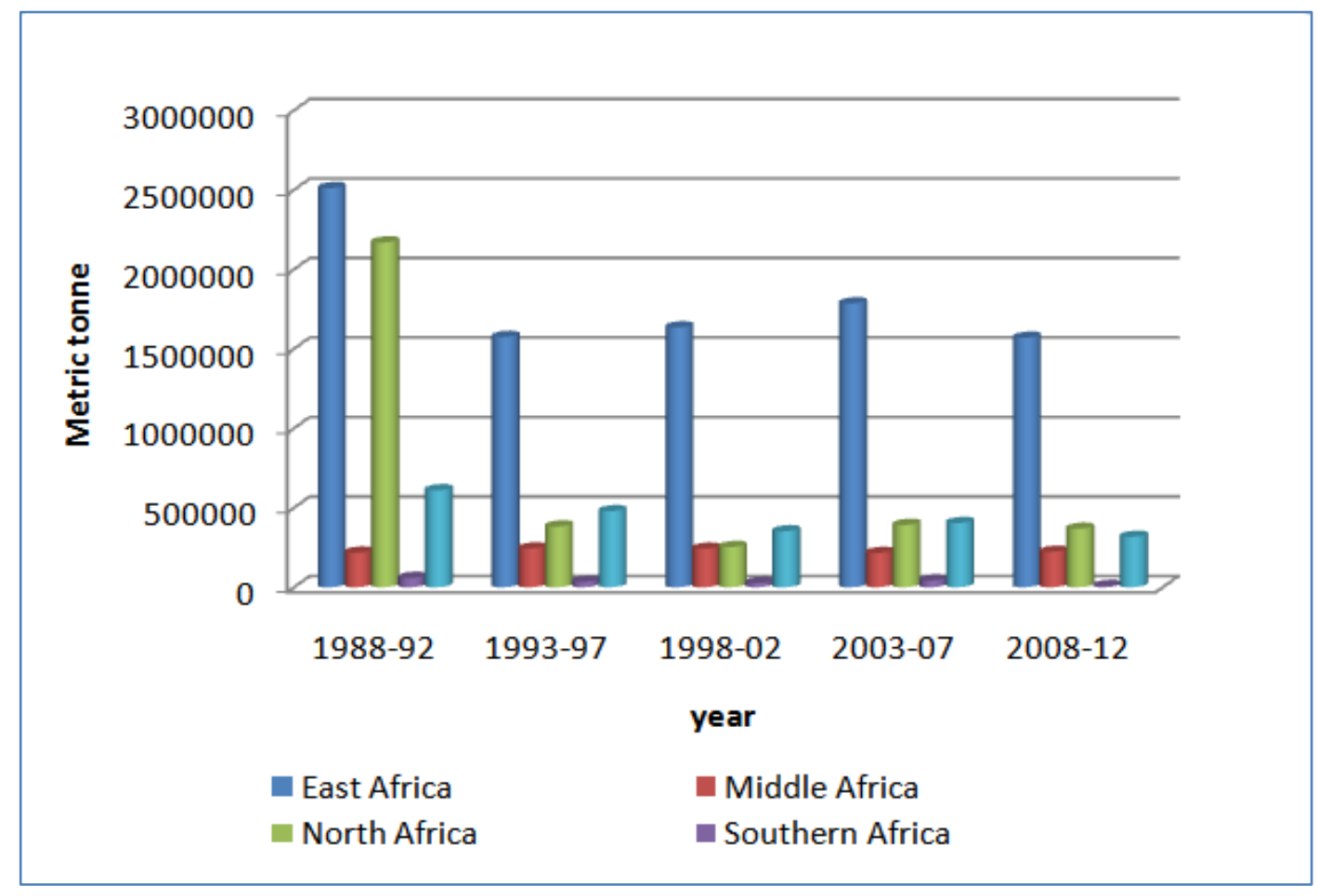

Figure 2.16: Average total cereal aid to Africa (1988 to 2012)

Source: Based on FAOSTAT (2013) data southern 
As shown in Figure 2.16, the East Africa region is the biggest food aid recipient of all the subregions. The Northern Africa region had the highest level of food aid from 1988 to 1992, whereas Egypt was the recipient that showed the most dramatic decline in consecutive years (see Figure 2.17). Except for the Middle Africa region, which showed an increase of 2.7\%, the rest of the sub-regions received less cereal aid from 2008 to 2012 than from 1988 to 1992. Accordingly, the Southern Africa region recorded the highest decline in cereal aid receipts, by $86 \%$, followed by Northern Africa by $83 \%$, Western Africa by $48 \%$ and Eastern Africa by $38 \%$.

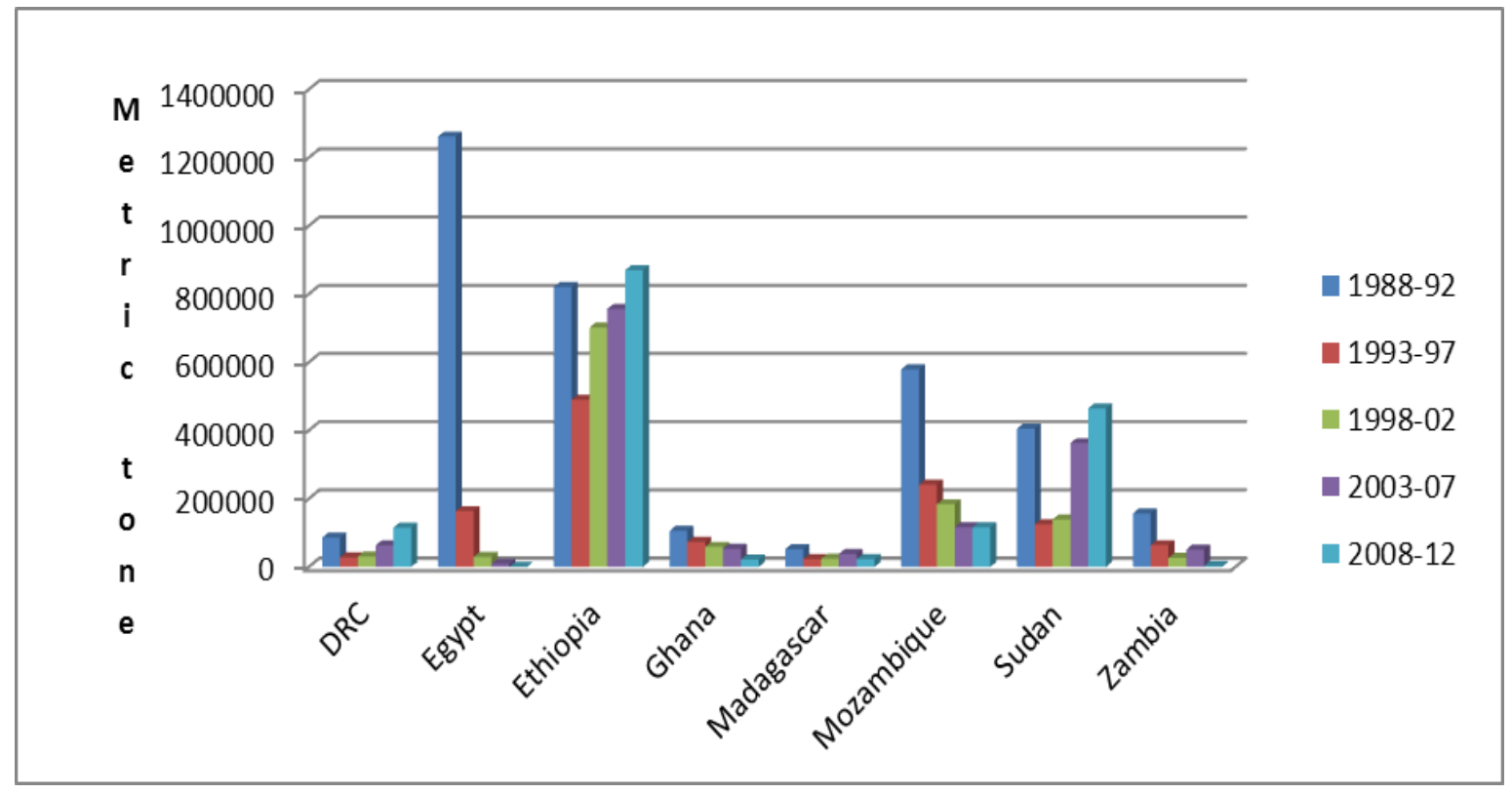

Figure 2.17: Five-year average cereal aid in selected countries (1988 to 2012)

Source: Based on FAOSTAT (2013) data

According to the EIU'S qualitative assessment in its global food security index, ten of the twelve countries that have been receiving chronic food aid on an increasing base over the past five years are in SSA (EIU, 2012). Only a few countries in Africa, namely Botswana, Nigeria, South Africa, Morocco and Tunisia, receive no chronic food aid. In this respect, based on FAOSTAT data, the percentage performance of cereal aid has been calculated for the case study countries between the period 1988/92 to 2008/12. Accordingly, a huge reduction in cereal aid was recorded in Egypt, by $99 \%$, in Zambia by $98 \%$, and by $80 \%$ in each of Mozambique and Ghana. While Madagascar recorded a decline of 56\%, the DRC, Sudan and Ethiopia showed an increase in cereal aid by $35 \%, 15 \%$ and $6 \%$ respectively between the two periods (EIU, 2012; FAOSTAT, 2013).

While the political instability in the DRC may be to blame for the increase in food aid, a detailed study is necessary in Ethiopia. Despite the fact that the country succeeded in reducing 
the number of undernourished people and increasing per capita cereal production, especially over the last decade, the increasing rate of chronic food aid might be associated with factors such as the countryes sigh prevalence of disasters and shocks, coupled with rapid population growth.

Recently, targeted market-oriented interventions to enhance local small-scale producers, while running targeted nutritional interventions such as school feeding, are being undertaken by international organisations such as the World Food Programme ees purchase for progress initiative (P4P) (WFP, 2013). This programme works by buying locally produced food and redistributing it via targeted nutrition interventions for those in need inside that country, including refugees in the case of Ethiopia (WFP, 2013).

\subsection{Summary}

Food availability represents the food supply dimension of the food security analysis. It has been used in food security debates since the $18^{\text {th }}$ century, when the famous Malthusian hypothesis claimed that food security can be threatened by increasing population growth. In this regard, despite the success in world agricultural productivity over the past half century well above the population growth rate the recent food price spike and associated increase in demand for agricultural products placed the food supply debate at the forefront of food security discussions.

The food balance sheet (FBS) is a national account of annual food production, changes in stocks, imports and exports, and agricultural and industrial uses within a country. It also provides information regarding per capita per day nutrient availability of calories, protein and fat. Although the FBS overestimates the average food supply, since it does not consider food and nutrient loss at the point of consumption on the household level, it remains the best available source of food supply information.

African agriculture is found to be threatened by different factors, such as rapid population growth, climate change, HIV/AIDS, political instability, civil strife, and so on. Owing to its low performance and the challenges surrounding it, there also is some scepticism about agricultural success in Africa. Some researchers argue that, in order for Africa to reap the benefits of agriculture, large commercial farms may be a better option (Collier, 2008, cited in Wiggins, 2009:3). As a result, Dercon (2009) has argued that agriculture as an engine of growth in Africa is unlikely, and that it must be context specific, depending on geography and resource endowment. 
The analysis of long-term caloric food supply trends identified the Northern and Western Africa regions as those with relatively better performance. The Southern Africa region recorded rather stagnant performance, while Middle and Eastern Africa started realising a growth rate since the mid-1990s in caloric supply after long-term deterioration. Out of fifty African countries with available data, twenty-one countries of SSA were still below the FAO ${ }^{\text {ee }}$ s standard of daily caloric food supply of $2300 \mathrm{Kcal} /$ capita/day by the year 2009 (see Addendum A). Impressive growth in caloric food supply was registered in Ghana and Egypt between 1970 and 2012. These countries performed better than the average growth rate in Southeast Asia. Moreover, of the selected countries, Ghana and Ethiopia registered steep growth in caloric food supply in the last twenty years, after a declining performance between 1970 and 1990. In contrast, Madagascar and Zambia recorded a declining growth rate in caloric food supply during the same period.

According to the FAO ${ }^{\text {ee }}$ s estimate, about $62 \%$ of the dietary energy supply in Africa is derived from cereals, roots and tubers. In between 1984/86 to 2010/12, Africa recorded a 0.4\% increase in annual per capita cereal production. Except the Southern Africa region, the rest of sub-regions of Africa also recorded an increasing rate. Among the case study countries, the highest declining rate observed in Sudan (-1.6\%) followed by DRC(-1.4\%). Madagascar ($0.2 \%)$ and South Africa (-0.4\%) have also showed a declining rate with a marginal reduction rate recorded in Nigeria (-0.1). Ethiopia (2.5\%), Mozambique (2.2\%), Egypt (1.7\%) and Ghana (1.7\%) performed the best in this regard, recording the highest rate even more than S-E Asia region (1.4\%).

Per capita roots and tubers production in Africa showed higher growth rate than the S-E Asia region (Figure 2.9). Only the Middle Africa sub region recorded a declining rate of $-0.5 \%$ of all the sub-regions. Out of the case study countries, the Western Africa countries of Nigeria and Ghana recorded the highest rate of $4.2 \%$ and $3.7 \%$ respectively. DRC recorded the highest decline rate of $-2.9 \%$ followed by Madagascar with a $-1.3 \%$ decline during the study period of $1984 / 86$ to $2010 / 12$. In all of the sub-regions of Africa and the case study countries an increasing rate of yield and area harvest of roots and tubers recorded except for DRC that experienced a marginal rate of decline in yield.

Agricultural production variability is one of the important factors that affect national food availability. Although it is categorised as a parameter of the food stability dimension, it has been analysed in the food availability section of the EIU (2012) global food security index. According to the $\mathrm{FAO}^{\mathrm{ee}}$ s production variability measurement, most of the Northern Africa 
countries recorded higher production variability, such as Morocco (20), Algeria (15.4) and Tunisia (12). The highest food production volatility in sub-Saharan Africa in 2010 was recorded in Niger (18.5), Malawi (18) and Namibia (17.1), and the lowest was recorded in Western Sahara (0.4), Equatorial Guinea (1) and Congo (1.5). Among the case study countries, Nigeria and South Africa each recorded the highest value of 11.8. They are followed by Ghana (8.9), Egypt (8.5) and Mozambique (6.4). The lowest was recorded in the DRC (1.9), followed by Ethiopia (3.6) and Zambia (4.9).

The agricultural trade analysis of the continent showed that, although agriculture is the main economic sector in Africa, the region generally has turned out to be a net agricultural commodities importer since the early 1980s and net food importer since the early 1970s. About $88 \%$ of the imports originated from outside of Africa between 2004 and 2007. Also, cereals and livestock represented a minimum of $50 \%$ of the imports (Rakotoarisoa et al., 2011). Among the case study countries, the highest increase in net agricultural import observed in Egypt followed by Nigeria. While most of the countries started experiencing agricultural trade deficit since the 1970s, by the year 2011 four of the ten case study countries are in agricultural trade surplus. These countries are Ghana, Ethiopia, South Africa and Zambia. Also wheat and poultry meat are observed to be important import commodities to the region especially over the recent years.

The calculated value of SSR and IDR also showed the increased import dependency of Africa for its cereal demand, coupled with declining self-sufficiency, especially when compared to the Southeast Asia region. A 23\% decline in the level of self-sufficiency in cereal production in Africa was registered in 2010 from that of 1970. Of the sub-regions, the Northern Africa region registered the highest decline in SSR, at 44\%, followed by Middle Africa, Southern Africa, Eastern Africa and West Africa, which recorded declines of 18\%, 17\%, 12\% and 11\% respectively in 2010 from that of 1970 .

The import dependency ratio also showed increasing performance in Africa and all over the case study countries, except in Zambia. The analysis revealed that, in 2010, Africa was four times more import dependent for its cereal consumption than in 1970. The Northern Africa region recorded the highest increase in IDR value from 1970 to 2010, of 86\%. Eastern Africa, Western Africa and Southern Africa become three times more import dependent for their cereal consumption by 2010 compared to 1970. The Middle Africa region also registered a $19 \%$ increase in IDR during the study period. 
There are different factors responsible for the dramatic increase in Africaes import dependency for agricultural and food products. While population growth and an increasing demand for food, coupled with economic growth, comprise one factor, insufficient level of per capita agricultural growth also played an important role (Rakotoarisoa et al., 2011). However, beyond these factors is the international market distortion linked to the OECD countries $^{e e}$ adoption of domestic agricultural production and export subsidies is found to be important factor.

With a high proportion of Africaes agricultural import originating from the EU and the U.S.A, at nearly $29 \%$ and $13 \%$ respectively (Rakotoarisoa et al., 2011), Africa clearly is a victim of the dumping of highly subsidised agricultural surplus. For instance, the observed subsidised poultry dumping in Africa is a good example (FAO, 2006b). Such dumping of agricultural commodities can hinder the competitiveness of Africaes agricultural sector, which in turn directly affects economic growth and employment and exacerbates the level of poverty and food insecurity.

Food aid is the other factor that plays a role in the national food balance sheet equation. According to Kidane et al. (2006), while around $90 \%$ of the food aid is composed of cereals. . The analysis revealed that, food aid to SSA has increased significantly since the 1970s, and reached a peak of six million tons by 1992 (Kidane et al., 2006). Between 1988 to 1992 and 2008 to 1012, a huge reduction in cereal aid was recorded in Egypt, by 99\%, Zambia, by 98\%, and $80 \%$ in each of Mozambique and Ghana. While Madagascar also recorded a decline of $56 \%$ in this period, the DRC, Sudan and Ethiopia showed an increase in the percentage of cereal aid, by $35 \%, 15 \%$ and $6 \%$ respectively (EIU, 2012; FAOSTAT, 2013). 


\section{Chapter Three}

\section{Analysis of food accessibility}

\subsection{Introduction}

The concept of food accessibility as an important dimension of food security analysis was originated in the entitlement approach of Amartya Sen in the early 1980s (Sen, 1981). He argued that "starvation is a matter of some people not having enough food to eat and is not a matter of there being not enough food to eat" (Sen, 1981). This approach shifted the conception of food security from being only limited to food availability to include the concept of food accessibility at the national, regional, household and individual level. The current definition of food security also incorporates this concept as: "Access by all people at all times to enough food for an active and healthy life" (World Bank, 1986).

The entitlement approach consists of three important elements: endowment set, entitlement set and entitlement mapping (E-mapping) (Sen, 1981). The endowment set refers to the combination of all resources (land, equipment, animals, skill, labour power, membership of a community, etc.) that are legally owned by a person. The entitlement set refers to the use of endowed resources in different combinations to obtain final goods and services. This, for instance, can be a farmer"s act of production using his endowed resources, a fish catch by a fisherman and its exchange for rice in the market, and unemployment benefits for an unemployed person using his resource of being a citizen of a welfare state; these are all entitlement sets, excluding illegal actions such as looting (Osmani, 1993). Entitlement mapping represents the rate of exchange of endowed assets for the final goods and services in the entitlement set, for example the ratio of money wage to the price of food (Osmani, 1993).

Therefore, a change in either of them, or in both the endowment set and E-mapping, can affect the entitlement set, as these are the final goods and services derived from the two. Accordingly, famine or starvation can occur only through an adverse change in endowment set or E-mapping or both (Osmani, 1993). It could happen as a result of: direct entitlement failure, which can result from either endowment loss or production failure; trade entitlement failure, which can result from endowment loss, production failure, or exchange failure; and transfer failure, which could be failure of emergency aid (Sen, 1981). For example, a fisherman can starve because of losing his boat (endowment loss) or not being able to catch enough fish (production failure) or, while both are intact, he may not be able to get enough rice if the relative price of fish collapses (exchange failure) (Osmani, 1993). 
Sen went further in his pragmatic capability approach by explaining other important circumstances that may not be incorporated in the above cases of endowment loss or entitlement failure (Burchi \& De Muro, 2012). In this case he showed that different people and societies typically differ in their capacity to convert income and commodities into valuable achievements (including access to food) (Clark, 2005). For example, a disabled person may need extra resources to function as an able bodied person (wheelchairs, ramps, lifts, etc.). Similarly, a child typically has different nutritional requirements from that of an adult, pregnant woman, or someone with a specific illness. Also, other cultural or religious factors such as customs, conventions or class could play important role for realization of an individual's capability (Clark, 2005). This approach laid the foundation for the measurement of the human development index of the UNDP (Vink, 2012), which will be discussed in section (3.3).

In this chapter and the next one, Sen 's entitlement and capability approach are used as a theoretical background for a food access analysis of Africa and the case study countries. As identified by the entitlement approach, food access is directly related to the purchasing power of an individual, which is linked to the national poverty reduction policies and strategies of a country. As discussed in Kidane et al. (2006), different physical, economic, political and sociocultural aspects determine this objective and, ultimately, food accessibility. Based on these categories, the study will analyse the food accessibility situation in the study area.

\subsection{Food accessibility indicators}

While most of the food security indicators are usually concerned with economic factors of food accessibility, Sen ${ }^{\text {ee }}$ capability approach provided the background to incorporate both tangible and intangible factors of accessibility. The approach also laid the foundation for UNDPee $^{\mathrm{s}}$ Human Development Index (HDI) (Vink, 2012). The HDI incorporates other determinant factors of development besides economic factors, such as education and health. The economic indicators of food accessibility basically rely on factors such as real GDP per capita growth, poverty level, the GINI index and income share of household food expenditure (Kidane et al., 2006).

In analysing the context of the capability approach, household ${ }^{\text {ee }}$ s and individual's food access can actually be affected by other, non-economic factors such as political, physical and sociocultural factors (Kidane et al., 2006). The FAO ees food security indicators incorporate physical access, which consists of percentage of paved roads over total road, rail-line density 
and road density (FAO, 2013). It also includes economic access, which is determined by an estimation of the domestic food price index.

In the EIU's global food security index, food accessibility has been limited to food affordability, which is mostly associated with economic factors that only determine an individual's purchasing power. Six indicators of food affordability, namely food consumption as a share of household expenditure, proportion of population under the global poverty line, GDP per capita, agricultural import tariffs, presence of food safety net programmes and access to financing for farmers, are the parameters used in the EIU's index (EIU, 2012). Based on its ranking, South Africa, Botswana and Cote d'Tvoire are the top three foodaffordable countries in SSA, and Nigeria, Chad and the DRC are the three countries with the lowest food affordability (see Figure 3.1).

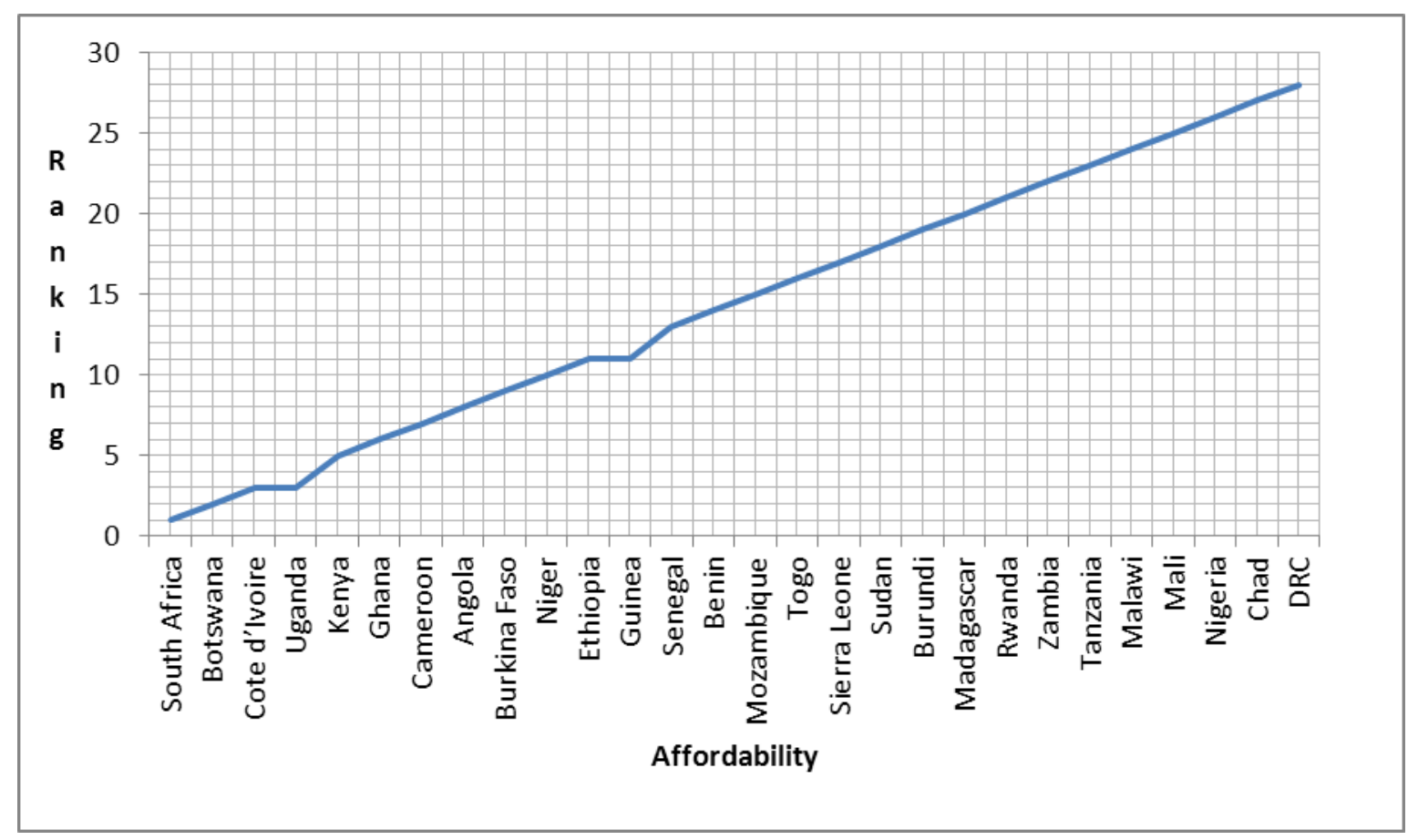

Figure 3.1: The food affordability ranking of 28 SSA countries in 2013

Source: Based on EIU (2013)

The index also gives more weight to household food expenditure and GDP per capita, at 22\% each. Population under the global poverty line and presence of safety nets are weights of $20.2 \%$ and $14.1 \%$ respectively, while financial access to farmers and agriculture import tariffs account for $11.1 \%$ and $10.1 \%$ respectively. In this study, while EIU's food affordability is considered to be part of economic accessibility, the impact of other, non-economic factors of food accessibility, such as physical accessibility, political accessibility and sociocultural factors in the context of Africa, is also incorporated. The food affordability indicators used in 
the EIU's index, which are household food expenditure, GDP per capita, population under global poverty line, and others such as the HDI and GINI index, are applied in the economic accessibility analysis in this chapter.

\subsection{Economic access}

As discussed above, the UNDPees HDI is one of the best indicators of individualse economic capability. The other common indicator of national food accessibility is the growth rate in GDP per capita. In the light of this, this section starts by analysing the performance of the Human Development Index (HDI) in the selected countries, and then discusses the per capita GDP growth pattern in the selected countries. It also elaborates the main drivers behind the recent economic growth pattern in Africa, focusing on the case study countries. Economic growth and its correspondence with poverty reduction and income distribution will also be scrutinised.

In terms of HDI, although about 15 countries with the lowest HDI are in SSA, the region realised an improvement in HDI from the 1980s onwards (Vink, 2012). According to the UNDP (2013), HDI improved in SSA at a growth rate of 1.3\% per annum between 2000 and 2012. Sierra Leone and Ethiopia registered annual growth rates of $3.3 \%$ and $3.1 \%$ respectively, which is the highest in the world next to Afghanistan, which recorded a growth rate of $3.9 \%$ during the same period. However, both countries started from a relatively lower level of HDI values. Of the case study countries, South Africa showed the slowest improvement in HDI, with a $0.09 \%$ annual growth rate between 2000 and 2012. The percentage growth performance of HDI since 1980 in the selected countries is illustrated in Table 3.1. 
Table 3.1: HDI performance in selected African countries

\begin{tabular}{|c|c|c|c|c|c|c|c|c|c|}
\hline & 1980 & 1990 & 2000 & 2005 & 2007 & 2010 & 2011 & 2012 & $\begin{array}{l}\text { \% annual } \\
\text { growth rate } \\
\text { between } \\
2000 \& 2012\end{array}$ \\
\hline SSA & 0.37 & 0.39 & 0.41 & 0.43 & 0.45 & 0.47 & 0.47 & 0.48 & 1.34 \\
\hline DRC & 0.29 & 0.30 & 0.23 & 0.26 & 0.28 & 0.30 & 0.30 & 0.30 & 2.20 \\
\hline Egypt & 0.41 & 0.50 & 0.59 & 0.63 & 0.64 & 0.66 & 0.66 & 0.66 & 0.92 \\
\hline Ethiopia & $\ldots$ & $\ldots$ & 0.28 & 0.32 & 0.35 & 0.39 & 0.39 & 0.40 & 3.09 \\
\hline Ghana & 0.39 & 0.43 & 0.46 & 0.49 & 0.51 & 0.54 & 0.55 & 0.56 & 1.60 \\
\hline Madagascar & $\ldots$ & $\ldots$ & 0.43 & 0.47 & 0.48 & 0.48 & 0.48 & 0.48 & 1.01 \\
\hline Mozambique & 0.22 & 0.20 & 0.25 & 0.29 & 0.30 & 0.32 & 0.32 & 0.33 & 2.37 \\
\hline Nigeria & $\ldots$ & $\ldots$ & $\ldots$ & 0.43 & 0.45 & 0.46 & 0.47 & 0.47 & $1.18^{*}$ \\
\hline Sudan & 0.27 & 0.30 & 0.36 & 0.39 & 0.40 & 0.41 & 0.42 & 0.41 & 1.08 \\
\hline South Africa & 0.57 & 0.62 & 0.62 & 0.60 & 0.61 & 0.62 & 0.63 & 0.63 & 0.09 \\
\hline Zambia & 0.41 & 0.40 & 0.38 & 0.40 & 0.41 & 0.44 & 0.44 & 0.45 & 1.47 \\
\hline
\end{tabular}

Source: HDR, 2013

*For Nigeria the growth rate given was between 2005 and 2012

In terms of GDP per capita, the SSA region registered a robust growth rate, especially during the last decade as shown in Figure 3.2. The GDP per capita growth performance in SSA during the last decade was $2.2 \%$ per annum on average (Figure 3.2). In 2012, the SSA region (excluding South Africa) recorded a GDP growth rate of 5.8\%, which is higher than that of the developing world (excluding China), with an average of 4.9\% (World Bank, 2013b). Moreover, in 2012 about a quarter of the countries in the region recorded an average real GDP growth rate of more than $7 \%$, which ranked them among the fastest growing economies in the world (World Bank, 2013b). 


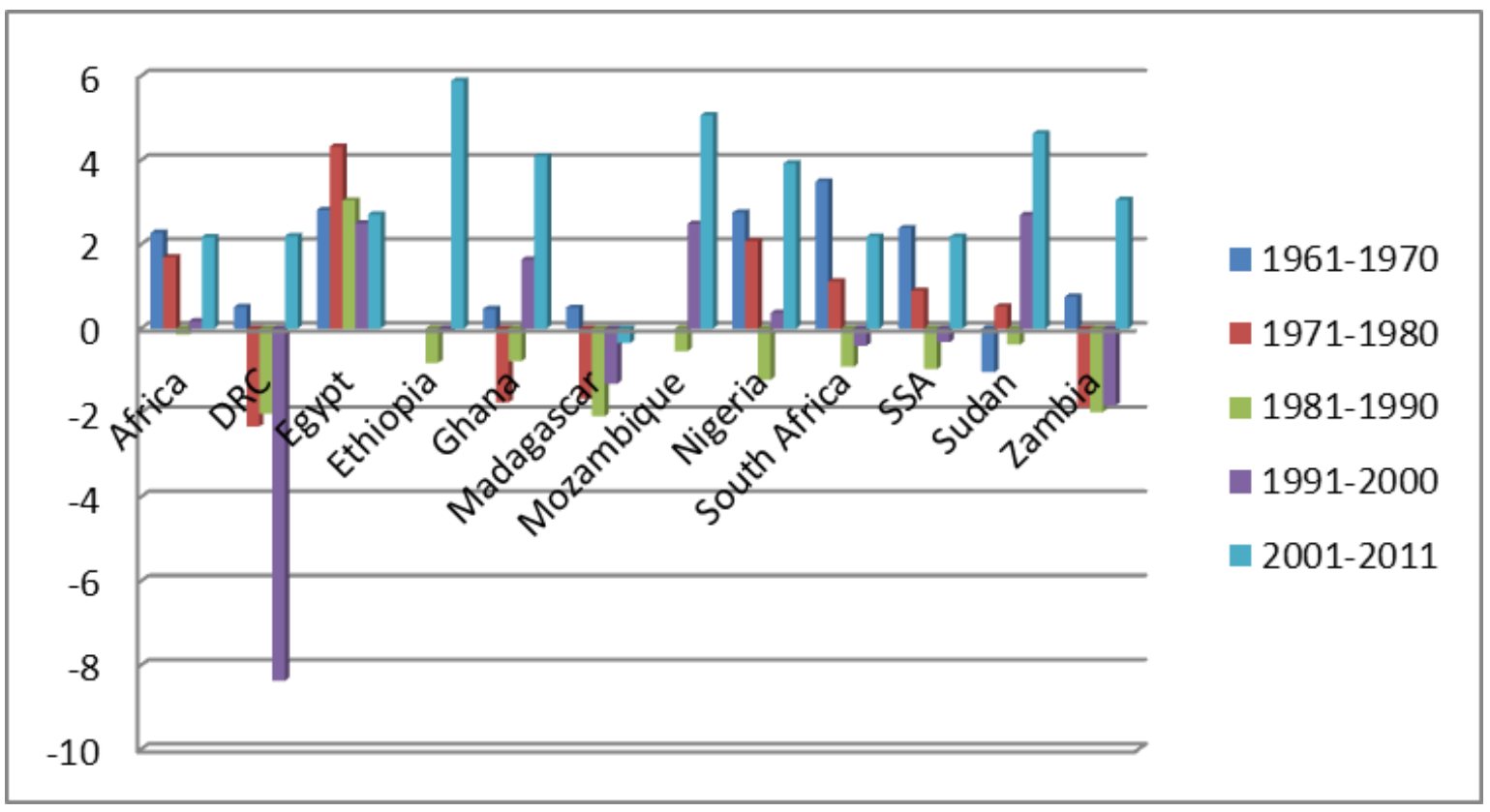

Figure 3.2: The decadal average GDP per capita growth rate over selected countries

Source: World Bank (2013a), Africa Development Indicators

The recent economic growth in SSA can be associated with an increase in domestic demand and investment; the investment to GDP ratio grew at a rate of $0.5 \%$ a year over the last decade (World Bank, 2013b). While other sectors, such as infrastructure-related investments, were important, the increased flow of foreign direct investment, which is largely dominated by extractive industries, was also significant. According to IFPRI (2008), agricultural growth in sub-Saharan Africa has also been remarkable over the past 10 to 15 years. Between 2003 and 2005 , thirteen countries in SSA achieved an annual agricultural growth rate of greater than $5 \%$, and most of them succeeded in maintaining the CAADP target rate of growth, which is $6 \%$ per annum (IFPRI, 2008).

There are other factors that also contributed to the recent good performance in economic growth in Africa. Among the main factors were the political and macroeconomic stability, as well as microeconomic reforms implemented by many of those countries (McKinsey, 2010). Moreover, the relatively stable political situation following the ending of deadly hostilities in many countries, lower inflation, reduced foreign debt, narrowed budget deficits, privatisation of state owned enterprises, reduced trade barriers, and strengthening of regulatory and legal systems were important adjustments that favoured economic growth (McKinsey, 2010).

Beyond those factors, Africa ${ }^{e e}$ s economic growth over the last decade was also driven by a spike in global commodity prices of minerals, grains and other raw materials, as observed in the oil price spike from $\$ 20$ a barrel in 1999 to $\$ 145$ in 2008 (McKinsey, 2010). In 
association with this, the growth trend also differed, with the resource-rich ${ }^{6}$ countries recording a higher rate than the non-resource-rich countries in the region. According to the World Bank (2013b), while there was significant economic growth in some resource-poor countries, the overall GDP per capita growth was 2.2 times faster in resource-rich countries than in resource-poor ones between 1996 and 2011.

However, the transformation of economic growth into poverty reduction and food security is the most important case in point. In the light of this, economic growth must focus on income distribution so that significant poverty reduction can be realised. An empirical study by Geda et al., (2009) found that a much more significant poverty decline was observed in Ethiopia in a scenario of economic growth with equitable wealth distribution, than in the case of economic growth neutral to income distribution.

Therefore, economic growth actually might not result in poverty reduction and an increased level of food security at the national level. For instance, according to the World Bank ranking, Nigeria is $38^{\text {th }}$ in the world with the highest GDP level, but in terms of the food security ranking by the EIU, it is ranked $80^{\text {th }}$ in the world (EIU, 2012). In this respect, the performance of economic growth in poverty reduction and achieving food security deals with the question of how national income growth is being distributed in society at large.

Table 3.2: Economic growth on poverty reduction and income inequality over selected African countries

\begin{tabular}{|l|r|r|r|r|l|r|r|}
\hline & $\begin{array}{l}\text { Base } \\
\text { year }\end{array}$ & $\begin{array}{l}\text { \% population } \\
\text { below national } \\
\text { poverty line } \\
(<1.25 \$ / \text { day })\end{array}$ & $\begin{array}{l}\text { GINI } \\
\text { index }\end{array}$ & $\begin{array}{l}\text { End } \\
\text { year }\end{array}$ & $\begin{array}{l}\text { \% population } \\
\text { below national } \\
\text { poverty line } \\
(<1.25 \$ / \text { day })\end{array}$ & $\begin{array}{l}\text { GINI } \\
\text { index }\end{array}$ & $\begin{array}{l}\text { \% average } \\
\text { GDP/capita } \\
\text { growth rate } \\
\text { (PPP) * }\end{array}$ \\
\hline Egypt & 1991 & 4.46 & 32 & 2008 & 1.69 & 30.7 & 2.7 \\
\hline Ethiopia & 1995 & 60.5 & 40 & 2011 & 30.7 & 33.6 & 4.5 \\
\hline Ghana & 1992 & 51.1 & 38.1 & 2006 & 28.6 & 42.8 & 2.0 \\
\hline Madagascar & 1993 & 72.5 & 46.1 & 2010 & 81.3 & 44.1 & -0.2 \\
\hline Mozambique & 1996 & 80.6 & 44.5 & 2008 & 59.6 & 45.7 & 5.1 \\
\hline Nigeria & 1996 & 68.5 & 46.5 & 2010 & 68 & 48.8 & 2.5 \\
\hline South Africa & 1995 & 21.4 & 56.6 & 2009 & 13.8 & 63.1 & 1.6 \\
\hline Zambia & 1996 & 62.1 & 49.8 & 2006 & 68.5 & 54.6 & 1.5 \\
\hline
\end{tabular}

Source: World Bank (2013a), Africa Development Indicators

* refers to the average per capita GDP growth rate between the base year and the end year

Note: The DRC and Sudan are not included in the calculation due to data constraints; PPP, purchasing power parity

Table 3.2 illustrates the extent to which the effect of economic growth reduced the level of poverty and inequality in the selected countries over a certain period of time. GDP per capita

\footnotetext{
${ }^{6}$ Resource rich refers to countries primarily relay on minerals and/or especially those oil exporting.
} 
showed an increasing performance between the periods of the study for each country except Madagascar. In resource-poor countries such as Ethiopia and Mozambique ${ }^{7}$, economic growth led to a significant reduction in poverty of $30 \%$ and $21 \%$ respectively, estimated by the percentage of the population living under the national poverty line. Also, income inequality measured by the GINI index showed a reduction in Ethiopia, while it showed only a marginal increase in Mozambique. By contrast, economic growth in the resource-rich countries such as South Africa, Nigeria and Zambia did not result in a sizable poverty reduction. A World Bank study also found out that, the poverty headcount in resource-poor countries declined from $65 \%$ in 1995 to 2000 to an estimated $49 \%$ in 2008 to 2011 , while it showed only an estimated $7 \%$ decline during the same period in resource-rich countries (World Bank, 2013b).

In this regard, in analysing the drivers of economic growth in resource-poor countries, agriculture was found to be at the forefront of the economic sectors, in contrast to the situation in resource-rich countries. One example is Ethiopia, which adopted an agricultural development-led industrialisation policy in the mid-1990s. Ghana is another case. Agriculture, being the primary source of income for rural Ghana, enabled the country to achieve MDG1 of halving the poverty level of the 1990s before 2015 (Diao, 2010). This implies that the role of agriculture in economic development and poverty reduction is much more significant, especially in those resource-poor SSA countries.

Kidane et al. (2006) also argued that resource-exporting countries often experience a considerable inflow of foreign currency, which may lead to an overvalued local currency, which in turn reduces the competitiveness of agriculture and other sectors in the domestic and export markets. They therefore suggested macroeconomic measures such as public investment in non-resource sectors, investment in agriculture and others to increase their competitiveness, and safety nets targeting vulnerable groups so as to quickly eradicate food insecurity (Kidane et al., 2006). In the light of this, there is a bigger opportunity for those oil-exporting countries to diversify their economy by creating a business environment that enables companies to flourish across industries (McKinsey, 2010).

\subsubsection{Agriculture as engine of economic growth}

Empirical studies on the relationship between economic growth and poverty reduction have revealed that growth in per capita GDP can be a powerful tool in poverty reduction and human development (Ran et al., 2000; Roemer \& Gugerty, 1997). However, as discussed in the previous section, all sorts of economic growth per se does not result in the same level of

\footnotetext{
${ }^{7}$ Income from mineral rents has only come on board in Mozambique from 2004 onwards
} 
poverty reduction and equitable wealth distribution (Loayza \& Raddatz, 2010). Carmignani (2011) found that a combination of growth and redistribution (declining inequality) is a favourable scenario for poverty reduction. His analysis also found that there is no trade-off between growth and redistribution.

It should also be noted that economic growth by itself is pro poor (Valdés \& Foster, 2005), but the growth process and associated policy measures determine the rate of poverty reduction and food security, especially in those countries with high levels of income inequality (World Bank, 2000). For instance, although there is economic growth in most mineral-rich countries in sub-Saharan Africa, they could not realise the widely shared poverty reduction and food security due to a lack of wealth redistribution, as partly discussed in the previous section (Pegg, 2003).

From an economic point of view, economic growth without effective poverty reduction hinders the realisation of optimal economic potential. This is because the poor and food insecure are not participating in economic growth, but rather remain dependent on it (Kidane et al., 2006). The result of increasing inequality could also more often be associated with social unrest and violence, which in turn increase risk in the business environment. Consequently, an increase in the poverty headcount further slows down growth and increases inequality and food insecurity (Carmignani, 2011).

Historical and analytical evidence supports agricultural growth as a driver of economic growth while effectively reducing poverty, especially at the early stages of economic development (De Janvry \& Sadoulet, 2010; Diao, 2007; Diao et al., 2010; Hazell et al., 2007; World Bank, 2008). Historical evidence also shows that only a few countries have industrialised without prior agricultural development (Hazell et al., 2007). This was also experienced in the Asian Green Revolution of the 1970s and 1980s, in which, through the adoption of science and technology, traditional agriculture was transformed into a fastgrowing modern sector that enhanced economic growth and reduced poverty (Christiaensen, Demery \& Kuhl, 2011). For instance, in China, growth that came out of agriculture is estimated to have reduced poverty 3.5 times more than growth generated outside of agriculture- and for Latin America 2.7 times more than other sectors (Dercon, 2009; World Bank, 2008).

Agriculture stimulates economic growth and development in five different ways, according to Johnson and Mellor (1961). Firstly, agricultural is a source of food and agricultural outputs. Secondly, agriculture can serve as a source of foreign exchange, by exporting agricultural 
commodities. Thirdly, it can serve as a means of livelihood and as a safety net for the rural poor. Fourth, it supplies raw materials for the industry and, finally, it can enhance the growth of non-agricultural sectors via increased domestic demand and market for manufactured products.

Kidane et al. (2006) say that, to achieve more direct reduction of poverty and hunger, priority has to be given to economic growth in the sectors in which the poor work, that use factors of production the poor and undernourished possess (mainly unskilled labour), that generate the outputs they consume, and the development of which occurs in the areas where they live which in this case is agriculture. Moreover, the importance of agriculture in fulfilling these criteria has recently been proven in growth strategies followed in countries such as China, India, Vietnam and so on (Pasha, 2002, cited in Kidane et al., 2006)).

The international community acknowledged this fact and adopted the Millennium Development Goals (MDGs) to shift the focus of development initiatives to support poverty reduction away from only economic growth per se. In this manner, the importance of agriculture in poverty reduction was highlighted during the World Food Summit of the FAO in 2002 as "the goal of halving the number of hungry requires that the most food insecure and impoverished countries promote the alleviation of rural poverty, especially through sustained growth of agricultural production, particularly in sub-Saharan Africa" (FAO, 2002, cited in Boussard et al., 2005).

\subsubsection{The rural non-farm sector}

In line with agricultural growth, the role of the non-farm sector cannot be overemphasised in maintaining more equitable income distribution and reducing poverty. The sector has an important role in economic growth, rural employment, poverty reduction, lowering rural urban migration and more equitable income distribution (Haggblade, Hazell \& Reardon, 2010; Lanjouw \& Lanjouw, 2001). According to Haggblade et al. (2010), the rural non-farm sector is more crucial when it comes to women, the landless and near landless households; women account for about a quarter of the total rural non-farm employment in developing countries. This sector also constitutes about $30 \%$ to $90 \%$ of the income of those households with less than 0.5 ha landholding. Moreover, in rural Africa, 35\% to $50 \%$ of the average household income is estimated to be generated from the non-farm sector (Haggblade et al., 2010). Moreover, the linkages and multiplier effect of agricultural growth on non-farm income growth is vital. 


\subsubsection{Impact of food price volatility}

According to the World Bank, because of the food price increase in 2007/2008, around 44 million people living in developing world were driven into poverty (World Bank, 2011, cited in EIU, 2012). The FAO food price index started increasing in 2002 and increased sharply in 2006/2007. Between 2005 and 2008, the global food price increased by 83\% (FAO, 2008b). This crisis posed short-term and medium-term risks to the vulnerable rural poor and urban dwellers of Africa, who could not take advantage from the market opportunity (IFPRI, 2011). However, high food prices could also be an opportunity for increased output and employment in the agricultural sector in the long run (FAO, 2008b).

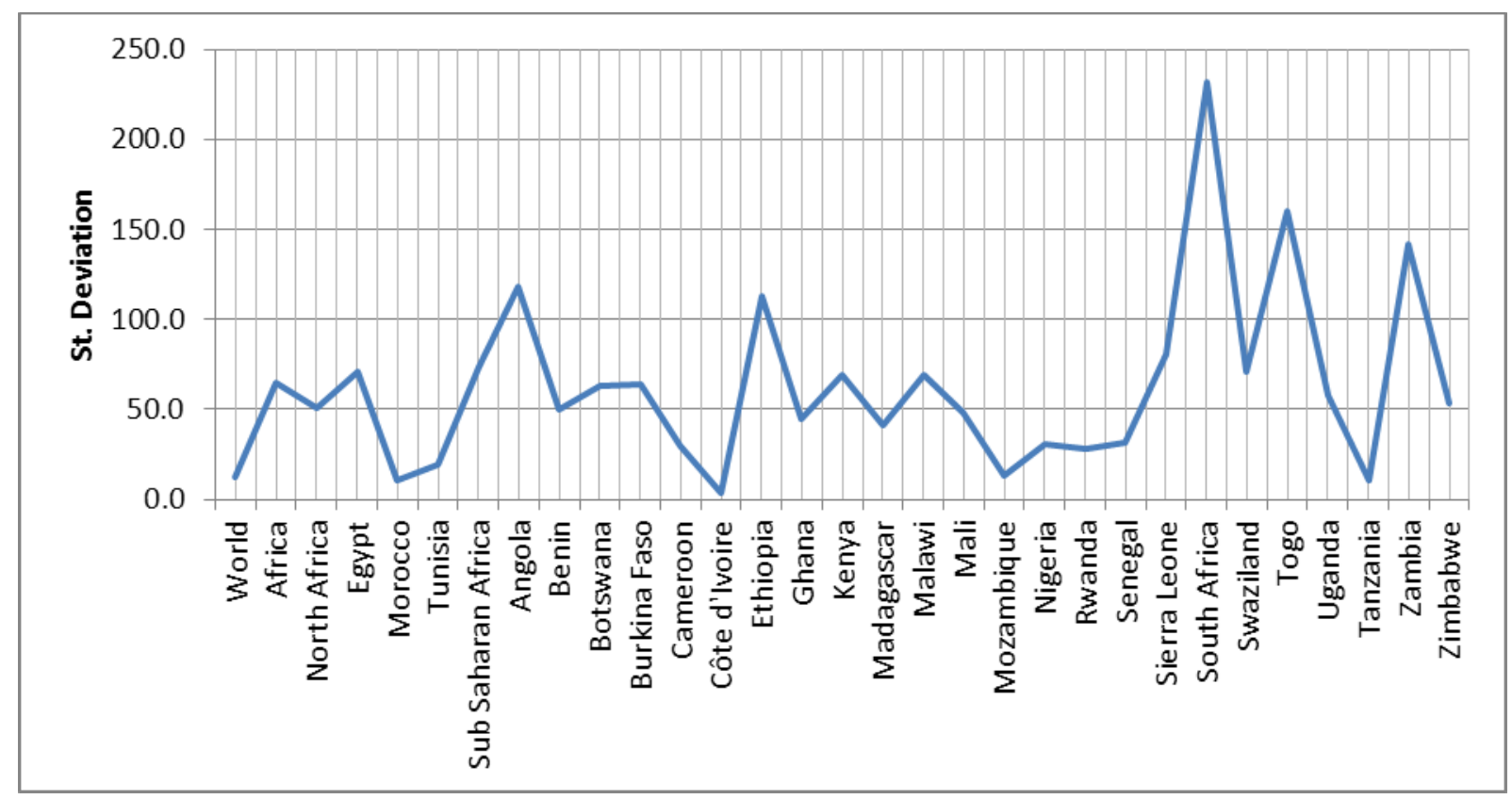

Figure 3.3: Domestic food price variability measured as deviation over the trend of the previous five years (2012)

Source: FAO (2013a)

As shown in Figure 3.3, the local food price variation, measured as standard deviation from the trend over the previous five years, was the highest in SSA compared to the other regions in the world in 2012. While the Northern Africa region showed relatively lower variability compared to other regions in Africa, Egypt particularly showed higher deviation in that subregion. South Africa showed the highest deviation in food price in 2012 to that of the average of previous five years in Africa. Togo, Zambia, Angola and Ethiopia were the countries that showed a significant level of deviation in food prices, which soared in the same year.

Different factors contribute to food price volatility. The FAO (2008) discussed supply-side and demand-side factors that contributed to the 2007/2008 food price spike. Among the supply-side factors, the historically low level of cereal stocks due to a change in agricultural 
policy by the world"s primary cereal-producing countries, which in turn resulted in price volatility due to uncertainties about the sufficiency of supplies, had played a role. The production shortfall due to extreme weather in major cereal producing countries from 2005 to 2007 was another supply-side factor. Beyond that, the increased oil price resulted in a tripled fertiliser price and doubled the cost of transport, which affected the overall cost of production (FAO, 2008b).

The demand surge from biofuel production is the main demand-side factor. By 2007/2008, biofuel production was suing about 100 million tons of cereals $(4.7 \%$ of global cereal production) (FAO, 2008b). According to Karugia et al., (2009), the U.S.A, which supplies $60 \%$ of the worldee s corn, is spending US\$7 billion a year to support biofuel production that consumes 20\% of American corn production. Moreover, it passed a law in December 2007 requiring the use of 15 billion gallons of ethanol by 2015, which is more than double the 2009 value. The European Union (EU) is planning to obtain 10\% of its transport fuel from biofuels by the year 2020 (Evans, 2008, cited in Karugia et al., 2009).

In the light of this there is intense debate on the emergence of biofuels associated with energy security and food security. While biofuel supporters argue that the world see farmers are capable of meeting the world ${ }^{\text {ee }} \mathrm{s}$ cereal demand, their opponents argue that biofuel production is a crime against humanity, taking food away from the poor (Westhoff, 2010). Meanwhile, global biofuel production tripled between 2000 and 2007, and was projected to double again by 2011 (Molony \& Smith, 2010). As a matter of fact, according to a World Bank document leaked to The Guardian newspaper, biofuel production was responsible for $75 \%$ of the increase in food prices between 2002 and 2008 (Molony \& Smith, 2010).

Other demand-side factors such as change in consumption patterns and economic growth in emerging economies can also be responsible for the food price soaring, while cereal import by China and India showed a significant decline from 14 million tons in the 1980s to six million tons in first decade of the $21^{\text {st }}$ century (FAO, 2008b). Linked to the economic growth is that per capita demand for meat and dairy products has been increasing steadily, and has resulted in greater demand for staple grains to supply animal feed. In addition, other factors such as trade policies that exacerbated the above factors and speculative pre-stocking by large importers also had an effect on the food price spike (Westhoff, 2010).

Evidence from poor slum dwellers in Kenya and smallholders in Tajikistan shows that food price spikes and volatility can greatly affect peri-urban poor dwellers and rural poor smallholders (IFPRI, 2011). For the peri-urban poor, the fact that many of them are already 
spending a larger share of their incomes on food leaves them unable to pay for their food, healthcare, housing, education and other needs (Gates, 2012).

For rural poor smallholders, the lack of the means to strategically interact with market dynamics leaves them susceptible to the shocks. This is due to constrained market access resulting from a lack of infrastructure, very low bargaining power, and also due to selling their produce soon after harvest because of a lack of access to storage facilities and to earn income, repay debts, and buy other goods and services (IFPRI, 2011). Moreover, because the majority of them are subsistence farmers, they are precluded from seeing price spikes as opportunities.

The extent to which global prices are transmitted to domestic markets is another important point. Global price transmission can be affected by different factors depending on how domestic markets are integrated to the global markets (Karugia et al., 2009). In the case of a free trade environment between a country and the world market, the global prices and domestic prices will be related directly (Ortiz et al., 2011). This means that the equilibrium price will be maintained in a perfect competition environment, where transportation costs will be the main difference between international and domestic prices. But in the real world, the rate and extent of price transmission is affected by various factors, such as public policies (subsidies, tariffs and non-tariff barriers), exchange rates, consumer preferences and international costs (Ortiz et al., 2011). However, according to Ortiz et al. (2011), local food prices in developing countries follow the global food price index quite closely, with a lag time of roughly three month in 2007/2008, four months in 2009 and one month after the international price escalation in July 2010 (Ortiz et al., 2011).

The extent to which the global food price is transmitted to the domestic food price can be affected by local factors, such as whether the countryees main staple is traded or non-traded, its level of infrastructure, if the country is a net importer of food or not, if the country is landlocked or not, and so on (Karugia et al., 2009). The level of global price transmission to Eastern and Southern Africa (ESA) in 2007/2008 was studied by Karugia et al. (2009). They found diverse outcomes over different countries and various commodities, in which the level of import dependence was the driver of price transmission to domestic markets, since these countries were more import dependent on these commodities of vegetable oil, rice and wheat.

They further analysed two cases of landlocked countries, and whether the commodity was traded or not traded. Accordingly, traded commodities experienced higher prices compared to non-traded commodities. While both landlocked and coastal countries were affected by the 
price increase almost equally, evidence from the analysis showed that domestic policies played a rather significant role in food price escalation. For instance, a non-traded commodity in Ethiopia, teff, experienced a high price increase, which was associated mostly with domestic factors, such as increased demand due to nominal income increase (increase in government expenditure), credit access, an increase in value of export receipt, increased remittances and productive safety net programmes, while all played an important role coupled with an increase in population (Dorosh \& Subran, 2007, cited in Karugia et al., 2009). The increase in fuel price also played an important role in increasing domestic prices through increased transportation costs, while speculative hoarding of commodities by traders exacerbated the situation.

\subsection{Physical access}

According to Kidane et al. (2006), food access can be affected considerably by transaction costs associated with natural and geographical barriers to trade at the national level as well as at the household level. The driving factors of high transaction costs are associated mainly with poor infrastructure, storage and port facilities, coupled with inefficient agricultural marketing institutions. According to Kidane et al. (2006), the ratio of import price referred as CIF (cost, insurance and freight) to FOB (free on board) can provide an idea of how much transport, handling and insurance costs are with respect to the FOB price. In their analysis, which compared the ratios for SSA and Asia in 1980 and 1994, they found that the ratio increased from $11.2 \%$ to $15.7 \%$ for SSA, while it declined from $9.3 \%$ to $8.6 \%$ in Asia (Kidane et al., 2006). Freight costs as percentage of import value are increasing over time in Africa (AfDR, 2010). This implies that, in Africa, the landed price of imported food would be higher than in other regions because of higher freight and port handling costs.

While there is an abundant food supply at the national level in most SSA countries, some rural locations often remain food insecure due to a lack of adequate infrastructure and a lower income level. For instance, while a bumper harvest was experienced in Ethiopia in 2004, at the same time around two million people were declared to be in need of emergency food aid (Kidane et al., 2006). This shows that infrastructural barriers preclude the efficient distribution of food at the national level. They also hinder the potential gain of local producers from exploiting the market demand on the other side of the country, which diminishes their motivation and capacity to produce more in consecutive years due to associated marketing risk. 
Table 3.3: Infrastructure situation in selected countries in Africa

\begin{tabular}{|l|l|l|l|l|l|}
\hline & $\begin{array}{l}\text { Paved roads } \\
\text { over total road } \\
\text { network (\%) }\end{array}$ & $\begin{array}{l}\text { Rail line } \\
\text { density (per } \\
100 \mathrm{sq} \mathrm{km} \text { of } \\
\text { land area) }\end{array}$ & $\begin{array}{l}\text { Road density } \\
\text { (per 100 sq km } \\
\text { of land area) }\end{array}$ & $\begin{array}{l}\text { Electricity } \\
\text { consumption } \\
\text { (kWh per } \\
\text { capita in 2010) }\end{array}$ & $\begin{array}{l}\text { Mobile phone } \\
\text { subscribers (per } \\
100 \text { people in } \\
2012)\end{array}$ \\
\hline DRC & $1.8(2004)$ & $0.16(2009)$ & $6.55(2004)$ & 95 & 28 \\
\hline Egypt & $89.4(2009)$ & $0.52(2009)$ & $10.03(2009)$ & 1,671 & 115 \\
\hline Ethiopia & $13.7(2007)$ & $0.06(1991)$ & $4.02(2007)$ & 54 & 24 \\
\hline Ghana & $12.6(2009)$ & $0.4(2008)$ & $45.91(2009)$ & 298 & 100 \\
\hline Madagascar & $16.3(2010)$ & $0.15(2008)$ & $8.49(2000)$ & $62 *$ & 39 \\
\hline Mozambique & $20.8(2009)$ & $0.39(2009)$ & $3.79(2009)$ & 444 & 33 \\
\hline Nigeria & $15(2004)$ & $0.38(2007)$ & $20.91(2004)$ & 136 & 68 \\
\hline South Africa & $17.3(2001)$ & $1.81(2009)$ & $29.7(2000)$ & 4,803 & 135 \\
\hline Sudan & $36.3(2001)$ & $0.18(2009)$ & $0.47(2000)$ & 141 & 60 \\
\hline Zambia & $22(2001)$ & $0.17(2004)$ & $8.87(2000)$ & 623 & 76 \\
\hline
\end{tabular}

Source: Based on World Bank (2013a) data

*Referred 2009 data

Note: the first, second and third columns consist of the most recent data available in the year in brackets

As shown in Table 3.3, the distribution of basic infrastructures in the case study countries is at a very low level, except in South Africa and Egypt. The road density measured per $100 \mathrm{~km}^{2}$ in SSA was only 7.9 in 2000 , which was much lower than that of Southeast Asia, which was 20.2 by 1999 (World Bank, 2013a). Rail line density is also at a lower level in all the case study countries, except for South Africa, compared to the world average of 0.87 per $100 \mathrm{~km}^{2}$ in 2009. The percentage of paved roads over the total road network is also lower in most of the SSA countries than in Southeast Asia, although the Northern Africa region generally has a better status of around 73.9\% (World Bank, 2013a).

While the lack of infrastructure and low level of productivity have precluded Africae s rural poor from harnessing the potential of an increase in productivity, improvements in infrastructure, especially adequate energy and water/irrigation supplies, high-speed communications and seamless transportation, can greatly improve food security (AfDB, 2012). Since agricultural resources are unevenly distributed across national as well as subregional territories in Africa, the enhancement of modern infrastructure, such as transportation, telecommunications and energy, can provide cheaper, long-distance product movement and better regional commercialisation, as well as regional integration (AfDB, 2012). 


\subsection{Political access}

Political factors often referred to as a "food war" arise from the situation in which governments deliberately use the available food as a political tool or weapon to starve their opponents into submission by constraining access to food, natural resources or means of livelihood (De Rose et al., 1998). There could be both international and national vested interests for politicians to use food as an instrument (Kroef, 1995). For instance, during the Sudanese civil war in the 1980s, the government allegedly used food as a weapon to subdue rebels in the south-western part of the country (Kroef, 1995). One foreign donor also claimed to have used food aid as a strategy in overthrowing the Ethiopian government in the civil war in the 1980s (Shepherd, 1993, cited in Kidane et al., 2006).

This approach can also include repressive measures and government policies intended to restrict access to productive resources, as well as to income, as in the case of forced resettlement plans or the adoption of discriminatory legal frameworks or social practices (De Rose et al., 1998). Armed conflict is the main cause of food shortage, due to its devastating impact on existing food systems. For instance, as a result of conflict in 2004, more than 45 million people in developing countries were in need of emergency humanitarian assistance, $80 \%$ of which were in sub-Saharan Africa (Messer \& Cohen, 2004).

Verwimp (2012) illustrated how violent conflict can affect the command of food in an average farm household. Accordingly, the income sources of farm households, viz. production for own consumption, crop sales, livestock production, off-farm income and transfers received from other sources, are all affected by violent conflict. A study by IFPRI on the impact of violent conflict on food production also showed a reduction of an average $12.3 \%$ in over 13 case study countries during war years (IFPRI, 1998; cited in Verwimp, 2012). This, in turn, pushes food prices up, which might lead to famine if infrastructure and marketing are affected by the conflict, especially in remote areas.

On the other hand, soaring food prices and hyperinflation trigger food riots and violence, as was witnessed after the food price spike in 2007/2008, which gave rise to more than 25 demonstrations, marches and rallies in different countries (Bush, 2010). Historical evidence also supports the link between food price volatility and violence, as in the case of the food price spike that stimulated the French revolution, and the falling of coffee prices coupled with widespread unemployment presumed to be linked to the Rwandan genocide (Messer \& Cohen, 2008, cited in Messer \& Cohen, 2011). It can therefore be concluded that, violent conflict and hunger are somehow interrelated to one another. 
Corruption, which is the "sale of government property for private gain" (Aidt, 2009), is the other political factor that can significantly affect food access and overall national food security. It adversely affects social and economic development, distorts market operation, increases income inequality, and deprives ordinary citizens of their right to access basic services. A study by Mo (2001) showed that a $1 \%$ increase in corruption reduces economic growth by about $0.72 \%$. Also, the impact of corruption is significant in inhibiting economic growth as it results in political instability and a reduced level of human capital and share of private investment (Mo, 2001).

While there is general consensus that corruption can distort efficient resource allocation and economic growth, there are arguments in favour of corruption for economic growth (Aidt, 2009). For instance, Leff (1964), cited in Aidt (2009) argued that bribery might help overcome bureaucratic rules and regulations that hinder economic activity by enhancing quicker decision making, and especially might help facilitate beneficial trade that would otherwise not have taken place.

In the light of this, De Vaal and Ebben (2011) identified the direct effect of corruption, which is a reduction of economic growth through the misallocation of resources, and its indirect effect on the institutional framework, which might affect economic growth positively. Accordingly, the impact of corruption on the three main determinant factors of growth, namely political stability, property rights and political system, have been analysed empirically. The authors concluded that only when political stability or the protection of property rights is above some threshold value, will corruption affect these institutions negatively, thereby hindering economic growth (De Vaal \& Ebben, 2011). Aidt (2009) argued that "undisputed, but isolated, instances of efficiency-enhancing corruption at the microeconomic level cannot be taken as evidence that corruption can be efficiency-enhancing at the macroeconomic level".

As shown in Figure 3.10, of the countries analysed, Ghana was in a relatively better position in terms of its rate of transparency, accountability and corruption level. On the other hand, low levels of these parameters were observed in Zimbabwe and Sudan in particular. It also can be seen from the figure that there is progress in this respect in most countries in SSA. According to the EIU's 2013 update of the global food security index, thirteen countries in SSA are regarded as having the highest risk of corruption of 28 countries studied (EIU, 2013). On the other hand, Botswana is ranked as having the lowest risk of corruption in SSA, followed by Ghana, Madagascar, Rwanda and South Africa (World Bank, 2013a). 


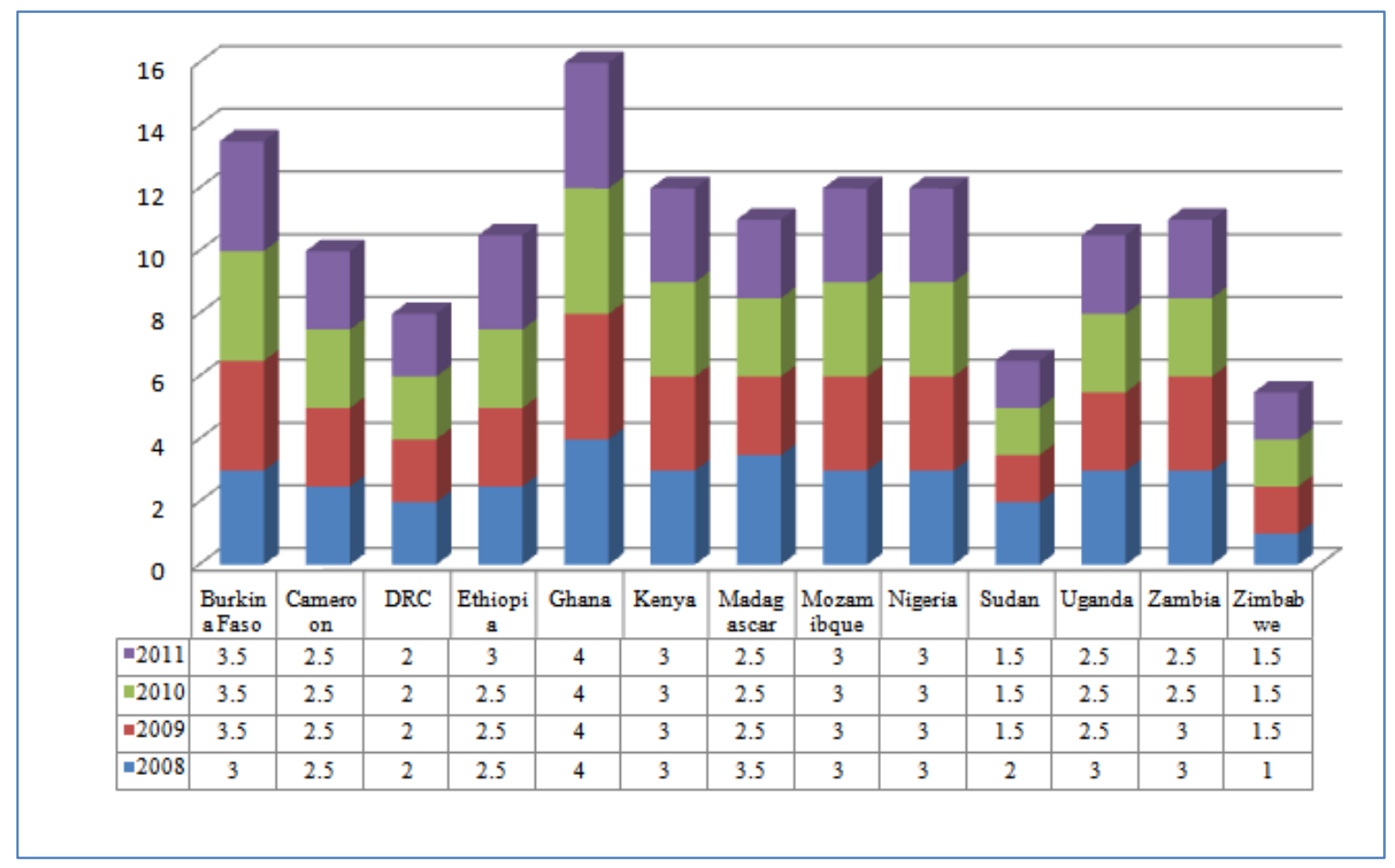

Figure 3.4: The rate of transparency, accountability and corruption in the public sector ( $1=$ low to $6=$ high)

Source: Based on World Bank (2013a) data

\subsection{Sociocultural factors}

While women in developing countries are responsible for around $80 \%$ of food production (Ivers \& Cullen, 2011), they are at greater risk of hunger and food insecurity than men. This is due to the discrimination they often encounter with respect to accessing resources such as land, credit and agricultural inputs and services (UN Women, 2011-2013). Women represent about $70 \%$ of the world ${ }^{\text {ee }}$ s poor and are highly vulnerable to social, economic and political marginalisation, with a limited role in decision making (UN Women, 2011-2013). A study in rural Bangladesh showed that, compared to women, men have more choices of jobs that do not require a higher level of education, which implies that female-headed households are more likely to be food insecure than male-headed households (Rahman \& Karim, 2013).

Studies have also shown that household welfare and food security depend not only on the level of income, but also who earns the income. It has been found that women have a higher tendency than men to spend their income on food for the family, and also on the betterment of children's health and nutritional situation (Quisumbing et al., 1995). Therefore, women"s education and empowerment should be a priority in rural development and food security policies and strategies.

Beyond this, intra-household food distribution is also affected by sociocultural factors such as gender bias and the social and cultural marginalisation of certain individuals and groups 
(Kidane et al., 2006). An empirical study on the relationship between household and adolescent food insecurity in South-western Ethiopia showed that $41 \%$ of girls were found to be food insecure compared to $20 \%$ of boys in households facing equally severe food insecurity (Hadley et al., 2008).

\subsection{Issues regarding food accessibility}

\subsubsection{Supermarkets and food access}

The other important role player in food availability, accessibility and utilisation is the rise and expansion of supermarkets. Reardon et al. (2005) identified three waves in the spread of supermarkets through the developing world. The first wave was from the early to mid-1990s, from mainstream retailing in South America, East Asia (excluding China and Japan), Northern-Central Europe and South Africa. The second wave started from the mid- to late1990s in Southeast Asia and Central America, Mexico, and Southern-Central Europe. The third wave started in the late 1990s and early 2000s in some countries in Central and South America, Southeast Asia, China, India, Russia and Africa, mainly in Eastern and Southern Africa (excluding South Africa) (Reardon et al., 2005). There is late third and even fourth wave, which has recently started mainly in South Asia and parts of Africa, such as Madagascar (Minten \& Reardon, 2008). The modern food retail sector (supermarkets) is characterised by its fast diffusion. In the early 1990s it had a small share of $5 \%$ to $10 \%$ of the overall food retailing, but this grew to more than $50 \%$ by the mid-2000s in the first-wave countries. Also, while it started in the mid- to late-1990s in the second-wave countries, it reached a $30 \%$ to $50 \%$ share by the mid-2000s (Reardon, 2011).

The most recent venue for supermarket diffusion is Africa, more specifically Southern and Eastern Africa (Reardon et al., 2003). Comprising about 55\% of overall food retailing and 1700 supermarkets, South African supermarkets were the first in Africa and grew rapidly after the end of apartheid in 1994 (Reardon et al., 2003). Around 90\% to 94.5\% of the modern retailing sector in South Africa is held by four big retailers (Pick n Pay, Shoprite, Spar and Woolworths), with a share of about $52 \%$ of the food retailing sector (Weatherspoon \& Reardon, 2003). The modern retailing sectors of South Africa have already diffused into Zimbabwe, Zambia, Namibia, Botswana, Swaziland, Madagascar, Mauritius, Angola, Mozambique, Kenya, Uganda, Tanzania, Ghana, Nigeria and the DRC (Reardon et al., 2003).

Tandon et al. (2011) studied the main drivers of the rapid expansion of supermarkets in relation to two factors, namely price decrease as a result of efficiency gain by supermarkets, 
and an increase in demand by consumers for non-price factors such as convenience and highquality goods. They found that growth in demand for non-food parameters has more of an impact on the expansion of supermarkets. Reardon (2006) discussed some of the demand-side factors that drive the expansion of supermarkets - the rise in real mean per capita income, lower price of processed products due to economies of scale of supermarkets, increasing consumer ownership of refrigerators and cars, and public transport have all played an important role, spurred by demand incentives such as urbanisation. On the supply side, the five- to tenfold growth in FDI in the 1990s, and growth in retail procurement logistics technology and inventory management, as well as the use of computers and the Internet for inventory control, are important factors (Reardon, 2006).

As a result, Reardon (2011) says that, through their evolution, supermarkets rolled out from large cities to small ones, from upper to middle to poorer classes, from processed to semiprocessed to fresh produce, and from domestic local chains to multi-nationalised sectors. In addition, their procurement processes were also transformed from spot wholesale markets with few standards, to direct sourcing from preferred wholesalers, food companies, cooperatives or farmers with higher standards (Reardon, 2006).

The emergence of modern retailers is also accompanied by the need to meet the increasing demand for safety, health, nutritional, environmental and labour concerns of consumers and buyers, while incurring the lowest possible transaction costs (Reardon 2006, 2011). This, in turn, demands a reduction in production and transaction costs by retailers, through effective coordination and logistics systems. Often, supermarkets impose private safety and quality standards, which reduce their transaction cost (Reardon, 2006). Since consumers in rich countries are increasingly willing to pay for differentiated and convenient products, retailing companies are striving to fulfil consumerse demands, while imposing even more stringent quality and safety standards on producers and suppliers (Reardon et al., 2005).

In this respect, supermarkets are often shifting away from dealing with many small-scale producers to a few big producers and suppliers that can satisfy their requirements and standards at the lowest possible transaction cost (Heijden \& Vink, 2013; Reardon, 2006). This leads to an increase in the scale and volume of procurement, which tends to promote big suppliers that can meet these requirements, with sufficient new investments in capital, technology and management (Reardon \& Berdegue, 2002). As a result, small farmers increasingly face challenges in accessing the market due to market failures and an increasing demand for specified quality and safety standards of production and processing, coupled with 
their primitive production systems and management efficiency (Reardon \& Berdegue, 2002; Reardon et al., 2005).

Hayes (2000, cited in Reardon et al., 2005) listed the types of transaction costs agribusinesses incur when dealing with small farmers:

- The bureaucratic costs incurred by managing and coordinating integrated production, processing and marketing

- The opportunity cost of time used to communicate with farmers and coordinate with them

- The costs involved in establishing and monitoring long-term contracts

- The screening costs linked to uncertainties about the reliability of potential suppliers or buyers, and uncertainty about the actual quality of the goods

- The transfer costs associated with the legal or physical constraints on the movement and transfer of goods, including handling and storage costs, transport costs, etc.

On the other hand, supermarkets have a significant role to play in addressing the consumer market and rising urban and middle class market demand (Reardon \& Berdegue, 2002). Minten and Reardon (2008) empirically studied whether supermarkets actually offer highquality products and charge lower prices compared to traditional markets. They found that supermarkets offer processed products at a lower price than the best traditional retailers, taking advantage of a procurement system that allows economies of scale. Also, at the early stage, supermarkets were found to charge a higher price for fruit and vegetables, and slowly to offer a competitive price. They also found that supermarkets initially focus on high-quality packaged products with a higher price, and eventually tend to offer different quality products to include the mass market. There also is a difference in quality and price, while better quality products at lower prices are sometimes found (Minten \& Reardon, 2008).

A study by Hausman and Leibtag (2007) also found that, in the U.S.A. Wal-Mart on average offers a price that is $15 \%$ to $25 \%$ lower than that of traditional supermarkets. According to their study, the entry of Wal-Mart and other supercentres into new geographical regions results in direct price reduction and indirectly helps traditional supermarkets to reduce their prices as a result of competition, which encourages lower income households to shop at these lower priced outlets (Hausman \& Leibtag, 2007). Minten, Reardon and Sutradhar (2010) also studied the impact of the rise of modern food retailers on food prices for consumers, taking Delhi as a case study. They found that the emergence of modern retails offered more labelled and branded food products and more choice than traditional markets (Minten et al., 2010). 
This also provides basic foods at similar or lower prices than that found in traditional retail (Minten et al., 2010).

D'Haese and Van Huylenbroeck (2005) investigated the impact of the expansion of supermarkets on two villages in the Transkei area in rural South Africa. Their study was based on the hypothesis that supermarkets offer cheaper food, which can reduce local demand as it restricts the potential of local growers. Accordingly, while South African supermarkets are supplied by large commercial farms, larger groups of households go shopping outside of the village, mostly at supermarkets in the nearest centre. As a result, local growers are challenged both by supplying their produce to supermarkets (because of private standards and quality issues) and losing local demand for their produce as local consumers are increasingly attracted to supermarkets (D'Haese \& Van Huylenbroeck, 2005). This could offer an opportunity by supplying quality food at low prices, which may help to invest household labour in other forms of income generation apart from production. But this is unlikely with the prevalence of weak production capacity and trade deficiency, which hinder locals from harnessing this potential. The presence of supermarkets also precludes the multiplier effect, as households spend their money in supermarkets, outside the local economy (D'Haese \& Van Huylenbroeck, 2005).

In conclusion, supermarkets positively affect food access, at least for the relatively better-off consumers in urban areas, as well as for the rural poor who are net food buyers in developing countries, by providing cheaper and better quality products (Arda, 2006). Also, small farmers and suppliers can use the advantage of supermarket to reduce transaction costs and cope with market failures through contractual arrangements (Reardon \& Berdegue, 2002). On the other hand, supermarkets ${ }^{e e}$ increasing demand for stringent quality and safety standards has a negative effect especially on small-scale producers. These smaller and poorer producers are often challenged in two ways: first, they lose local demand for their produce because of consumers $^{\text {ee }}$ tendency to buy in supermarkets. This can also negatively affect rural development, as rural income is spent outside of the village, thereby reducing the would-be multiplier effect. Secondly, they often fail to exploit this new trading opportunity to supply their produce to supermarkets due to their smaller capacity and the stringent quality and safety standards set by modern retailers (Heijden \& Vink, 2013; Weatherspoon \& Reardon, 2003). Therefore, unless there is institutional support or appropriate policy and strategies in place, the future of small farmers is in danger, in line with the rapid expansion of supermarkets. According to Reardon et al. (2003:1146), "supermarketse procurement system is setting the 
„nule of the game ${ }^{e e}$ therefore it is important to understand „market oriented ${ }^{\text {ee }}$ policy means „supermarket oriented ${ }^{\text {ee }}$, as a few supermarkets command the entire chain”.

\subsubsection{Social protection and safety nets}

The role of social protection and safety nets in buffering against food insecurity, especially for those who are vulnerable, cannot be overstated. The essence of safety nets is the provision of equity and efficiency (Alderman \& Hoddinott, 2007). While the poor in most of SSA remain largely susceptible to food production and accessibility shocks, coupled with their high level of poverty and tendency to allocate a large proportion of their income to food, the advantage of social protection and safety nets remain vital. Social protection is defined as:

A specific set of actions to address the vulnerability of people se life through social insurance, offering protection against risk and adversity throughout life; through social assistance, offering payments and in kind transfers to support and enable the poor; and through inclusion efforts that enhance the capability of the marginalized to access social insurance and assistance (European Communities, 2010:1; cited in Devereux, 2012:1)

According to Devereux (2012), this definition has three components: social assistance (protection against poverty), social insurance (protection against vulnerability), and social justice and inclusion (reduction of social risks such as discrimination or abuse). He argues that food security can be enhanced by social protection through income stabilisation, raising income and promoting social justice. Income stabilisation can be maintained by agricultural insurance, offering temporary employment in public work programmes, giving food aid or cash transfers to targeted individuals, by providing employment guarantees, and by managing food supplies through strategic grain reserves (Devereux, 2012).

Effective social protection interventions can raise income and create assets, especially in rural Africa, through the promotion of small-scale farmers, the non-farm sector and the landless poor (Alderman \& Hoddinott, 2007; Devereux, 2012). While there is a positive synergy between agricultural promotions and social protection, the role of social protection in promoting agricultural growth and poverty reduction is more vital (Devereux, 2012). Carefully designed social protection schemes can reduce seasonal hunger, increase farm income (which gives rise to better nutrition and stabilises agricultural yield) and also, through weather-indexed insurance, promote farmers ${ }^{\text {ee }}$ risk-taking behaviours, such as adopting high yield varieties (Devereux, 2012; Ethiopian Government, 2009). 
Social protection can also be designed effectively to include agricultural input subsidies, inputs for work and inputs for trade fairs, as well as interventions that enhance public works projects that construct roads that link markets and reduce transaction costs (Ethiopian Government, 2009). In this regard, social protection should be well designed, as public work must not attract farm labour in a way that compromises farming, food aid should not discourage local production and trade, and cash transfers should not be introduced where markets are weak, since this might lead to inflation (Devereux, 2012; Ethiopian Government, 2009).

The social justice aspect of social protection can be implemented by examining and tackling the main social and political causes of the marginalisation and exclusion of the poor and vulnerable (Devereux, 2012). Accordingly, addressing these fundamental issues is even more effective and sustainable than dealing with technical issues such as input subsidy and food aid. As a result Devereux (2012) identified a rights-based approach, consisting of permanent programmes such as those implemented by government rather than external donor projects, hence based on rights and a social contract. Although it is sometimes exposed to local elites and powerful groups in the village, community-based targeting is more effective in identifying more vulnerable communities in a socially just manner. Social audits are another mechanism for effective implementation of the rights-based approach and providing improved service delivery and good governance (Devereux, 2012).

The effectiveness of social protection for poverty reduction and food security in rural Africa has been demonstrated in the Productive Safety Net Programme (PSNP) in Ethiopia (Ethiopian Government, 2009). The programme was launched in 2005 on a large scale with an estimated budget of 500 million USD, comprising around one million participants selected through geographic and community targeting (Gilligan et al., 2009). As of April 2009, around 56895 households had graduated from the programme upon sizable improvements in asset holding and food availability (Ethiopian Government, 2009). The programme mostly uses public work schemes, such as paying beneficiaries 10 birr $^{8} /$ day or three kilograms of cereal for work on labour-intensive projects to build community assets during January and June of each year, so that the project does not interfere with farming activities (Ethiopian Government, 2009). While a small proportion of beneficiaries (the elderly or disabled) get direct support, the programme has been complemented by agricultural productivity enhancement services, such as access to credit, extension services, technology transfer and irrigation and water harvesting schemes (Gilligan et al., 2009).

\footnotetext{
${ }^{8} 1$ USD = approximately 18 birr
} 


\subsection{Summary}

Amartya Senes (1981) entitlement approach was the first to introduce the concept of food accessibility in the early 1980s by claiming that it was as important as food availability in determining food security. According to Sen ${ }^{\text {ee }}$ analysis, a person would go hungry as a result of direct entitlement failure, which is production failure or endowment loss. Equally, a person could starve as a result of trade entitlement failure, which is failure to exchange his endowed assets or produce for food. Moreover, his capability theory argues that different people and societies typically differ in their capacity to convert income and commodities into valuable achievements (including access to food) (Clark, 2005). For example, a disabled person may need extra resources to function as an able-bodied person (wheel chairs, ramps, lifts, etc.).

In the light of this, this section investigated the food accessibility situation of Africa by identifying economic, physical, political and sociocultural factors. In the economic accessibility analysis, the DRC was found to have the lowest HDI level of the case study countries, while Egypt had the highest. In terms of GDP per capita growth rate in the year 2012, Ethiopia (5.7\%) recorded the highest growth rate, followed by Ghana $(5.6 \%)$ and Mozambique (4.6\%). The lowest GDP per capita growth rate was recorded in Madagascar $(0.3 \%)$

The study also comparatively analysed the impact of economic growth on poverty reduction and income distribution over a specific time period in the case study countries. The result revealed that economic growth in non-oil-exporting (resource poor) countries was more effective in poverty reduction and income distribution. This could be a result of agricultureled economic growth, which has a relatively better effect in addressing poverty. The later sections also elaborated the theoretical and empirical justifications for the effectiveness of agriculture-led economic growth in fighting poverty and maintaining food security in the context of Africa.

The rural non-farm sector is the other important economic activity that enhances economic growth, rural employment and poverty reduction, lowers rural-urban migration and ensures more equitable income distribution (Haggblade et al., 2010; Lanjouw \& Lanjouw, 2001). It has been found to be more crucial when it comes to women, the landless and near landless households. It also constitutes about $30 \%$ to $90 \%$ of the income of those households with less than 0.5 ha landholding. Moreover, in rural Africa, $35 \%$ to $50 \%$ of the average household income is estimated to be generated by the non-farm sector (Haggblade et al., 2010). 
Although global food and agricultural price increases could be a market opportunity for the predominantly agrarian economies of Africa in the long term, when it comes to short-term food accessibility, these price increases have been found to be a big challenge. While different supply-side factors are responsible for the $2007 / 2008$ food price spike, the demand surge from biofuels production is identified as the main demand-side factor. In this respect, while a detailed investigation of global price transmission to the domestic market in Africa is important, generally factors such as level of integration of domestic economy with the global market is one factor. Other factors are whether the commodity is traded or non-traded, the level of infrastructure, whether the country is a net importer of food or not, and whether is landlocked or not (Karugia et al., 2009).

The physical accessibility analysis showed that, comparatively, most of SSA countries have a low level of infrastructure, which significantly increases transaction costs. While the lack of infrastructure, coupled with the low level of productivity, precluded Africa ${ }^{\text {ee }}$ s rural poor from harnessing the potential of an increase in productivity, improvements in infrastructure, especially in adequate energy and water/irrigation supplies, high-speed communications and seamless transport, can greatly improve food security (AfDB, 2012).

The political access analysis revealed that, in times of war and civil strife, politicians could use food access as a weapon to carry out their interests. This could include repressive measures and government policies intended to restrict access to productive resources and income, as in the case of forced resettlement plans or the adoption of discriminatory legal frameworks or social practices (De Rose et al., 1998). The analysis also showed that conflict and civil unrest could exacerbate food insecurity and vice versa. While there is an argument that corruption can enhance economic growth, empirical studies have shown that it has a negative effect on economic growth. In terms of transparency, accountability and corruption, Zimbabwe and Sudan recorded the lowest levels, while Ghana performed best in these indicators.

Sociocultural factors, such as gender-biased allocation of resources and intra-household food accessibility, are also important factors of food security. Women are highly vulnerable to food insecurity because of social and cultural trends. This is due to the discrimination they often encounter with respect to accessing resources such as land, credit and agricultural inputs and services (UN Women, 2011-2013).

The last section of this chapter discussed some of the issues relating to food accessibility, such as the rise and expansion of supermarkets and the concept of social protection and safety 
nets. The rise of supermarkets and large-scale modern retailing industries have had a positive impact on the physical as well as economic accessibility of food, especially in urban and periurban areas, by supplying cheap and high-quality products. However, the rise of supermarkets has also put intense pressure on the livelihoods and survival of small-scale farmers. The importance of safety nets and social protection were highlighted in terms of buffering against food supply and accessibility shocks, and building the capabilities of the vulnerable and marginalised groups in society. Effective social protection interventions can raise income and create assets, especially in rural Africa, through the promotion of small-scale farmers, the nonfarm sector and the landless poor (Alderman \& Hoddinott, 2007; Devereux, 2012). 


\section{Chapter Four}

\section{Analysis of food utilisation}

\subsection{Introduction}

Food utilisation is one of the three main dimensions of food security. Although food availability and accessibility are necessary, if there is a failure in food utilisation there is still a possibility for an individual to be food insecure (Fanzo, 2012). It is a concept usually associated with nutritional security, which can be viewed as perspectives of food quality and safety (EIU, 2010; Gross et al., 2000). Food quality refers to the nutritional standards and dietary micronutrient availability of food, whereas food safety represents the non-food parameters, such as access to clean water, health, education and sanitation (Fanzo, 2012).

The concept of undernutrition goes beyond the concept of undernourishment (lower caloric food intake) to deficiency in one or all of the micronutrients, such as protein, essential vitamins and minerals (IFPRI, 2012). Benson (2004) also argued that nutritional security is maintained when secure food access is accommodated, along with sufficient health services, a sanitary environment and knowledgeable care to assure a healthy and active life for all household members.

In this respect, nutritional security is a critical factor that determines an individuale $\mathrm{s}$ ability to reach his or her physical, economic and cognitive potential and sustain health over the ageing process (Benson, 2004; Pinstrup-Andersen, 2012). For Pinstrup-Andersen (2012), the end result of the overall food system is health and nutrition. Moreover, while change in any part of the food system could affect health and nutrition, the impact could also be the other way round. For instance, energy and nutritional deficiency, obesity or chronic diseases might affect the food system via reduced labour productivity, adoption of technology, use of input and credit, and overall underutilisation of natural resources (Pinstrup-Andersen, 2012). How society is organised in terms of economic structure, political and ideological expectations, and its institutions, can also determine nutritional availability and access (Benson, 2004).

The objective of nutritional security, however, is affected by both under- and overnutrition, which are characterised by increased malnutrition, micronutrient deficiency, stunting, obesity and so on. Therefore, food utilisation necessarily goes beyond the concept of food availability and food accessibility, to the type of food that is available and accessible and how it is being utilised. This concept, in turn, can be divided into both food and other non-food parameters, which are equally important. 
This section starts by investigating the basic indicators of food utilisation. It then assesses Africaes nutritional situation by investigating child malnutrition, micronutrient malnutrition and other, non-food parameters such as improved water and sanitation access. After that the role of agriculture and the value chain in nutrition will be discussed. Nutritional intervention strategies and the concept of bio-fortification will lead to the final summary.

\subsection{Indicators of food utilisation}

Sen 's capability approach, which is elaborated on by Dreze and Sen (1989), is the best framework for explaining the concept of food utilisation and nutritional security (Burchi \& De Muro, 2012). According to Dreze and Sen (1989), this approach can provide the framework for nutritional security by focusing beyond the achievement of a certain level of income or caloric intake on overall health and wellbeing. Moreover, it allows for dealing with individuals or groups disadvantaged for biological or social reasons. This is particularly true because the conversion of personal income, resources and commodities into wellbeing and freedom depends crucially on a number of contingent personal and social factors (Dreze \& Sen, 1989). There are also other important factors, such as health care and medical facilities, clean drinking water, sanitation, eradication of infectious epidemics and basic education that are complementary parameters of individual wellbeing and food security (Burchi \& De Muro, 2012).

The underweight indicator is the other most common measure of child malnutrition, which is the proportion of children under the age of five years who are less than negative 2 standard deviation (for moderate and severe) and less than negative 3 (for severe) from the median weight for the age of the benchmark population (Fanzo, 2012). The prevalence of stunting (height for age below $-2 \mathrm{SD})^{9}$ could be the best indicator of malnutrition, as it results from overall long-term social, physical and economic deprivation, leading to dietary deficiencies and exposure to infectious diseases (Headey, 2012). Wasting (weight for height below -2 SD) and overweight (weight for height above $+2 \mathrm{SD}$ ) are other main indicators of child malnutrition (WHO, 2012).

The WHO uses all four child malnutrition indicators, namely stunting, underweight, wasting and overweight in determining child malnutrition under the age of five (WHO, 2012). In its Global Hunger Index (GHI), the International Food Policy Research Institute (IFPRI) uses three equally weighted indicators, which are percentage of population undernourished, proportion of children underweight younger than age five, and mortality of children younger

\footnotetext{
${ }^{9} \mathrm{SD}$ refers to standard deviation.
} 
than age five (as partial indicator of inadequate caloric intake and unhealthy environments) (IFPRI, 2012).

International initiatives such as the Millennium Development Goals (MDGs) also adopted objectives that are directly and indirectly associated with nutritional security. For instance, child malnutrition measured by child stunting and undernutrition has been used as an indicator of progress in achieving the MDGs in the World Health Organization report (De Onis et al., 2004).

The Economist Intelligence Unit, on the other hand, used quality and safety indicators of diet diversification, nutritional standards, micronutrient availability, protein quality and food safety as indicators of food utilisation. Moreover, the prevalence of undernourishment, the percentage of children stunted and the percentage of children underweight have been used as background parameters. Accordingly, micronutrient availability, protein quality, diet diversification, food safety and nutritional standards have been weighted at $25.4 \%, 23.7 \%$, $20.3 \%, 16.9 \%$ and $13.6 \%$ respectively (EIU, 2012). In this research, the performance of nutritional security in Africa is assessed based on the indicators of child malnutrition, micronutrient availability and food safety over the selected countries by incorporating the rankings of the EIU and other indexes.

\subsection{Assessment of African nutritional security}

According to the EIU's global food security index world ranking, the SSA region is ranked $11^{\text {th }}$ out of 12 regions included in the study. However, the region performed the best of all the regions in the world on the indicator of dietary availability of vegetal iron. It also performed well in terms of national nutrition plan or strategy, which measures if a government has published a strategy to improve nutrition at the national level. The ranking of 28 sub-Saharan Africa countries in terms of food quality and safety is depicted in Figure 4.1. 


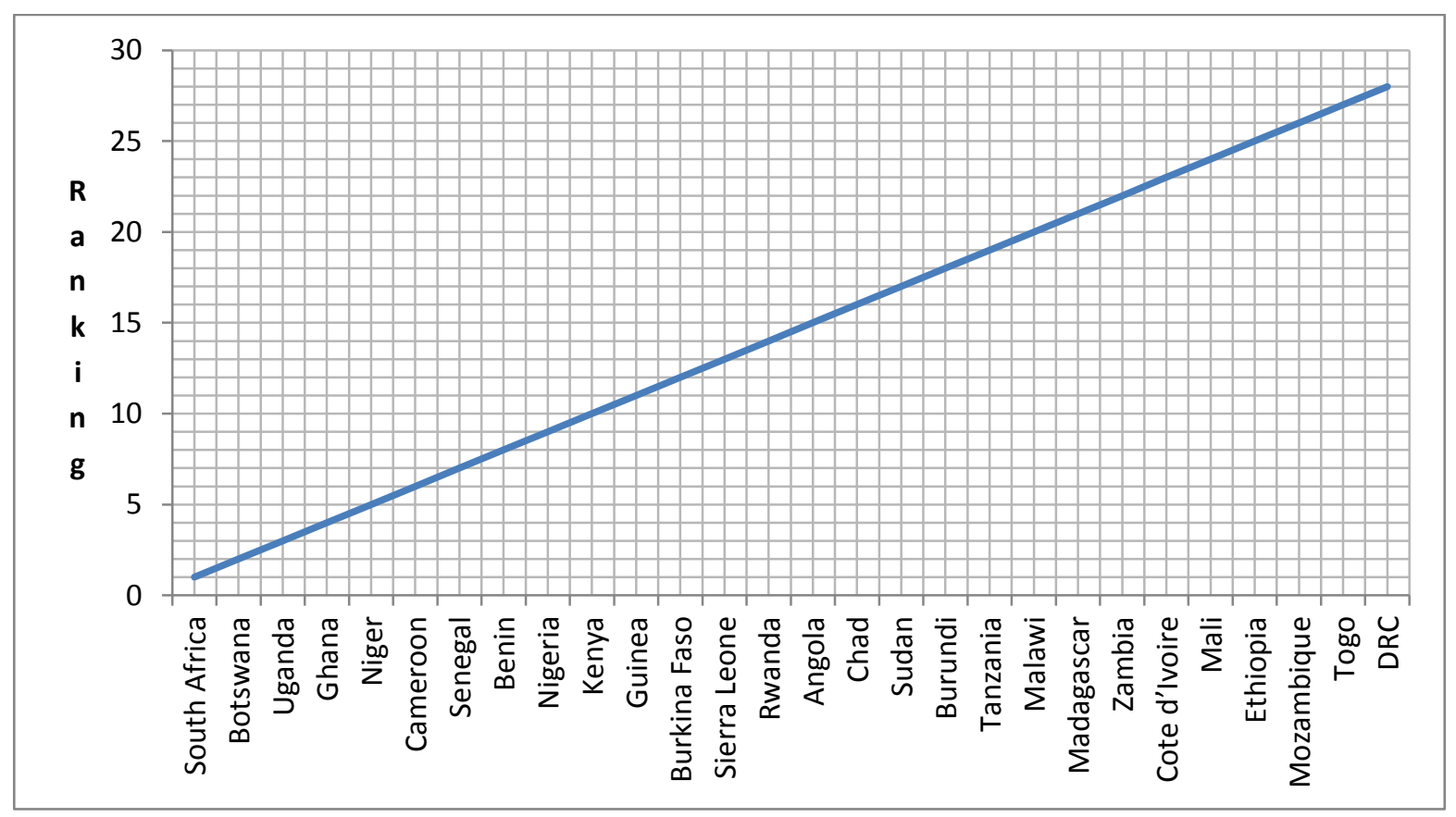

Figure 4.1: Food quality and safety ranking of SSA countries

Source: Based on EIU (2013)

According to the EIU (2013) food security ranking, most of the sub-Saharan Africa countries are at the bottom end of the index in terms of food quality and safety. Among the countries analysed in SSA, South Africa, Botswana and Uganda are ranked as the top three in the region, while Ethiopia, Mozambique, Togo and the DRC are ranked at the bottom end of the index (see Figure 4.1). In terms of utilisation, South Africa performed better than any country in Africa. Some countries, like Uganda, performed the best in the region in indicators such as diet diversification. Also, in some indicators such as dietary availability of vegetal iron, all the top ten countries in the world are in Africa, except for Greece, which is ranked $7^{\text {th }}$ (EIU, 2013). The performance of the case study countries in terms of food quality and safety ranking of the EIU is illustrated in Figure 4.2. 


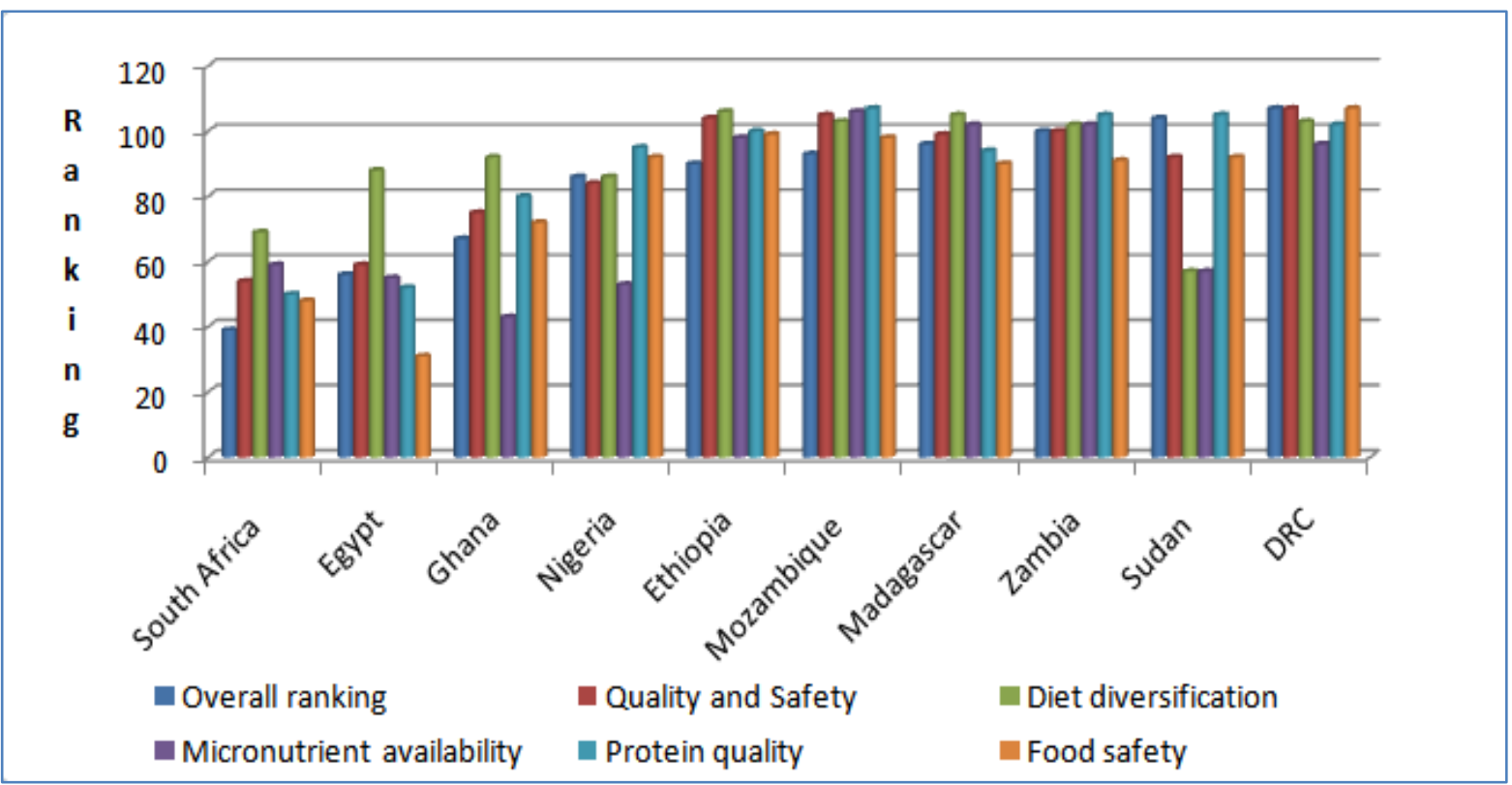

Figure 4.2: World ranking of food quality and safety over the case study countries

Source: Constructed Based on EIU (2013)

Note that the lower the number, the higher the rank of the specific country

As a result, the burden of malnutrition, especially in poor countries such as those in Africa, is very significant. In this regard, "The cost of hunger in Africa", a project led by the African Union and supported by the UN Economic Commission for Africa (ECA) and the World Food Programme (WFP), is concerned with estimating the economic and social costs of child undernutrition in Africa (AU, 2013). The project selected four pilot countries, namely Egypt, Ethiopia, Uganda and Swaziland, for its initial study. All the countries except Swaziland have already released their reports (AU, 2013).

According to the released reports, child undernutrition costs an estimated $16.5 \%$ of Ethiopia $\mathrm{s}$ GDP, $5.6 \%$ of Ugandaes GDP, and 1.9\% of Egyptes GDP. About 28\%, 15\% and 11\% of child mortality in Ethiopia, Uganda, and Egypt respectively is linked to undernutrition. Repeating years in primary schools associated with stunting is estimated to be $16 \%$ in Ethiopia, $10 \%$ in Egypt and 7\% in Uganda. Also, 44\% of the health cost in Ethiopia and Uganda, and 51\% in Egypt is devoted to causes related to undernutrition until a child turns one year old. Child mortality coupled with undernutrition reduced around $8 \%, 4 \%$ and $1 \%$ of the workforce in Ethiopia, Uganda and Egypt respectively (AU, 2013).

Moreover, according to IFPRI (2004:1, cited in Benson, 2004:3), the impact of malnutrition can be perpetuated in future generations and can cause routine effects: 
A girl born to a mother that is undernourished will likely be born stunted in height and low in weight, even at full term. If the infant survives, her growth will be more likely falter. Her ability to learn will be, to a large extent, irreversibly damaged as will her ability to develop other skills that pay off in the labour market, in the home, and in the community. She will be more susceptible to infectious diseases and to noncommunicable diseases in later life. Throughout her life, her options and her power to make choices about those options will be as stunted as her growth will be. Society will be worse off in a social and economic sense. During her childbearing years, she will bear low birth-weight babies of her own. And so the cycle of intergenerational poverty and ill-health continues.

\subsection{Child malnutrition}

Child malnutrition is a major social illness that can impose a long-lasting physical and mental burden on society. Every year, African countries spend a significant share of their GDP on causes associated with malnutrition and its consequences (AU, 2013). While around one-third of child mortality in Africa is associated with child malnutrition, adults who survive malnutrition as children are also more likely to experience low levels of physical and intellectual productivity and suffer from higher levels of chronic illnesses and disability (UNICEF, 2012).

Table 4.1 summarises progress in terms of the main indicators of child malnutrition in the selected countries in Africa. Outstandingly good performance in terms of percentage change in wasting and percentage change in underweight children was observed in South Africa and Madagascar. On the other hand, the prevalence of wasting increased in five countries in the same time period. The highest rate of decline in the percentage of under-five mortality was recorded in Egypt, followed by Ethiopia and Madagascar. 
Table 4.1: Prevalence of child malnutrition under the age of five in selected countries and different time periods

\begin{tabular}{|c|c|c|c|c|c|}
\hline Country (period) & $\begin{array}{c}\% \text { change } \\
\text { in wasting }\end{array}$ & $\begin{array}{r}\% \text { change in } \\
\text { stunting }\end{array}$ & $\begin{array}{l}\% \text { change In } \\
\text { underweight }\end{array}$ & $\begin{array}{l}\% \text { change in } \\
\text { under-five } \\
\text { mortality } \\
\text { rate (1990- } \\
\text { 2011) }\end{array}$ & $\begin{array}{l}\text { Annual } \\
\text { GDP per } \\
\text { capita } \\
\text { growth } \\
\text { rate }\end{array}$ \\
\hline DRC (1995-2010) & 25 & 15 & 21 & 8 & -0.8 \\
\hline Egypt (1995-2008) & -39 & 17 & 33 & 76 & 3.3 \\
\hline Ethiopia (1992-2011) & -10 & 34 & 30 & 61 & 3.7 \\
\hline Ghana (1988-2008) & -30 & 26 & 37 & 36 & 2.3 \\
\hline Madagascar (1992-2009) & 116 & 19 & 103 & 62 & -0.3 \\
\hline Mozambique (1995-2008) & 56 & 27 & 23 & 54 & 4.8 \\
\hline Nigeria (1990-2008) & -22 & 19 & 24 & 42 & 1.7 \\
\hline Sudan (1993-2006) & -37 & 2 & 0 & 30 & 3.4 \\
\hline South Africa (1994-2008) & 570 & 24 & 970 & 25 & 1.8 \\
\hline Zambia (1992-2007) & 11 & 1 & 30 & 57 & 0.2 \\
\hline
\end{tabular}

Source: Based on WHO (2013), World Bank (2013) and UNICEF (2013) data

According to the WHO (2012), the prevalence of stunting (height for age below -2 SD) for children under the age of five in 2011 was $36 \%$ in Africa, which is the highest of all regions, followed by Asia, with 27\%. About $90 \%$ of the world 's stunted children under the age of five are living in Africa and Asia (WHO, 2012). In Africa, the absolute number of stunted children under the age five increased from 45 million in 1990 to 60 million in 2010, coupled with population growth and other factors (De Onis, Blössner \& Borghi, 2012).

The interregional analysis of the prevalence of stunting in Africa by De Onis et al. (2012) also showed that, in 2010, the highest prevalence was observed in Eastern Africa (45\%), Middle Africa (39\%) and Western Africa (38\%) (see Addendum D). In SSA, slower progress of a 5\% reduction in the proportion of stunted pre-schooler children was recorded between 1990 and 2010. According to De Onis et al. (2012), little progress is expected by 2020 in terms of reducing stunting in Africa. According to Benson (2004), around 19\%, 14\% and 8\% of Africa ${ }^{e e}$ s stunted children are found in Nigeria, Ethiopia and the DRC respectively, constituting about $40 \%$ of stunted pre-schoolers on the continent.

In all of the selected countries shown in (Figure 4.3), a higher proportion of stunted children is observed in rural areas than in urban areas. Also, the prevalence of child malnutrition is found to be more severe in male children than in their female counterparts (Addendum E). While food is produced primarily in rural areas in Africa, there is a higher challenge in terms of accessing nutritious food and micronutrients in rural areas (Benson, 2004). However, the 
prevalence of malnutrition in urban and peri-urban areas is also significant and is increasing in some poor countries (Fotso, 2007).

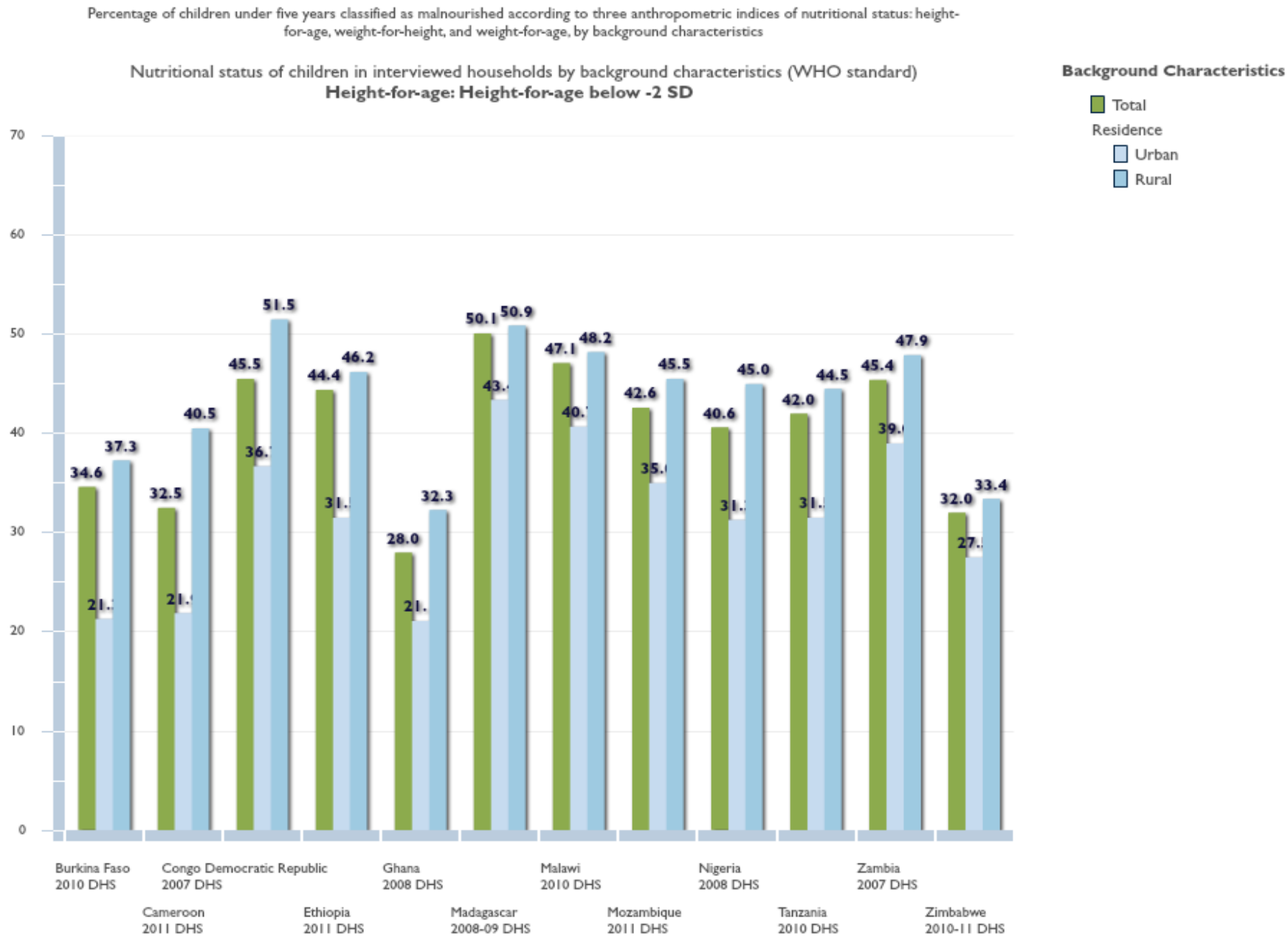

ICF International, 2012. MEASURE DHS STATcompiler - http:iMmw.statcompiler.com - July 312013.

Figure 4.3: Urban and rural prevalence of stunting in selected SSA countries based on recent DHS data

Source: MEASURE DHS (2013)

The biggest reduction in the number of stunted children was observed in Asia - from 190 million in 1990 to 100 million in 2010; this number is forecasted to decrease even further to 68 million by 2020 (MEASURE DHS, 2013). In Africa, however, is expected to show a slight increase to about 64 million by then (De Onis et al., 2012). Among the African countries that registered the highest reduction in the rate of stunting between 1990 and 2008 are Mauritania ( $57 \%$ to $27 \%$ ), Uganda ( $45 \%$ to $32 \%$ ), Mozambique (55\% to $44 \%$ ), Ethiopia ( $64 \%$ to $47 \%$ ) and Eritrea (66\% to 38\%) (MEASURE DHS, 2013).

In other parts of the world, a dramatic decline in the prevalence of stunting has been observed in Brazil, from 34\% in 1986 to 6\% in 2006 (De Onis et al., 2012). According to Lima et al. (2010, cited in De Onis et al., 2012), this success can be attributed to four reasons: (i) 
increased purchasing power of low-income families, (ii) improved educational levels of mothers, (iii) expanded public water and sewage systems, and (iv) virtual universalisation of basic health care, including parental care.

Another important indicator of child malnutrition is prevalence of underweight in children under the age of five. This is incorporated in the Millennium Development Goals as target 1, which is halving the proportion of people who suffer from hunger between 1990 and 2015 (Fanzo, 2012). Its prevalence in Africa is more severe in the Eastern, Central and Sahel regions (CIESIN, 2005). Chad, Eritrea, Ethiopia, Madagascar and Niger are the countries with the highest number of underweight children in sub-Saharan Africa (Fanzo, 2012).

The performance in terms of reduction in underweight children under the age of five in selected SSA countries is shown in Figure 4.4. As can be seen from the graph, most of the case study countries showed a reduction in the prevalence of underweight pre-school children in recent times (where data was available), except for South Africa. Of the countries in Figure 4.8, Mozambique and Ghana are on track to achieve MDG1 by 2015. The rest are largely showing insufficient progress (UNICEF, 2012), while countries like Madagascar and South Africa are showing no progress.

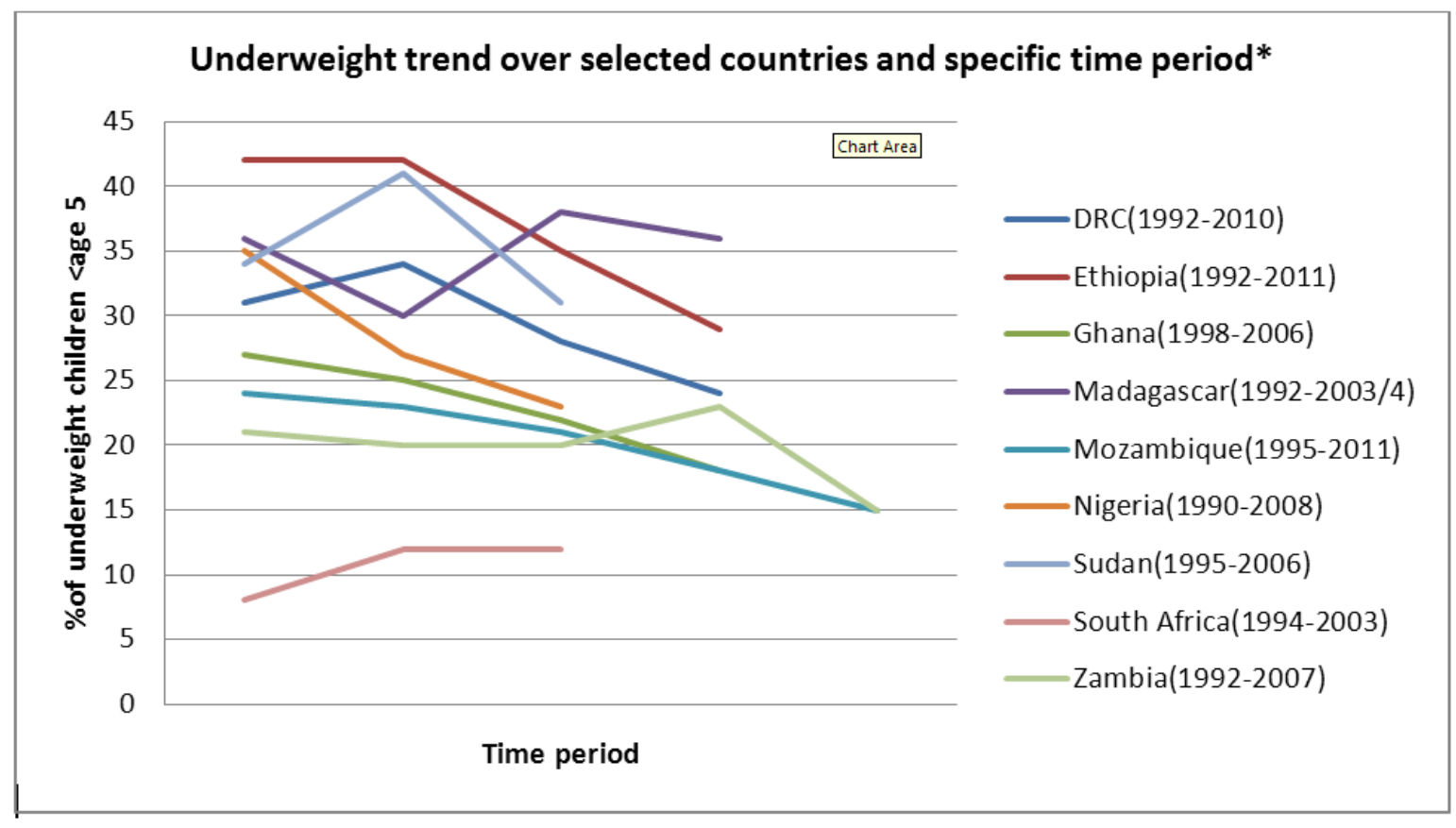

Figure 4.4: Performance in reducing the prevalence of underweight in the case study countries

Source: Based on UNCEF data (UNICEF, 2012)

*The most recent available data differed for each country 
Wasting is the other indicator of malnutrition that mostly affects infants and younger children and results from a deficiency in macronutrients (fat, carbohydrate and protein) and micronutrients (vitamins and minerals). The prevalence of wasting in children younger than five years of age in selected countries is shown in Figure 4.5. Most of the countries exhibited poor performance in reducing the proportion of wasting in pre-school children. An increasing level of wasting was recorded in the DRC, Mozambique, Kenya, Tanzania and Ghana.

Nigeria (14\%), Ethiopia (12\%), Sudan (16\%), the DRC (10\%) and Egypt $(7 \%)$ are the countries in the world with the highest rate of wasting in children under the age of five (Fanzo, 2012). Although still at a high level, the proportion of wasting showed a reduction over the last decade in countries like Burkina Faso, Ethiopia, Malawi and Zambia. In all of these countries, the prevalence of wasting is found to be higher in rural areas and in male children than in their urban and female counterparts. However, because of a less hygienic environment, low employment and a high proportion of the population living in most African cities, Benson (2004) argued that the absolute number of malnourished pre-schoolers living in urban areas in Africa is significant.

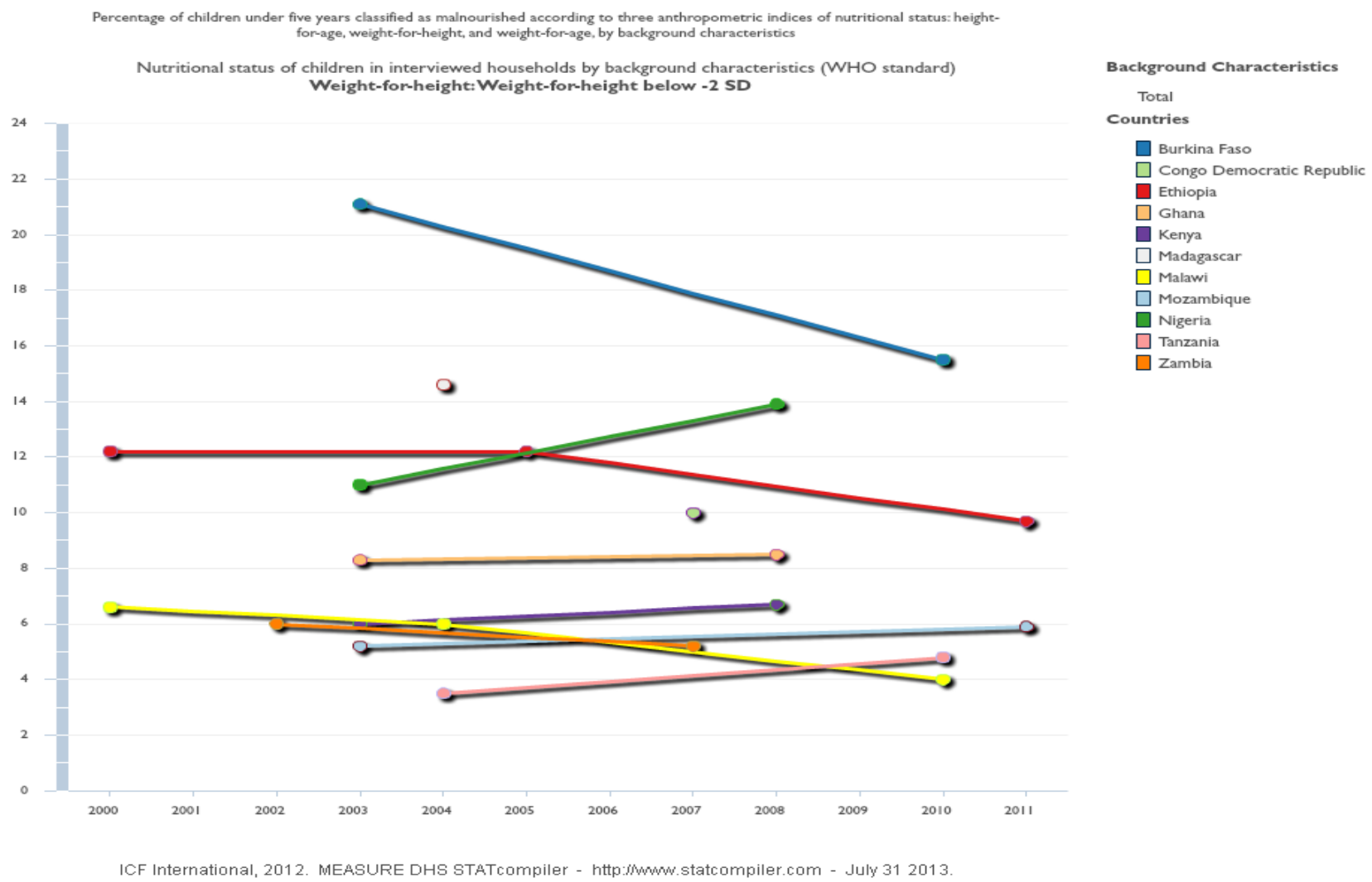

Figure 4.5: Proportion of wasting in children under the age of five in selected SSA countries Source: MEASURE DHS (2013) 
The end result of child malnutrition is staggering, especially when considering child mortality in the developing world. According to Black et al., (2013), more than half of global child mortality is found in only six countries. The situation is worse in poor countries in Africa, with two out of five children in Ethiopia being stunted, and as many as $81 \%$ of children suffer from undernutrition (UNICEF, 2012). Black et al. (2013) also found that around 3.1 million children under the age of five die annually because of undernutrition, which includes stunting, wasting and micronutrient deficiencies, coupled with inadequate breastfeeding.

Consequently, the prevalence of child mortality in Africa was analysed and progress in terms of achieving MDG4 is presented in Figure 4.6. MDG4 has the target of reducing child mortality by two-thirds between 1990 and 2015. All of the selected countries showed progress towards achieving this target, except for South Africa. Egypt has already surpassed the goal. Madagascar, Ethiopia, Zambia and Mozambique also showed impressive progress in reducing the annual rate and are expected to achieve the goal (see Figure 4.6). While Nigeria and Ghana recorded a significant reduction, the DRC and Sudan registered sluggish performance below the expected rate. South Africa showed poor performance, recording an increase in the child mortality rate between 1990 and 2009 (Figure 4.6).

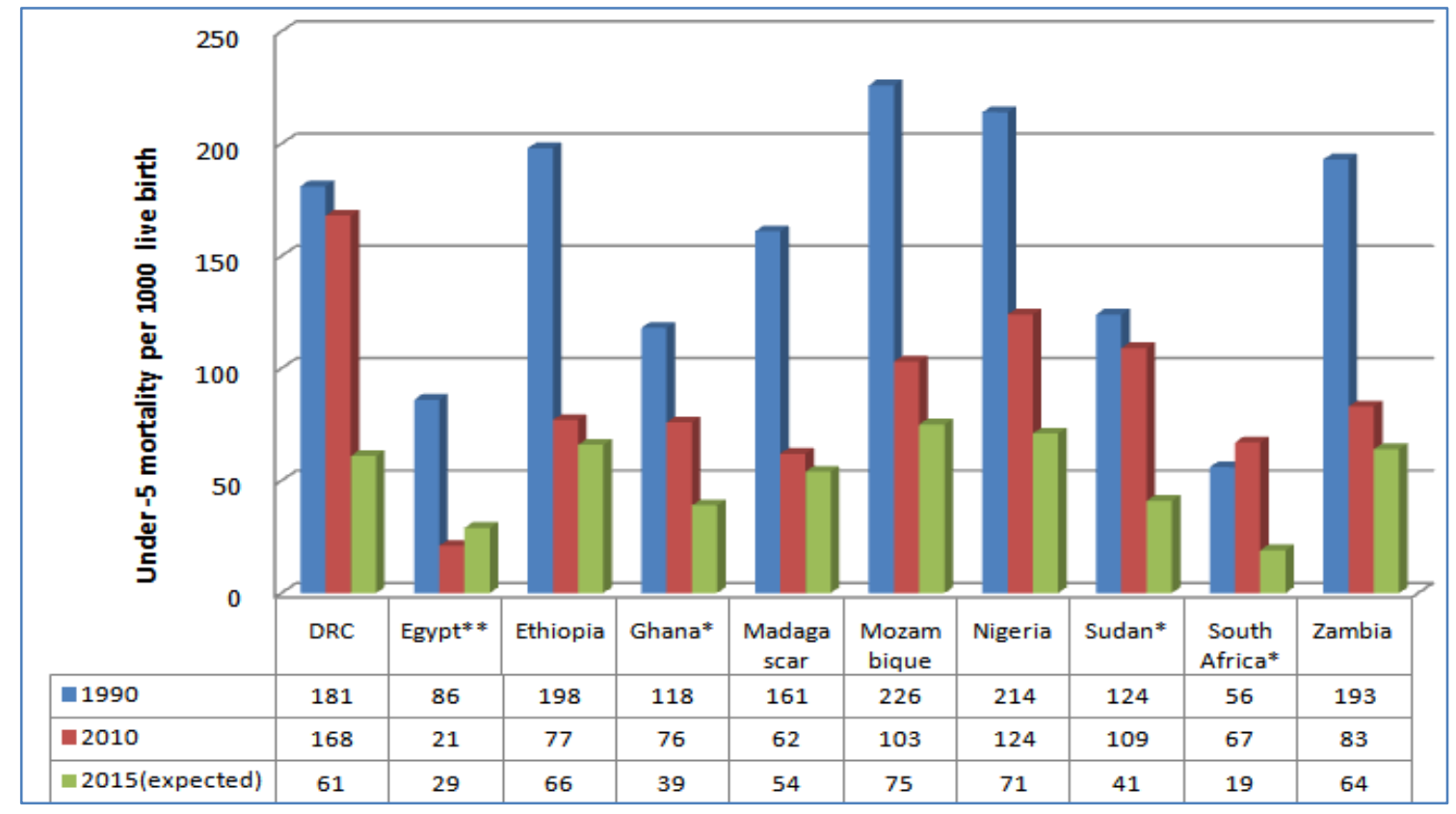

Figure 4.6: Progress in relation to the under-five mortality rate per 1000 live births (MDG4) in selected countries

Source: UNICEF (2012)

*The most recent available data used was for 2009 and ** 2011 


\subsection{Micronutrient malnutrition}

Micronutrients are defined as substances in foods that are necessary for healthy life that need to be taken in small amounts (Miller \& Welch, 2013). Deficiencies of vitamin A, iron, zinc and iodine are the most common forms of micronutrient malnutrition (Ecker et al., 2010). While it affects one-third to one-half of the world population, in sub-Saharan Africa $40 \%$ and $70 \%$ of children under the age of five years are affected by deficiencies of vitamin $\mathrm{A}$ and dietary iron (anaemia) respectively (Ecker et al., 2010; Miller \& Welch, 2013). Globally, vitamin A deficiency affects around $47 \%$ of children under the age of five, and its social and economic burden is more significant in low-income countries in Asia and Africa (Balarajan et al., 2011).

As shown in Figure 4.7, the prevalence of anaemia (iron deficiency) is greater than iodine and vitamin A deficiency in the selected countries, except in Zambia, where vitamin A deficiency is higher. A possible explanation for the high level of anaemia in these countries could be the low level of caloric food intake. Ecker et al. (2010) identified a close correlation between calories and bioavailable iron and zinc, the main sources of which are staple foods. They also pointed out that there is a risk of deficiency of iron and zinc specifically in those households with calorie deficiency. As a result, they concluded that calorie deficiency could result in multiple nutritional deficiencies in countries such as Uganda, Rwanda and Tanzania (Ecker et al., 2010).

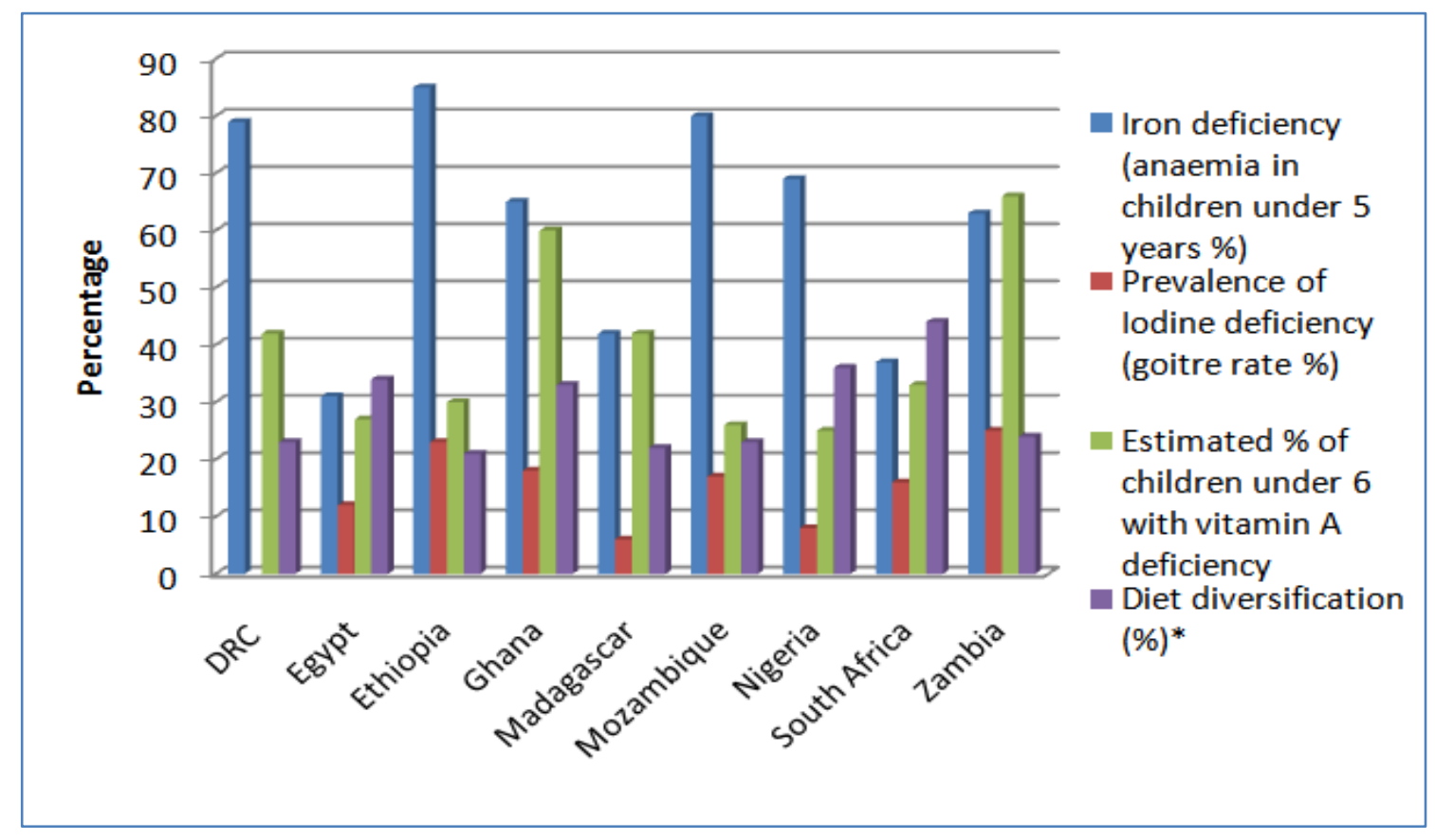

Figure 4.7: Prevalence of micronutrient malnutrition in selected countries in 2011

Source: Constructed based on UNICEF and MI (2013); *Based on EIU (2013) 
Miller \& Welch (2013) classified three strategies to address micronutrient malnutrition: agricultural production strategies, food-processing strategies, and economic and education strategies. Different techniques in agricultural practice, such as the use of fertilisers, improved cropping systems and plant breeding, can enhance the nutritional quality of agricultural output. Agricultural development strategies like that of the green revolution have been successful in increasing calorie and protein intake in countries such as India (Miller \& Welch, 2013). This ultimately resulted in micronutrient deficiency diseases linked to iron, zinc and vitamin A because of the low micronutrient content of milled cereals (Welch \& Graham, 2000, cited in Miller \& Welch, 2013).

In this respect, dietary diversification plays an important role in calorie as well as micronutrient availability (Hoddinott \& Yohannes, 2002). Of the countries analysed in Figure 4.8 above, the highest dietary diversity exists in South Africa and the lowest in Ethiopia. In most of the countries analysed, dietary iron deficiency was more closely related to a low level of dietary diversity than iodine and vitamin deficiency. However, in Nigeria and Ghana, for instance, as countries with relatively better dietary diversity, a higher dietary iron deficiency was recorded. Ghana also recorded a comparatively higher level of vitamin A deficiency, while despite its lowest dietary diversity, Ethiopia had a lower level of vitamin A deficiency. These scenarios imply that, although dietary diversity and economic growth are important, targeted nutritional interventions play the most important role when it comes to nutritional security (Ecker et al., 2010; Hurrell, 1997).

\subsection{Non-food parameters}

Food quality and safety can also be determined by other, non-food parameters such as clean water, sanitation, education and health infrastructure, which are equally important for nutritional security. Figures 4.8 and 4.9 show the percentage of the total population with access to improved water sources and sanitation services. SSA is lagging behind the world average in both parameters, and even falls below the average of low-income countries, especially in terms of access to water. 


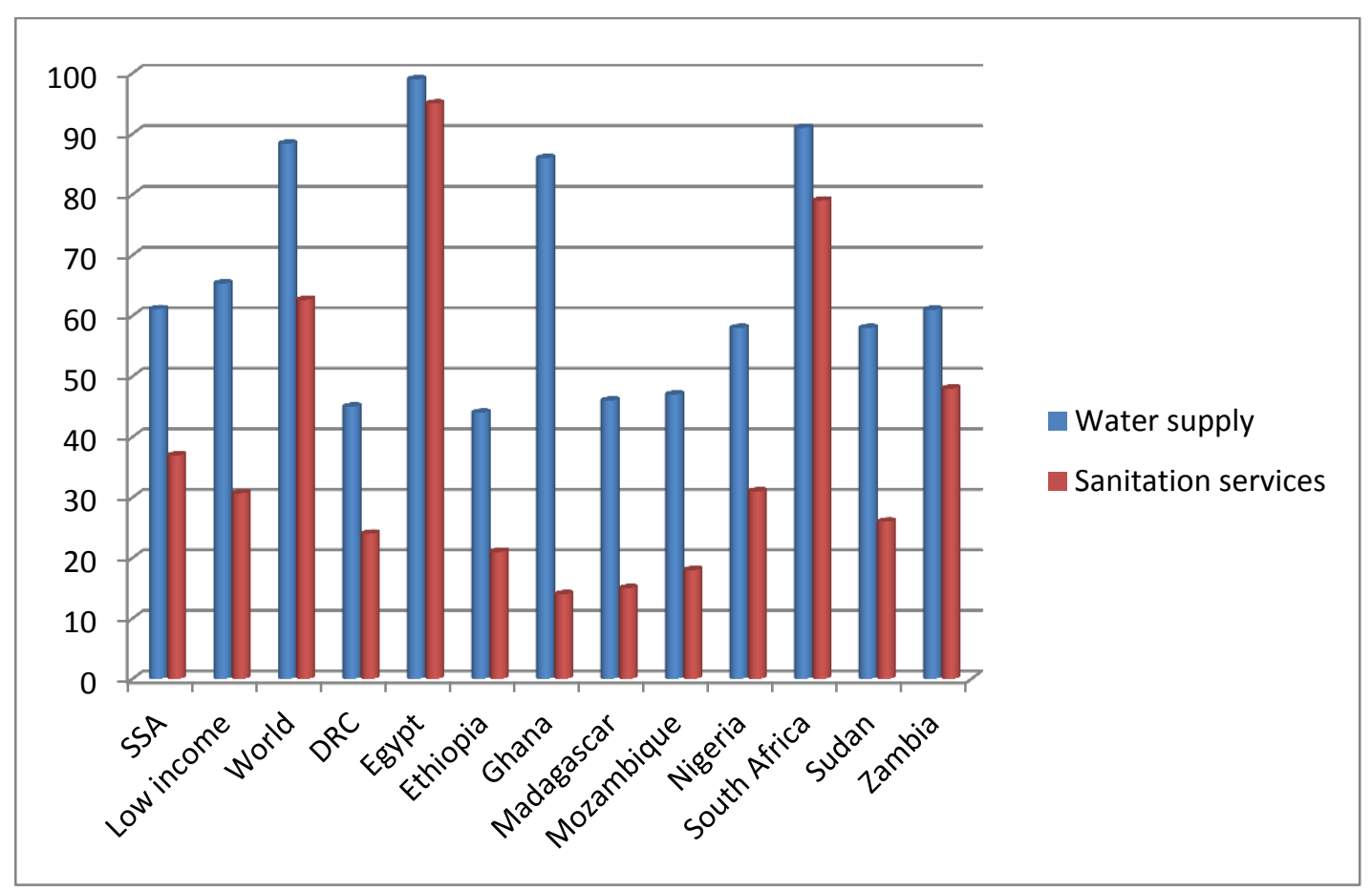

Figure 4.8: Percentage of population with improved access to water and sanitation in 2010

Source: Based on World Bank (2013a) data

Of the selected countries, Ethiopia, the DRC, Madagascar and Mozambique have the lowest level of improved water supply; below 50\%. Egypt performed very well, with more than 90\% in the supply of both water and sanitation services, followed by South Africa. Ghana showed an exceptionally contrasting performance in terms of these two parameters. It recorded a higher level of improved water supply, but a significantly low level of access to sanitation (see Figure 4.8).

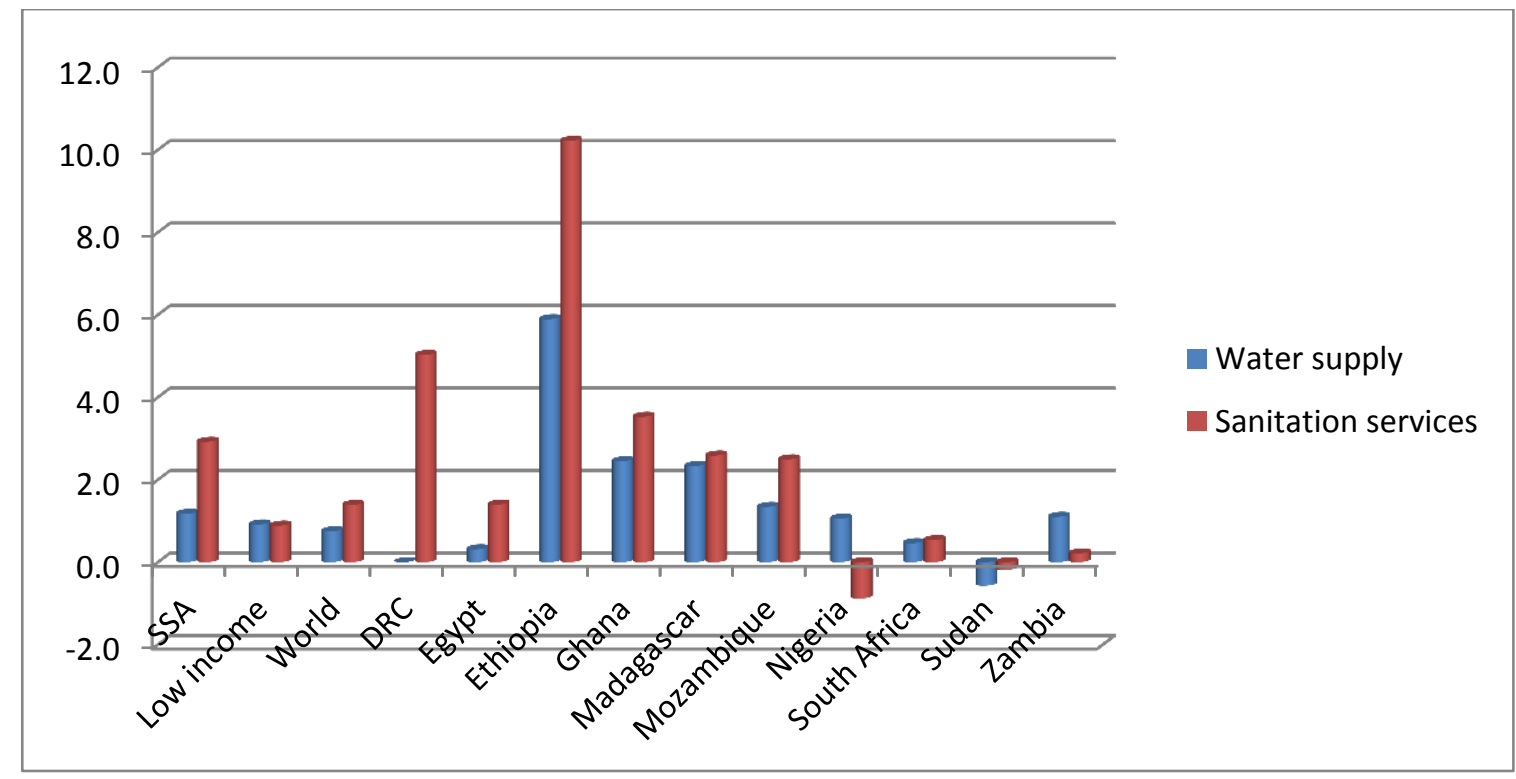

Figure 4.9: The growth rate in access to improved water sources and sanitation services between 1990 and 2010

Source: Based on World Bank (2013a) data 
Figure 4.9 shows the annual growth rate in the percentage of the population with access to both an improved water supply and sanitation facilities. In this respect, although it started from a much lower level, Ethiopia showed outstanding progress in improving both parameters. The DRC also recorded high performance in terms of improving sanitation facilities, although access to drinking water did not show an improvement. Nigeria and Zambia recorded sluggish performance, with a declining rate of supply of sanitation in Nigeria. Sudan also showed a declining rate in the provision of both parameters.

\subsection{Factors affecting food utilisation}

There is a widely accepted assumption that economic growth will enhance nutritional security by default through increased income and food consumption (Ecker et al., 2010; Hurrell, 1997). In this regard, some studies have attempted to empirically prove a direct relationship between the two. For instance, a study by Smith and Haddad (2002) found that an increase in per capita income promotes private and public investment that can enhance nutritional status through increased national food availability, and improved women ${ }^{\text {ee }}$ education, health and environment quality. Also, a statistical finding shows that an annual increase of $0.5 \%$ in GDP per capita resulted in a $0.9 \%$ annual reduction in stunting (Headey, 2012).

A study by Abdulai and Aubert (2004) showed that demand for food and nutrients are highly affected by income and other socioeconomic variables such as women's education and household size in Tanzania. The results also revealed that the expenditure elasticity of micronutrient consumption from animal products such as meat, fish, milk, eggs and dairy products, as well as fruit and vegetables, is higher than that obtained from staple foods. This implies that increasing income leads to an increase in demand for vitamins A and B12, and also for calcium and zinc (Abdulai \& Aubert, 2004). The magnitude of expenditure elasticity for these food items was found to be higher than own price elasticity, which implies that income policies are more effective in enhancing consumption than price policies (Abdulai \& Aubert, 2004).

Ecker et al. (2010) studied the dietary patterns and socioeconomic determinants of nutrient intakes in the rural East African countries of Rwanda, Uganda and Tanzania. Their study found that the majority of households were food and nutrition insecure. Diets had less diversity and were more dependent on staple foods such as roots and tubers, with low consumption of animal products and fruit and vegetables. Their econometric model showed that there is improvement in the nutritional situation with an increase in household income, with a stronger correlation with calories, iron and zinc than vitamin A. They also recommend 
that nutritional intervention is essential to fill the gap in terms of households ${ }^{\text {ee }}$ nutritional access (Ecker et al., 2010).

A study by Headey (2012) found that rapid economic growth is a necessary condition for a sustainable reduction in malnutrition, especially at lower levels of development. However, for the effective reduction of undernutrition, the increase in per capita income has to be shared by the deprived in order to enhance their ability to access private health and nutritional inputs (Smith \& Haddad, 2002). Even if their income increased, the intended result may not be achieved if they do not have awareness of the advantage of accessing such inputs. In line with this, if an increase in national income is not transformed into increased accessibility of public health and nutritional services, or the provision of a better quality of service, undernutrition would not be reduced (Smith \& Haddad, 2002).

Haddad, Alderman, Appleton, Song and Yohannes (2003) argued that the increase in income at both household and national level resulted in the same level of reduction of malnutrition. According to their household data survey, child malnutrition was unlikely to be addressed effectively by income growth objectives alone. Hence the authors recommended that, besides income growth, effective nutrition and health interventions were the best way to address malnutrition and child undernutrition rapidly (Haddad et al., 2003).

Therefore, besides mere economic growth objectives, achieving nutritional security demands well-designed policy directions and targeted nutritional interventions. Economic growth therefore should be „nutritional sensitive availability, reduced poverty and important social development (Headey, 2012). Consequently, the promotion of agricultural growth rather than the non-agricultural sector has a more pronounced effect on minimising undernutrition and enhancing human wellbeing (Fan \& Pandya-Lorch, 2012; Headey, 2012). The relationship, impact and synergy between agricultural growth, health and nutrition are discussed in the next section.

\subsubsection{The role of agriculture in nutrition}

As discussed in the previous chapters, growth in the agricultural sector, especially in smallscale farming, promotes faster poverty reduction and better income distribution that allow better calorie intake and nutrition. This is primarily because of two reasons - the existence of backward and forward linkages in production and consumption between agriculture and the rest of the economy, and the fact that agriculture constitutes the larger share of rural household income, expenditure and employment (Fan \& Brzeska, 2011). Its impact is actually not limited only to an increase in household income, but it also leads to an increase in 
household spending power through reduced food prices, enabling other, non-food nutritionenhancing activities (Pauw \& Thurlow, 2011). At the national level, an increase in government revenue enhances the financing of important infrastructure development and nutritional intervention programmes (Fan \& Brzeska, 2011).

According to Headey (2012), economic growth accompanied by agricultural growth results in an effective reduction in child malnutrition, especially in poor agrarian economies like that of Ethiopia. The more pronounced impact of agriculture on nutrition is its important role of increasing food production and the associated increase in caloric intake (Headey, 2012). In this regard, agricultural sub-sectors such as livestock or staple crops have different impacts on enhancing poverty reduction, as well as on reducing malnutrition. Their impact could be a factor of their linkage with the rest of the economy, their initial size and geographic concentration, market opportunities, and their growth potential (Fan \& Brzeska, 2011).

Ecker, Mabiso, Kennedy and Diao (2011) give at least six nutrition enhancement pathways of investing in agriculture and the food value chain. The first is the role that increased agricultural productivity plays in farm householdse income growth and/or reduced food price. The increased income, both at the micro- and macro-level, enhances spending on diet, health, education, sanitation, safety nets and so on. Secondly, agriculture can enhance nutritional security through different techniques, such as bio-fortification, drought-resistant crops and irrigation schemes. Bio-fortification will be explained in section 4.7.4.

Thirdly, agricultural development can improve direct access to quality and nutritious food rich in micronutrients, such as fish, meat, vegetables and fruit. This could include the promotion of home, school and community gardens, and small-scale livestock husbandry and aquaculture (Berti et al., 2004). Fourthly, agro-processing allows for the nutritional modification of food products through industrial fortification. Examples are iodisation of salt that reduces iodine deficiency, enriching flour with iron or zinc, and oils and fats with vitamin A and fat-soluble B vitamins (Ecker et al., 2011).

Fifth, agricultural growth can enhance nutritional security, especially by increasing income for households controlled by women. Although it is argued that this could give rise to a negative child nutrition situation because women engaged in household income generation will spend less time on child care, it generally is found that households controlled by lowincome women showed better nutritional outcomes than high-income male-headed households (Fan \& Brzeska, 2011). Finally, through agricultural extension it is possible to 
address nutrition-enhancing knowledge transfer to and awareness creation in rural poor households (Ecker et al., 2011).

Berti et al. (2004) also studied the impact of agricultural intervention on household nutritional security and health status. It was found that most agricultural interventions increased food production, but did not necessarily increase the nutritional or health outcomes of the participating households. Interventions with a high investment in human capital, such as nutrition education and women empowerment, resulted in increased nutritional outcomes. However, this does not mean that it is a sufficient or necessary condition for nutritional security (Berti et al., 2004).

\subsubsection{Value chains in nutrition}

Food utilisation is closely associated with the food value chain, which is concerned with how food is produced, stored, distributed, retailed, prepared and consumed, essentially determining the availability, affordability, acceptability and nutritional quality of food for the consumer (Hawkes \& Ruel, 2012). In the food value chain, consumers are not only a market for products, as is mostly perceived, but are also actors in the value chain whose activities, such as consumption and lobbying, can add value to products in return for benefits like nutritional value (Hawkes \& Ruel, 2012).

Hawkes \& Ruel (2012) argued that, although consumption patterns usually dictate the value chain, production and consumption actually are mutually constitutive processes. As consumption patterns influence production in the globalised food system, post-production activities and actors are also becoming important role players (Hawkes \& Ruel, 2012). In fact, the food industry is extremely influential at present in determining what people eat through advertising and advanced marketing strategies (Nestle, 2013).

The food processing sector is the most important constituent of the value chain. Besides the opportunity for increased employment and economic gain, it can also reduce food waste, prevent micronutrient losses, reduce food-associated illness and increase nutrients through fortification (Miller \& Welch, 2013). The accessibility of processed food also reduces the time requited for home food preparation, which gives way to other activities such as increased time for child care and so on. 
On the other hand, there are different health risks associated with the agrifood value chain, for instance microbiological hazards that includes food-borne pathogens and zoonoses ${ }^{10}$ (Trench et al., 2012). Also, physical and chemical contaminants due to high levels of pesticide, herbicide and fungicide usage to maintain high productivity can result in plant toxins found in food crops. Moreover, the low level of monitoring of the usage of contaminated wastewater in urban and peri-urban areas and the high level of usage of sugars, additives and preservatives in processed food pose significant health risks (Miller \& Welch, 2013; Trench et al., 2012).

Critics argue that the modern food industry is more concerned with profit than public health and nutritional security (Bouis \& Welch, 2010). In her book, "Food Politics: How the food industry influences nutrition and health", Nestle (2013) exposed the ways in which food companies use political processes to obtain government and professional support for the sale of their products - which are high in calories but low in nutritional value. Their capacity and potential enable them to lobby health, nutritional and other government institutions, such as when the US sugar industry threatened the WHO about its guidelines for healthy eating (The Guardian, 2003).

The food-processing industry is growing at a faster rate than farm values, offering new and diversified processed food items. For instance, in the US, while farm value has remained constant in recent years, the value of food processing and marketing, including retail and food services, has grown three times higher than farm value (Goodman, 1997, cited in Chopra, Galbraith \& Darnton-Hill, 2002). This influenced the dietary shift in developing and developed countries to high-value animal products, such as meat and dairy products with a high level of saturated fats, resulting in an increased incidence of obesity and other noncommunicable diseases such as diabetes, coronary heart disease, stroke, hypertension (Popkin, 2001).

\subsubsection{Nutritional intervention strategies}

Besides poverty reduction and economic growth, targeted nutritional interventions are key remedies to reduce the impact of malnutrition. These interventions include food supplementation, industrial fortification, and nutrition education programmes (Allen, 2003; Qaim et al., 2007). Supplementation has a rapid effect and is important when targeting large doses of micronutrients for specific individuals (like iron for pregnant women). Its main drawback is that it is a less sustainable top-down approach and also may not supply all micronutrients or include non-targeted groups of society (Allen, 2003).

\footnotetext{
${ }^{10}$ According to the Encyclopedia Britannica (2013), this refers to all diseases transmitted from animals to humans.
} 
Industrial food fortification, on the other hand, can increase the intake of various micronutrients at the same time with a cheap and sustainable means of supply (Allen, 2003). The problem of industrial fortification is the gap in consumption of these foods by the poor and rural households, who mostly produce their own subsistence staple food. Educational nutritional programmes can enhance the quality of household food consumption, for instance through the promotion of animal sources of food (Allen, 2003).

School feeding programmes are another important nutritional intervention strategy. Although these might not reach the poorest people in poor countries, they have the advantage of increased school attendance, cognition and educational achievement, especially when complemented with other techniques such as micronutrient fortification or supplementation (Bundy, 2009). An empirical study on the effectiveness of school feeding, especially diets from animal sources, in the cognitive development of Kenyan school children, revealed that children supplemented with meat products outperformed all the other children in the sample (Whaley et al., 2003). Also, children supplemented with meat and energy performed better in arithmetic ability than the rest of the children. In terms of verbal comprehension, no difference was observed between the groups of children (Whaley et al., 2003).

\subsubsection{Bio-fortification}

Bio-fortification is an innovative way of enhancing micronutrient availability that involves plant breeding or the use of transgenic techniques, such as the application of micronutrientrich fertilisers to enhance the concentration of important micronutrients in staple crops (Bouis \& Welch, 2010; Nestel et al., 2006). It is a process that directly links agricultural research with human health and nutritional security (Bouis, 2003; Bouis et al., 2013). Therefore, biofortification has the advantage of enhancing nutritional security as a complementary technique to other agricultural and nutritional interventions.

There are various advantages of bio-fortification. First, since low-income households are largely dependent on staple crops it can address the situation in remote rural areas and enhance the nutritional security of the poor (Bouis \& Welch, 2010). Secondly, it is cost effective, as it is a one-time investment during the development of fortified seeds (Qaim et al., 2007). Consequently, it can be adopted with low recurrent costs and also has the advantage of expansion in different parts of the world (Bouis \& Welch, 2010). Thirdly, once adopted it can be sustained even without government or donor support (Nestel et al., 2006). Finally, it does not compromise agricultural productivity, but rather enhances higher yields, as nutritionally fortified seeds have more resistance to disease and environmental stress (Nestel et al., 2006). 
It has been demonstrated that micronutrient density can be increased in food staples through conventional breeding without a negative effect on other farmer-preferred traits (Bouis et al., 2013). In this respect, recently bio-fortified crops are being disseminated through Harvest Plus and its partners in Uganda (orange-fleshed sweet potato, OFSP), Zambia (maize), Nigeria (cassava), the DRC (cassava and beans), Rwanda (beans) and India (pearl millet) (Saltzman et al., 2013, cited in Bouis et al., 2013). Although it still needs more scaling up, bio-fortification is regarded as a promising mechanism of addressing nutrition challenges in developing countries (Bouis et al., 2013).

However, there are some important points that need to be considered in the adoption of biofortification. For instance, it has not yet been established practically how the repeated reproduction of the seeds will affect the stability of the micronutrient traits (Qaim et al., 2007). Also, the application of transgenic techniques, which are applied when a particular micronutrient is naturally absent in a particular crop, might lead to complications of regulatory needs and consumer acceptance. However, a preliminary cost-benefit analysis of the social returns of bio-fortification highlighted their significant role in the nutritional security of the rural poor (Qaim et al., 2007).

\subsection{Summary}

Food utilisation is one of the three pillars of food security. Neither food availability nor food accessibility alone necessarily guarantees overall food security unless there is effective and efficient food utilisation. It has been found that nutritional security is the ultimate goal of the overall food system to enhance an active and healthy life. The term utilisation describes food quality and safety, which aim to maintain nutritional security. The food quality and safety aspects of food utilisation comprise diverse and complex factors. While food quality refers to the nutritional standards and dietary micronutrient availability, food safety represents the nonfood parameters, such as access to clean water, health, education and sanitation.

Malnutrition costs a significant share of the GDP of poor countries through increased healthcare expenses and loss of potential labour force. Also, its impact could be sustained throughout the life cycle and across generations. As a result, the African Union recently implemented a project to assess the burden of undernutrition on the continent as a theme of "The cost of hunger in Africa" (AU, 2013). The prevalence of malnutrition can best be monitored by measures to counter child undernutrition, including anthropometric measurements such as stunting, underweight, wasting and overweight. Child mortality rate is 
also a major indicator of nutritional security, as around one-third of child mortality under the age of five globally is associated with undernutrition.

In this respect, the assessment of African nutritional status across the representative countries revealed that malnutrition remains the primary challenge to growth and development in the region. Performance in reducing child undernutrition in the selected countries showed diverse outcomes, irrespective of the GDP per capita growth rate. Overall in terms of achieving MDG4, which is a two-thirds reduction in the mortality of children under the age of five between 1990 and 2015, most of the countries were on the right track towards achieving it. However, the DRC, Sudan and South Africa were below the rate of achieving MDG4.

The study also revealed that about $36 \%$ of children under the age of five in SSA are stunted, however sub-regional and intra-country variation were observed. The highest prevalence of stunting was recorded in Eastern Africa (45\%), Middle Africa (39\%) and Western Africa $(38 \%)$. There was only a $5 \%$ reduction in the prevalence of stunting in SSA compared to the 43\% reduction in Southeast Asia between 1990 and 2010 (De Onis et al., 2012). Three countries, Nigeria, Ethiopia and the DRC, contributed about $40 \%$ of the share of stunted children in Africa, with 19\%, 14\% and 8\% respectively (Benson, 2004).

The prevalence of micronutrient malnutrition (hidden hunger) is the most important factor in African nutritional security. Deficiencies of vitamin A, iron, zinc and iodine are the most common forms of micronutrient malnutrition (Ecker et al., 2010). Around $40 \%$ to $70 \%$ of children under the age of five in sub-Saharan Africa are affected by deficiencies of vitamin A and dietary iron (anaemia). Most of the case study countries were significantly affected by higher levels of dietary iron deficiency (anaemia), of which the prevalence in children under five in the DRC, Ethiopia, Ghana, Mozambique, Nigeria and Zambia was found to be more than $60 \%$. The DRC, Ghana, Madagascar and Zambia also recorded more than $40 \%$ of the prevalence of vitamin A deficiency in children under the age six. Only Nigeria and Madagascar among the case study countries showed a prevalence of iodine deficiency of less than $10 \%$.

In terms of the non-food parameters of nutritional security, such as access to clean water and sanitation, the majority of the case study countries recorded a very low level of provision of sanitation. Except for Egypt, South Africa and Zambia, the percentage of the population with access to better sanitation services in the rest of the countries was below $30 \%$. In the DRC, Ethiopia, Madagascar and Mozambique, the percentage of the population with access to improved water service was less than $50 \%$. 
The review of literature on factors that enhance food utilisation and nutritional security showed a close correlation between economic growth and better nutrition. Some studies showed that there is higher income elasticity of consumption of high-value nutritious food items such as meat, fish, milk, eggs and dairy products, as well as fruit and vegetables (Abdulai \& Aubert, 2004). However, per capita income growth alone cannot effectively address nutritional security and child malnutrition (Haddad et al., 2003; Smith \& Haddad, 2002).

Therefore, besides economic growth objectives, achieving nutritional security demands welldesigned policy directions and targeted nutritional interventions. That is, economic growth should be „nutritional sensitive poverty and important social development (Headey, 2011). Compared to the non-agricultural sector, the promotion of agricultural growth has a more pronounced effect on minimising undernutrition and enhancing human wellbeing (Fan \& Pandya-Lorch, 2012; Headey, 2012). This is because agriculture enhances the supply of adequate and nutritional food items (especially through bio-fortification techniques), thereby enhancing rural income growth and food utilisation concepts in the rural community using agricultural extension services. 


\section{Chapter Five}

\section{Findings and Conclusion}

\subsection{Chapter one: Introduction}

The food security concept came up in international discourse in the early 1940s with a limited scope of concern of a secure, adequate and suitable supply of food for all. Since then, there has been a consistent paradigm shift, in which the concern about food supply was dominant until the early 1980s. The introduction of demand-side factors after Amartya Sen $\mathrm{s}$ entitlement approach shed light on perceive food security as being more than mere food supply. His argument emphasised that the lack of "effective demand" could be the primary cause of individual food insecurity. As a result, over the past half century the concept of food security has shifted from the global to the national and individual level; from a primarily food-first perspective to a livelihood-first perspective, and from more objective indicators to subjective factors (Devereux \& Maxwell, 2001).

The definition of food security followed the same trend of modification along with the concept. Currently it is defined as "a situation that exists when all people, at all times, have physical, social and economic access to sufficient, safe and nutritious food that meets their dietary needs and food preferences for an active and healthy life" (Panagariya, 2002). However, the introduction of "food preferences" into the current definition of food security changed the concept from access to enough food to access to preference. And this can be a big challenge when it comes to measuring individuals ${ }^{e e}$ food preferences, which in turn can have policy implications. Therefore, through its evolution and progress, the definition of food security has lost its simplicity. As a result, there is an argument for a move away from a conception of food security as a goal in itself to perceiving it as a means to maintain an active and healthy life.

The overall picture of Africa with regard to food and nutritional security remain still negative. The countries with a high level of undernourishment and with the lowest level of food security are concentrated in the sub-Saharan Africa region (EIU, 2012). However, the proportion of food insecurity is also higher in rural areas with poor subsistence farmers and landless tenants, which collectively account for around $80 \%$ of the undernourished population in Africa (Panagariya, 2002). Studies have shown that agriculture in sub-Saharan Africa (SSA) plays a very important role in employment and gross domestic product (GDP) share 
(Devereux, 1999; FAO, 2012a). In this regard, small-scale farmers account for more than $90 \%$ of agricultural production in the region (IFPRI, 2004).

While different studies have analysed food security at the regional, national and household level in Africa, this thesis aimed to investigate the food security situation of the continent on the basis of food availability, accessibility and utilisation as analytical framework. To this end, ten countries from the Northern, Western, Eastern, Middle and Southern Africa subregions were selected on the basis of their geographical representation and their ranking in the global food security index of the EIU (2012). These countries are the DRC, Egypt, Ethiopia, Ghana, Madagascar, Mozambique, Nigeria, Sudan, South Africa and Zambia. Both quantitative and qualitative methods of data analysis were employed in this study.

\subsection{Chapter two: Food availability analysis}

Food availability represents the food supply dimension of the food security analysis. It has been longstanding in food security discussions following the Malthusian demographic hypothesis that claimed food security can be threatened by increasing population growth. In this regard, despite the past half a century of success in world agricultural productivity growth, which was well above the population growth rate, the recent spike in food prices brought the food supply debate to the forefront of food security discussions.

The food balance sheet (FBS) is a national account of annual food production, changes in stocks, imports and exports, and agricultural and industrial uses within a country. It also provides information regarding per capita per day nutrient availability of calories, protein and fat. Although the FBS overestimates the average food supply, as it does not consider food and nutrient lost at the point of consumption at household level, it remains the best available source of food supply information. The food availability in the case study countries in Africa was investigated using the three main components of FBS: production, trade and aid, as summarised in Table 5.1.

The analysis of long-term caloric food supply trends identified the Northern and Western Africa regions as having relatively better performance. The Southern Africa region recorded rather stagnant performance, while Middle and Eastern Africa started realising a growth rate of caloric supply after long-term deterioration. Out of fifty African countries, with available data, twenty-one countries of SSA were still below the FAO ${ }^{\text {ee }}$ standard of daily caloric food supply of $2300 \mathrm{Kcal} /$ capita/day by 2009. There was impressive growth in caloric food supply in Ghana and Egypt registered between 1970 and 2012, and these countries performed better than the average growth rate in Southeast Asia. Moreover, of the selected countries, Ghana 
and Ethiopia registered steep growth in caloric food supply in the last twenty years, after declining performance between 1970 and 1990. In contrast, Madagascar and Zambia recorded a declining growth rate in caloric food supply during the same period.

During the period of $1984 / 86$ to $2010 / 12$, Africa recorded a $0.4 \%$ growth rate of annual per capita cereal production. Except the Southern Africa region, the rest of the sub-regions of Africa also recorded an increasing rate. Among the case study countries, the highest declining rate observed in Sudan (-1.6\%) followed by DRC (-1.4\%). Madagascar $(-0.2 \%)$ and South Africa (-0.4\%) have also showed a declining rate with a marginal reduction rate recorded in Nigeria (-0.1\%). Ethiopia (2.5\%), Mozambique (2.2\%), Egypt (1.7\%) and Ghana (1.7\%) performed the best in this regard, recording the highest rate even more than S-E Asia region $(1.4 \%)$.

Except Southern Africa region and South Africa in all of the sub-regions and case study countries the rate of expansion of area harvest is positive. Also except for DRC, the rest of the case study countries recorded a positive rate of yield growth. Although South Africa recorded the highest decline in area harvest of cereals, it also registered the highest rate of increase in cereal yield growth during the study period of $1984 / 86$ to $2010 / 12$. However, the overall production growth in this country remains below the population growth rate which resulted in negative per capita cereal production rate.

Maize is the most important food crop in SSA; for instance, in 2009 it accounted for around $32 \%, 23 \%$ and $20 \%$ of total dietary intake in the Eastern Africa countries of Kenya, Tanzania and Ethiopia respectively (Dillon \& Barrett, 2013). In this study it showed an increasing per capita growth rate in all the case study countries except for the DRC and Sudan for the period of $1984 / 86$ to $2010 / 12$. The highest yield increase in per capita maize production was recorded in Sudan (4.1\%) and South Africa (4\%). However, both these countries also recorded a declining rate of area harvest at a rate of $-2 \%$ each during 1984/86 to 2010/12. Mozambique (3.3\%), Ethiopia (3\%) and Nigeria (3\%) are the best performers of increased per capita maize production even more than S-E Asia which recorded 2.3\% during the same period.

South Africa, Egypt and Ethiopia are identified as the primary wheat producers on the continent. The per capita growth in production for the study period of 1961 to 2011 showed an increase of $1.5 \%$ and $0.5 \%$ in Egypt and Ethiopia respectively, while a $-0.4 \%$ annual rate of reduction was recorded in South Africa, coupled with a reduction in area harvested of this crop. The highest yield growth rate of wheat production was recorded in South Africa (3.4\%), 
followed by Egypt (2\%) and Ethiopia (1.9\%). In terms of expansion in area harvested, Egypt recorded a growth rate of $1.6 \%$ and Ethiopia 1.1\%, while South Africa recorded a declining rate of $-1.7 \%$ per annum.

Per capita roots and tubers production in Africa showed higher growth rate than the S-E Asia region (Figure 2.9). Only the Middle Africa sub region recorded a declining rate of $-0.5 \%$ of all the sub-regions. Out of the case study countries, the Western Africa countries of Nigeria and Ghana recorded the highest rate of $4.2 \%$ and $3.7 \%$ respectively. DRC recorded the highest decline rate of $-2.9 \%$ followed by Madagascar with a $-1.3 \%$ decline during the study period of $1984 / 86$ to $2010 / 12$. In all of the sub-regions of Africa and the case study countries an increasing rate of yield and area harvest of roots and tubers recorded except for DRC that experienced a marginal rate of decline in yield.

Table 5.1: Food availability indicating parameters growth rate over selected countries

\begin{tabular}{|c|c|c|c|c|c|c|c|c|c|c|c|}
\hline & & DRC & Egypt & $\begin{array}{c}\text { Ethio- } \\
\text { pia }\end{array}$ & $\begin{array}{l}\text { Gha } \\
\text {-na }\end{array}$ & $\begin{array}{c}\text { Nige } \\
\text {-ria }\end{array}$ & $\begin{array}{l}\text { Mada- } \\
\text { gascar }\end{array}$ & $\begin{array}{l}\text { Mozam } \\
\text {-bique }\end{array}$ & $\begin{array}{l}\text { Sud- } \\
\text { an }\end{array}$ & $\begin{array}{l}\text { South } \\
\text { Africa }\end{array}$ & $\begin{array}{c}\text { Zam- } \\
\text { bia }\end{array}$ \\
\hline $\begin{array}{c}\text { Dietary } \\
\text { energy } \\
\text { supply } \\
\text { (1961- } \\
\text { 2011) }\end{array}$ & $\begin{array}{c}\text { Per capita } \\
\text { calorie } \\
\text { intake }\end{array}$ & .... & 1.2 & 0.4 & 1.1 & -0.4 & 0.3 & 0.8 & 0.3 & 0.8 & -0.4 \\
\hline \multirow{3}{*}{$\begin{array}{c}\text { Cereals } \\
(1984 / 86 \\
- \\
2010 / 12)\end{array}$} & $\begin{array}{l}\text { Productio } \\
\text { n per } \\
\text { capita }\end{array}$ & -1.4 & 1.7 & 2.5 & 1.7 & -0.2 & 2.2 & -0.1 & -0.4 & -1.6 & 1.4 \\
\hline & Yield & -0.2 & 1.8 & 2.3 & 2.5 & 1.6 & 2.0 & 0.5 & 4.0 & 0.2 & 1.5 \\
\hline & $\begin{array}{c}\text { Area } \\
\text { harvested }\end{array}$ & 1.7 & 1.8 & 2.6 & 1.6 & 1.1 & 2.4 & 1.9 & -2.6 & 0.8 & 2.5 \\
\hline \multirow{3}{*}{$\begin{array}{c}\text { Maize } \\
(1984 / 86 \\
- \\
2010 / 12)\end{array}$} & $\begin{array}{c}\text { Productio } \\
\text { n per } \\
\text { capita }\end{array}$ & -0.9 & 0.6 & 3.0 & 1.7 & 1.1 & 3.3 & 3.0 & 0.3 & -0.6 & 1.2 \\
\hline & Yield & -0.1 & 2.1 & 2.4 & 2.1 & 1.1 & 3.2 & 1.4 & 4.0 & 4.1 & 1.3 \\
\hline & $\begin{array}{c}\text { Area } \\
\text { harvested }\end{array}$ & 2.2 & 2.2 & 2.2 & 2.2 & 2.2 & 2.2 & 2.2 & 2.2 & 2.2 & 2.2 \\
\hline \multirow{3}{*}{$\begin{array}{c}\text { Roots } \\
\text { and } \\
\text { tubers } \\
(1984 / 86 \\
- \\
2010 / 12)\end{array}$} & $\begin{array}{c}\text { Productio } \\
\text { n per } \\
\text { capita }\end{array}$ & -2.9 & 2.3 & 1.1 & 3.7 & -1.3 & 2.0 & 4.2 & 1.2 & 1.7 & 2.3 \\
\hline & Yield & -0.2 & 1.1 & 0.3 & 3.7 & 0.7 & 3.2 & 1.1 & 2.7 & 3.1 & 0.1 \\
\hline & $\begin{array}{c}\text { Area } \\
\text { harvested }\end{array}$ & 0.3 & 3.1 & 3.5 & 2.6 & 1.1 & 1.2 & 5.5 & 0.2 & 1.1 & 4.9 \\
\hline \multirow{3}{*}{$\begin{array}{l}\text { Agricultu } \\
\text { ral trade } \\
\text { (1961- } \\
2011)\end{array}$} & $\begin{array}{l}\text { Agricultur } \\
\text { al import }\end{array}$ & 7.8 & 8.8 & 11.1 & 6.2 & 6.3 & 7.8 & 9.4 & 7.6 & 8.4 & 5.1 \\
\hline & $\begin{array}{l}\text { Agricultur } \\
\text { al export }\end{array}$ & -0.7 & 3.9 & 7.0 & 3.8 & 1.8 & 3.6 & 2.3 & 5.6 & 2.1 & 9.5 \\
\hline & $\begin{array}{l}\text { Net } \\
\text { agricultur } \\
\text { al trade }\end{array}$ & -8.5 & -4.8 & -4.0 & -2.4 & -4.5 & -4.2 & -7.1 & -1.9 & -6.3 & 4.3 \\
\hline
\end{tabular}




\begin{tabular}{|c|c|c|c|c|c|c|c|c|c|c|c|} 
& SSR* & -0.2 & -0.4 & -0.3 & -0.1 & -0.2 & -0.4 & -0.5 & -0.4 & -1.1 & 0.6 \\
\cline { 2 - 11 } & IDR* & 0.8 & 8.0 & 5.7 & 0.9 & 1.9 & 2.1 & 5.0 & 2.7 & 4.7 & -8.7 \\
\hline Food aid & $\begin{array}{c}\text { Cereal } \\
\text { aid** }\end{array}$ & -0.4 & -43.6 & -3.3 & -5.1 & $\ldots$ & -4.2 & -8.2 & 0.7 & $\ldots$ & -16.4 \\
\hline
\end{tabular}

Source: Author's calculation based on FAOSTAT (2013) data

*These values indicate the annual growth rate of SSR and IDR from 1970 to 2010 (- values represent annual rate of decline)

** Data used from 1988 to 2012, except for Zambia (until 2011) and Sudan (until 2010)

Agricultural production volatility is among the main indicators used in EIU ${ }^{\text {ee }}$ s food availability measurement, in which the standard deviation of the annual growth in agricultural production between the 1990 and 2010 was used. On the other hand, per capita food production variability was measured as a factor of stability or sustainability of food supply in the FAO's food security indicators (2012b). Accordingly, in 2010, Africaees per capita food production variability measured with respect to a constant 2004-2006 int $\$$ per capita value stands at a level of standard deviation of 3.1. The Northern Africa region recorded a standard deviation of 6.3, which is higher than the SSA average value.

In terms of agricultural trade, Africa became net agricultural commodities importer especially from the 1980s onwards. Total agricultural commodities import increased at a rate of $7.7 \%$ between 1961 and 2010. In the same period, total agricultural export rose at a rate of $4.7 \%$. Compared to agricultural export growth rate the highest rate of increase in import observed in Middle and Northern Africa regions at a rate of $4.1 \%$ each during the same period.

Among the important commodities imported in to Africa, wheat and poultry meat are the main ones especially over the recent years. Egypt is observed to be the highest importer of wheat followed by Nigeria. Over the last decade, increased rate of wheat import is also observed in most of the case study countries. South Africa recorded the highest rate of poultry meat import in the year 2011. It followed by Ghana, Egypt and DRC. In the rest of the case study countries its value is insignificant.

Different factors are responsible for increased level of agricultural import in Africa. According to Rakotoarisoa et al., (2011), although there is an increased per capita agricultural growth especially since the 1985, its insufficient growth coupled with poor land ownership and management, low yield and productivity, poor infrastructure and the low level of agricultural investment, as well as institutional deficiencies, conflicts and instability, are the main supply-side constraints. On the demand side, high population growth rate and increasing demand to high value products such as meat products, could be the main factors. Moreover, 
beyond these factors, the international market distortions linked with adoption of domestic agricultural production and export subsidies by member countries of the OECD have also played an important role (Rakotoarisoa et al., 2011).

In conclusion, although it is hard to generalise the national food availability situation using only specific commodities, the chapter highlighted the general situation and the performance of associated parameters. In some countries, like Ethiopia, non-tradable staple crops such as teff play a significant role in national food availability. Therefore studies should also take into consideration other possible role players in food availability, such as home gardening, nontradable items and so forth.

\subsection{Chapter three: Food accessibility analysis}

Amartya Sen ees entitlement approach in the early 1980s was the first to introduce the concept of food accessibility by claiming it as being as important as food availability in determining an individual 'es food security (Sen, 1981). According to his analysis, a person could go hungry as a result of direct entitlement failure, which is production failure or endowment loss. A person equally could starve as a result of entitlement failure, which is failure to exchange his endowed asset or produce for food. Moreover, his capability theory argues that different people and societies typically differ in their capacity to convert income and commodities into valuable achievements (including access to food) (Clark, 2005). For example, a disabled person may need extra resources to function as an able-bodied person (wheel chairs, ramps, lifts, etc.).

It has been pointed out that different approaches use different techniques to measure food accessibility. Therefore, the broader scope and complexity of the factors incorporated in the capability approach made direct measurement of food accessibility difficult, hence most of the indicators are proxy measures. For instance, the UNDPees HDI incorporated some, but not all, of the important factors such as education, health and standard of living as primary indicators of development. The EIU's global food security index also incorporated most of the proxy indicators of economic accessibility to measure food affordability at the national level.

Based on the capability approach and a study by Kidane et al. (2006), this chapter analysed the basic determinant factors of food accessibility from the broader context of economic, physical, political and sociocultural perspectives. In terms of the economic accessibility analysis, although still at the lowest level, HDI performance in Africa has shown a promising improvement, especially over the last decade. It showed a $1.34 \%$ annual increase in SSA between 2000 and 2012, with Sierra Leone and Ethiopia registering the world second and 
third highest annual growth rates of 3.29\% and 3.09\% respectively. The average GDP per capita growth rate was also the highest in SSA over the last decade, where more than a quarter of the countries in the region were among the fastest growing economies of the world.

Political and macroeconomic stability and microeconomic reforms undertaken are some of the background factors for the recent economic growth of SSA. The growth performance can be attributed to an increase in domestic demand and investment, which grew at a rate of $0.5 \%$ of investment to GDP ratio over the last decade. While public expenditure on basic infrastructure was significant, increased foreign direct investment in extractive industries was also prominent. This was driven by a surge in the global commodity prices of minerals, grains and other raw materials, as observed in the oil price spike from 20 USD a barrel in 1999 to 145 USD in 2008.

The empirical analysis of food affordability in the selected countries, based on the EIU global food security index, is summarised in Table 5.2. South Africa outperformed Egypt in terms of all indicators of food affordability, except for the proportion of population under the global poverty line. Also, Egypt ranked the lowest of all the case study countries in terms of agricultural import tariffs, where the lowest ranked countries overall, such as the DRC, Mozambique and Madagascar, ranked best in terms of this indicator. Ghana performed much better than Nigeria with respect to affordability. Nigeria showed the poorest performance in terms of key food affordability parameters, such as household food expenditure, proportion of population under the global poverty line, as well as presence of food safety nets.

Table 5.2: The world ranking of food affordability and its indicators by the EIU (2013)

\begin{tabular}{|c|c|c|c|c|c|c|c|c|}
\hline & $\begin{array}{l}\text { Overall } \\
\text { ranking }\end{array}$ & $\begin{array}{l}\text { Afford- } \\
\text { ability }\end{array}$ & $\begin{array}{l}\text { House- } \\
\text { hold food } \\
\text { expendi- } \\
\text { ture }\end{array}$ & $\begin{array}{l}\text { Propor- } \\
\text { tion of } \\
\text { people } \\
\text { under } \\
\text { global } \\
\text { poverty } \\
\text { line }\end{array}$ & $\begin{array}{l}\text { GDP } \\
\text { per } \\
\text { capita }\end{array}$ & $\begin{array}{l}\text { Agricult } \\
\text {-ural } \\
\text { import } \\
\text { tariffs }\end{array}$ & $\begin{array}{l}\text { Presen- } \\
\text { ce of } \\
\text { food } \\
\text { safety } \\
\text { nets }\end{array}$ & $\begin{array}{l}\text { Access } \\
\text { to fi- } \\
\text { nance } \\
\text { by } \\
\text { farmers }\end{array}$ \\
\hline South Africa & $39^{\text {th }}$ & $40^{\text {th }}$ & $13^{\text {th }}$ & $69^{\text {th }}$ & $47^{\text {th }}$ & $12^{\text {th }}$ & $32^{\text {nd }}$ & $47^{\text {th }}$ \\
\hline Egypt & $56^{\text {th }}$ & $69^{\text {th }}$ & $62^{\text {nd }}$ & $57^{\text {th }}$ & $61^{\mathrm{st}}$ & $107^{\text {th }}$ & $51^{\text {st }}$ & $47^{\text {th }}$ \\
\hline Ghana & $67^{\text {th }}$ & $77^{\text {th }}$ & $82^{\text {nd }}$ & $79^{\text {th }}$ & $75^{\text {th }}$ & $79^{\text {th }}$ & $51^{\text {st }}$ & $73^{\text {ro }}$ \\
\hline Nigeria & $86^{\text {th }}$ & $105^{\text {th }}$ & $101^{\mathrm{st}}$ & $103^{\text {rd }}$ & $84^{\text {th }}$ & $71^{\mathrm{st}}$ & $95^{\text {th }}$ & $73^{\text {rd }}$ \\
\hline Ethiopia & $90^{\text {th }}$ & $88^{\text {th }}$ & $80^{\text {th }}$ & $85^{\text {th }}$ & $97^{\text {th }}$ & $94^{\text {th }}$ & $76^{\text {th }}$ & $73^{\text {ro }}$ \\
\hline Mozambique & $93^{\text {rd }}$ & $93^{\text {rd }}$ & $90^{\text {th }}$ & $99^{\text {th }}$ & $100^{\text {th }}$ & $32^{\text {nd }}$ & $76^{\text {th }}$ & $73^{\text {rd }}$ \\
\hline Madagascar & $96^{\text {th }}$ & $99^{\text {th }}$ & $92^{\text {nd }}$ & $106^{\text {th }}$ & $103^{\text {rd }}$ & $58^{\text {th }}$ & $76^{\text {th }}$ & $73^{\text {rd }}$ \\
\hline Zambia & $100^{\text {th }}$ & $101^{\text {st }}$ & $100^{\text {th }}$ & $101^{\mathrm{st}}$ & $89^{\text {th }}$ & $84^{\text {th }}$ & $76^{\text {th }}$ & $73^{\text {rd }}$ \\
\hline Sudan & $104^{\text {th }}$ & $97^{\text {th }}$ & $96^{\text {th }}$ & $74^{\text {th }}$ & $79^{\text {th }}$ & $99^{\text {th }}$ & $95^{\text {th }}$ & $105^{\text {th }}$ \\
\hline DRC & $107^{\text {th }}$ & $107^{\text {th }}$ & $105^{\text {th }}$ & $91^{\mathrm{st}}$ & $107^{\text {th }}$ & $24^{\text {th }}$ & $95^{\text {th }}$ & $105^{\text {th }}$ \\
\hline
\end{tabular}

Source: EIU (2013) 
Although Ethiopia and Mozambique showed a similar ranking, the former outperformed the latter in most of the indicators except that of agricultural import tariffs. Madagascar and Zambia were also ranked close together, although the former outperformed the latter except in terms of the percentage of the population living under poverty line and GDP per capita. The same trend was observed between Sudan and the DRC, where the latter did better only in terms of agricultural import tariffs. From this it can be observed that the agricultural import tariff is a less relevant indicator of food affordability.

While GDP per capita showed a growing performance in both resource-rich and resourcepoor countries, the study showed that poverty reduction and wealth distribution were robust in resource-poor countries. Agriculture was the centrepiece of economic growth in resource-poor countries compared to resource-rich ones, which reinforces the fact that agriculture is a driver of poverty reduction and food security. Therefore, macroeconomic measures such as public investment in non-resource sectors, investment in agriculture and infrastructure to increase the countries competitiveness, and safety nets targeting vulnerable groups so as to quickly eradicate food insecurity, are important in resource-rich countries (Kidane et al., 2006).

The analysis of physical access showed that in most of the SSA region, infrastructure was at a very low level. This increases the transaction cost of production as well as marketing, which could be reflected in food price increases. While the lack of infrastructure and low level of productivity precludes Africa ${ }^{e e}$ s rural poor from harnessing their potential to increase productivity, improvements in infrastructure, especially in adequate energy and water/irrigation supplies, high-speed communications and seamless transport, can greatly improve food security (AfDB, 2012).

The political access analysis pointed out that politicians use food as a weapon to subdue opponents during situations of violent conflict. There is also an interrelationship between violent conflict and hunger, as causes and effects of one another. As was witnessed in the food price spike in 2007/2008, which resulted in a lack of access to food, riots and violence are triggered by such incidents. Corruption is another part of political access, which can reduce equitable income distribution overall and can hinder economic growth, which can directly affect individual food access. Food accessibility can also be affected by sociocultural factors, such as gender-biased household food allocation and social and cultural marginalisation of certain individuals and groups.

The review of the literature on the impact of economic growth and the role of agriculture in African food security reconfirmed that an agriculture-led economic growth strategy is a viable 
way of achieving food security objectives. It was highlighted that economic growth in itself is pro-poor, however the way of economic growth has greater implication in poverty reduction, achieving food security and equitable income distribution. In this regard, despite some scepticism about African agriculture, the role it plays as a driver of economic growth and poverty reduction, as well as a way to food security and maintaining equitable wealth distribution, was reinforced by theoretical, empirical and historical evidence.

From the recent experience of China, India and Vietnam, it is clear that resource distribution and investment priorities are important. For economic growth to have a more pronounced impact on poverty reduction, resources should be employed in economic sectors in which the poor are engaged, areas where the poor live, factors of production the poor possess (mostly unskilled labour) and outputs that the poor consume (e.g. food) (Pasha, 2002, cited in Kidane et al., 2006).

It is explicitly shown that agriculture fulfils these criteria, specifically in the case of Africa. While the challenges and constraints of the sector in achieving its goals are profound, SSA countries still have immense potential to harness the advantages of agricultural development. In the light of this, African countries have committed themselves to employ $10 \%$ of their GDP in agriculture through the NEPAD/CAADP initiative. Moreover, the importance of rural nonfarm sector and its linkage with the agricultural sectors has been highlighted as a tool in enhancing food security.

Food price volatility was identified as one of the major factors that influence household and individual economic accessibility of food. The 2007/2008 food price spike pushed about 44 million people in the developing world into poverty (World Bank, 2011, cited in EIU, 2012). Different reasons are identified for the price spike of 2007/2008, in which historically low levels of cereal stock, bad weather and a rise in the cost of production due to the high oil price were the supply-side factors. Biofuels have been identified as an important demand-side factor of the food price increase; according to some sources, biofuel production was responsible for $75 \%$ of the increase in food prices between 2002 and 2008 (Molony \& Smith, 2010). Also, increased utilisation of crops for animal feed associated with the increasing demand for high-value products in the emerging economies is another demand-side factor, besides market failure due to speculative pre-stocking.

The extent to which the global price is transmitted to the domestic price can be affected by local factors such as whether the countryes main staple is traded or non-traded, its level of infrastructure, whether the country is a net importer of food or not, and whether it is 
landlocked or not. While high food prices can be an opportunity for increased output and employment in agriculture in the long run, in the short term the urban and rural poor could be at risk of food insecurity, unless appropriate social protection and safety net mechanisms are put in place. Effective social protection schemes can enhance protection against poverty and protection against vulnerability via social insurance, and reduce the impact of social injustice and exclusion.

The rise of supermarkets and large-scale modern retailing industries have had a positive impact on the physical as well as economic accessibility of food, especially in urban and periurban areas, by supplying cheap and high-quality products. However, the rise of supermarkets has also put intense pressure on the livelihood and survival of small-scale farmers. The rapid and targeted expansion of supermarkets can affect small-scale farmers in SSA in two ways. First, small-scale farmers lose the local demand for their produce because of consumers buying in supermarkets, which in turn undermine the agricultural income multiplier effect. Secondly, because of stringent quality and safety standards set by the modern supply chain, small-scale farmers are often constrained in accessing the market (Heijden \& Vink, 2013; Weatherspoon \& Reardon, 2003). Therefore, supermarket-oriented approach is essential in promoting small-scale farmers while taking advantage of the quality and low-price products offered by them.

In terms of buffering against food supply and accessibility shocks and building the capabilities of vulnerable and marginalised groups in society, the importance of safety nets and social protection were highlighted. Effective social protection interventions can increase income and create assets, especially in rural Africa through the promotion of small-scale farmers, the rural non-farm sector and the landless poor (Alderman \& Hoddinott, 2007; Devereux, 2012). While there is a positive synergy between agricultural promotions and social protection, the role of social protection in promoting agricultural growth and poverty reduction is more vital (Devereux, 2012). Carefully designed social protection schemes can reduce seasonal hunger, increase farm income (which gives rise to better nutrition and stabilises agricultural yield) and also, through weather-indexed insurance, promote farmers ${ }^{\mathrm{ee}}$ risk-taking behaviours such as adopting high yield varieties and so on (Devereux, 2012; Ethiopian Government, 2009).

\subsection{Chapter Four: Analysis of food utilisation}

Although food utilisation is one of the three pillars of food security, neither food availability nor food accessibility necessarily guarantees overall food security, unless there is effective 
and efficient food utilisation. It has been found that nutritional security is the ultimate goal of the overall food system to enhance an active and healthy life. The term utilisation describes food quality and safety that aim to maintain nutritional security. The food quality and safety aspects of food utilisation comprise diverse and complex factors. While food quality refers to the nutritional standards and dietary micronutrient availability, food safety represents the nonfood parameters, such as access to clean water, health, education, and sanitation.

Malnutrition costs a significant share of the GDP of poor countries through increased healthcare expenses and losses of potential labour force. Also, its impact could be sustained throughout the life cycle and across generations. As a result, the African Union has implemented a project to assess the burden of undernutrition on the continent, with the theme "The cost of hunger in Africa" (AU, 2013). The prevalence of malnutrition can best be monitored through measures of child undernutrition, namely stunting, underweight, wasting and overweight. Child mortality rate is a major indicator of nutritional security, as about onethird of child mortality under the age of five globally is associated with undernutrition.

In this respect, the assessment of the nutritional status in the representative countries in Africa revealed that malnutrition remains the primary challenge of growth and development in the region. The performance in reducing child undernutrition in selected countries showed diverse outcomes, irrespective of the rate of GDP per capita growth (see Table 4.1). Overall, in terms of achieving MDG4, which is a two-thirds reduction in the mortality rate of children under the age of five between 1990 and 2015, most of the countries selected were on track. Only the DRC, Sudan and South Africa were below the required rate to achieve MDG4.

According to the analysis, the prevalence of stunting, underweight and wasting in children under the age of five showed the intensity of child malnutrition in Africa. While around 36\% of children under the age of five were stunted in SSA, sub-regional and intra-country variation was observed. The highest prevalence of stunting was recorded in Eastern Africa (45\%), Middle Africa (39\%) and Western Africa (38\%). There was only a 5\% reduction in the prevalence of stunting in SSA compared to the $43 \%$ reduction in Southeast Asia between 1990 and 2010 (De Onis et al., 2012). Three countries, Nigeria, Ethiopia and the DRC, contributed about $40 \%$ of the share of stunted children in Africa, with $19 \%, 14 \%$ and $8 \%$ respectively (Benson, 2004).

The review of the literature on factors that affect food utilisation and nutritional security showed a close correlation between economic growth and better nutrition. Some studies showed that there is a higher income elasticity of consumption of high-value nutritious food 
items such as meat, fish, milk, eggs and dairy products, as well as fruit and vegetables (Abdulai \& Aubert, 2004). However, per capita income growth alone cannot effectively address nutritional security and child malnutrition (Haddad et al., 2003; Smith \& Haddad, 2002).

Therefore, besides economic growth objectives, achieving nutritional security demands welldesigned policy and targeted nutritional intervention strategies. That is, economic growth should be „nutritional sensitive poverty and important social development (Headey, 2011). Compared to the non-agricultural sector, the promotion of agricultural growth has a more pronounced effect on minimising undernutrition and enhancing human wellbeing (Fan \& Pandya-Lorch, 2012; Headey, 2012).

In this respect, agriculture can better address nutritional security through various mechanisms attributed to it:-

i) An increase in farm income, both at the rural poor household level and the national level, will enhance better access to nutritious food and spending on other non-food factors of nutritional security (e.g. better health, education and sanitation). Also, small-scale farmers ${ }^{\text {ee }}$ income growth, especially in households controlled by women, has been proven to be highly effective.

ii) The food value chain, which comprises food production, storage, distribution, retail, preparation and consumption, is strongly correlated to nutrition and health. Besides the opportunity for increased employment and economic gain, the agroprocessing sector can reduce food waste, prevent micronutrient losses, reduce food-associated illnesses and increase nutrients through fortification (Miller \& Welch, 2013). However, critics also argue that the modern food industry is more concerned with profit than public health and nutritional security (Bouis \& Welch, 2010). In this respect, policy issues should incorporate the opportunities and threats associated with the rapid expansion of the modern food-processing and retail industries.

iii) Bio-fortification, which is a process that involves plant breeding or the use of "transgenic techniques", such as the application of micronutrients in fertilisers to enrich staple crops, is a promising mechanism of addressing nutritional challenges in developing countries (Bouis et al., 2013).

iv) Agriculture can be the most effective tool to overcome nutritional challenges, especially those facing rural poor households living in remote areas, through the 
supply of bio-fortified crop cultivars, by creating awareness and providing better nutritional security through agricultural extension programmes.

\subsection{Conclusion}

The recently updated concept of food security defines it as a situation that exists when all people, at all times, have physical, social and economic access to sufficient, safe and nutritious food that meets their dietary needs and food preferences for an active and healthy life. This definition of food security is found to be ambiguous when the point of analysis is at the household and individual level. This is because the adoption of the concept of "food preference" goes far beyond the actual measureable factors that practically determine individuals ${ }^{e e}$ choices and dietary preferences. To this end, it has been highlighted that the measurement of food security at the household and individual level remains open ended.

This definition of food security can also be broken down further into the four pillars of food security: food availability, accessibility, utilisation and stability. These pillars acknowledge both the physical and temporal determinates of food security, laying the foundation for a complex analysis of the concept according to both food and non-food parameters. As a result, food security analysis advanced from a simple target of achieving a specific dietary energy supply level (daily caloric food supply), to a more complex capability analysis. In this respect, by using the analytical framework of the EIU in their global food security index, this study investigated the food and nutritional security situation of Africa based on the three pillars of food security - food availability, accessibility, and utilisation. The stability dimension has been indirectly analysed considering production and food price volatility amongest its indicators.

The food availability analysis of the continent was done on the basis of the FBS method of the FAO, which focuses on per capita caloric food supply and its determining factors of food production, trade and food aid. The analysis of long-term caloric food supply trends identified the Northern and Western Africa regions as those with relatively better performance. The Southern Africa region recorded rather stagnant performance, while Middle and Eastern Africa started realising a growth rate since the mid-1990s in caloric supply after long-term deterioration. Out of fifty African countries with available data, twenty-one countries of SSA were still below the FAO's standard of daily caloric food supply of $2300 \mathrm{Kcal} /$ capita/day by the year 2009, which are mostly located in Eastern and Middle Africa (see Addendum A).

Among the case study countries, impressive growth in caloric food supply was registered in Ghana and Egypt between 1970 and 2012. These countries performed better than the average 
growth rate in South East Asia. Moreover, of the selected countries, Ghana and Ethiopia registered steep growth in caloric food supply in the last twenty years, after a declining performance between 1970 and 1990. In contrast, Madagascar and Zambia recorded a declining growth rate in caloric food supply during the same period.

In terms of other important food availability indicators, the DRC was found to be outstandingly negative. The agricultural production growth rate of all commodities studied showed a deteriorating performance, coupled with the highest level of agricultural trade deficit and the lowest level of food accessibility and utilisation. It could be argued that political instability and civil strife have contributed a lot to the intensification of food insecurity in that country. Therefore the study concludes that political stability, peace and security are the most important preconditions for food security.

Out of the case study countries Zambia was also found to have a high level of food insecurity. Around $47 \%$ of the population was found to be undernourished, with the lowest dietary energy supply of only $1860 \mathrm{kcal} / \mathrm{capita} / \mathrm{day}$ in 2012. While it showed a deteriorating performance in terms of caloric food supply and per capita production of most of the commodities studied, the level of agricultural import was found to be lower than the level of agricultural export. The food accessibility parameters also indicated that, between 1996 and 2006 , the level of poverty and inequality increased, in spite of a $1.5 \%$ annual GDP per capita growth rate. In terms of utilisation, although some progress was recorded (especially in access to improved water access and sanitation services) relative to some of the case study countries, it remained at the lowest level overall.

Nigeria also recorded a deteriorating performance in caloric food supply and per capita production of all of the commodities analysed, with an increasing rate of agricultural trade deficit. Although the country is recognised for a relatively higher level of caloric food supply (2 $700 \mathrm{kcal} / \mathrm{capita} /$ day) and a lower level of prevalence of undernourishment $(8.5 \%)$, the food supply variability was found to be the highest of all the countries investigated in the year 2012. Moreover, although a 2.5\% per capita GDP growth rate was recorded between 1996 and 2010, the level of poverty did not show a significant reduction; rather, the level of inequality increased within the same period. While a relatively better performance was recorded in terms of food availability, Nigeria showed the lowest level of food affordability according to the EIU index (2013). It also recorded insufficient progress towards reducing child mortality, and had a high level of dietary iron deficiency. Access to improved water and sanitation was also observed to be low. 
Mozambique and Ethiopia showed an almost similar trend in food security situation, where the latter slightly outperformed the former in terms of the per capita production growth rate of some commodities. While both registered a marginal growth rate of per capita caloric intake, Ethiopia showed a higher import dependency than Mozambique. On the other hand, cereal aid showed higher reduction in Mozambique than in Ethiopia during the case study period. While both countries showed a relatively higher per capita GDP growth rate, the level of poverty was also reduced significantly in both compared to the other case study countries. However, in terms of reducing inequality, Ethiopia outperformed Mozambique, which showed a slight increase. In terms of food utilisation, the two countries showed an almost similar trend of micronutrient availability and a lower level of water and sanitation accessibility.

Madagascar and Sudan showed a marginal growth rate of $0.3 \%$ in per capita caloric food supply in the study period of 1961 to 2011 . While a marginal increase in production of most agricultural commodities was recorded in Madagascar, Sudan recorded the reverse. The agricultural trade deficit was also found to be higher in Sudan. Moreover, cereal aid showed a slight increasing rate in Sudan than in the rest of the case study countries. The economic analysis of the period between 1993 and 2010 showed that, while a reduction of $-0.2 \%$ in GDP per capita was recorded in Sudan, the level of poverty showed an increase from $72 \%$ to $81 \%$. In terms of utilisation, Sudan outperformed Madagascar in micronutrient availability, diet diversification and improved access to water and sanitation.

Although South Africa was the most food secure country in the SSA region, it was outperformed by Egypt and Ghana in terms of the level of dietary energy supply and its annual growth rate. South Africa recorded the highest rate of reduction in per capita cereal and roots and tuber production of all the case study countries (except the DRC). This is also confirmed by South Africa showing the highest rate of reduction in SSR, a significant increase in IDR and a high rate of growth in the agricultural trade deficit. While Ghana showed impressive progress in the majority of the food security indicators, it lagged behind in average protein supply and micronutrient availability. It recorded a prevalence of more than $50 \%$ of dietary iron and vitamin A deficiency in children under the age of five. South Africa, Egypt and Ghana all showed a reduction in the level of poverty, coupled with an increase in GDP per capita, while Ghana and South Africa showed increment in the level of inequality (increase in GINI index).

With respect to the food utilisation rankings of the EIU (2013), South Africa outperformed Egypt, although the latter did well in terms of food safety and child malnutrition. Egypt 
outperformed South Africa and the rest of the case study countries in terms of non-food parameters of nutritional indicators, such as access to clean water and sanitation. Ghana, on the other hand, fared very well in terms of improved access to water, while it recorded one of the lowest levels of improved access to sanitation.

Generally, the qualitative research on the role of agriculture in food security identified it as a vital means of promotion of all the three dimensions of food security. When it comes to food availability, agricultural growth was found to be the most important segment of national food supply. To this end, Egypt, Ethiopia, Mozambique, Sudan and Zambia registered a higher level of yield growth rate than area expansion for cereal production in the study period. It has been also highlighted that African agricultural productivity was hampered significantly by conflict and political instability, rapid population growth, climate change and the spread of HIV/AIDS, among other things. The fact that the majority of the rural poor and food insecure population of Africa is dependent on small-scale subsistence farming calls for more support strategies that will help them overcome the challenges they face.

As far as food accessibility is concerned, agricultural growth was found to be the backbone of economic growth and the equitable distribution of wealth in Africa. Compared to the mineral resource-dependent economies among the case study countries, such as South Africa, Nigeria and Zambia, those countries that relied on agriculture for their economic growth achieved more poverty reduction and income distribution in recent years. Moreover, agricultural growth enhanced the growth of the rural non-farm sector through its multiplier effect, which can reduce poverty and increase food accessibility.

Agricultural growth was also identified as the best way of addressing Africaes nutritional insecurity and enhancing better food utilisation. Its linkage with the rest of the economy and the engagement of the majority of Africa ${ }^{e e s}$ poor in agriculture make it a valuable means of economic growth and raising household income to improve nutrition and access to better education, health and sanitation. Agricultural growth enhances nutritional security through the provision of cheap and nutritious food, and its important relationship with the food value chain (industrial fortification), bio-fortification and the advantage of using extension services as a tool for addressing nutritional objectives in remote rural areas makes it vital. However, for agriculture to become the engine of economic growth and a means of food and nutritional security, African countries should find ways of overcoming the barriers and constraints faced by each country 
In conclusion, the study found great diversity in food and nutritional security status of the countries studied. Comparatively resource poor countries that primarily relay on agriculture performed better in terms of poverty reduction and wealth distribution. It can be argued that agricultural promotion accompanied with political stability, investment on infrastructure, national and regional market integration together with maintaining productive and sustainable safety nets and social protection schemes are very important determinants of food and nutritional security in Africa. Further studies at the national and household level are essential for effective implementation of agricultural led strategies of addressing food and nutritional security that are highlighted in this study. 


\section{Bibliography}

ABDULAI, A. and AUBERT, D., 2004. A cross-section analysis of household demand for food and nutrients in Tanzania. Agricultural Economics, 31(1), pp. 67-79..

AFDB, 2012. Highlights of the food security situation in Africa. AfDB brief Africa food security, Quarterly Bulletin(Issue 3), pp. 1-16.

AFDR, 2010. African Development Report 2010. New York: Oxford University Press Inc.,.

AIDT, T.S., 2009. Corruption, institutions, and economic development. Oxford Review of Economic Policy, 25(2), pp. 271-291.

AKSOY, M.A. and BEGHIN, J.C., 2005. Global agricultural trade and developing countries. Washington DC: World Bank Publications.

ALDERMAN, H. \& HODDINOTT, J. 2007. Growth-promoting social safety nets. 2020 Focus Brief on the World's poor and hungry people, Washington, DC: International Food Policy Research Institute.

ALEXANDRATOS, N. \& BRUINSMA, J. 2012. World agriculture towards 2030/2050: The 2012 Revision. ESA Working paper No. 12-03. Rome: FAO.

ALLEN, L.H. 2003. Interventions for micronutrient deficiency control in developing countries: Past, present and future. The Journal of Nutrition, 133(11): 3875S-3878S.

ARDA, M., 2006. Food Retailing, Supermarkets and Food Security. Research Paper No. 2006/107. Helsinki, Finland: United Nations University-World Institute for Development Economics Research.

ASONGU, S.A. 2012. Politics \& consumer prices in Africa. Global Journal of HUMAN SOCIAL SCIENCE Sociology, Economics \& Political Science, 12(11): 1-10.

AU. 2013. The cost of hunger in Africa. African Union, UN Economic Commission for Africa, World Food Program.

BABU, S.C. and SANYAL, P., 2009. Chapter 1 - Introduction to food security: concepts and measurement. In: S.N. GAJANAN, ed, Food Security, Poverty and Nutrition Policy Analysis. San Diego: Academic Press, pp. 5-15.

BADIANE, O. and DELGADO, C.L., eds, 1995. A 2020 Vision for Food, Agriculture, and the Environment in Sub-Saharan Africa. Washington DC: Intl Food Policy Res Inst.

BAKKER, H. 2011. Food security in Africa and Asia: Strategies for small-scale agricultural development. London, UK: CAB International.

BALARAJAN, Y., RAMAKRISHNAN, U., ÖZALTIN, E., SHANKAR, A.H. \& SUBRAMANIAN, S. 2011. Anaemia in low-income and middle-income countries. The Lancet, 378(9809):2123-2135. 
BARRETT, C.B. 2010. Measuring food insecurity. Science, 327(5967): 825-828.

BENSON, T.D., 2004. Africa's food and nutrition security situation: where are we and how did we get here? Assuring Food and Nutrition Security in Africa by 2020: Prioritizing Actions, Strengthening Actors, and Facilitating Partnership, April 1-3, 2004, International Food Policy Research Institute, pp. 1-65.

BERTI, P.R., KRASEVEC, J. \& FITZGERALD, S. 2004. A review of the effectiveness of agriculture interventions in improving nutrition outcomes. Public Health Nutrition, 7(05): 599-609.

BINSWANGER-MKHIZE, H.P. 2009. Challenges and opportunities for African agriculture and food security: High food prices, climate change, population growth, and HIV and AIDS. In How to feed the World in 2050. Proceedings of a technical meeting of experts, Rome, Italy, 24-26 June 2009. Food and Agriculture Organization of the United Nations (FAO): 1-54.

Black, R.E. 2013. Maternal and Child Undernutrition and Overweight in Low-Income and Middle-Income Countries. The Lancet, 382(9890):427-51.

BOUIS, H.E. 2003. Micronutrient fortification of plants through plant breeding: Can it improve nutrition in man at low cost? Proceedings of the Nutrition Society, 62(2):403-412.

BOUIS, H.E. \& WELCH, R.M. 2010. Biofortification-A sustainable agricultural strategy for reducing micronutrient malnutrition in the global south. Crop Science, 50(Supplement_1):S-20-S-32.

BOUIS, H., LOW, J., MCEWAN, M. \& TANUMIHARDJO, S. 2013. Biofortification: Evidence and lessons learned linking agriculture and nutrition [Online]. Available:

http://www.fao.org/fileadmin/user upload/agn/pdf/Biofortification paper.pdf [2013, August 8].

BOUSSARD, J., DAVIRON, B., GÉRARD, F. and VOITURIEZ, T., 2005. Food security and agricultural development in Sub-Saharan Africa: Building a case for more support. Citeseer.

BREMNER, J. 2012. Population and food security: Africa's challenge [Online]. Available: http://www.prb.org/pdf12/population-food-security-africa.pdf [2013, February 2].

BUNDY, D.A. 2009. Rethinking school feeding: Social safety nets, child development, and the education sector. Washington DC: World Bank Publications.

BURCHI, F. \& DE MURO, P. 2012. A human development and capability approach to food security: Conceptual framework and informational basis. Rome: United Nations Development Programme Regional Bureau for Africa.

BUSH, R. 2010. Food Riots: Poverty, power and protest. Journal of Agrarian Change, 10(1):119-129.

CARMIGNANI, F. 2011. The making of pro-poor growth. Scottish Journal of Political Economy, 58(5):656-684.

CHOPRA, M., GALBRAITH, S. \& DARNTON-HILL, I. 2002. A global response to a global problem: The epidemic of over nutrition. Bulletin of the World Health Organization, 80(12):952-958.

CHRISTIAENSEN, L., DEMERY, L. \& KUHL, J. 2011. The (evolving) role of agriculture in poverty reduction-An empirical perspective. Journal of Development Economics, 96(2):239-254. 
CIA, Nov. 4, 2013-last update, The World Fact Book [Homepage of Central Intelligence Agency], [Online]. Available: https:/www.cia.gov/library/publications/the-world-factbook/ [November/16, 2013].

CIESIN, 2005. Poverty mapping project: Global subnational prevalence of child malnutrition. Palisades. Center for International Earth Science Information Network (CIESIN)/Columbia University edn. New York: NASA Socioeconomic Data and Applications Center (SEDAC).

CLARK, D.A. 2005. The capability approach: Its development, critiques and recent advances. GPRG-WPS-032.University of Manchester, UK: Global Poverty Research Group.

CLAY, E. 2002. Food security: concepts and measurement. Trade and Food Security: Conceptualizing the Linkages, 11-12 July 2002, pp. 25-34.

COLLIER, P. 2002. Primary commodity dependence and Africa's future. Annual World Bank Conference on Development Economics 2003. World Bank Publications, pp. 139-161.

CUNNINGHAM, L. 2005. Assessing the contribution of aquaculture to food security: A survey of methodologies. Rome: Food and Agricultural Organization of the United Nations.

DEB, U., HOSSAIN, M. \& JONES, S. 2009. Rethinking food security strategy: Self-sufficiency or selfreliance [Online]. Available: http://www.bracresearch.org/publications/monograph dfid3.pdf [2013, April 6].

DE JANVRY, A. \& SADOULET, E. 2010. Agriculture for development: new paradigm and options for success. Agricultural Economics, 41:17-36.

DE ONIS, M., BLÖSSNER, M. \& BORGHI, E., 2012. Prevalence and trends of stunting among pre-school children, 1990-2020. Public Health Nutrition, 15(1):142-148.

DE ONIS, M., BLÖSSNER, M., BORGHI, E., MORRIS, R. \& FRONGILLO, E.A. 2004. Methodology for estimating regional and global trends of child malnutrition. International Journal of Epidemiology, 33(6):1260-1270.

DERCON, S. 2009. Rural poverty: Old challenges in new contexts. The World Bank Research Observer, 24(1):1-28.

DE ROSE, L.F., MESSER, E. \& MILLMAN, S. 1998. Who's hungry? And how do we know? Food shortage, poverty, and deprivation. Tokyo [u.a.]: United Nations Univ. Press.

DE VAAL, A. \& EBBEN, W. 2011. Institutions and the relation between corruption and economic growth. Review of Development Economics, 15(1):108-123.

DEVEREUX, S. 1999. 'Making less last longer': Informal safety nets in Malawi. Brighton, England: Institute of Development Studies, University of Sussex.

DEVEREUX, S. 2012. Social protection for enhanced food security in sub-Saharan Africa. WP 2012-010. Brighton, UK: UNDP Regional Bureau for Africa.

DEVEREUX, S. \& MAXWELL, S. 2001. Food security in sub-Saharan Africa. illustrated, reprint edn. University of Sussex, Institute of Development Studies: ITDG Publishing. 
DE WAAL, A. and TUMUSHABE, J., 2003. HIV/AIDS and food security in Africa. http://www.sarpn.org/documents/d0000235/P227 AIDS Food Security.pdf edn. DFID.

D'HAESE, M. \& VAN HUYLENBROECK, G. 2005. The rise of supermarkets and changing expenditure patterns of poor rural households case study in the Transkei area, South Africa. Food Policy, 30(1):97113.

DIAO, X. 2007. The role of agriculture in development: Implications for Sub-Saharan Africa.

Washington DC: International Food Policy Research Inst.

DIAO, X. 2010. Economic Importance of agriculture for sustainable development and poverty reduction: Findings from a case study of Ghana. Global Forum on Agriculture: Policies for Agricultural Development, Poverty Reduction and Food Security, 29-30 November, OECD.

DIAO, X. 2012. Strategies and priorities for African agriculture: Economy wide perspectives from country studies. Washington DC: Intl Food Policy Res Inst.

DIAO, X., HAZELL, P. \& THURLOW, J. 2010. The role of agriculture in African development. World Development, 38(10):1375-1383.

DILLON, B.M. \& BARRETT, C.B. 2013. The impact of world oil price shocks on maize prices in East Africa [Online]. Available: http://cf.fbe.unimelb.edu.au/seminars/app/UploadedDocs/Doc236.pdf date accessed?.

DREZE, J. \& SEN, A. 1989. Hunger and public action. New York: Oxford University Press.

ECKER, O., MABISO, A., KENNEDY, A. \& DIAO, X. 2011. Making agriculture pro-nutrition: Opportunities in Tanzania. IFPRI Discussion Paper 01124. Washington DC: International Food Policy Research Institute (IFPRI).

ECKER, O., WEINBERGER, K. \& QAIM, M. 2010. Patterns and determinants of dietary micronutrient deficiencies in rural areas of East Africa. AfJARE, 4(2):175-194.

EIU. 2012. Global food security index 2012 an assessment of food affordability, availability and quality London: Economics intelligence Unit.

EIU. 2013. Global food security index [Online]. Available: http://foodsecurityindex.eiu.com/ [2013, August 10].

ELLIS, F. 2005. Small farms, livelihood diversification, and rural-urban transitions: Strategic issues in sub-Saharan Africa. The Future of Small Farms, June 26-29, 2005, International Food Policy Research Institute (IFPRI), Washington, DC., pp. 135-149.

ELMULTHUM, N.A.M., AWAAD, M.E.A. \& ELAMIN, A.E.M. 2011. Can Sudan achieve food security during the next decade? Some forecasts of self-sufficiency in cereals. Scientific Research and Essays, 6(3):529-532.

Encyclopædia Britannica. 2013. Zoonosis. [Online]. Available: http://www.britannica.com/EBchecked/topic/657986/zoonosis [2013, October19]

ETHIOPIAN GOVERNMENT. 2009. Food Security Programme 2010-2014: Productive Safety Net. Addis Ababa: Ministry of Agriculture and Rural Development. 
FAN, S. \& BRZESKA, J. 2011. The nexus between agriculture and nutrition: Do growth patterns and conditional factors matter? Leveraging agriculture for improving nutrition and health: 2020 CONFERENCE BRIEF 1, International Food Policy Research Institute, pp. 31-38.

Fan, S. \& R. Pandya-Lorch(eds.) 2012. Reshaping agriculture for nutrition and health. An IFPRI 2020 book. Washington, DC 20006-1002, U.S.A: Intl Food Policy Res Inst

FANZO, J. 2012. The nutrition challenge in sub-Saharan Africa. Rome: United Nations Development Programme Regional Bureau for Africa.

FAO, 1996. Rome Declaration on World Food Security and World Food Summit Plan of Action, World Food Summit, November 13-17, Food and Agricultural Organization of United Nations.

FAO. 2001. Food balance sheets - $A$ handbook [Online]. Available: http://www.fao.org/docrep/003/X9892E/X9892E00.htm\#TopOfPage [2013, May 15].

FAO. 2006a. Food security. Rome: FAO Agriculture and Development Economics Division.

FAO. 2006b. Import surges in developing countries, the case of poultry [Online]. Available: ftp://ftp.fao.org/docrep/fao/009//8672e/i8672e00.pdf [2013, May 13].

FAO. 2008a. An introduction to the basic concepts of food security [Online]. Available: www.foodsec.org/docs/concepts guide.pdf [2013, January 16]

FAO. 2008b. The state of food insecurity in the world 2008: High food prices and food security threats and opportunities. Italy, Rome: Food and Agricultural Organization of United Nations.

FAO. 2012a. The state of food insecurity in the world 2012: Economic growth is necessary but not sufficient to accelerate reduction of hunger and malnutrition. Rome: Food and Agricultural Organization of United Nations.

FAO. 2012b. Food balance sheets [Online]. Available: http://faostat3.fao.org/home/index.html\#DOWNLOAD [2013, March 5].

FAO. 2013. Food security indicators [Online]. Available: http://www.fao.org/publications/sofi/foodsecurity-indicators/en/ [2013, March 5].

FAOSTAT. 2013. FAOSTAT database [Online]. Available: http://faostat.fao.org/site/291/default.aspx [2013, May 14].

FOTSO, J. 2007. Urban-rural differentials in child malnutrition: Trends and socioeconomic correlates in sub-Saharan Africa. Health \& Place, 13(1):205-223.

FUGLIE, K. \& NIN-PRATT, A. 2012. A changing global harvest [Online]. Available: http://www.ifpri.org/sites/default/files/publications/gfpr2012 ch02.pdf [2013, March 18].

GATES, B. 2012. Annual letter 2012 - Bill \& Melinda Gates Foundation [Online]. Available: http://www.gatesfoundation.org/Who-We-Are/Resources-and-Media/Annual-Letters-List/AnnualLetter-2012 [2013, February 26].

GEDA, A., SHIMELES, A. \& WEEKS, J. 2009. Growth, poverty and inequality in Ethiopia: Which way for pro-poor growth? Journal of International Development, 21(7):947-970. 
GILLIGAN, D., HODDINOTT, J., KUMAR, N. \& TAFFESSE, A. 2009. Can social protection work in Africa? Evidence on the impact of Ethiopia's Productive Safety Net Programme on food security, assets and incentives. (August 18, 2009), Available at SSRN: http://ssrn.com/abstract=1457172 or http://dx.doi.org/10.2139/ssrn.1457172 .

GODFRAY, H.C.J., CRUTE, I.R., HADDAD, L., LAWRENCE, D., MUIR, J.F., NISBETT, N., PRETTY, J., ROBINSON, S., TOULMIN, C. \& WHITELEY, R. 2010. The future of the global food system. Philosophical Transactions of the Royal Society B: Biological Sciences, 365(1554):2769-2777.

GRAAFF, J., KESSLER, A. \& NIBBERING, J. 2011. Agriculture and food security in selected countries in sub-Saharan Africa: Diversity in trends and opportunities. Food Security, 3(2):195-213.

GROSS, R., SCHOENEBERGER, H., PFEIFER, H. \& PREUSS, H. 2000. The four dimensions of food and nutrition security: Definitions and concepts. SCN News, 20:20-25.

HADDAD, L., ALDERMAN, H., APPLETON, S., SONG, L. \& YOHANNES, Y. 2003. Reducing child malnutrition: How far does income growth take us? The World Bank Economic Review, 17(1):107131.

HADLEY, C., LINDSTROM, D., TESSEMA, F. \& BELACHEW, T. 2008. Gender bias in the food insecurity experience of Ethiopian adolescents. Social Science \& Medicine, 66(2):427-438.

HAGGBLADE, S., HAZELL, P. \& REARDON, T. 2010. The rural non-farm economy: Prospects for growth and poverty reduction. World Development, 38(10):1429-1441.

HAUSMAN, J. \& LEIBTAG, E. 2007. Consumer benefits from increased competition in shopping outlets: Measuring the effect of Wal-Mart. Journal of Applied Econometrics, 22(7):1157-1177.

HAWKES, C. \& RUEL, M.T. 2012. Value chains for nutrition, in S. FAN \& R. PANDYA-LORCH (eds.). Reshaping agriculture for nutrition and health (pp. 73-82). Washington DC: International Food Policy Research Institute.

HAZELL, P., POULTON, C., WIGGINS, S. \& DORWARD, A. 2007. The future of small farms for poverty reduction and growth. 2020 Discussion Paper 42, Washington, D.C.: International Food Policy Research Institute.

HDR. 2013. The rise of the South: Human Progress in a diverse world. Statistical annex. New York: United Nations Development Programme (UNDP).

HEADEY, D. 2012. Turning economic growth into nutrition-sensitive growth, in S. FAN \& R. PANDYALORCH (eds.). Reshaping agriculture for nutrition and health (pp. 35-46). Washington DC: International Food Policy Research Institute.

HEATON, J. 2004. What is secondary analysis? in J. HEATON (ed.). Reworking qualitative data (pp. 119). PLACE?: SAGE Publications Ltd.

HEIDHUES, F., ATSAIN, A., NYANGITO, H., PADILLA, MARTINE, GHERSI, GERARD and LE VALLEE, J., 2004. Development strategies and food and nutrition security in Africa: An assessment. Washington DC: International Food Policy Research Institute. 
HEIJDEN, T.V.D. \& VINK, N. 2013. Good for whom? Supermarkets and small farmers in South Africa A critical review of current approaches to increasing access to modern markets. Agrekon, 52(1):6886.

HODDINOTT, J. \& YOHANNES, Y. 2002. Dietary diversity as a food security indicator. Washington, DC: International Food Policy Research Institute.

HURRELL, R.F. 1997. Preventing iron deficiency through food fortification. Nutrition Reviews, 55(6):210-222.

IFPRI. 2004. Ending hunger in Africa: Prospects for the small farmer [Online]. Available: http://www.ifpri.org/sites/default/files/pubs/pubs/ib/ib16.pdf [2013, January 24].

IFPRI. 2008. Sustaining and accelerating Africa's agricultural growth recovery in the context of changing global food prices [Online]. Available:

http://www.ifpri.org/sites/default/files/pubs/pubs/bp/bp009.pdf [2013, June 5]

IPAR. 2009. Rwandan agricultural sector situational analysis. IPAR Rwanda Report. Rwanda: Institute of Policy Analysis and Research.

IFPRI. 2011. Global Hunger Index 2011. The challenge of hunger: Taming price spikes and excessive food price volatility. Washington DC: International Food Policy Research Institute.

IFPRI. 2012. The challenge of hunger: Ensuring sustainable food security under land, water, and energy stresses. Global Hunger Index 2012. Washington DC: International Food Policy Research Institute.

IVERS, L.C. \& CULLEN, K.A. 2011. Food insecurity: Special considerations for women. The American Journal of Clinical Nutrition, 94(6):1740S-1744S.

JACOBS, K. \& SUMNER, D.A. 2002. The food balance sheets of the Food and Agriculture Organization: A review of potential ways to broaden the appropriate uses of the data [Online]. Available: ftp://ksph.kz/Chemistry Food\%20Safety/TotalDietStudies/FBS Rev.pdf [2013, March 4].

Johnston, B.F. \& Mellor, J.W. 1961. The Role of Agriculture in Economic Development. The American Economic Review, 51(4):566-93.

KALA, N., KURUKULASURIYA, P. \& MENDELSOHN, R. 2012. The impact of climate change on agroecological zones: Evidence from Africa. Environment and Development Economics, 17(6):663-687.

KARUGIA, J., WAITHAKA, M., FREEMAN, A., PRABHU, R., SHIFERAW, B., GBEGBELEGBE, S., MASSAWE, S., KYOTALIMYE, M., WANJIKU, J. \& MACHARIA, E. 2009. Responding to food price crisis in Eastern and Southern Africa: Policy options for national and regional action. ReSAKSS Working Paper No. 27. Nairobi, Kenya: IFPRI.

KEARNEY, J. 2010. Food consumption trends and drivers. Philosophical Transactions of the Royal Society B: Biological Sciences, 365(1554):2793-2807.

KELLY, A., BECKER, W. \& HELSING, E. 1991. Food balance sheets, in W. BECKER \& HELSING E. (eds.). Food and health data: Their use in nutrition policy-making (pp. 39-47). WHO Regional Publications, European Series. DENMARK: World Health Organization. 
KIDANE, W., MAETZ, M. \& DARDEL, P. 2006. Food security and agricultural development in subSaharan Africa: Building a case for more public support. Policy assistance series 2. Rome: FAO.

KROEF, J.M.V.D. 1995. The benefits of famine: A political economy of famine and relief in Southwestern Sudan,1983-1989 by David Keen. Annals of the American Academy of Political and Social Science, 541(1):191-192.

LANDIS, R.P. 2010. EU protectionism killing Africa's poor [Online]. Available: http://www.la.org.au/opinion/041010/eu-protectionism-killing-africa's-poor [2013, February 26].

LANJOUW, J.O. \& LANJOUW, P. 2001. The rural non-farm sector: Issues and evidence from developing countries. Agricultural Economics, 26(1):1-23.

LOAYZA, N.V. \& RADDATZ, C. 2010. The composition of growth matters for poverty alleviation. Journal of Development Economics, 93(1):137-151.

LUAN, Y., CUI, X. \& FERRAT, M. 2013. Historical trends of food self-sufficiency in Africa. Food Security, something missing:1-13.

Madziakapita, A. 2009. An evaluation of the impact of food aid on food security: The case of ngabu area in Malawi. Unpublished thesis. Pretoria: University of South Africa. Master of Administration

MALTHUS, T.R. 1798. An essay on the principle of population as it affects the future improvement of society, with remarks on the speculations of Mr. Godwin, M. Condorcet, and other writers. London: St. Paul's Church-Yard.

MAXWEL, L. 2012. Food security and its implications for political stability: A humanitarian perspective. NOT CLEAR WHAT TYPE OF REFERENCE THIS IS, Food Security and Its Implications for global stability, September 13-14 2012, Food and Agricultural Organization of United Nations.

MAXWELL, S. 1996. Food security: A post-modern perspective. Food Policy, 21(2):155-170.

MCKINSEY. 2010. Lions on the move: The progress and potential of African economies. New York: McKinsey Global Institute. Available: http://www.mckinsey.com/insights/africa/lions_on_the_move

MEADE, B. \& ROSEN, S. 2013. International Food Security Assessment, 2013-2023. GFA-24. Washington, DC: United States Department of Agriculture, Economic Research Service.

MEASURE DHS. 2013. MEASURE DHS - Demographic and Health Survey [Online]. Available: http://www.measuredhs.com/What-We-Do/Survey-Types/DHS.cfm [2013, July 20].

MESSER, E. \& COHEN, M.J. 2004. Breaking the links between conflict and hunger in Africa. 2020 Africa Conference Brief 10 edn. PLACE? International Food Policy Research Institute.

MESSER, E. \& COHEN, M.J. 2011. Understanding and responding to the links between conflict and hunger. Development in Practice, 21(4-5):481-487.

Miller, B.D.D. \& Welch, R.M. 2013. Food System Strategies for Preventing Micronutrient Malnutrition. Food Policy, 42(0):115-28. 
MINTEN, B. \& REARDON, T. 2008. Food prices, quality, and quality's pricing in supermarkets versus traditional markets in developing countries. Applied Economic Perspectives and Policy, 30(3):480-490.

MINTEN, B., REARDON, T. \& SUTRADHAR, R. 2010. Food prices and modern retail: The case of Delhi. World Development, 38(12):1775-1787.

MO, P.H. 2001. Corruption and economic growth. Journal of Comparative Economics, 29(1):66-79.

MOLONY, T. \& SMITH, J. 2010. Biofuels, food security, and Africa. African Affairs, 109(436):489-498.

MOSS, T. \& BANNON, A. 2004. Africa and the battle over agricultural protectionism. World Policy Journal, 21(2):53-61.

MSANGI, S., UTAH, A. \& BATKA, M. 2012. African agricultural futures: Opportunities, challenges and priorities. Food security in Africa: Bridging research and practice, 29-30 November 2012, Australian Centre for International Agricultural Research. p. 3.

MÜLLER, C., CRAMER, W., HARE, W.L. \& LOTZE-CAMPEN, H. 2011. Climate change risks for African agriculture. Proceedings of the National Academy of Sciences of the United States of America, 108(11):4313.

MWANIKI, A. 2006. Achieving food security in Africa: challenges and issues [Online]. Available: http://www.un.org/africa/osaa/reports/Achieving\%20Food\%20Security\%20in\%20AfricaChallenges\%20and\%20lssues.pdf [2012, September 10].

NESTEL, P., BOUIS, H.E., MEENAKSHI, J.V. \& PFEIFFER, W. 2006. Biofortification of staple food crops. The Journal of Nutrition, 136(4):1064-1067.

Nestle, M. 2007. Food politics: How the food industry influences nutrition and health. Berkeley and Los Angeles, California: University of California Press, Ltd.

OECD. 2012. Agricultural Policy Monitoring and Evaluation 201: OECD Countries. OECD Publishing. Available at: http://dx.doi.org/10.1787/agr_pol-2012-en

ORTIZ, I., CHAI, J. \& CUMMINS, M. 2011. Escalating food prices: The threat to poor households and policies to safeguard a recovery for all. New York: UNICEF Working Paper.

Osmani, S.R. 1993. The entitlement approach to famine: An assessment. Helsinki, Finland: The United Nations University

PAARLBERG, R. 2010. Food politics: What everyone needs to know. U.S.A: Oxford University Press.

PANAGARIYA, A. 2002. Trade and food security: Conceptualizing the linkages. Presentation at the Conference on Trade, Agricultural Development, and Food Security: The Impact of Recent Economic and Trade Policy Reform, Food and Agricultural Organization, Rome, July 2002, pp. 11-12.

Patel, R. \& McMichael, P. 2010. A Political Economy of the Food Riot. A Political-Economy of Some Twenty-First Century Food Rebellions, 1(9-35). http://rajpatel.org/wpcontent/uploads/2009/11/patel-mcmichael-2010Review321.pdf

PAUW, K. \& THURLOW, J. 2011. Agricultural growth, poverty, and nutrition in Tanzania. Food Policy, 36(6):795-804. 
Pegg, S. 2003. Poverty Reduction Or Poverty Exacerbation? Paper presented at World Bank Group support for extractive industries in Africa. Report sponsored by Oxfam America, Friends of the Earth-US, Environmental Defense, Catholic Relief Services, Bank Information Center, Washington, DC.

PINSTRUP-ANDERSEN, P. 2009. Food security: Definition and measurement. Food Security, 1(1):5-7.

PINSTRUP-ANDERSEN, P. 2012. The food system and its interaction with human health and nutrition, in S. FAN \& R. PANDYA-LORCH (eds.). Reshaping agriculture for nutrition and health (p. 21). Intl Food Policy Res Inst,. publisher and place of publication required.

POPKIN, B.M. 2001. Nutrition in transition: The changing global nutrition challenge. Asia Pacific Journal of Clinical Nutrition, 10:S13-S18.

QAIM, M., STEIN, A.J. \& MEENAKSHI, J.V. 2007. Economics of bio fortification. Agricultural Economics, 37:119-133.

QUISUMBING, A.R., BROWN, L.R., FELDSTEIN, H.S., HADDAD, L. \& PEÑA, C. 1995. Women: The key to food security. Washington DC: International Food Policy Research Institute.

RAHMAN, A. \& KARIM, R. 2013. Prevalence of food insecurity among women in rural area of North West Bangladesh. Pakistan Journal of Nutrition, 12(4):329-333.

RAKOTOARISOA, M., IAFRATE, M. \& PASCHALI, M. 2011. Why has Africa become a net food importer. PLACE? Trade and Markets Division, Food and Agriculture Organization of the United Nations.

RANIS, G., STEWART, F. \& RAMIREZ, A. 2000. Economic growth and human development. World Development, 28(2):197-219.

REARDON, T. 2006. The rapid rise of supermarkets and the use of private standards in their food product procurement systems in developing countries, in R. RUBEN, M. SLINGERLAND \& H. NIJHOFF (eds.). Agro-food chains and networks for development (pp. 79-105). Netherlands: Springer.

Reardon, T. 2011. The Global Rise and Impact of Supermarkets: An International Perspective. Paper presented at Supermarket revolution in Asia and emerging development strategies to include small farmers. Canberra, Australia. 14-16 August

REARDON, T. \& BERDEGUE, J.A. 2002. The rapid rise of supermarkets in Latin America: Challenges and opportunities for development. Development Policy Review, 20(4):371-388.

REARDON, T., BERDEGUE, J.A., TIMMER, C.P., CABOT, T., MAINVILLE, D., FLORES, L., HERNANDEZ, R., NEVEN, D. \& BALSEVICH, F. 2005. Links among supermarkets, wholesalers, and small farmers in developing countries: Conceptualization and emerging evidence. The Future of Small Farms, June 2629 2005, IFPRI, pp. 45-60.Wye, UK.

REARDON, T., TIMMER, C.P., BARRETT, C.B. \& BERDEGUE, J. 2003. The rise of supermarkets in Africa, Asia, and Latin America. American Journal of Agricultural Economics, 85(5):1140-1146.

ROEMER, M. \& GUGERTY, M.K. 1997. Does economic growth reduce poverty? [Online]. Available: http://pdf.usaid.gov/pdf docs/PNACA656.pdf [2013, March 16]. 
ROSEGRANT, M.W. \& CLINE, S.A. 2003. Global food security: challenges and policies. Science, 302(5652):1917-1919.

ROSEGRANT, M.W. \& HAZELL, P. 2000. Transforming the rural Asian economy: The unfinished revolution. Hong Kong: Oxford University Press.

SALA-I-MARTIN, X. \& PINKOVSKIY, M. 2010. African poverty is falling...much faster than you think! Cambridge: National Bureau of Economic Research.

SCHMIDHUBER, J. \& TUBIELLO, F.N. 2007. Global food security under climate change. Proceedings of the National Academy of Sciences of the United States of America, 104(50):19703-19708.

SCHNEIDER, U.A., HAVLÍK, P., SCHMID, E., VALIN, H., MOSNIER, A., OBERSTEINER, M., BÖTTCHER, H., SKALSKÝ, R., BALKOVIČ, J., SAUER, T. \& FRITZ, S. 2011. Impacts of population growth, economic development, and technical change on global food production and consumption. Agricultural Systems, 104(2):204-215.

SEN, A. 1981. Poverty and famines. Oxford: Clarendon Press.

SMITH, L.C. \& HADDAD, L. 2002. How potent is economic growth in reducing under nutrition? What are the pathways of impact? New cross-country evidence*. Economic Development and Cultural Change, 51(1):55-76.

TANDON, S., WOOLVERTON, A.E. \& LANDES, M.R. 2011. Analyzing modern food retailing expansion drivers in developing countries. Agribusiness, 27(3):327-343.

THE GUARDIAN. 2003. Sugar industry threatens to scupper WHO | Society | The Guardian 21 April 2003 [Online]. Available: http://www.guardian.co.uk/society/2003/apr/21/usnews.food [2013, July 24].

The New York Times. 2013. HARVESTING POVERTY; the fabric of lubbock's life. [Online]. Available: http://www.nytimes.com/2003/10/19/opinion/harvesting-poverty-the-fabric-oflubbock-s-life.html [May, 22]

TRENCH, P.C., NARROD, C., ROY, D. \& TIONGCO, M. 2012. Responding to health risks along the value chain, in S. FAN \& R. PANDYA-LORCH (eds.). Reshaping agriculture for nutrition and health (pp. 93102). Washington, DC: International Food Policy Research Institute.

UNICEF. 2012. Child info: Monitoring the situation of children and women [Online]. Available: http://www.childinfo.org/country list.php [2013, July 30].

UNICEF AND MI. 2013. Vitamin and mineral deficiency: A global damage assessment report [Online]. Available: http://www.micronutrient.org/english/View.asp? $x=614$ [2013, August 01].

UNITED NATIONS, 2013. World Population Prospects: The 2012 Revision. DVD edn. New York: United Nations, Department of Economic and Social affairs.

UN WOMEN. 2011-2013. Women, poverty \& economics - Gender Issues - UNIFEM [Online]. Available: http://www.unifem.org/gender issues/women poverty economics/ [2013, June 23]. 
VALDÉS, A. \& FOSTER, W. 2005. The role of agriculture in pro-poor growth. The future of small farms: Proceedings of a research workshop, June 26-29 2005, IFPRI (International Food Policy Research Institute), pp. 3-22.

VERWIMP, P. 2012. Food security, violent conflict and human development: Causes and consequences. WP 2012-016. Brussels, Belgium: United Nations Development Programme Regional Bureau of Africa.

VINK, N. 2012. Food security and African agriculture. South African Journal of International Affairs, 19(2):157-177.

WEATHERSPOON, D.D. \& REARDON, T. 2003. The rise of supermarkets in Africa: Implications for agrifood systems and the rural poor. Development Policy Review, 21(3):333-355.

WEBB, P., COATES, J., FRONGILLO, E.A., ROGERS, B.L., SWINDALE, A. \& BILINSKY, P. 2006. Measuring household food insecurity: Why it's so important and yet so difficult to do. The Journal of Nutrition, 136(5):1404S-1408S.

WEINGÄRTNER, L. 2005. The concept of food and nutrition security. Achieving Food and Nutrition Security, NOT COMPLETE, pp. 1.

WESTHOFF, P. 2010. The economics of food: How feeding and fuelling the planet affects food prices. New Jersey: Pearson Education, Inc.

WFP. 2013. WFP buys record quantity of maize from Ethiopian cooperative unions [Online]. Available: http://www.wfp.org/news/news-release/wfp-buys-record-quantity-maize-ethiopiancooperative-unions [2013, May 14].

WHALEY, S.E., SIGMAN, M., NEUMANN, C., BWIBO, N., GUTHRIE, D., WEISS, R.E., ALBER, S. \& MURPHY, S.P. 2003. The impact of dietary intervention on the cognitive development of Kenyan school children. The Journal of Nutrition, 133(11):3965S-3971S.

WHO \& UNICEF, 2010. Progress on sanitation and drinking-water - 2010 update. Geneva: UNICEF and World Health Organization.

WHO \& UNICEF, 2012. Levels \& trends in child malnutrition. UNICEF-WHO-The World Bank Joint Child Malnutrition Estimates. UNICEF, New York; WHO, Geneva; The World Bank, Washington, DC: WHO Library Cataloguing-in-Publication Data.

WIGGINS, S. 2009. Can the smallholder model deliver poverty reduction and food security for a rapidly growing population in Africa? FAO Expert Meeting on How to feed the World in 2050 , 24-26 June 2009, Future Agricultures Consortium, pp. 1.

WIGGINS, S. \& KEATS, S. 2009. Current state of food security in Africa and the Africa - EU partnership on the Millennium Development Goals. Paper for Second Joint Experts Group Meeting, Africa-EU MDGs Partnership, 24 March 2009, Future Agricultures Consortium \& Overseas Development Institute, pp. 2-37.

WORLD BANK. 1986. Poverty and hunger: Issues and options for food security in developing countries. Washington DC: World Bank.

WORLD BANK. 2000. The quality of growth. New York: Oxford University Press, Inc. 
WORLD BANK. 2008. Agriculture for development. World Development Indicators 2008. Washington DC: The International Bank for Reconstruction and Development / The World Bank.

WORLD BANK. 2013a. World Bank Data and Research [Online]. Available: http://go.worldbank.org/3QT2P1GNHO [2013, February 25].

WORLD BANK. 2013b. Africa's pulse: An analysis of issues shaping Africa's economic future [Online]. Available: http://www.worldbank.org/content/dam/Worldbank/document/Africa/Report/AfricasPulse-brochure Vol7.pdf [2013, May 6].

YOSHII, K., TRUNG, N. \& OYAMA, T. 2009. Quantitative data analyses for the recent change of the Japanese food self-sufficiency ratios. Lecture Notes in Operations Research, 10:372-386.

\section{Addenda}

Addendum A: Africa regional classification based on United Nations (2013)

\begin{tabular}{|c|c|c|c|c|}
\hline Eastern Africa & Middle Africa & $\begin{array}{l}\text { Northern } \\
\text { Africa }\end{array}$ & $\begin{array}{l}\text { Southern } \\
\text { Africa }\end{array}$ & Western Africa \\
\hline Burundi & Angola & Algeria & Botswana & Benin \\
\hline Comoros & Cameroon & Egypt & Lesotho & Burkina Faso \\
\hline Djibouti & CAR & Libya & Namibia & Cape Verde \\
\hline Eritrea & Chad & Morocco & South Africa & Côte d'Ivoire \\
\hline Ethiopia & Congo & Sudan & Swaziland & Gambia \\
\hline Kenya & DRC & Tunisia & & Ghana \\
\hline Madagascar & $\begin{array}{l}\text { Equatorial } \\
\text { Guinea }\end{array}$ & Western Sahara & & Guinea \\
\hline Malawi & Gabon & & & Guinea-Bissau \\
\hline Mauritius & $\begin{array}{l}\text { Sao Tome and } \\
\text { Principe }\end{array}$ & & & Liberia \\
\hline Mayotte & & & & Mali \\
\hline Mozambique & & & & Mauritania \\
\hline Réunion & & & & Niger \\
\hline Rwanda & & & & Nigeria \\
\hline Seychelles & & & & Saint Helena \\
\hline Somalia & & & & Senegal \\
\hline South Sudan & & & & Sierra Leone \\
\hline Uganda & & & & Togo \\
\hline \multicolumn{5}{|l|}{ Tanzania } \\
\hline \multicolumn{5}{|l|}{ Zambia } \\
\hline Zimbabwe & & & & \\
\hline
\end{tabular}

Source: United Nations (2013) 
Addendum B: African countries below and above FAO"s recommended value of daily food calorie intake (2 $300 \mathrm{kcal} / \mathrm{capita} /$ day) in 2009

\begin{tabular}{|l|r|l|r|}
\hline \multicolumn{2}{|c|}{$>2300 \mathrm{kcal} /$ capita/day } & \multicolumn{2}{c|}{$<2300 \mathrm{kcal} /$ capita/day } \\
\hline Malawi & 2318 & Burundi & 1604 \\
\hline Sudan (former) & 2326 & Eritrea & 1640 \\
\hline Togo & 2363 & Zambia & 1879 \\
\hline Lesotho & 2371 & Congo & 2056 \\
\hline Djibouti & 2419 & Chad & 2074 \\
\hline Seychelles & 2426 & Angola & 2079 \\
\hline Cameroon & 2457 & Kenya & 2092 \\
\hline Guinea-Bissau & 2476 & Ethiopia & 2097 \\
\hline Senegal & 2479 & Mozambique & 2112 \\
\hline Niger & 2489 & Madagascar & 2117 \\
\hline Benin & 2592 & United Republic of Tanzania & 2137 \\
\hline Mali & 2624 & Comoros & 2139 \\
\hline Gambia & 2643 & Namibia & 2151 \\
\hline Cape Verde & 2644 & Sierra Leone & 2162 \\
\hline Burkina Faso & 2647 & Botswana & 2164 \\
\hline Guinea & 2652 & Central African Republic & 2181 \\
\hline Côte d'Ivoire & 2670 & Rwanda & 2188 \\
\hline Nigeria & 2711 & Zimbabwe & 2219 \\
\hline Sao Tome and Principe & 2734 & Swaziland & 2249 \\
\hline Gabon & 2745 & Uganda & 2260 \\
\hline Mauritania & 2856 & Liberia & 2261 \\
\hline Ghana & 2934 & & \\
\hline Mauritius & 2993 & & \\
\hline South Africa & 3017 & & \\
\hline Libya & 3157 & & \\
\hline Algeria & 3239 & & \\
\hline Morocco & 3264 & & \\
\hline Tunisia & 3314 & & \\
\hline Egypt & 3349 & & \\
\hline Source:Bar & \\
\hline
\end{tabular}

Source: Based on FAOSTAT (2013) database. 
Addendum C: Caloric food supply over selected countries (1970-2012)

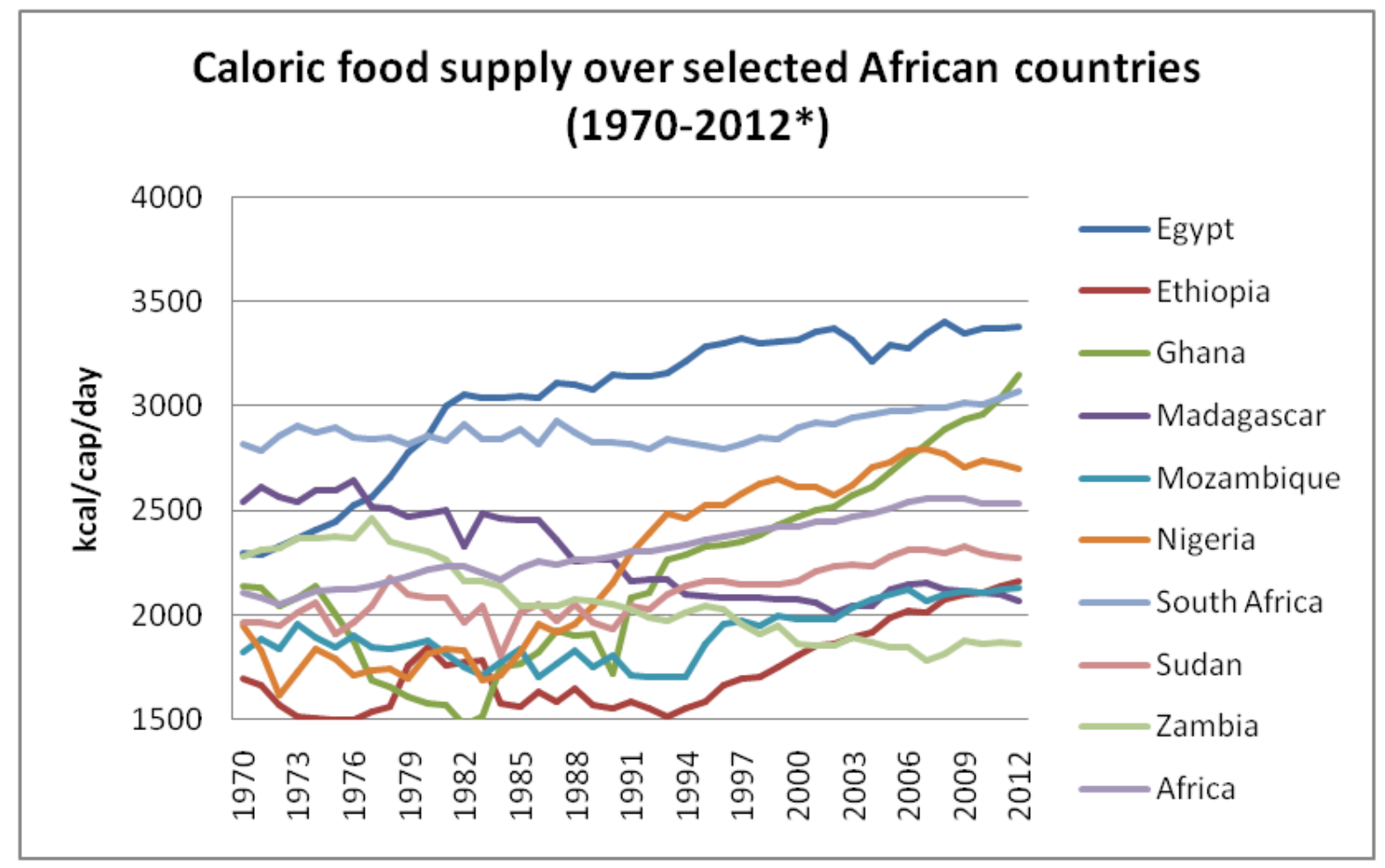

Source: constructed based on FAOSTAT (2013) data \& FAO’s food security indicators (FAO 2013a) *2010-2012 data values are estimated 
Addendum D: Sub-Saharan Africa countries' food affordability indicators based on the Economist Intelligence Unit (Global food security index ranking)

\begin{tabular}{|c|c|c|c|c|c|}
\hline & $\begin{array}{l}\text { Household food } \\
\text { expenditure (\%) }\end{array}$ & $\begin{array}{l}\text { Population } \\
\text { living under } \\
\text { \$2/day ppp } \\
(\%)\end{array}$ & $\begin{array}{l}\text { GDP per } \\
\text { capita (US\$ } \\
\text { ppp/capita }\end{array}$ & $\begin{array}{l}\text { Agricultural } \\
\text { import tariff \% }\end{array}$ & $\begin{array}{l}\text { Affordability } \\
\text { (SSA/world rank) }\end{array}$ \\
\hline South Africa & 17.8 & 31.3 & 11260 & 9 & $1 / 38$ \\
\hline Botswana & 23.7 & 30.2 & 14840 & 9.1 & $2 / 50$ \\
\hline Uganda & 45 & 64.7 & 1460 & 19.6 & $3 / 69$ \\
\hline Ghana & 51 & 51.8 & 2970 & 17.5 & $4 / 71$ \\
\hline Cote dee Tvoire & 30.61 & 46.3 & 1620 & 14.5 & $5 / 73$ \\
\hline Kenya & 45.8 & 67.2 & 1700 & 19.7 & $6 / 75$ \\
\hline Cameroon & 52.3 & 30.4 & 2320 & 22.3 & $7 / 76$ \\
\hline Angola & 52.3 & 70.2 & 7120 & 10 & $8 / 82$ \\
\hline Niger & 29.7 & 75.2 & 732 & 14.5 & $9 / 84$ \\
\hline Senegal & 54.2 & 60.4 & 1920 & 14.5 & $10 / 85$ \\
\hline Ethiopia & 50.84 & 77.6 & 1230 & 22.3 & $11 / 86$ \\
\hline Guinea & 52.3 & 69.6 & 1130 & 14.1 & $12 / 87$ \\
\hline Burkina Faso & 48.8 & 72.6 & 1330 & 14.5 & $13 / 88$ \\
\hline Mozambique & 54.5 & 81.8 & 1000 & 13.8 & $14 / 90$ \\
\hline Mali & 66.5 & 78.7 & 1150 & 14.5 & $15 / 92$ \\
\hline Rwanda & 62.3 & 82.4 & 1240 & 19.5 & $=16 / 93$ \\
\hline Sierra Leone & 49.3 & 76.1 & 1040 & 16.4 & $=16 / 93$ \\
\hline Benin & 52.3 & 75.3 & 1640 & 14.5 & $18 / 95$ \\
\hline Zambia & 64 & 82.6 & 1630 & 19 & $19 / 96$ \\
\hline Tanzania & 62.7 & 87.9 & 1460 & 19.7 & $20 / 97$ \\
\hline Sudan & 61.4 & 44.1 & 2210 & 30.4 & $21 / 98$ \\
\hline Togo & 63.7 & 69.3 & 1040 & 14.5 & $22 / 99$ \\
\hline Madagascar & 57 & 92.6 & 957 & 14.6 & $23 / 100$ \\
\hline Malawi & 65.5 & 90.5 & 963 & 17.4 & $24 / 101$ \\
\hline Burundi & 52.3 & 93.5 & 419 & 19.6 & $25 / 102$ \\
\hline
\end{tabular}

${ }^{11}$ PPP- Refers to an international dollars using purchasing power parity rate World Bank (2013a) 


\begin{tabular}{|l|l|l|l|l|l|}
\hline & $\begin{array}{l}\text { Household food } \\
\text { expenditure (\%) }\end{array}$ & $\begin{array}{l}\text { Population } \\
\text { living under } \\
\$ 2 / \text { day ppp }^{11} \\
(\%)\end{array}$ & $\begin{array}{l}\text { GDP per } \\
\text { capita (US\$ } \\
\text { ppp/capita }\end{array}$ & $\begin{array}{l}\text { Agricultural } \\
\text { import tariff \% }\end{array}$ & $\begin{array}{l}\text { Affordability } \\
\text { (SSA/world rank) }\end{array}$ \\
\hline Nigeria & 64.68 & 84.5 & 2080 & 15.5 & $26 / 103$ \\
\hline $\begin{array}{l}\text { Congo (Dem. } \\
\text { Rep.) }\end{array}$ & 70 & 74.4 & 371 & 11 & $27 / 104$ \\
\hline Chad & 68 & 83.3 & 1510 & 21.9 & $28 / 105$ \\
\hline
\end{tabular}

Source: EIU (2012)

Addendum E: Estimated prevalence (\%) of stunted pre-school children 1990-2020,

Based on UN region and sub-region classification

\begin{tabular}{|l|c|c|c|c|c|c|c|c|}
\hline Region/country & 1990 & 1995 & 2000 & 2005 & 2010 & 2015 & 2020 & $\begin{array}{c}\text { \%change } \\
\text { (1990-2010) }\end{array}$ \\
\hline Africa & 40.3 & 39.8 & 39.3 & 38.8 & 38.2 & 37.6 & 37.7 & 5 \\
\hline Eastern Africa & 48.1 & 47.4 & 46.7 & 46 & 45.3 & 44.6 & 43.9 & 6 \\
\hline Middle Africa & 45.3 & 43.8 & 42.3 & 40.8 & 39.4 & 37.9 & 36.5 & 13 \\
\hline Northern Africa & 29.4 & 27.4 & 25.5 & 23.7 & 21.9 & 20.3 & 18.7 & 26 \\
\hline Southern Africa & 35.4 & 34.7 & 34.1 & 33.5 & 32.9 & 32.3 & 31.7 & 7 \\
\hline Western Africa & 38.1 & 38.1 & 38.1 & 38.1 & 38.2 & 38.2 & 38.2 & 0 \\
\hline & & & & & & & & 43 \\
\hline
\end{tabular}

Source: Adapted from De Onis et al. (2012) 
Addendum F: Gender disparity in prevalence of underweight children under the age of five in selected countries

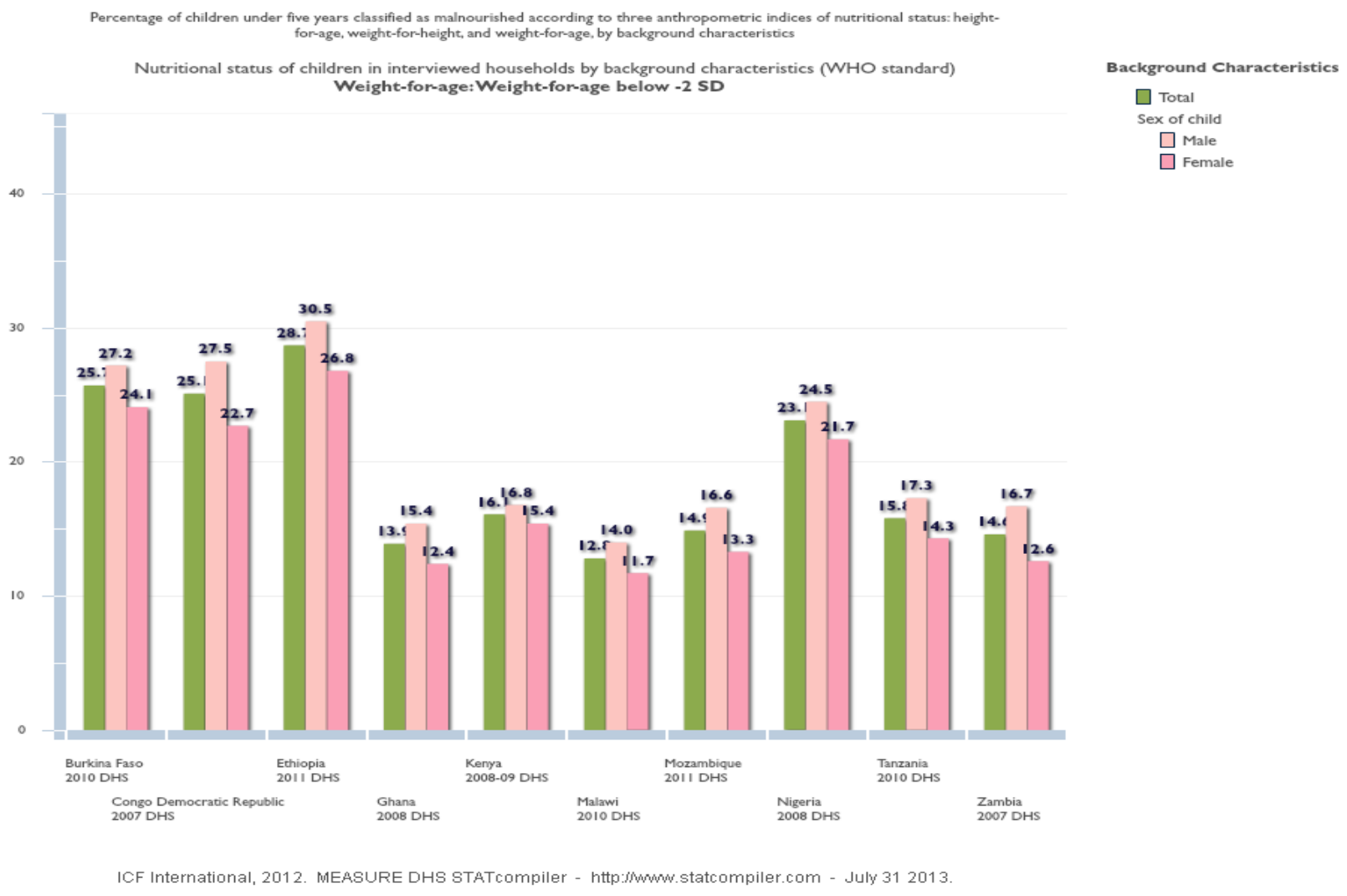

Source: MEASURE DHS (2013) 
Addendum G:Rural-urban prevalence of underweight in children under the age five in selected countries

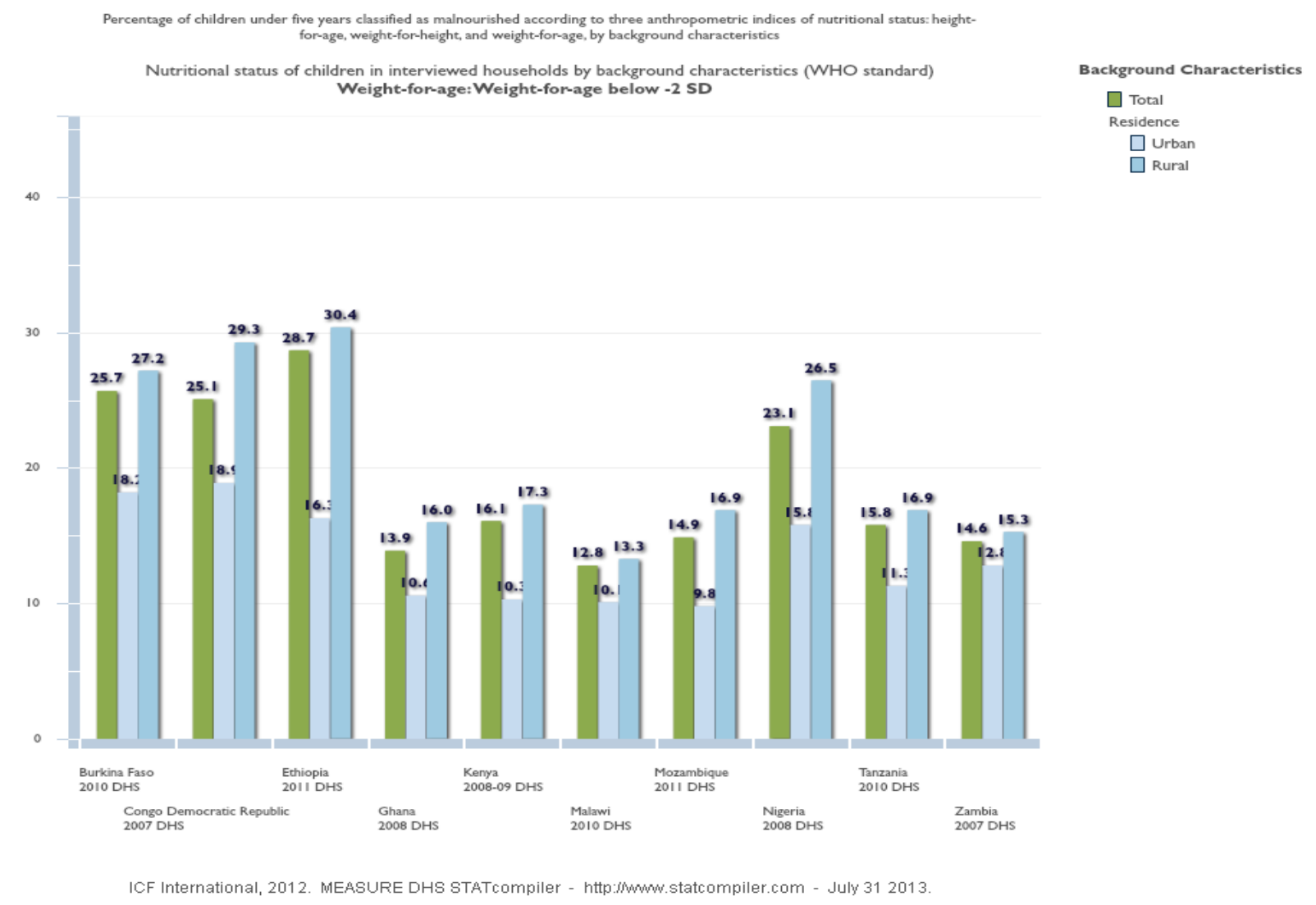

Source: MEASURE DHS (2013) 